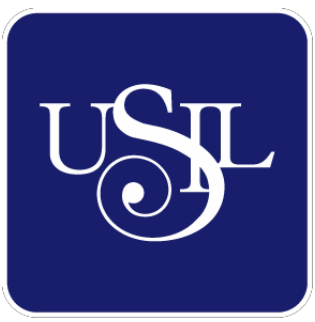

UNIVERSIDAD

SAN IGNACIO

DE LOYOLA

ESCUELA DE POSTGRADO

\title{
PLAN DE NEGOCIOS PARA LA CREACIÓN DE UN CENTRO DE SERVICIOS TURÍSTICOS EN EL DESTINO DE MOLLEPATA CUSCO
}

Trabajo de Investigación para optar el grado de:

ANGEL JOSEPH BONNETT PEREZ

Maestro en Ciencias Empresariales con Mención en Gestión de Marketing

PABEL GUSTAVO SURCO DUEÑAS

Maestro en Ciencias Empresariales con Mención en Gestión de Marketing

HUGO GALLEGOS DELGADO DE LA FLOR Maestro en Ciencias Empresariales con Mención en Gestión del Capital Humano

Asesor:

Horacio Javier Barrios Cruz

Lima - Perú

2019 

"PLAN DE NEGOCIOS PARA LA CREACIÓN DE UN CENTRO DE SERVICIOS TURÍSTICOS EN EL DESTINO DE MOLLEPATA CUSCO” 


\section{DEDICATORIA}

Dedicamos el presente plan de negocios a Dios, que nos ampara cada día, a nuestros padres, nuestros hermanos, a nuestras hijas y a nuestras familias, que siempre creyeron en nosotros, que nos aman y nos han brindado su apoyo en todo momento.

Asimismo, agradecemos a nuestro asesor, al profesor Horacio Barrios Cruz por su interés y dedicación por el desarrollo del presente plan de negocio. 


\section{RESUMEN EJECUTIVO}

Hoy en día los circuitos de trekking en el mundo suponen experiencias exclusivas, diferenciadas y memorables para quienes las realizan, con una duración mayor a los cuatro días. En la mayoría de los casos, el trekking representa una ocasión de contacto único entre el hombre y la naturaleza, este es el caso del circuito de trekking Mollepata - Salkantay Machupicchu, que viene registrando un crecimiento constante de usuarios y que representa una nueva forma de ingresar a la ciudadela de Machupicchu. El presente proyecto busca atender la necesidad de un adecuado servicio turístico (trekking) que este creciente mercado busca y por ello surge la alternativa de este negocio, con la finalidad de atender los requerimientos de necesidades básicas que esta actividad demanda, junto con su necesidad de información sobre la zona que va a recorrer, lo cual facilitará la visita de los viajeros.

El plan de negocios consiste en la creación de un Centro de Servicios Turísticos que se ubicará en el distrito de Mollepata, punto de partida del trekking Salkantay - Machupicchu, con una propuesta de desayunos turísticos para los visitantes y usuarios que inicien el trekking. El presente proyecto propone, por una parte, la elaboración de desayunos que serán preparados con insumos oriundos de la zona, todo esto complementado con una adecuada calidad de servicio y, por otro lado, un recorrido gratuito al Centro de Interpretación del circuito Mollepata - Salkantay - Machupicchu, representando este último, un valor agregado al servicio propuesto. Para ello se cuenta con un terreno propio que se encuentra en el punto de partida del trekking Mollepata - Salkantay - Machupicchu, lo cual permite atender la demanda turística que llega a la zona.

El mercado objetivo del presente proyecto son las agencias de viajes operadoras de este circuito, cuyos clientes y grupos arriban a Mollepata en un rango de 06:00 am hasta las 10:00 am para abastecerse y comenzar la actividad de trekking, por lo que el horario de atención del 
presente proyecto será de domingo a domingo, con un sistema de trabajo de medio día, acogido al régimen especial de tributación.

Los factores claves de éxito serán la atención al cliente, la variedad de opciones, la calidad de los productos y la higiene del lugar que reflejan la aceptación del producto por parte del mercado objetivo, según las entrevistas y encuestas aplicadas.

La infraestructura del restaurante y del Centro de Interpretación estará localizada en el distrito de Mollepata, estratégicamente en el punto de inicio del trekking, a tres cuadras del poblado, el terreno tendrá una extensión de 800 metros cuadrados y contará además con una amplia zona de parqueo, el predio es de propiedad de uno de los inversionistas. De esta forma se tiene el punto de venta en la misma zona donde se encuentra ubicado el mercado meta y donde se produce el $80 \%$ de insumos de la carta.

La preparación del terreno, la infraestructura de las dos unidades de servicio y la capacidad instalada, llámense estas, maquinarias especializadas, activos fijos, activos variables, mano de obra, ascienden a un total de S/ 106,929, inversión que será asumida por los socios del proyecto, es decir, cuenta con financiamiento propio.

El VAN se determinó en S/ 488,721 y la TIR es de $66 \%$, este resultado demuestra la rentabilidad del proyecto. 24 desayunos expendidos diariamente representan el punto de equilibrio, permitiendo una diferencia favorable al proyecto, que simboliza un soporte frente a situaciones imprevistas para el negocio.

Finalmente, por todos estos hechos, condiciones y resultados favorables para la implementación de dicho proyecto, se recomienda la ejecución de este en un corto plazo, aprovechando la actual coyuntura turística y su tendencia en años venideros. 


\section{INTRODUCCIÓN}

El presente plan de negocios tiene como objetivo evaluar la viabilidad de crear un Centro de Servicios Turísticos en el distrito de Mollepata - Cusco, como parte del circuito turístico de trekking Salkantay - Machupicchu.

En el primer capítulo se desarrollarán los antecedentes propios del plan de negocios, identificando la oportunidad que se encontró en el sector, se justificará el mismo y señalará el objetivo general y específicos, así mismo, se detallarán los alcances y las limitaciones que se encontraron en el desarrollo del proyecto.

El segundo capítulo se explicará detalladamente todos los aspectos del sector turístico en el Perú, la segmentación del sector, las empresas que la conforman, las tendencias. Igualmente, se analizará a la competencia mediante la matriz de perfil competitivo que permitirá identificar nuevas oportunidades de crecimiento.

En el tercer capítulo se describirá a fondo el producto y servicio que será ofrecido, señalando sus principales funciones y su ventaja diferencial, también se identificará el segmento del mercado que atenderá el plan de negocios. Además, se desarrollará la investigación cualitativa y cuantitativa, con los respectivos análisis y procesamientos de datos, y las conclusiones.

En el cuarto capítulo se realizará la proyección de la demanda para el presente plan de negocios de acuerdo a la segmentación de mercado. Se determinará el mercado potencial, mercado disponible, mercado efectivo y finalmente el mercado objetivo, y a partir de esa información, se elaborará el pronóstico de ventas.

En el quinto capítulo se identificarán los materiales, equipos e insumos que forman parte del negocio, comenzando con la ingeniería del producto, modelamiento y selección de procesos, recursos, tecnología, equipos maquinarias, y la infraestructura del proyecto. 
El capítulo seis engloba la descripción organizacional y legal; en la primera parte se desarrollará la misión, visión y principios del proyecto, además de las competencias de las diferentes áreas de la estructura organizacional. La segunda parte comprende las retribuciones, políticas de recursos humanos e incentivos.

Con relación al capítulo siete se diseñará el plan de marketing, se determinaron las estrategias de producto, precio, distribución y ventas. Asimismo, se desarrollará las políticas con respecto a los servicios y garantías, además de el plan de ventas que tendrá el presente plan de negocios.

En el capítulo ocho, se estructurará la planificación financiera, en ella se desarrollará el capital de trabajo, la inversión pre operativa y las inversiones posteriores; las restricciones de financiamiento también estarán descritas, señalando aquí que el financiamiento es propio. Señalar también que las compras, costos de ventas, los gastos administrativos, de marketing, ventas, gastos financieros y los presupuestos base de ventas, resultarán en la estructura de los Estados Financieros Proyectados.

El capítulo nueve demostrará la evaluación y el análisis financiero de indicadores como, VAN, TIR y ratios financieros. Además, se realizará el estudio del punto de equilibrio y las posibles situaciones a presentarse en un futuro próximo. Con la consolidación de toda esta información se analizará las conclusiones obtenidas y se proporcionará las recomendaciones específicas para la realización del presente proyecto. 


\section{INDICE}

Índice de Tablas .............................................................................................................................. 13

Índice de Figuras.....................................................................................................................1

Capítulo I. Generalidades ................................................................................................................ 1

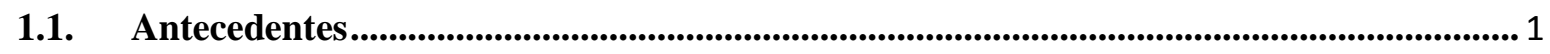

1.2. Determinación del Problema u Oportunidad ....................................................................... 3

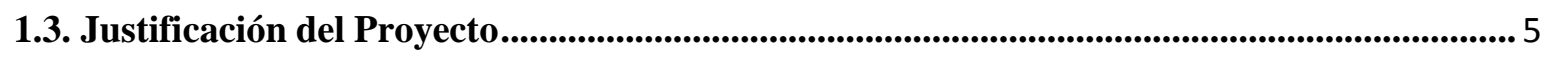

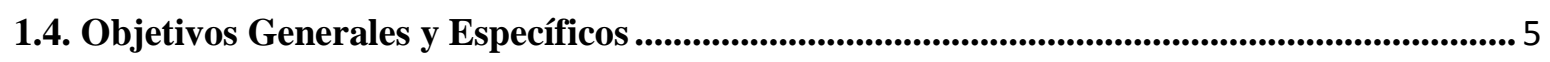

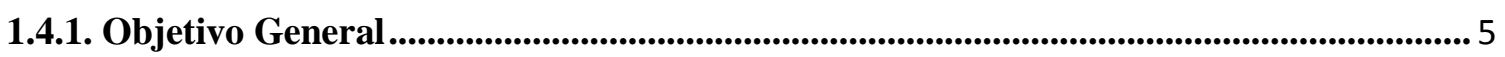

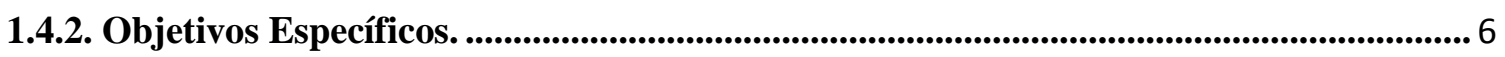

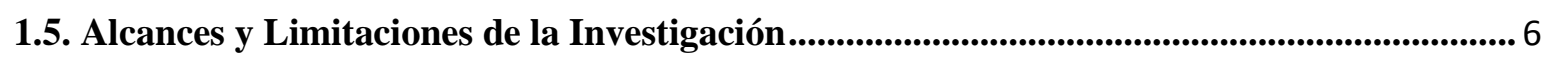

Capítulo II. Estructura Económica del Sector .................................................................

2.1. Descripción del Estado Actual de la Industria ................................................................ 8

2.1.1. Segmentación de la Industria......................................................................................................... 11

2.1.2. Empresas que la conforman (ubicación, volumen de ventas, empleados, etc.)............ 14

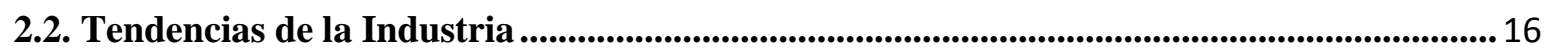

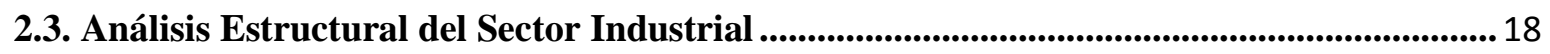

2.3.1. Poder de negociación de los consumidores. .............................................................................. 19

2.3.2. Poder de negociación de los proveedores...................................................................................... 20

2.3.3. Entrada potencial de nuevos competidores ................................................................................... 21

2.3.4. Desarrollo Potencial de productos sustitutos.......................................................................... 24

2.3.5. Rivalidad entre empresas competidoras. ........................................................................ 25

2.4. Análisis de la Competencia .............................................................................................................. 27

2.4.1. Empresas que of recen el mismo producto o servicio, indicando las semejanzas y diferencias que tienen con el proyecto de Empresa. .......................................................................... 30

2.4.2. Participación de mercado de cada uno de ellos......................................................................... 36

2.4.3. Matriz De Perfil Competitivo. .......................................................................................... 39

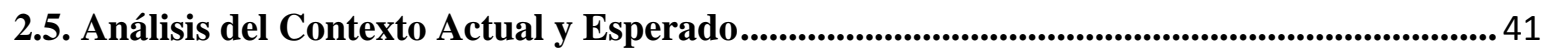

2.5.1. Análisis Político - Gubernamental ................................................................................................ 41

2.5.2. Análisis Económico. ........................................................................................................................... 44

2.5.3. Análisis Legal ................................................................................................................................ 47

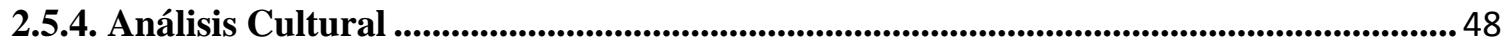

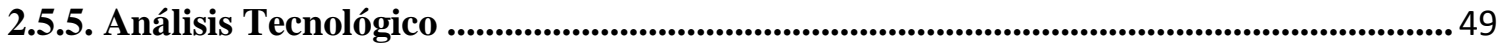

2.5.6. Análisis Ecológico. ...................................................................................................................... 51 
2.6. Oportunidades y Amenazas .................................................................................................................... 52

Capítulo III. Estudio de Mercado ...........................................................................56

3.1. Descripción del Servicio o Producto.......................................................................................... 56

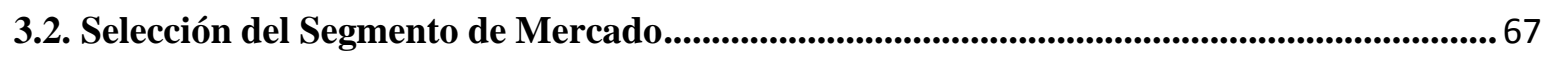

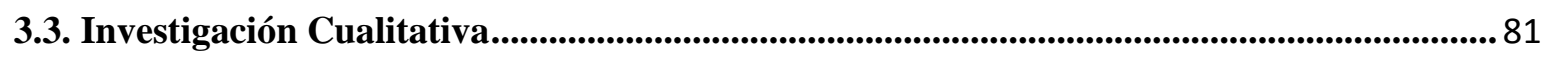

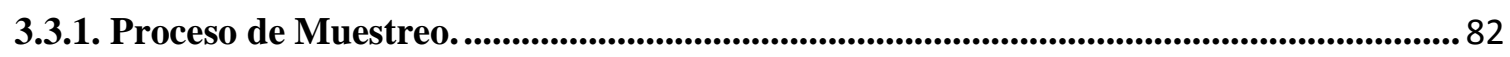

3.3.2. Diseño de Instrumento..................................................................................................... 83

3.3.3. Análisis y Procesamiento de Datos. ............................................................................................... 90

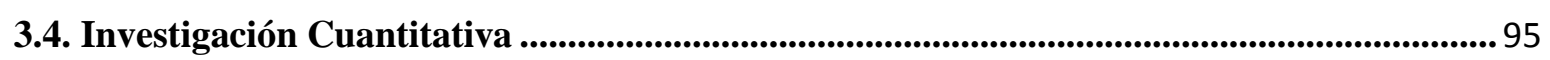

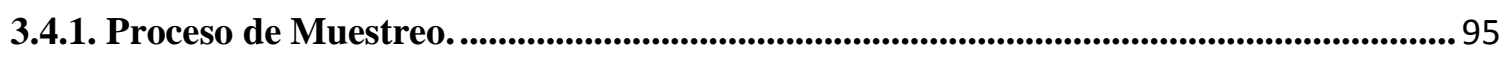

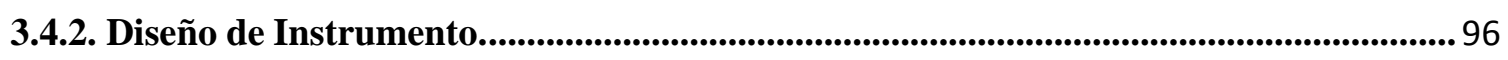

3.4.3. Análisis y Procesamiento de Datos. ........................................................................ 97

3.5. Conclusiones y Recomendaciones del Estudio Cualitativo y Cuantitativo ........................ 123

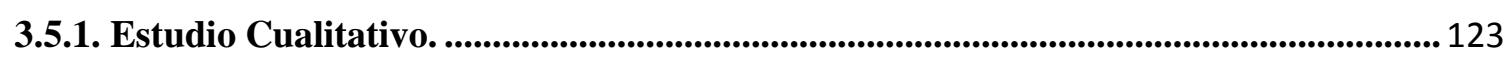

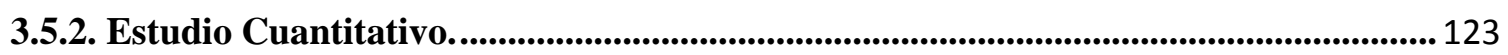

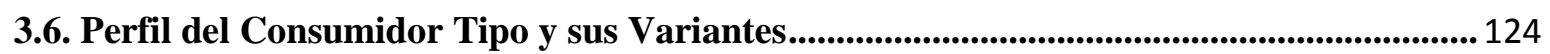

Capítulo IV: Proyección del Mercado Objetivo.................................................................... 127

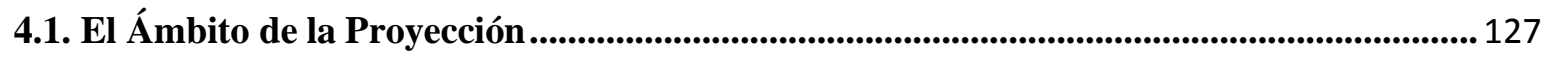

4.2. Selección del Método de Proyección................................................................................127

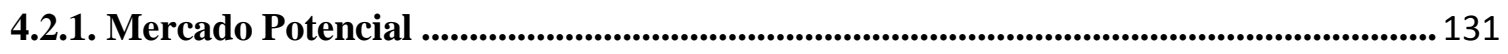

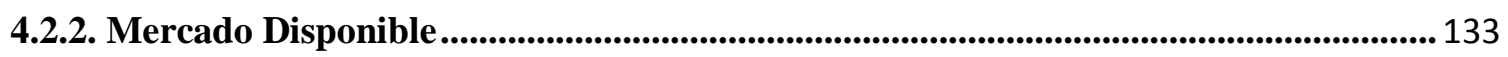

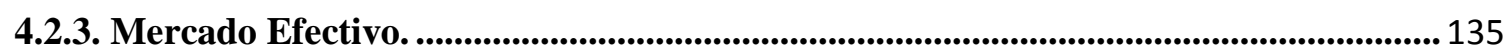

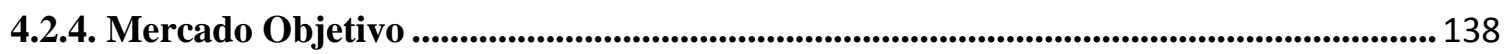

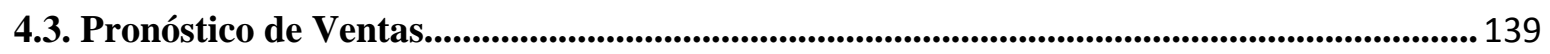

4.4. Aspectos Críticos que impactan el Pronóstico de Ventas ................................................... 140

Capítulo V: Ingeniería del Proyecto........................................................................... 143

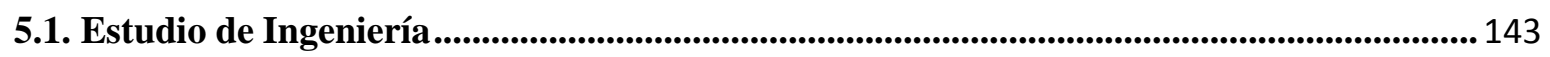

5.1.1. Modelamiento y Selección de Procesos Productivos...................................................... 143

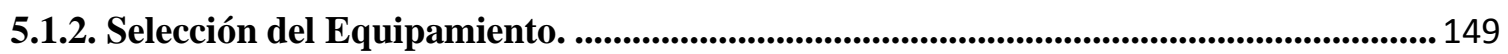

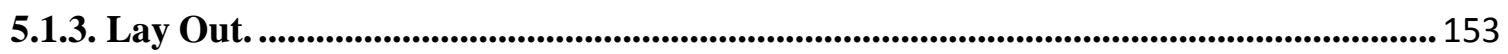

5.1.4. Distribución de Equipos y Maquinarias. ..................................................................... 154

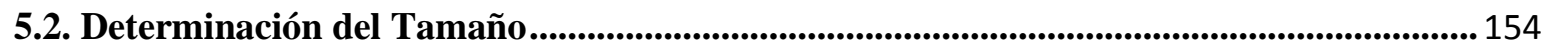

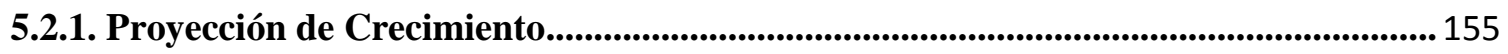

5.2.2. Recursos............................................................................................................................................... 155

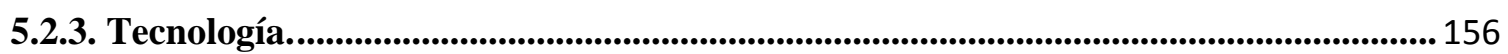


5.2.4. Flexibilidad ......................................................................................................................................... 156

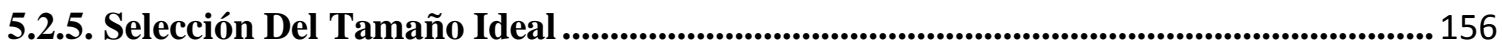

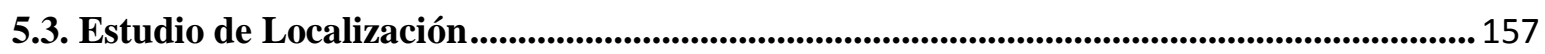

5.3.1. Definición de Factores Locacionales ...................................................................................... 157

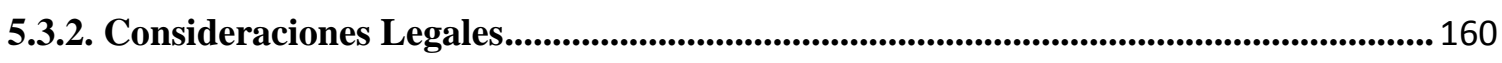

5.4. Determinación de la Localización Óptima............................................................................... 162

Capítulo VI: Aspectos Organizacionales ............................................................... 163

6.1. Caracterización de la Cultura Organizacional deseada ............................................................ 163

6.1.1. Visión. 164

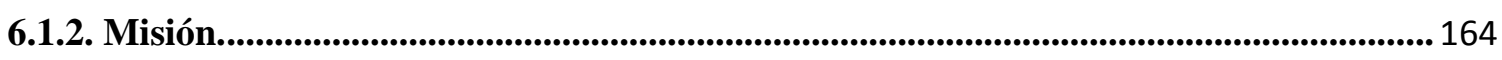

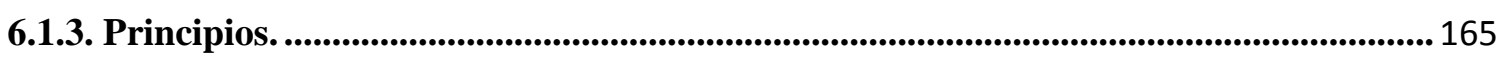

6.2. Formulación de Estrategias del Negocio......................................................................167

6.3. Determinación de las Ventajas Competitivas Críticas ........................................................ 169

6.4. Diseño de la Estructura Organizacional Deseada .................................................................. 171

6.5. Diseño de los Perfiles de Puestos Clave _............................................................................ 172

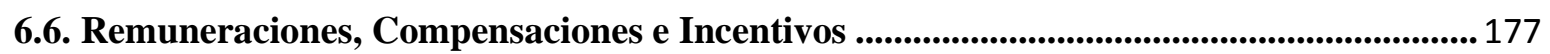

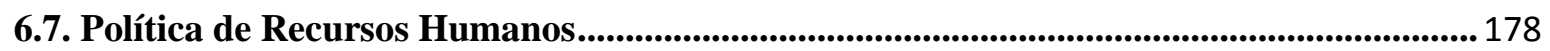

Capítulo VII: Plan de Marketing ............................................................................. 182

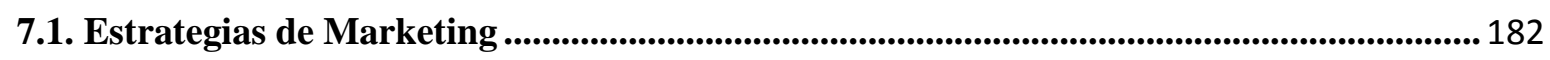

7.1.1. Estrategia de Producto. .................................................................................................. 182

7.1.2. Estrategia de Precio ................................................................................................ 187

7.1.3. Estrategia de Distribución......................................................................................... 189

7.1.4. Estrategia de Promoción y Publicidad......................................................................... 189

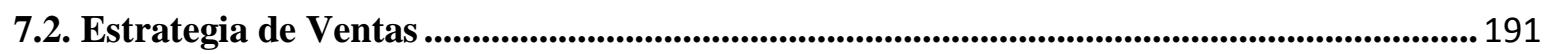

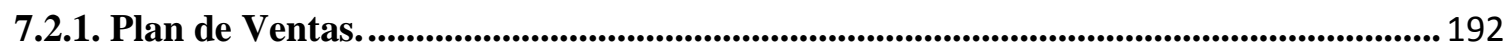

Capítulo VIII: Planificación Financiera ...................................................................... 201

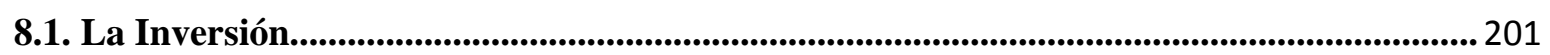

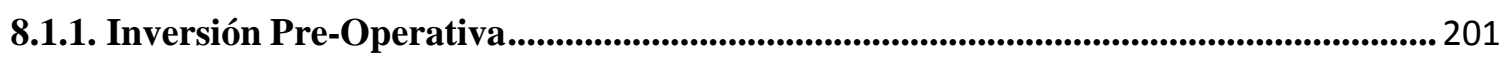

8.1.2. Inversión en Capital de Trabajo........................................................................................... 203

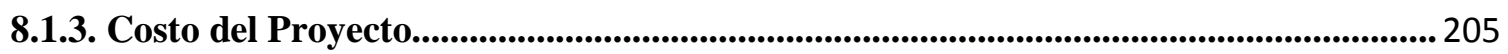

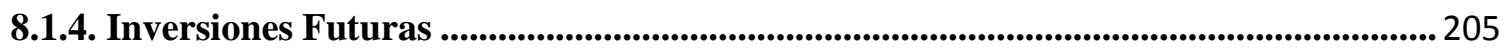

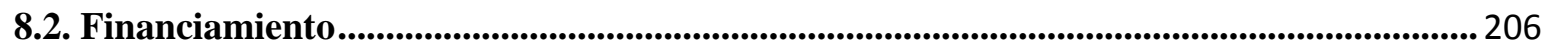

8.2.1. Endeudamiento y Condiciones............................................................................................. 206

8.2.2. Capital y Costo de Oportunidad..................................................................................................... 206

8.2.3. Costo de Capital Promedio Ponderado ................................................................................ 208 
8.3. Presupuestos Base ................................................................................................................................... 209

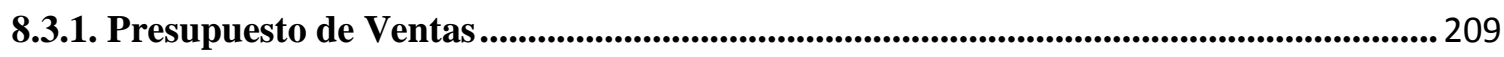

8.3.2. Presupuesto de Costos de Producción............................................................................ 209

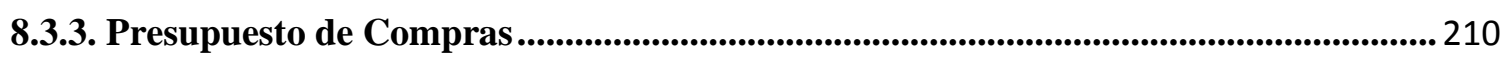

8.3.4. Presupuesto de Costo de Ventas ................................................................................ 211

8.3.5. Presupuesto de Gastos Administrativos.............................................................................. 211

8.3.6. Presupuesto de Marketing y Ventas................................................................................. 212

8.3.7. Presupuesto de Gastos Financieros .............................................................................................. 213

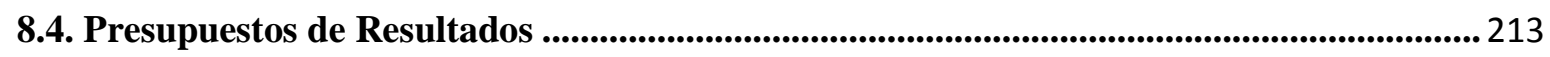

8.4.1. Estado de Ganancias y Pérdidas Proyectado...................................................................... 213

8.4.2. Balance Proyectado......................................................................................................... 214

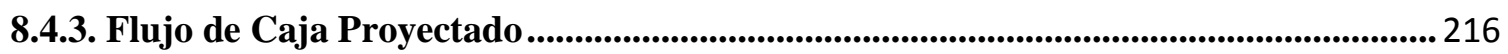

Capítulo IX: Evaluación Económico Financiera .............................................................. 218

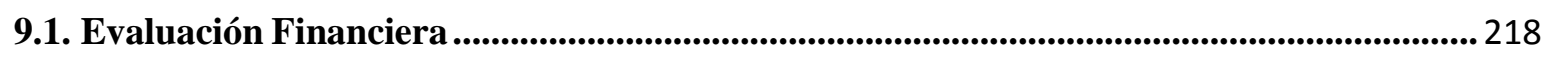

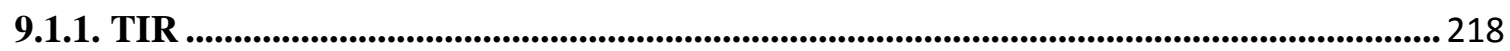

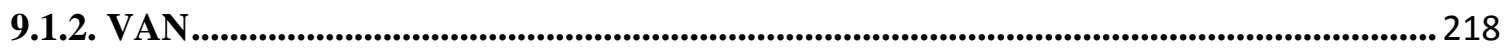

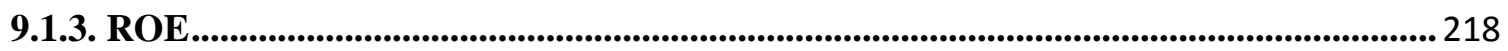

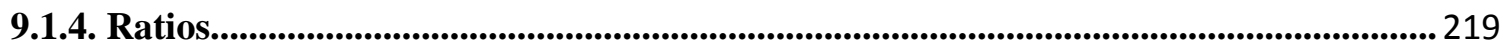

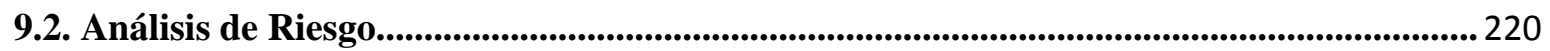

9.2.1. Análisis de Punto de Equilibrio .............................................................................................. 220

9.2.2. Análisis de Sensibilidad ................................................................................................................... 221

9.2.3. Análisis de Escenarios......................................................................................................................... 222

Conclusiones y Recomendaciones............................................................................................. 223

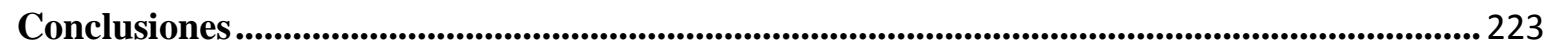

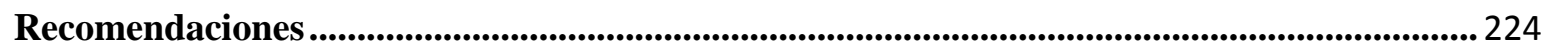

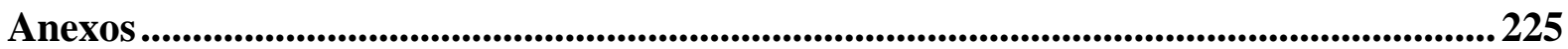

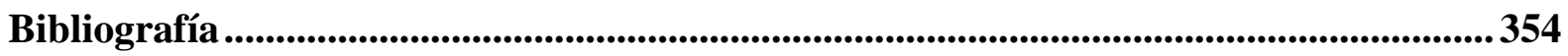

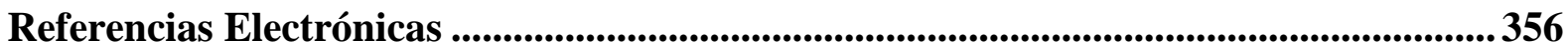




\section{Índice de Tablas}

Tabla 1 Crecimiento del sector hospedajes y restaurantes.................................................. 9

Tabla 2 Empresas que conforman la industria de restaurantes en el distrito de Mollepata... 15

Tabla 3 Principales tendencias en las industrias de turismo y restaurantes.......................... 17

Tabla 4 Resultado de las cinco fuerzas de Porter................................................................ 27

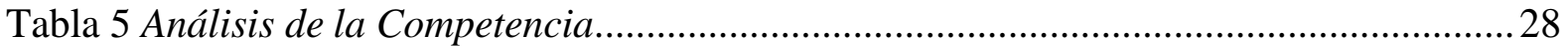

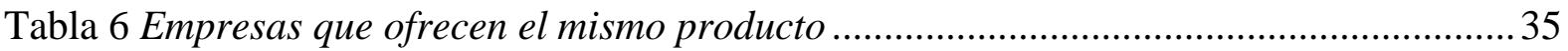


Tabla 7 Participación de mercado

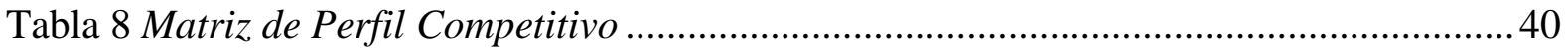

Tabla 9 Matriz de Evaluación de Factores Externos (EFE).................................................54

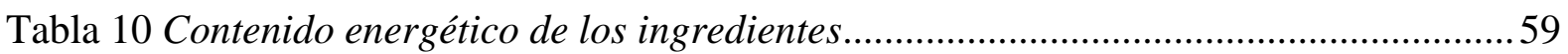

Tabla 11 Agencias emisoras de turistas a la ruta Mollepata - Salkantay-Machupicchu...... 72

Tabla 12 Afluencia de turistas a Mollepata 2016, según nacionalidad .................................. 73

Tabla 13 Agencias especializadas en actividad de aventura, ruta Mollep.-Salk.-Machupic. 76

Tabla 14 Agencias de viajes tour operadoras de alta demanda .......................................... 77

Tabla 15 Agencias de viajes tour operadoras de regular demanda ........................................ 78

Tabla 16 Agencias de viajes tour operadoras de baja demanda ........................................... 79

Tabla 17 Segmentación por tamaño de agencias de viajes .................................................... 80

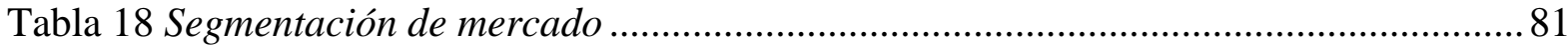

Tabla 19 Resumen de ficha técnica entrevistas en profundidad............................................ 84

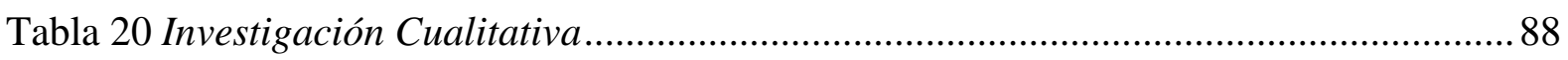

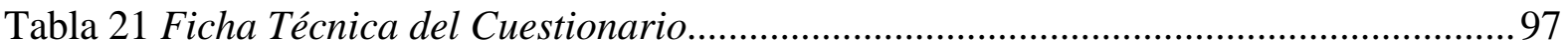

Tabla 22 Agrupación de agencias de viajes según ventas .................................................... 98

Tabla 23 Participación mensual de la agencia por temporadas ........................................... 99

Tabla 24 Hoteles de donde provienen los clientes de las agencias de viajes ........................ 102

Tabla 25 Hoteles de donde provienen los clientes de las agencias de viajes ......................... 103

Tabla 26 Agencias de viajes que incluyen el desayuno en su tarifa ..................................... 105

Tabla 27 Proporción de diez viajeros que desayunan en Mollepata...................................... 106

Tabla 28 Proporción de diez viajeros que desayunan en Mollepata..................................... 108

Tabla 29 Decisión para la elección del restaurante ................................................................ 109

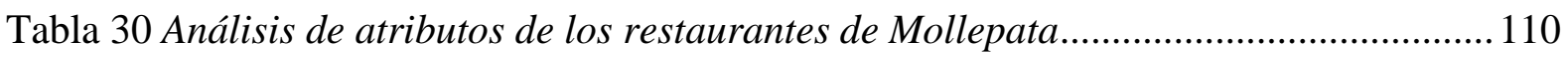

Tabla 31 Satisfacción de los turistas con los restaurantes de Mollepata............................... 111

Tabla 32 Atributos que el turista más valora en un restaurante en Mollepata ...................... 113 
Tabla 33 Tipo de desayuno que más consumen los turistas

Tabla 34 Testeo del producto.

Tabla 35 Testeo de ubicación y diseño

Tabla 36 Testeo centro de interpretación

Tabla 37 Testeo promoción.

Tabla 38 Testeo Marca

Tabla 39 Decisión de cambio a la propuesta de negocio 121

Tabla 40 Ingreso anual de turistas a Mollepata. 128

Tabla 41 Datos para la regresión lineal.

Tabla 42 Determinación de los valores de las variables.

Tabla 43 Proyección del ingreso de turistas a Mollepata.

Tabla 44 Selección del mercado potencial

Tabla 45 Lista de agencias que conforman el mercado potencial.

Tabla 46 Proyección del mercado potencial

Tabla 47 Proyección del mercado disponible.

Tabla 48 Pregunta de filtro.

Tabla 49 Determinación de mercado efectivo según criterio Pope.

Tabla 50 Proyección del mercado efectivo 138

Tabla 51 Proyección del mercado objetivo

Tabla 52 Pronóstico de ventas.

Tabla 53 Personal para el negocio.

Tabla 54 Balance de implementos para la administración

Tabla 55 Balance de implementos para la cocina 150

Tabla 56 Balance de equipos para el proceso de producción

Tabla 57 Balance de implementos para salón principal

Tabla 58 Balance de equipos para el Centro de Interpretación. 
Tabla 59 Factores Locacionales.

Tabla 60 Análisis de la misión

Tabla 61 Correlación entre principios y valores institucionales.

Tabla 62 Matriz VRIO de ventajas competitivas criticas

Tabla 63 Planilla de remuneraciones y compensaciones

Tabla 64 Los cinco niveles de producto de Kotler.

Tabla 65 Activos Tangibles

Tabla 66 Activos Intangibles.

Tabla 67 Variación anual del capital de trabajo 204

Tabla 68 Capital de Trabajo 204

Tabla 69 Costo del proyecto 205

Tabla 70 Inversiones Futuras .205

Tabla 71 Financiamiento del proyecto 206

Tabla 72 Datos para la tasa de descuento del accionista 207

Tabla 73 Beta del sector 207

Tabla 74 Presupuesto de Ventas. 209

Tabla 75 Presupuesto de Costos de Producción. 210

Tabla 76 Promedio de Costo de Insumos 210

Tabla 77 Presupuesto de Compras

Tabla 78 Presupuesto de Costo de Ventas.

Tabla 79 Presupuesto de Gastos Administrativos

Tabla 80 Presupuesto de Marketing y Ventas.

Tabla 81 Presupuesto de Gastos Financieros

Tabla 82 Estado de Ganancias y Pérdidas Proyectado.

Tabla 83 Balance Proyectado

Tabla 84 Flujo de Caja Económico 216 


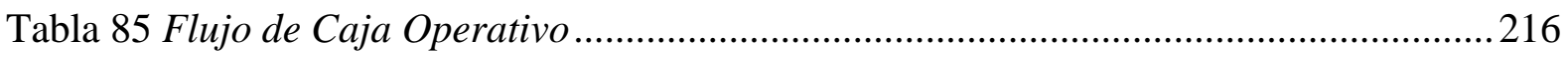

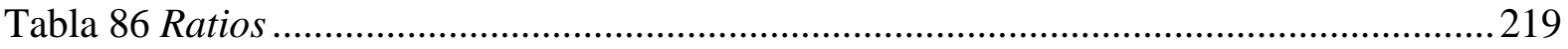

Tabla 87 Costos y gastos mensuales (costos fijos y costos variables).................................. 220

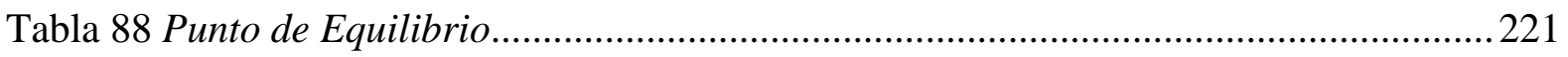

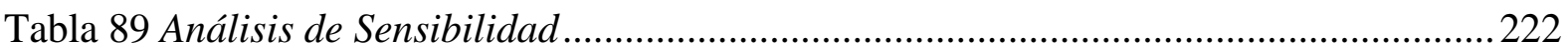

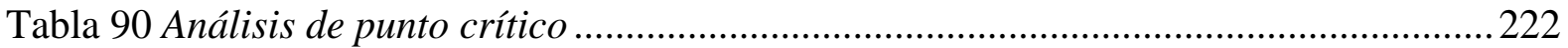

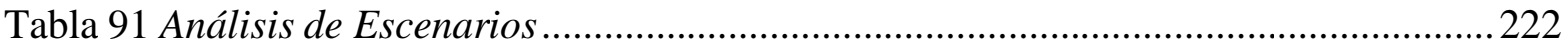




\section{Índice de Figuras}

Figura 1. El turismo y las exportaciones no tradicionales, ............................................. 10

Figura 2. Producción Nacional 2016..................................................................................... 11

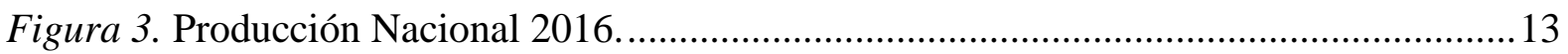

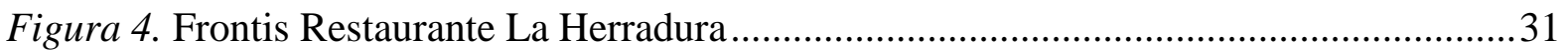

Figura 5. Interior Restaurante Sumaq Terminal Terrestre ...................................................32

Figura 6. Comedor del interior del restaurante Don Julio................................................... 33

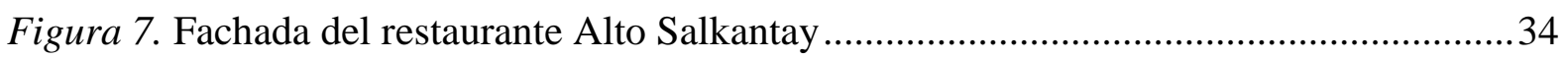

Figura 8. Participación de Mercado. ................................................................................. 38

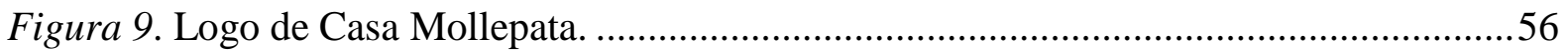

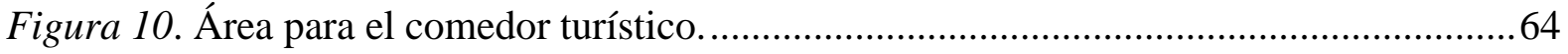

Figura 11. Vista panorámica del Restaurante en maqueta. ................................................65

Figura 12. Interior del Restaurante en maqueta ............................................................ 65

Figura 13. Vista panorámica del centro de interpretación en maqueta. ..................................66

Figura 14. Vista panorámica del centro de servicios turísticos en maqueta............................66

Figura 15. Operación de las agencias de viajes mayoristas según segmentación por distribución.

Figura 16. Registro del arribo de turistas nacionales y extranjeros al distrito de Mollepata... 80

Figura 17. Participación mensual de las agencias por temporadas. .................................... 100

Figura 18. Hoteles de procedencia de las agencias de viaje................................................ 102

Figura 19. Lugar donde desayunan los viajeros, análisis cuantitativo ................................. 104

Figura 20. Agencias que incluyen el desayuno en su tarifa, análisis cuantitativo. ................ 105

Figura 21. Proporción de cada diez viajeros que desayunan en Mollepata........................... 107

Figura 22. Gasto promedio de viajeros en el desayuno, análisis cuantitativo........................ 108

Figura 23. Total, satisfacción con los restaurantes............................................................. 112 
Figura 24. Decisión de cambio con la propuesta de negocio

Figura 25. Actividades de la cadena de valor..................................................................... 143

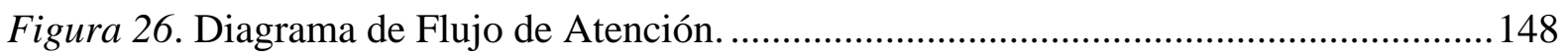

Figura 27. Diagrama de Flujo de la Cocina. ................................................................... 149

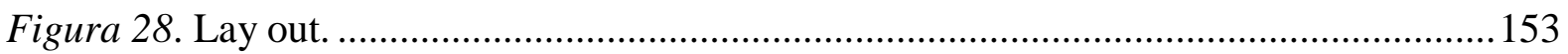

Figura 29. Las tres estrategias genéricas de Michael Porter. ................................................. 168

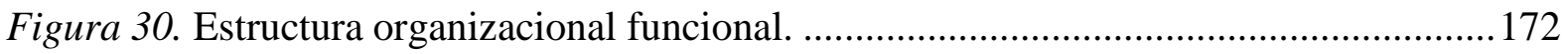

Figura 31. Descripción del puesto de Administrador............................................................ 173

Figura 32. Descripción del puesto de Asistente Administrativo........................................... 174

Figura 33. Descripción del puesto de Cocinero (Chef) …................................................ 175

Figura 34. Descripción del puesto de Asistente de Cocina. ..................................................176

Figura 35. Descripción del puesto de los mozos................................................................. 176

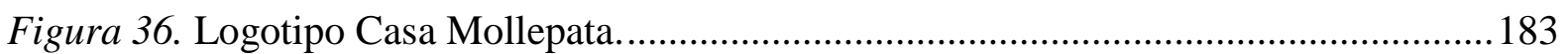

Figura 37. Gasto promedio de viajeros en restaurantes en Mollepata. ................................. 188 


\section{Capítulo I. Generalidades}

\subsection{Antecedentes}

El turismo es una actividad económica que cada día cobra mayor importancia, puesto que se ha convertido en un sector que viene contribuyendo a mejorar las economías de los países en especial de aquellos que están en vías de desarrollo. De acuerdo con las cifras que proporciona el Ministerio de Comercio Exterior y Turismo (MINCETUR), la actividad turística en el Perú viene creciendo sostenidamente; desde el 2011 al 2016 esta creció en un $43.3 \%$, lo que significa un crecimiento en promedio anual del $7.5 \%$ en estos últimos cinco años (MINCETUR, 2015); además el Perú recibió el 2016 un total 3.1 millones de turistas y se estima que para el 2020 llegara a los 10 millones de turistas (Gestión, 2016). Especialistas del sector, miembros de la Cámara Nacional de Turismo (CANATUR), indican que el Perú se verá beneficiado con el perfil de los nuevos viajeros, quienes están buscando destinos turísticos con características similares a las que Perú ofrece; tal como indican expertos en mercadeo norteamericano, "los viajeros de hoy, cada vez más buscan de nuevos destinos, culturas, gastronomía, naturaleza, viajes temáticos y deseo por experiencias que sean auténticas, aunadas al confort, calidad y altos estándares de servicio”. (Future Brand, 2013, pág. 17). El Perú es un destino que atrae a muchos turistas gracias al legado cultural de las civilizaciones antiguas, la biodiversidad de sus ecosistemas, pero sobre todo debido a la existencia de la ciudad Inca de Machupicchu, que año a año viene consolidándose como uno de los atractivos turísticos más importantes del mundo al igual que la gran muralla China o las pirámides de Giza en Egipto.

Por esta razón Machupicchu es el atractivo turístico emblemático de Perú y la región de Cusco es el destino más importante y articulador de la oferta turística en el país. Miles de turistas arriban diariamente a la ciudad del Cusco con el objetivo primordial de poder conocer 
la maravilla del mundo, Machupicchu. Los turistas programan diversas actividades turísticas de acuerdo con sus intereses y motivaciones, las cuales se pueden dividir en tres grupos que son: (a) turismo cultural, el cual consiste en visitar lugares históricos, arqueológicos, museos o participar en manifestaciones folclóricas y antropológicas; (b) turismo de naturaleza, que consiste en realizar actividades recreativas de apreciación y conocimiento de la naturaleza a través de la interacción con la misma, por ejemplo avistamiento de flora y fauna nativa, interacciones con los ecosistemas, etc.; y (c) turismo de aventura, el cual engloba actividades que requieren de destrezas especiales y condiciones físicas, dentro de las que se tienen: actividades en bicicletas, en caballos, en kayac, senderismo, trekking, etc. Es importante mencionar que los turistas que visitan la región del Cusco muchas veces combinan varios tipos de actividades, pero todas tienen como objetivo fundamental poder conocer la ciudad inca de Machupicchu.

De las muchas actividades turísticas mencionadas que se realizan en Cusco, la que se analiza en el presente plan de negocios es la actividad del Trekking, la cual se define como "una modalidad del turismo de aventura que consiste en recorrer a pie largas distancias o zonas determinadas, generalmente de alta montaña y poco frecuentadas por el turismo convencional" (Saavedra, 2011). Debido a lo accidentado de la geografía cusqueña, el trekking es una actividad que viene siendo muy demandada por los turistas extranjeros de preferencia jóvenes, quienes vienen con el objetivo de cruzar las altas montañas antes de llegar al destino final que es Machupicchu. El 32\% del total de turistas que ingresan a la ciudad del Cusco optan por realizar una actividad de trekking antes de llegar a Machupicchu (PROMPERU, 2015). La ruta más importante para hacer trekking en Cusco es el Camino Inca tradicional, que conecta directamente a la ciudadela de Machupicchu desde el pueblo de Piscacucho en el valle del rio Urubamba, pero debido a su alta demanda se vienen desarrollando otras rutas de trekking como la de Lares, Patachancha, Ollantaytambo y Machupicchu por el lado de la provincia de Calca; otra ruta que ingresa por la selva de La 
Convención conocida como Inca Jungle que es materia de estudio en el presente plan de negocios, la ruta de Mollepata - Salkantay - Machupicchu, por el lado de la provincia de Anta al lado noroeste de la ciudad del Cusco.

\subsection{Determinación del Problema u Oportunidad}

La ruta Camino Inca tradicional es la principal ruta de trekking para acceder a Machupicchu, en una aventura que, por lo general dura cuatro días y tres noches. Debido al incremento de la actividad turística en la zona es que existe a la fecha una saturación de visitantes, generando una sobredemanda. Según el Ministerio de Cultura se cuenta con un tope de 500 cupos diarios para hacer el Camino Inca y los turistas tienen que reservar inclusive, con ocho meses de anticipación para acceder a un cupo, siendo muchos los desafortunados que no logran hacer el trekking por el Camino Inca tradicional.

Debido a esta situación, los operadores en turismo del Cusco han explorado y aperturado nuevas rutas de trekking, utilizando antiguos caminos incas que conectaban los pueblos de los andes. Las nuevas rutas de trekking hoy son conocidas como caminos incas alternativos y están teniendo buena aceptación por los turistas debido a la variada geografía y la naturalidad paisajística que estos lugares aún conservan. De todas las rutas alternativas de trekking del Cusco la que más sobresale es la de Mollepata - Salkantay - Machupicchu, porque es una ruta donde el turista cruza una de las montañas más altas del Perú, como es el nevado Salkantay (6,271 m.s.n.m.), y además conecta directamente con la ciudad inca de Machupicchu. Para dicha ruta de trekking, la actividad turística en el distrito de Mollepata es aún muy precaria e improvisada, el gobierno municipal no cuenta con planes y expertos que regulen la actividad turística, la oferta turística local como son restaurantes y otros servicios, son bastante precarios a pesar de que diariamente decenas de turistas arriban al poblado de Mollepata (ámbito de influencia de la investigación), para iniciar con el trekking. En el caso específico, los turistas llegan a Mollepata para tomar el desayuno, y hacen uso de servicios 
turísticos; sin embargo, a pesar de que los pobladores se esfuerzan por satisfacer a los turistas, la falta de conocimiento en temas de restauración; estándares de calidad;

desconocimiento de los intereses específicos de la demanda turística y la carencia de innovación en servicios turísticos, origina la imperante necesidad de mejorar las cosas en pro de la satisfacción de los visitantes.

Ambientes improvisados, poca iluminación, servicios higiénicos insalubres y muchas veces para ambos sexos, cocinas y lugares de preparación de alimentos sin ninguna ventilación, utensilios sucios y desconocimiento de atención al cliente mínima, son las características principales de estos establecimientos, cuyos propietarios son los mismos que atienden y preparan los alimentos, en un conjunto de restaurantes que fueron pensados, en primer lugar, en satisfacer la escasa demanda local y que, al frente de una demanda turística súbita y creciente, hicieron poco por mejorar y adaptarse al nuevo consumidor, presentando un estancamiento en el servicio y en la preparación de platos.

Esta problemática ya ha sido percibida por los operadores de turismo, quienes tienen como objetivo cumplir las expectativas de sus clientes desde el inicio de la ruta, pero ante la carencia de servicios turísticos óptimos tienen que acomodarse a la realidad, motivo por el cual surge la oportunidad de crear una propuesta innovadora capaz de satisfacer dicha demanda ofreciendo un servicio especializado de calidad con buena infraestructura, que además ofrece valor agregado para que los visitantes disfruten y conozcan más acerca de la cultura del lugar; y de esta manera puedan continuar con la ruta de trekking. 


\subsection{Justificación del Proyecto}

El circuito turístico Mollepata - Salkantay- Machupicchu, viene consolidándose como una importante ruta de trekking para llegar a la ciudadela de Machupicchu, esto debido a la variedad geográfica y naturalidad paisajística, pero, con respecto a la infraestructura y servicios de soporte para la actividad turística estos son en realidad muy precarios, influenciando negativamente en la satisfacción del turista. Es necesario considerar que existe una demanda insatisfecha a demostrar, la cual necesita servicios turísticos correctamente implementados de acuerdo con las exigencias y estándares del turista de aventura. Este hecho mejorará la oferta turística de la ruta de trekking, lo que significará un beneficio directo al poblador local.

La idea de negocio para la creación de un Centro de Servicios Turísticos en el distrito de Mollepata, ayudará a profundizar los conocimientos de las ciencias administrativas aplicadas al sector turismo, y por otro lado es una innovadora idea de negocio que tiene mucho potencial de rentabilidad al mediano plazo.

\subsection{Objetivos Generales y Específicos}

\subsubsection{Objetivo General.}

- Evaluar la viabilidad del plan de negocios para la creación de un centro de servicios turísticos en el distrito de Mollepata, Cusco; como parte del circuito turístico de trekking Salkantay - Machupicchu. 
1.4.2. Objetivos Específicos.

- Analizar las condiciones especiales y potenciales del sector turístico en Cusco y Perú, haciendo un análisis del sector.

- Realizar un estudio de mercado, con el fin de elaborar el plan de marketing del negocio, y poder hacer una proyección de la demanda, basados en segmentos específicos del mercado.

- Diseñar la ingeniería del proyecto, determinar la información básica para el diseño de los servicios turísticos (restaurant - centro de interpretación) y desarrollo de las especificaciones de los mismos.

- Identificar los aspectos legales y administrativos, así como el tipo de organización legal, bajo la cual será constituida y su estructura organizativa.

- Elaborar una evaluación económico financiera del proyecto, de los criterios de evaluación, punto de equilibrio, análisis de la sensibilidad y riesgo.

\subsection{Alcances y Limitaciones de la Investigación}

El presente plan de negocios tiene como alcance proponer la creación de un centro de servicios turísticos, integrando un restaurant con centro de interpretación en el distrito de Mollepata, Cusco, como parte del circuito turístico de trekking Salkantay - Machupicchu.

El horizonte que se fijó para la evaluación del presente proyecto es de cinco años, comprendidos desde el 2017 al 2021, período representativo del ciclo de vida del producto. 
Las limitaciones que se encontraron para el desarrollo del plan de negocio son:

- Falta de accesibilidad a los antecedentes sobre la actividad turística en Mollepata, debido a que el Estado no cuenta con ningún registro de datos históricos sobre el desarrollo de la actividad turística en provincias emergentes, los únicos datos secundarios para armar la estadística son los que realiza la municipalidad desde el año 2015, controlando el ingreso de turistas a dicho distrito.

- Falta de un registro oficial de restaurantes turísticos en el distrito; en vista de que el Municipio de Mollepata no lleva un listado oficial de los restaurantes o empresas que brindan servicios turísticos en el área.

- Poca disponibilidad de los dueños de restaurantes y administradores de agencias de viajes de la zona, al momento de levantar información de tipo primaria, por el recelo y cautelo de estos frente a preguntas y cuestionarios sobre sus negocios y/o empresas. 


\section{Capítulo II. Estructura Económica del Sector}

\subsection{Descripción del Estado Actual de la Industria}

La industria donde se desarrolla el plan de negocios pertenece al sector terciario o de servicios definido por el Estado Peruano como aquellas actividades que tienen como elemento principal la capacidad humana para realizar trabajos físicos o intelectuales; comprende una gran variedad de empresas como las de transporte, bancos, comercio, seguros, hotelería, turismo, asesorías, restaurantes, educación entre otras (Produce, 2015). En la industria terciaria o de servicios, se encuentra ubicada la industria turística, y dentro de la misma se encuentran los restaurantes turísticos y centros de interpretación, este último no comprende una unidad de negocio, por el contrario, complementará al servicio de restaurante turístico, única unidad de negocio del presente plan.

El sector terciario o de servicios en el país está en constante crecimiento, así lo demuestran los primeros siete meses del año 2016, en los cuales dicho sector creció $4.8 \%$ con respecto al año anterior 2015 (El Economista América, 2016). Este resultado es el reflejo de un sector que cada vez va teniendo mayor participación en el Producto Bruto Interno (PBI) nacional, según un estudio realizado por el Instituto de Economía y Desarrollo Empresarial de la Cámara de Comercio de Lima, que refiere que los primeros tres meses del 2015, el sector servicios fue un aportante importante en el PBI, incluso, por encima del sector minero y comercio (Gestión, 2015).

El presente plan de negocios de un restaurante turístico en Mollepata, se ubica en el sector hospedajes y restaurantes; y de acuerdo con el informe técnico $N^{o} 1$, enero 2017 del Instituto Nacional de Estadística e Informática (INEI); este sector tuvo un incremento de $2.35 \%$ con respecto al mes de noviembre del año anterior, dicho crecimiento se sustenta en las promociones y descuentos implementados, descentralización de puntos de ventas, atención 
personalizada, presentación de líneas gourmet y nuevas propuestas gastronómicas de dichos establecimientos. Además, por el impulso del Estado, llámense Gobiernos Regionales, Municipios, asociaciones público privadas con iniciativas tales como el Día de la Salchipapa, Festival de Damasco, Feria Gastronómica de Mistura, Perú Mucho Gusto y el Festival del Camarón (INEI, 2017).

Tabla 1

Crecimiento del sector hospedajes y restaurantes

\begin{tabular}{|c|c|}
\hline Sector & Variación porcentual 2016/2015 1ro de Noviembre \\
\hline Restaurantes y Hospedajes & 2.35 \\
\hline $\begin{array}{l}\text { Nota. Adaptado de "Inform } \\
\text { de Estadística e Informática, } \\
\text { https://www.inei.gob.pe/med } \\
\text { n01_produccion-nacional-n }\end{array}$ & $\begin{array}{l}\text { 'écnico N 1", enero 2017, por Instituto Nacional } \\
\text { IEI 2017. Recuperado de } \\
\text { MenuRecursivo/boletines/01-informe-tecnico- } \\
\text { 2016.pdf }\end{array}$ \\
\hline
\end{tabular}

El sector de hospedajes y restaurantes, anteriormente analizado, se divide en dos subsectores, el de hospedajes y el de restaurantes. A continuación, se presenta un análisis de la situación actual del subsector de restaurantes en el mes de noviembre del 2016 (el cual registró un incremento de $1.65 \%$, gracias al desarrollo favorable de restaurantes como centros de comida rápida, pollerías, restaurantes turísticos, chifas y cevicherías), frente a los resultados del mes de noviembre del 2015. Este crecimiento, a su vez, va de la mano con la apertura de puntos de ventas, promociones, festivales, y diversas actividades gastronómicas descritas anteriormente. Con respecto al turismo nacional, los restaurantes preferidos por los nacionales son la comida criolla con un $59 \%$, el pollo a la brasa con un $14 \%$ y la cocina típica regional con un $9 \%$, cifras que fueron definidas en relación con la variable conductual de la industria (Sociedad Peruana de Gastronomía, APEGA, 2016). 


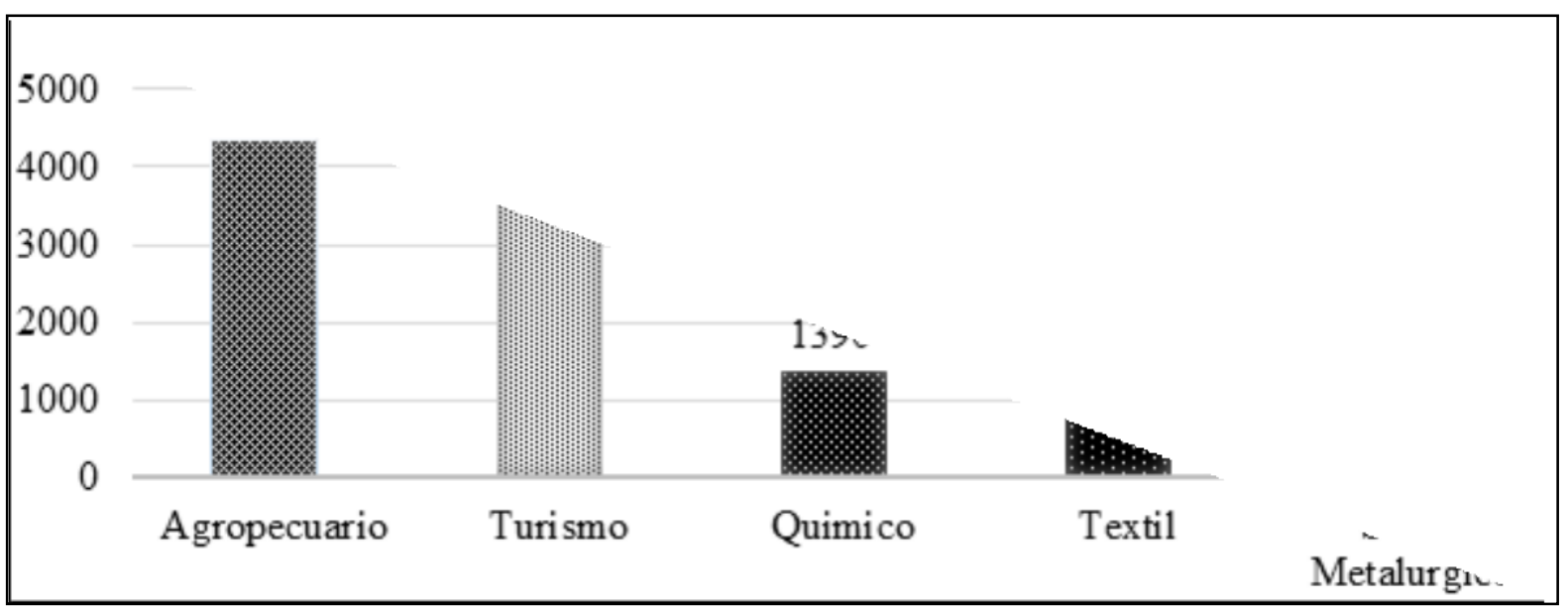

Figura 1. El turismo y las exportaciones no tradicionales, 2015. Tomado de "Medición Económica del Turismo" Ministerio de Comercio Exterior y Turismo (MINCETUR) (2016). Recuperado de: http://www.mincetur.gob.pe/wpcontent/uploads/documentos/turismo/ publicaciones/MEDICION_ECONOMICA_TURISMO_ALTA.pdf

Con respecto a la industria turística, es uno de las más importantes industrias que genera divisas al país, el ingreso de divisas significa 4,151 millones de dólares, demostrando un crecimiento de $47.5 \%$ entre el 2011 al 2015. Por este motivo, el PBI turístico representa el $3.9 \%$ del PBI total del país. El turismo al ser comparado con las exportaciones no tradicionales, tiene el segundo lugar, superado solamente por la industria agropecuaria (MINCETUR, 2016).

El turismo receptivo en el Perú tiene una tasa de crecimiento de arribos de turistas internacionales de $8.1 \%$, que está por encima de la tasa promedio de la región $3.7 \%$ y del mundo $2.2 \%$; demostrando así un incremento sostenido por parte de la demanda, siendo exactos 3’282,671 de visitantes extranjeros llegaron el 2015 al país, sin embargo, estos encuentran una oferta cada vez más estancada, poco diversificada y alejada de estrategias de promoción y renovación (PROMPERU, 2016). Con respecto al turismo interno nacional, este se incrementó $4 \%$ con respecto al año anterior 2014, lo cual significa 4.6 millones de visitas nacionales internas; y Cusco registra $4.8 \%$ más de ingreso de visitantes con respecto al año 
anterior (Gestión, 2015). Traduciendo esta información en números; se tiene 1’247,414.98 visitantes en Cusco el 2015, siendo la segunda región más visitada después de Lima (PROMPERU, 2015).

2.1.1. Segmentación de la Industria.

Como se mencionó anteriormente, la industria se divide en dos subsectores:

a) Subsector restaurantes

El subsector restaurantes se encuentra segmentado en cuatro áreas, las cuales son: servicios a empresas de transportes y concesionarios, restaurantes, servicios de bebidas y servicio de catering. En la siguiente figura se puede observar el crecimiento que dichas áreas tuvieron en comparación a noviembre del 2015.

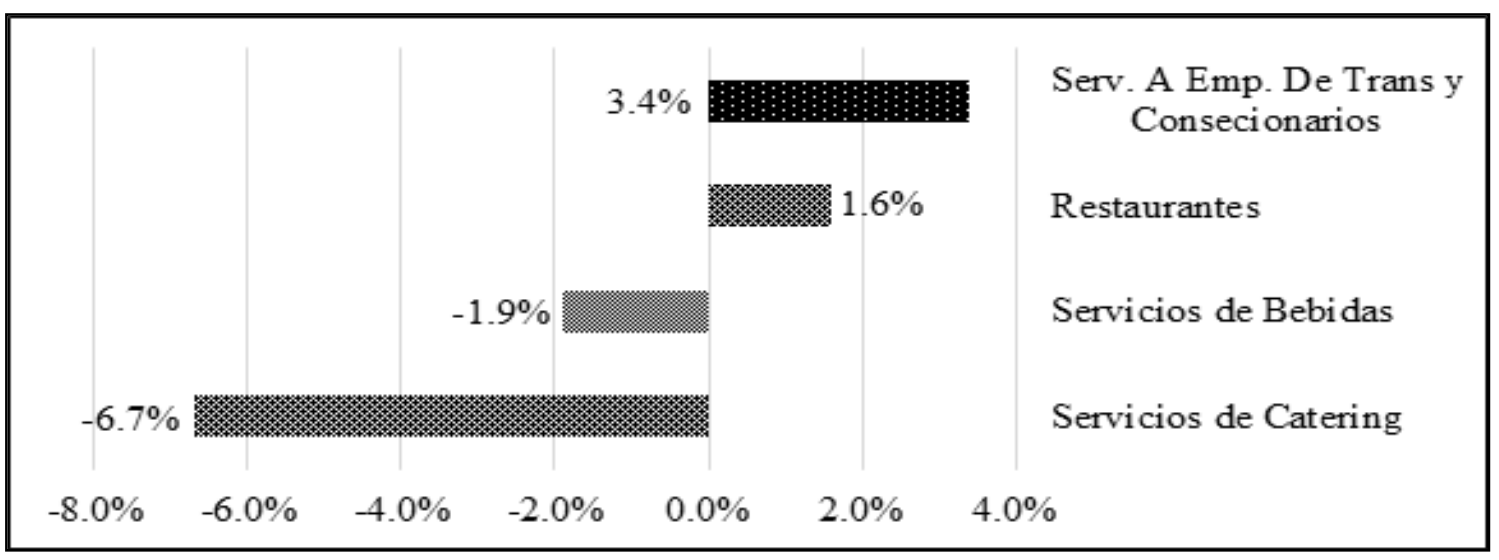

Figura 2. Producción Nacional 2016. Tomado de "Informe Técnico N01" (INEI), subsector restaurantes, enero 2017. Recuperado de:

https://www.inei.gob.pe/media/MenuRecursivo/ boletines/01-informe-tecnicon01_produccion-nacional-nov2016.pdf 
El área de servicios a empresas de transporte y concesionarios tuvo un incremento de $3.42 \%$ en noviembre del 2016, en comparación a los resultados de noviembre del 2015 , debido al incremento de concesionarios de alimentos, a través de contratos y proyectos en campamentos mineros, petrológicos, centros de salud e industrias; reflejando de esta manera una oferta variada y de calidad en servicios de comedor. El área de restaurantes, como se indicó en párrafos anteriores, también creció un $1.65 \%$ debido al desarrollo favorable de restaurantes turísticos, pollerías, comidas rápidas, heladerías, cevicherías, carnes y parrillas, comida japonesa, sandwicherías, café restaurantes, pizzerías, comida criolla y gracias a los factores clave como puntos de venta, promociones, festivales gastronómicos, entre otros.

Por otro lado, el servicio de bebidas registró una disminución de $-1.85 \%$ por la disminución del dinamismo en actividades como juguerías, bar restaurantes, discotecas y pubs; sin embargo, las cafeterías y bares crecieron motivadas por la expansión de franquicias, apertura de locales, mayor capacitación de clientes, promociones, entre otros.

El área de servicio de catering registró un decrecimiento notable, con $-6,67 \%$ por la disminución de la demanda en el servicio de preparación y distribución de alimentos para eventos y la atención de bufetes y banquetes (INEI, 2017).

La Dirección Regional de Comercio Exterior y turismo del Cusco (DIRCETUR) registra un total de 93 establecimientos, de los cuales el $94 \%$ están debidamente categorizados, mientras que el $37 \%$ pertenecen a la categoría de restaurantes de un tenedor. Los establecimientos con servicios básicos, no presentan diferenciación por género de servicios higiénicos, el comedor debe encontrarse separado del área de preparación de alimentos y cocina, el menú debe de estar compuesto por tres tiempos, sopas, guisados o especialidades y postres de la casa o frutas. 
De estos establecimientos, el $56 \%$ se encuentra identificado como restaurantes de dos tenedores (restaurantes que exigen diferenciación de servicios higiénicos por género, personal uniformado, materiales de comedor nuevos, vajilla sencilla pero irrompible, la carta de menú exige cuatro tiempos, considerando también la entrada de casa); el $7 \%$ son identificados como restaurantes de tres tenedores (también llamados restaurantes turísticos, exigen una entrada al establecimiento para comensales separada del ingreso de trabajadores del restaurante, personal uniformado, el espacio de comedor es más reducido, pero cuenta con una carta variada de menú, hasta de seis tiempos, como ejemplo se menciona el entremés, sopas y cremas, verduras, huevos o pastas, especialidades de pescado, especialidades de carne y postres, dulces o helados y fruta). En la siguiente figura se puede observar la cantidad de restaurantes con un tenedor, dos tenedores y tres tenedores.

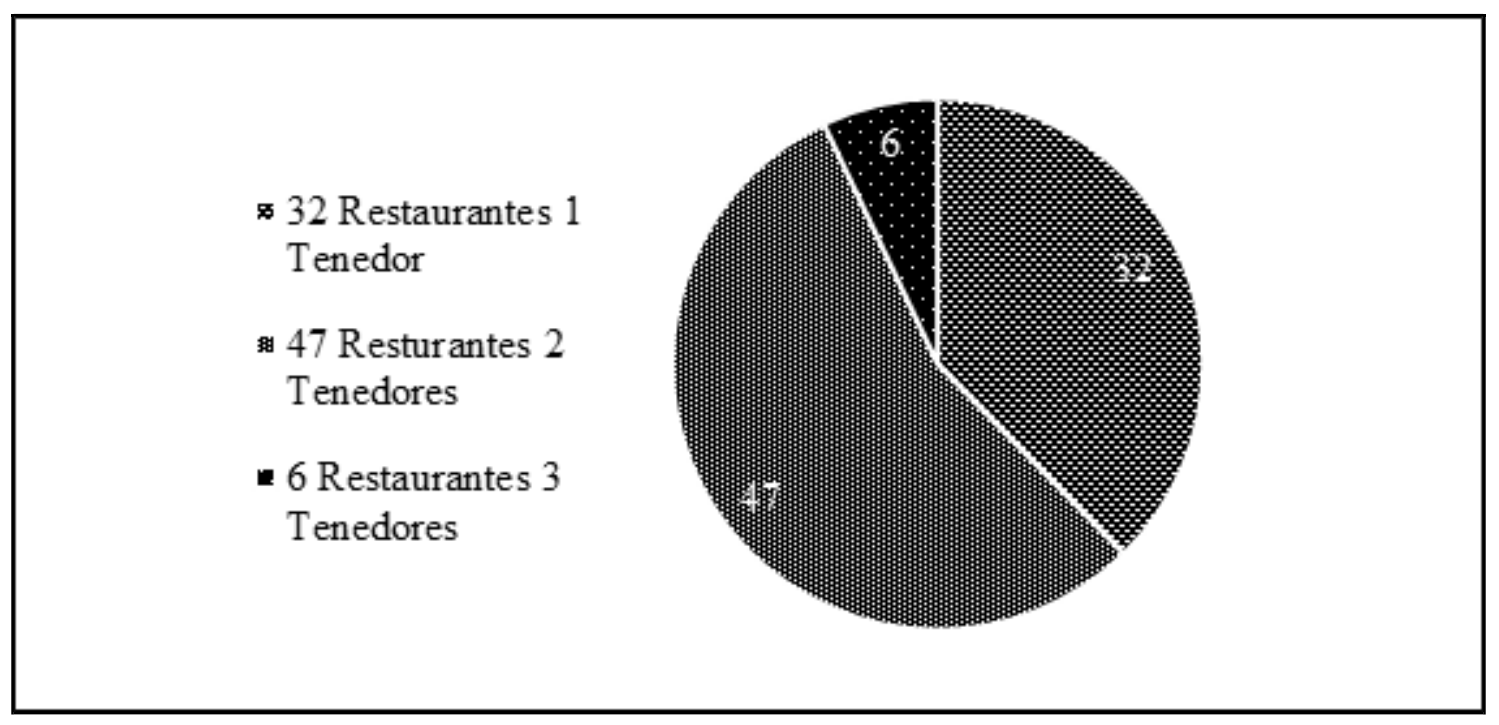

Figura 3. Producción Nacional 2016. Tomado de "Informe Técnico N 01" (INEI), noviembre 2016. Recuperado de: https://www.inei.gob.pe/media/MenuRecursivo/ boletines/01-informe-tecnico-n01_produccion-nacional-nov2016.pdf 
Respecto a los restaurantes cuatro tenedores, cuentan con una mesa de bar básico, personal uniformado y calificado, opción de menú siete tiempos y de cinco tenedores (que son aquellos establecimientos de restauración más sofisticados, personal uniformado y con altos conocimientos en atención al cliente, acceso al establecimiento diferenciado entre comensales y personal del establecimiento, valet parking, área de bar, sala de espera, aire acondicionado, menú de seis tiempos con opciones especiales); no se cuenta con registro alguno en la ciudad de Cusco (DIRCETUR, 2016).

2.1.2. Empresas que la conforman (ubicación, volumen de ventas, empleados, etc.)

Estos negocios se encuentran representados por todos los restaurantes registrados en la Municipalidad del Distrito de Mollepata, Provincia de Anta, Departamento del Cusco. Es necesario indicar que estos restaurantes registrados no tienen segmentada a la clientela por ser tradicionales, costumbristas y con atención al público en general, y mayormente intentan adaptarse a las exigencias del turista sin poder cumplir con sus expectativas, principalmente cuando consume en los establecimientos en las mañanas al comenzar el trekking al nevado de Salkantay.

A fin de obtener información sobre los restaurantes que conforman la industria, se realizó una recolección de datos, donde a través de un cuestionario de preguntas dirigido a los dueños y encargados de los restaurantes en Mollepata, se obtuvo información sobre el volumen de ventas, número de trabajadores, horarios de atención y el registro del equipamiento; que se detalla en la siguiente tabla: 
Tabla 2

Empresas que conforman la industria de restaurantes en el distrito de Mollepata

\begin{tabular}{|c|c|c|c|c|c|}
\hline Criterio & Restaurante La Herradura & $\begin{array}{c}\text { Restaurante } \\
\text { Sumac Terminal } \\
\end{array}$ & $\begin{array}{c}\text { Restaurante } \\
\text { Don Julio } \\
\end{array}$ & $\begin{array}{r}\text { Restaurante } \\
\text { Humantay } \\
\end{array}$ & $\begin{array}{c}\text { Otros } \\
\text { restaurantes }\end{array}$ \\
\hline Ubicación & Plaza de Armas S/N & $\begin{array}{c}\text { Terminal } \\
\text { terrestreS/N }\end{array}$ & $\begin{array}{c}\text { Calle } \\
\text { AyacuchoN } \\
321\end{array}$ & $\begin{array}{c}\text { Calle Ayacucho } \\
\text { N } 333\end{array}$ & Varios \\
\hline Cantidad de empleos & 5 & 5 & 5 & 4 & 3 \\
\hline Horarios de atencion & 5:30 a 10:00 horas & $\begin{array}{l}\text { 5:30 a 09:30 } \\
\text { horas }\end{array}$ & $\begin{array}{l}\text { 6:00 a 10:00 } \\
\text { horas }\end{array}$ & $\begin{array}{l}\text { 6:00 a 09:00 } \\
\quad \text { horas }\end{array}$ & $\begin{array}{l}\text { 6:00 a 09:00 } \\
\quad \text { horas }\end{array}$ \\
\hline $\begin{array}{l}\text { Volumen de Ventas en } \\
\text { numero de desayunos } \\
\text { Temporada BAJA } \\
\text { (Enero - Febrero) }\end{array}$ & 4 & 3 & 2 & 2 & 2 \\
\hline $\begin{array}{c}\text { Temporada MEDIA } \\
\text { BAJA (Marzo- } \\
\text { Noviembre- DIciembre) }\end{array}$ & 15 & 10 & 8 & 6 & 6 \\
\hline $\begin{array}{l}\text { Temporada ALTA } \\
\text { (Abril a Octubre) }\end{array}$ & 35 & 23 & 19 & 14 & 14 \\
\hline $\begin{array}{c}\text { Cantidad de mesas y } \\
\text { sillas }\end{array}$ & 10 & 10 & 8 & 8 & 6 \\
\hline Precio del Menú & $20-18$ soles & 19 - 15 soles & 20 - 15 soles & 20 - 15 soles & $18-15$ soles \\
\hline & -Servicio Higiénicos. & $\begin{array}{l}\text {-Servicio } \\
\text { Higiénicos. }\end{array}$ & $\begin{array}{l}\text {-Servicio } \\
\text { Higiénicos. }\end{array}$ & $\begin{array}{l}\text {-Servicio } \\
\text { Higiénicos. }\end{array}$ & $\begin{array}{l}\text {-Servicio } \\
\text { Higiénicos. }\end{array}$ \\
\hline $\begin{array}{c}\text { Servicios } \\
\text { Complementarios }\end{array}$ & $\begin{array}{l}\text {-Energla Eléctrica. } \\
\text {-Agua y Desagüe }\end{array}$ & $\begin{array}{l}\text {-Energía } \\
\text { Eléctrica. } \\
\text {-Agua y } \\
\text { Desagüe }\end{array}$ & $\begin{array}{l}\text {-Energía } \\
\text { Eléctrica. } \\
\text {-Agua y } \\
\text { Desagüe }\end{array}$ & $\begin{array}{l}\text {-Energía } \\
\text { Eléctrica. } \\
\text {-Agua y } \\
\text { Desagüe }\end{array}$ & $\begin{array}{l}\text {-Energía } \\
\text { Eléctrica. } \\
\text {-Agua y } \\
\text { Desagüe }\end{array}$ \\
\hline
\end{tabular}

Como se observa, existen cuatro restaurantes que son los más importantes, siendo "La Herradura" el restaurante turístico que tiene aproximadamente un 35\% de participación total de mercado, mientras que los demás tienen una participación menor al 25\%. Cabe resaltar que estos negocios operan de acuerdo al flujo de demanda durante un año, estos flujos determinan la temporada: (a) temporada baja, entre los meses de enero y febrero son los de menor demanda mensual y representa entre el $1 \%$ y $2 \%$ del año, siendo febrero el mes más bajo; (b) temporada media, que comprende los meses de marzo, octubre noviembre y diciembre. También se le conoce como temporada alta, aunque el volumen de turistas aún es regular, tiene un promedio del $6 \%$ mensual del año; y (c) temporada alta, 
que comprende los mejores meses del año desde mayo a octubre debido al temporal (sin lluvia); en esta temporada los restaurantes reciben hasta 60 turistas por día.

\subsection{Tendencias de la Industria}

La industria turística es una actividad dinámica, en busca de nuevas opciones adecuadas a las necesidades del turista, de esta manera la búsqueda de la autenticidad del visitante para explorar zonas únicas, particulares, especiales aunadas al confort calidad y altos estándares de servicio será la primera tendencia en los próximos años. El crecimiento de la demanda en países emergentes es otra tendencia identificada en el Plan Estratégico Nacional de Turismo 2012 - 2021, que indica que la demanda turística en países emergentes tuvo un crecimiento constante y más acelerado que economías desarrolladas, y esta ventaja se mantendrá los próximos años en continentes como Asia, América Latina, Europa Central, entre otros. El internet, como herramienta global de búsqueda y establecimiento de comercio, será importante para el turismo, las nuevas tecnologías de información que se desarrollen, están siendo aprovechados tanto por la demanda (al buscar información sobre los productos, atractivos y recursos turísticos) y por la oferta (que hace llegar sus propuestas y servicio a través de estas tecnologías de la información). La mayor influencia de la Marca País en la decisión de compra será importante, y el esfuerzo del gobierno por comunicar los potenciales atractivos del país, mostrándolo al mundo como una sola marca, genera interés en la demanda internacional (MINCETUR, 2015). 
Tabla 3

Principales tendencias en las industrias de turismo y restaurantes

\begin{tabular}{ll}
\hline \multicolumn{1}{c}{ Industria Turística } & \multicolumn{1}{c}{ Industria de Restaurante } \\
\hline Búsqueda de la identidad & $\begin{array}{l}\text { Platos con ingredientes naturales y } \\
\text { orgánicos }\end{array}$ \\
$\begin{array}{l}\text { Crecimiento del turismo en } \\
\text { economías emergentes }\end{array}$ & $\begin{array}{l}\text { Platos fusión con productos de la } \\
\text { zona, naturales }\end{array}$ \\
El internet & $\begin{array}{l}\text { Sabores y olores únicos y que sean } \\
\text { representativos del lugar } \\
\text { Cocina tradicional, respetando } \\
\text { procesos de preparación de alimentos } \\
\text { oriundos de la zona }\end{array}$ \\
Los motivos de viaje & \\
Mayor influencia de la Marca \\
País en la decisión de compra
\end{tabular}

El subsector de restaurantes presenta claras tendencias para el futuro, la variable que se considera es el tipo de comida que se expende en ellos y los insumos que utilizan en su preparación. De esta manera los restaurantes en los cuales se expenden platos a base de ingredientes naturales y orgánicos, presentarán un fuerte crecimiento en los próximos años; en el que los consumidores o comensales están cada vez más informados, el estado y origen de los insumos jugarán un papel fundamental a la hora de elegir un restaurante y la cocina, incluso obviando los platos con abundante grasa y aceite, como se mencionó anteriormente, el futuro consumidor solo priorizará aquellos establecimientos cuyas opciones de comida estén preparados en base a productos orgánicos y naturales, ya sean estos grasa o aceites pero de origen natural. (APEGA, 2012). Otra importante variable a la hora de identificar tendencias es la autenticidad de la cocina y sus productos, platos que sean únicos y representativos de cada establecimiento serán fundamentales para el consumidor que rescate sabores y olores que representen la región donde se encuentre viviendo o visitando. Esta característica va a la par con la tradición que tenga la cocina, que respete y rescate procesos 
de preparación y cocción de alimentos de acuerdo a la usanza de la localidad, región o zona (Masías, 2016).

En el caso particular del poblado de Mollepata, al ser el punto de partida de la ruta de trekking Salkantay - Machupicchu, actividad que ofrece experiencias y lugares únicos y novedosos, presenta una tendencia creciente en el nivel de demanda año tras año, sin embargo, la oferta turística del lugar como restaurantes, abarrotes y hospedajes; no acompaña este crecimiento, encontrándose estancado y presentando un nivel de servicios y productos pobres y escasos. El Municipio de Mollepata es consciente del potencial turístico de este distrito, por ser el acceso turístico a la montaña de Salkantay y por el futuro proyecto de accesibilidad al complejo arqueológico de Choquequirao (conocido como el segundo Machupicchu), en ese sentido, el Municipio Distrital de Mollepata y el Municipio Provincial de Anta han creado la denominación de "Mollepata, capital turística y arqueológica de la provincia de Anta", ante la oportunidad de desarrollo turístico para los siguientes años.

\subsection{Análisis Estructural del Sector Industrial}

Como David (2013) señala, para estructurar y aplicar habilidades en diferentes industrias del sector, el estudio del modelo de las cinco fuerzas de Porter es esencial. El análisis de estas fuerzas devela el grado de atractividad de un sector industrial y su vinculación con el logro de utilidades.

El Modelo de las Cinco Fuerzas de Porter se establece como referencia para el estudio estructural del sector industrial en referencia, que permitirá determinar si es que la industria es atractiva o no para el presente proyecto. 
2.3.1. Poder de negociación de los consumidores.

Se evalúa la posibilidad de que los clientes lleguen a fijar las reglas del juego en relación a los negocios, afectando de este modo la utilidad de las empresas del sector.

Depende de la cantidad de consumidores, de la relevancia que el producto tiene sobre los costes de los clientes, del grado de diferenciación de los servicios del sector, del valor de rentabilidad del sector del consumidor y de la cabida que tenga el cliente (Larrache, $\mathrm{H}$. Boyd and J., 2011).

El turismo y las empresas que se desarrollan en su ámbito, llámense agencias de viajes, hoteles, restaurantes, spas, centro de interpretación, entre otros, forjan sus relaciones comerciales mediante convenios, reconociendo a esta relación como primordial para el comercio entre empresas, es por esa razón que se identifica en el ámbito del negocio una relación Business to Business (B2B). Las agencias de viajes tour operadoras son proveedoras de clientes finales o turistas para el negocio a implementar, identificándolas como clientes o consumidores.

En general se observa que el poder de negociación de las agencias de viajes es alto por las siguientes razones: las agencias de viajes poseen un mediano grado de concentración de clientes, ya que son muy pocas agencias que operan el circuito de trekking Mollepata Salkantay - Machupicchu, a pesar que el volumen de venta de solo algunas agencias es más del $75 \%$ del total de la demanda total; estas agencias no están integradas ni unificadas; sin embargo, tienen algunas posibilidades de escoger o cambiar el lugar de compra a un costo mucho más bajo. En Mollepata se encuentran ubicados diversos restaurantes, pero no poseen un nivel de calidad de servicio comparables al proveído por el proyecto. Además, existe una posibilidad mínima de que las agencias de viajes decidan elaborar su propia oferta de desayunos para los viajeros que llegan a Mollepata, es el caso de la agencia de viajes Alpaca Expeditions, que prefiere llevar sus propios cocineros y 
armar un desayuno a las afueras del poblado de Mollepata, esta opción les resulta más costosa, pero le garantiza la calidad en el servicio que no encuentran en los restaurantes de Mollepata, que se propone en el presente plan de negocio.

De esta manera se puede concluir que el poder de negociación de los consumidores es medio alto, lo cual significa que la industria no es muy atractiva.

\subsubsection{Poder de negociación de los proveedores.}

Las empresas suministradoras pueden ejercer una gran influencia de negociación sobre los restaurantes y/o participantes del subsector restaurantes, elevando los precios de los insumos o materias primas, disminuyendo la calidad de los mismos, la calidad de servicios, y en el caso de maquinaria o tecnología utilizada en los restaurantes. Las condiciones que empoderan a los proveedores generalmente producen el mismo efecto en los consumidores (David, 2013).

El presente proyecto se localiza en el distrito y pueblo de Mollepata, ubicado en la provincia de Anta, a $120 \mathrm{~km}$ de la ciudad del Cusco. Para este negocio existen dos tipos de proveedores; los campesinos, quienes trabajan las tierras de cultivo y proveen productos agrícolas como tomates, espinacas, quinua y otros; estos proveedores son agricultores del distrito de Mollepata y del valle del Apurímac; este escenario propone también una oportunidad, ya que, trabajar y consumir productos oriundos de la zona y adquirirlos directamente del productor local significaría un gran ahorro en costes de transporte. Por otro lado, están los proveedores de productos de abarrotes como yogurt, leche, café, té, tostadas, entre otros; los cuales provienen de los supermercados ubicados en el Cusco, el poder de estos últimos es casi mínimo puesto que no existen barreras para acceder a ellos y hay una gran cantidad de supermercados donde los precios son accesibles; sin embargo, 
se tiene que considerar la logística para transportar dichos productos desde Cusco a Mollepata, que no representa un problema relevante.

Con respecto a los proveedores campesinos, que cosechan sus productos en la misma zona de Mollepata y alrededores, el poder de negociación es bajo, dado que existe una gran cantidad de proveedores que se encuentran ubicados dentro del ámbito de influencia del proyecto.

2.3.3. Entrada potencial de nuevos competidores.

Según David (2013) se presentan casos en los cuales, nuevos emprendimientos acceden a mercados determinados, traspasando las barreras de entradas sólidas que presentan los mismos. Por esta razón, las empresas están en la obligación de intuir y señalar a las nuevas compañías que entran al mismo mercado de desarrollo, de esta manera pueden evitar y reducir el impacto de las acciones de estos nuevos competidores, a través de acciones estructuradas y enfocadas a tiempo.

Los principales competidores son pequeños restaurantes que ofrecen alimentos de manera improvisada y sin considerar las mínimas normas de salubridad, también existen pequeñas tiendas de abarrotes que venden productos, muchas veces en mal estado o simplemente de dudosa procedencia (contrabando o adulterados). De esta forma, dentro de las barreras de ingreso al mercado se tiene:

a) Economías de escala

Se puede observar que, en el distrito de Mollepata, no existe ningún negocio y/o restaurante que puede producir o generar servicios en grandes cantidades, que le permita reducir los costos unitarios de los productos. Aproximadamente, cuatro negocios son los participantes en el mercado, enfocándose a un sector reducido de 
visitantes, por este motivo la producción es reducida. No existen economías de escala en la zona y, por ende, no representan una barrera de entrada para todos los nuevos competidores y/o restaurantes en la zona.

b) Diferenciación de productos

Actualmente, existen solo cinco restaurantes registrados en la Municipalidad de Mollepata, dichos restaurantes ofrecen desayunos básicos que contienen un plato de fondo (generalmente cocina regional y criolla), un mate y/o café y dos raciones de pan.

Por tratarse de negocios empíricos, cuyo mercado objetivo no ha sido especificado, expenden productos y servicios indistintamente, no existe ninguna característica de diferenciación e innovación, lo cual hace que la industria sea atractiva para una nueva propuesta con productos diferenciados y de acuerdo con las exigencias del turista de aventura que desea hacer el circuito Mollepata - Salkantay - Machupicchu.

c) Requerimiento de capital

La zona en la que se implementará el negocio, Mollepata; es una zona alejada del foco económico del Cusco, motivo por el cual el requerimiento de capital para implementar el proyecto (infraestructura, costos de transporte de insumos, implementación de servicios, entre otros), será determinante. Para cualquier competidor nuevo que quiera ingresar a este sector, este factor representará una barrera de entrada a considerar; sin embargo, para el presente plan de negocios no, dado que el terreno donde se planea implementar el restaurante es propio (parte de herencia). 
d) Acceso a Canales de Distribución

Cuando una empresa cuenta con varios canales de distribución es complicado que puedan aparecer competidores y sobre todo que los proveedores acepten el producto. Esto implicaría para las empresas tener que compartir costos de promoción, de distribución y reducción de precios en general. (Larrache, H. Boyd and J., 2011)

La mayoría de unidades de negocios en Mollepata, poseen canales de distribución basados en la amistad que han desarrollado las agencias de viajes con pobladores de Mollepata que tienen sus restaurantes, quienes a su vez apoyan a las agencias de viajes con temas de logística y arrieros, por ejemplo. Esta relación de confianza ha permitido que muchos de ellos tengan relaciones hasta de compadrazgo, a pesar que el servicio de los restaurantes es deficiente. En otros casos no poseen mayores canales de distribución, salvo los llamados "boca a boca", es decir, por recomendación de los guías turísticos que mencionan el restaurante a las agencias de viajes y empresas por quienes operan.

Con respecto a la política gubernamental, es necesario mencionar que la Municipalidad de Mollepata no cuenta con una regulación drástica y tampoco con un control de calidad riguroso a los restaurantes de la zona.

Según el análisis realizado anteriormente, se puede determinar que la atractividad de la industria con relación a la entrada de nuevos competidores es alta.

Con referencia a las barreras de salida, se tiene tres aspectos importantes: 
a) Activos especializados

El proyecto utiliza equipos genéricos de restaurant y cocina, que, ante una posible liquidación, estas existencias son perfectamente negociables. Este factor, no representa obstáculo alguno de salida.

b) Costos fijos de salida

Para el proyecto en referencia, estos costos no significan una barrera de salida importante, ya que las acciones a tomar serian encargarse de las reparaciones económicas a los trabajadores y liquidación de los haberes de almacén.

c) Restricciones sociales y gubernamentales

Al trabajar con gente del poblado de Mollepata y respetar acuerdos municipalidades de funcionamiento, este factor no representa mayor barrera de salida.

2.3.4. Desarrollo Potencial de productos sustitutos.

Cuando los clientes cuentan con un producto que tiene varios sustitutos en el mercado o que puede llegar a tener un costo más alto o bajo que otros productos similares en el mercado, se puede tratar de un problema en el sector. Si los compradores están bien organizados, esto hace que sus exigencias sean cada vez más altas y que exijan incluso una reducción de precios notable. En este sentido, una empresa puede tener muchos problemas si los sustitutos de los productos comienzan a ser reales, eficaces y más baratos que el que vende la empresa inicial. Esto hace que dicho negocio este obligado a disminuir precios, lo que lleva a una disminución de utilidades en la empresa (Riquelme 2015).

En el sector, los servicios de alimentos y servicios de restaurantes no se limitan a la atención turística, que es una parte; también existen otros actores dentro de ella, como: 
empresas abastecedoras de alimentos especializados, restaurantes de hoteles, cocineros especializados; que acompañan al turista en los recorridos de más de un día, también llamados empresas de "Cookers". La calidad de servicio, la autenticidad del producto y el confort son factores determinantes y bien valorados por el consumidor final dentro del sector turístico, dichos consumidores transmiten esta preferencia a su cuenta o agencia de viaje operadora, quien prepondera calidad sobre precio y/o costo, en este sentido la relación calidad - precio en los productos sustitutos es baja en Mollepata. El crecimiento de productos sustitutos en la zona es bajo, ya que los factores determinantes como: calidad de servicio, autenticidad de producto y el confort; son importantes para entablar una relación comercial con una empresa turística de servicios alimentarios; es necesario mencionar que estos factores no están presentes en los cuatro restaurantes existentes en la zona. Este hecho representa una oportunidad en un mercado, como el de Mollepata, en el que el concepto de calidad de servicio no está bien desarrollado, y la zona, como se mencionó anteriormente no se encuentra en la capacidad de poseer sustitutos, dado que es un punto de partida de la ruta de trekking Mollepata - Salkantay - Machupicchu.

\subsubsection{Rivalidad entre empresas competidoras.}

El objetivo es evaluar la rivalidad entre los competidores que ya están instalados en el sector. Depende del número de competidores y su concentración, del crecimiento del sector industrial, del grado de diferenciación del sector, de los costes fijos de la actividad y de las barreras de salida (Riquelme 2015).

Existen aproximadamente diez restaurantes turísticos de los cuales cuatro tienen un claro dominio del mercado de restaurantes que ofrecen desayunos en el distrito de Mollepata, por lo que haría pensar que la rivalidad es alta sin embargo se observan las siguientes características: 
Los desayunos que ofrece la competencia son estándares básicos (continental, americano) y el nivel de servicio es bajo, observándose que existe un rol comercial pasivo y con incipiente valor agregado.

La industria de restaurantes turísticos va en crecimiento, sin embargo, en Mollepata no se evidencia un incremento considerable de dichos restaurantes dado que es una zona en la cual los visitantes no permanecen más de un día, porque optan por realizar el trekking a Machupicchu. Si bien es cierto esta ruta Mollepata - Salkantay - Machupicchu ha sido reconocida internacionalmente como una de las mejores rutas de trekking y los turistas compran este paquete turístico ante la saturación del Camino Inca tradicional. Esto origina que con frecuencia las visitas a la zona tengan alta rotación y este flujo dirigido por las agencias de viajes, no permite que exista una rivalidad entre competidores, dado que dichas agencias contratan previamente el servicio de uno de estos restaurantes. No obstante, puede existir la posibilidad de que algunos de los restaurantes, imiten la propuesta del proyecto, a fin de competir en la industria, pero se generaran estrategias para hacer frente al rival.

Respecto a los competidores actuales se puede concluir que el nivel de atractividad es alto, destacando las variables de nivel de servicio, costos fijos e industria en crecimiento.

En la siguiente tabla se muestra el consolidado del grado de atractividad de las cinco fuerzas de Porter se puede apreciar que en general la atractividad de la industria es alto. 
Tabla 4

Resultado de las cinco fuerzas de Porter

\begin{tabular}{lcc}
\hline \multicolumn{1}{c}{ Fuerzas de Porter } & $\begin{array}{r}\text { Ponderación } \\
\text { de la Fuerza }\end{array}$ & Atractividad \\
\hline Entrada potencial de nuevos competidores & Alta & Baja \\
Barreras de salida & Alta & Baja \\
Rivalidad entre empresas competidoras & Baja & Alta \\
Desarrollo potencial de productos sustitutos & Baja & Alta \\
Poder de negociación de los consumidores & Baja & Alta \\
Poder de negociación de los proveedores & Baja & Alta \\
Total & & Alta \\
\hline
\end{tabular}

\subsection{Análisis de la Competencia}

Según Porter (2013) para conocer claramente el comportamiento de la competencia, se deberá estudiar aquellas capacidades, metas futuras, suposiciones y estrategia actual. Indica, que la mayoría de veces las empresas intuyen las estrategias de sus competidores, fijándose en el comportamiento, sin prestar atención a los objetivos y metas, que son los verdaderos impulsores de los rivales y que van a permitir saber los pasos futuros que llevarán a cabo, de esta forma elabora estrategias y políticas para poder llevar la ventaja en el mercado.

En la tabla siguiente, se desarrolla un análisis de los factores de éxito, ponderaciones y calificaciones, teniendo en cuenta componentes del estudio realizado a la competencia, todo esto como consecuencia de las entrevistas a profundidad realizadas a expertos y a las agencias de viajes que operan el circuito Mollepata - Salkantay - Machupicchu y que están directamente relacionados con el mercado a tratar. 
Tabla 5

Análisis de la Competencia

\begin{tabular}{|c|c|c|c|c|c|c|c|}
\hline \multirow[t]{2}{*}{ Factores criticos de exito } & \multirow[b]{2}{*}{ Peso } & \multicolumn{2}{|c|}{ Restaurantes de hoteles } & \multicolumn{2}{|c|}{$\begin{array}{l}\text { Servicios de suministro de } \\
\text { comida por encargo }\end{array}$} & \multicolumn{2}{|c|}{$\begin{array}{l}\text { Servicio de cocineros } \\
\text { personales o "Coockers" }\end{array}$} \\
\hline & & Calificacion & Ponderacion & Calificacion & Ponderacion & Calificacion & Ponderacion \\
\hline Precios accesibles & 0.05 & 4 & 0.2 & 3 & 0.15 & 1 & 0.05 \\
\hline Atencion al cliente & 0.18 & 1 & 0.18 & 2 & 0.36 & 4 & 0.72 \\
\hline Establecimientos e instalaciones & 0.10 & 1 & 0.1 & 1 & 0.1 & 2 & 0.2 \\
\hline Variedad de opciones & 0.08 & 2 & 0.16 & 2 & 0.16 & 3 & 0.24 \\
\hline Dominio de otros idiomas & 0.04 & 4 & 0.16 & 1 & 0.04 & 3 & 0.12 \\
\hline Limpieza y vistosa presentacion & 0.13 & 2 & 0.26 & 3 & 0.39 & 3 & 0.39 \\
\hline Cumplimiento con los tiempos de atencion & 0.15 & 2 & 0.3 & 2 & 0.3 & 4 & 0.6 \\
\hline Buen sabor & 0.27 & 2 & 0.54 & 3 & 0.81 & 3 & 0.81 \\
\hline TOTAL & 1 & & 1.9 & & 2.31 & & 3.13 \\
\hline
\end{tabular}

Nota: Adaptadao del perfil competitivo de F. David, México 2013 copyright Editorial Pearson Educación

Es necesario precisar que el sector se compone de diversos grupos como son los restaurantes, comidas rápidas y restaurantes turísticos; lo que significa que la competencia es mayor.

En este sentido se puede apreciar que tomando en cuenta los competidores indirectos, la oferta de desayunos que ofrecen algunas agencias de viajes a través de sus propios cookers o cocineros representa el competidor indirecto más cercano al presente proyecto. Como nota aparte, se entiende que los restaurantes ubicados en la zona de Mollepata representan a los competidores directos del presente proyecto, los cuales serán descritos posteriormente.

A continuación, se muestran las características de cada uno de los competidores indirectos.

a) Restaurantes de hoteles (servicio box breakfast o caja de desayuno)

La oferta de desayunos que dan los hoteles es un servicio incluído y no tienen intención de competir con la propuesta de negocio, pero si influyen en la decisión del viajero. 
Cuando un viajero parte del hotel rumbo a Mollepata en horas de la madrugada, el cocinero del hotel prepara una caja de desayuno para que el viajero se la pueda llevar en el viaje, cabe mencionar que este "box breakfast" varia en la calidad y contenido de acuerdo con el tipo de establecimiento de hospedaje, en general los hoteles de alta categoría pueden llegar a ofrecer una caja de desayuno sustanciosa con frutas y sándwich, mientras que los hoteles de baja categoría solo ofrecen frutas y una galleta. Todas estas situaciones hacen que su comparación en competitividad con la propuesta del proyecto sea de puntuación bastante baja. Además, según estudios cuantitativos los viajeros en su mayoría provienen de establecimientos de hospedaje inferiores a las tres estrellas, por lo cual se deduce que la calidad de las cajas de desayuno no es competitiva. Muy pocos de estos establecimientos ofrecen este servicio y los viajeros prefieren desayunar en la ruta, lo que permite inferir que no es una alternativa usada frecuentemente por los mismos.

b) Servicio de suministro de comida por encargo

Estas son empresas que preparan alimentos, de preferencia conservados, que van a ser consumidos en ruta por los turistas. En la actualidad no existe una empresa especializada en la preparación de esta clase de alimentos; solamente los restaurantes de hoteles son los únicos proveedores de las agencias tour operadores del circuito Mollepata - Salkantay Machupicchu.

Este servicio no es habitual en los restaurantes de hoteles, motivo por el cual, previa una reserva y pedido, se elaboran los mismos, los restaurantes más reconocidos en la preparación de esta clase de alimentos son el Hotel Sonesta Posada del Inca Cusco y dos restaurantes turísticos, como la Cicciolina y el Chullpi. 
c) Servicio de cocineros personales o "Cookers" de las agencias de viajes

Este servicio forma parte del paquete turístico desarrollado por las empresas tour operadoras que realizan el circuito Salkantay y otros de trekking de alta montaña, consiste en proveer al pasajero de un personal especializado para prepararle los alimentos durante los días que dure el trekking o caminata alrededor del nevado, estos viajan con el cliente, y le proveen desayuno, almuerzo y cena en los distintos lugares acondicionados para camping en la zona. Actualmente solo la agencia de viajes Alpaca Expeditions es quien ofrece este tipo de servicio en la ruta a Salkantay, sus cocineros parten muy de madrugada y a 10 minutos del pueblo de Mollepata preparan un desayuno al aire libre.

Esta propuesta hace que el servicio sea más personalizado, sin embargo, las carencias como la ausencia de servicios higiénicos y la propuesta gastronómica, debe ser restringida.

En el caso de la Agencia Mountain Lodge, ellos tienen un campamento privado para desayunos, el cual es parte de una serie de infraestructuras que ofrecen en toda la ruta desde Mollepata hasta Aguas Calientes.

2.4.1. Empresas que ofrecen el mismo producto o servicio, indicando las semejanzas y diferencias que tienen con el proyecto de Empresa.

Las empresas registradas en la Municipalidad de Mollepata descritas anteriormente, son las únicas operativas y legales en la zona, la semejanza con el proyecto de investigación es únicamente el servicio de expendio de comida, dado que no tienen ofrecen otro servicio adicional.

A continuación, se muestran los resultados de entrevistas que se realizaron a los propietarios de los restaurantes turisticos de Molleptata con el objetivo de conocer más acerca del producto que ofrecen en la zona de estudio, en vista de que la informacion del municipio es muy limitada (ver anexo 7). 
El Restaurante La Herradura es de propiedad de la familia Ocampo una familia de Mollepata que se dedica a la actividad turística desde hace 10 años, además son proveedores de caballos y arrieros para muchas agencias de viajes en la ruta a Salkantay; este restaurant esta ubicado al costado del terminal terrestre de Mollepata justo en el ingreso al Pueblo.

La Herradura es de los principales restaurantes turísticos por su antigüedad, y el fácil acceso para las empresas de turismo. El restaurante cuenta con una capacidad aproximada de 30 comensales y una pequeña área verde de unos 25 metros cuadrados. La propuesta gastronómica que ofrecen se basa en desayunos para los turistas que viajan al Salkantay donde los cocineros y personal de servicio al cliente son miembros de la familia; el personal de servicio no habla ingles y es el guia de turismo el que hace de traductor con los clientes y el personal del restaurante. El precio del ticket promedio es de S/ 22.00 y según el propietario, en temporada alta pueden vender hasta 40 desayunos diarios y en temporada baja solo 15 desayunos diarios aproximadamente.

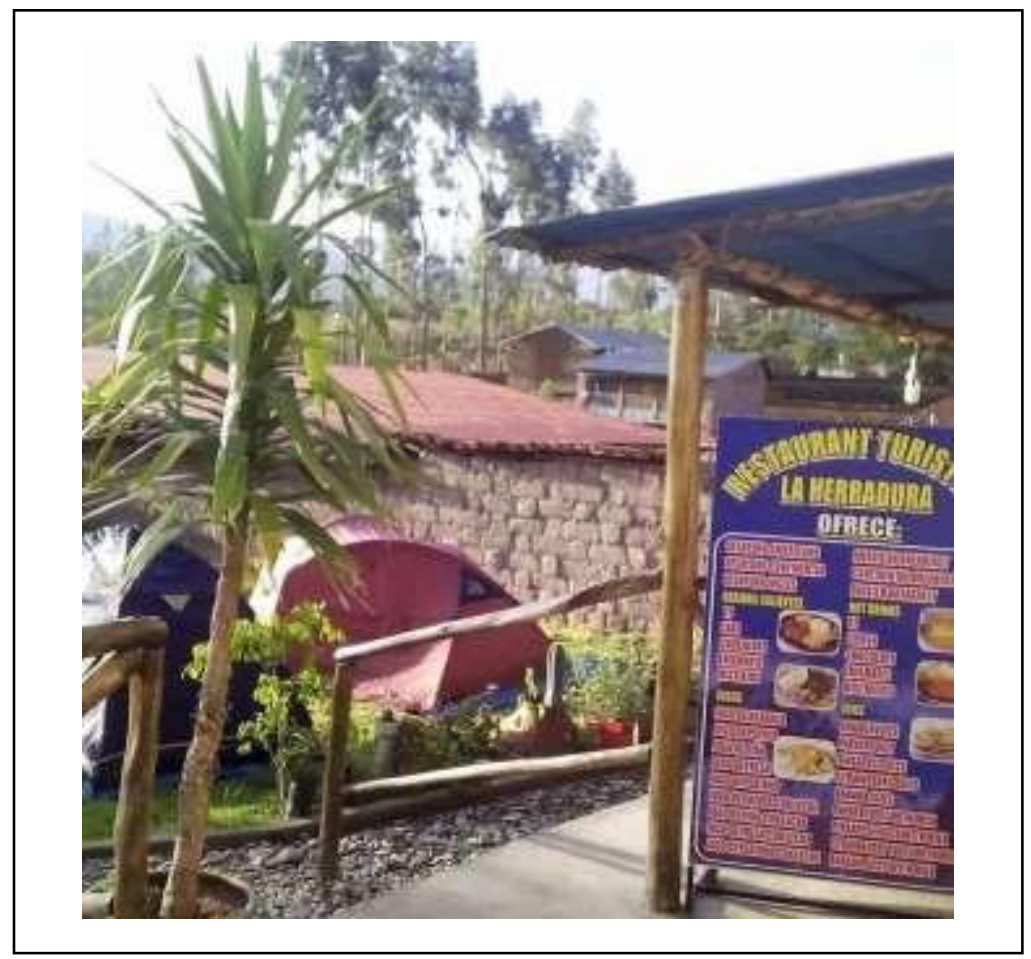

Figura 4. Frontis Restaurante La Herradura. 
El restaurante Sumaq Terminal Terrestre pertenece a otro poblador de Mollepata que alquiló un ambiente de 70 metros cuadrados del terminal terrestre y abrió un restaurante para que los viajeros ingresen a su restaurante justo cuando los buses de turismo ingresan al pueblo a registrarse en el terminal terrestre. Al igual que el restaurante La Herradura, son los mismos familiares que atienden a los viajeros, nadie habla ingles y tampoco tienen personal profesional en la elaboracion de los alimentos.

El local no cuenta con áreas verdes puesto que es un salón cerrado dentro del terminal terrestre, pero como se indicó anteriormente, los clientes lo eligen por la accesibilidad. El precio de venta promedio es de S/ 18.00, y según reporte del entrevistado se venden entre 35 desayunos en temporada alta y 15 desayunos diarios en temporada baja.

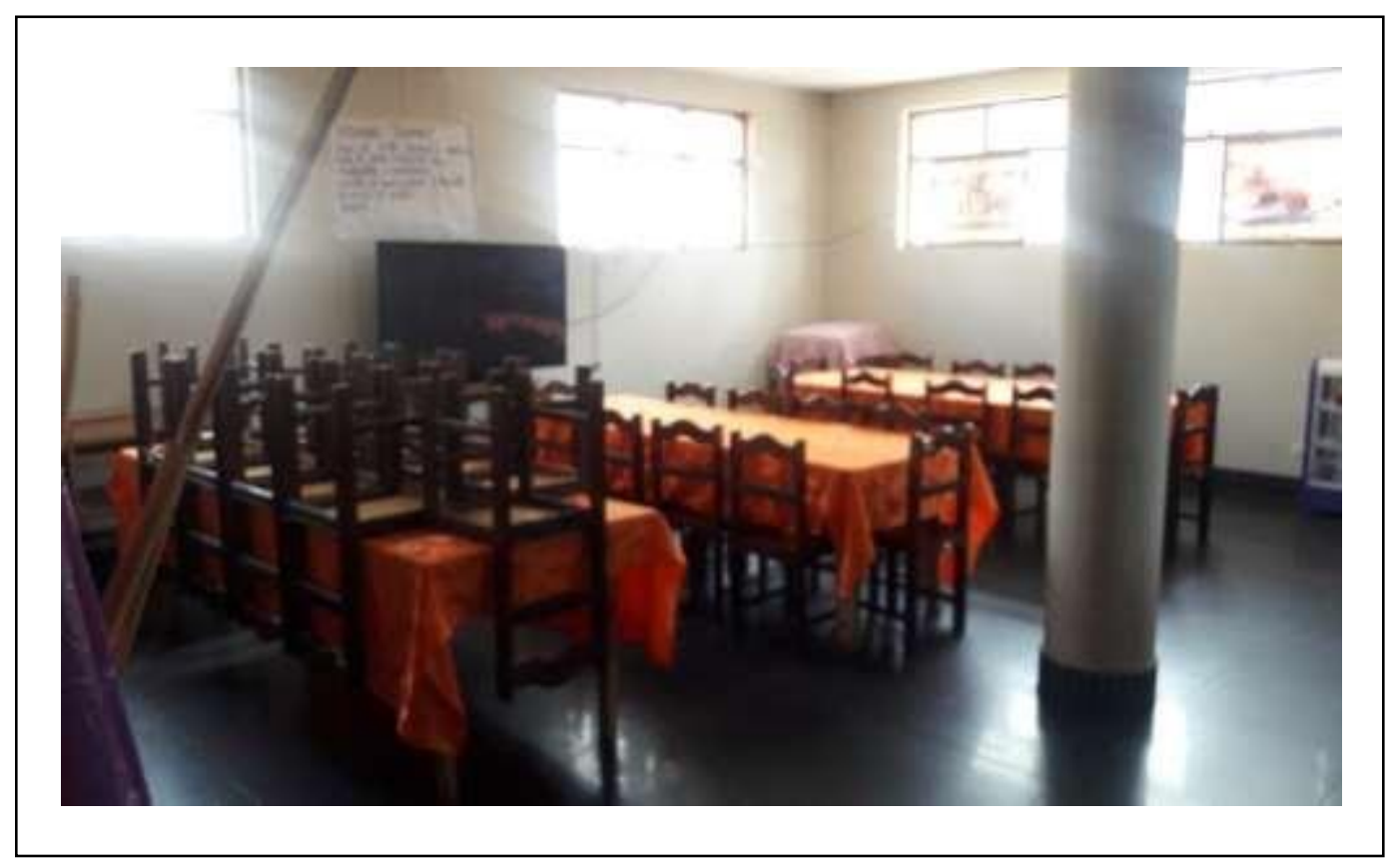

Figura 5. Interior Restaurante Sumaq Terminal Terrestre.

Don Julio Coffee and Breakfast, es otro restaurante que se encuentra en la plaza de Armas de Mollepata y pertenece al Sr. Julio Mendoza quien es un empresario que llegó al 
pueblo hace tres años y alquiló un salón de unos 60 metros cuadrados ubicado en la plaza de Armas de Mollepata y que tampoco tiene áreas verdes. La característica principal de este restaurante es el precio por debajo de la competencia (ticket promedio S/ 15.00) y ningun personal habla inglés y tampoco sus cocineros son profesionales. Según la entrevista que se hizo, este restaurant vende un promedio de 25 desayunos diarios en temporada alta y 10 desayunos en temporada baja.

El restaurante Humantay es de propiedad de la familia Portillo, familia de arrieros mollepatinos que tienen su restaurant en su misma casa desde hace unos cuatro años. La característica principal de este establecimiento es que solo trabajan con una agencia de viajes que es KB tours, una empresa dedicada a operar la ruta a Salkantay al menor precio del mercado, por lo que sus desayunos tienen un ticket promedio de S/ 12.00.

De acuerdo con las investigaciones existen relaciones de compadrazco entre los dueños del restaurante y la agencia de viajes KB Tours.

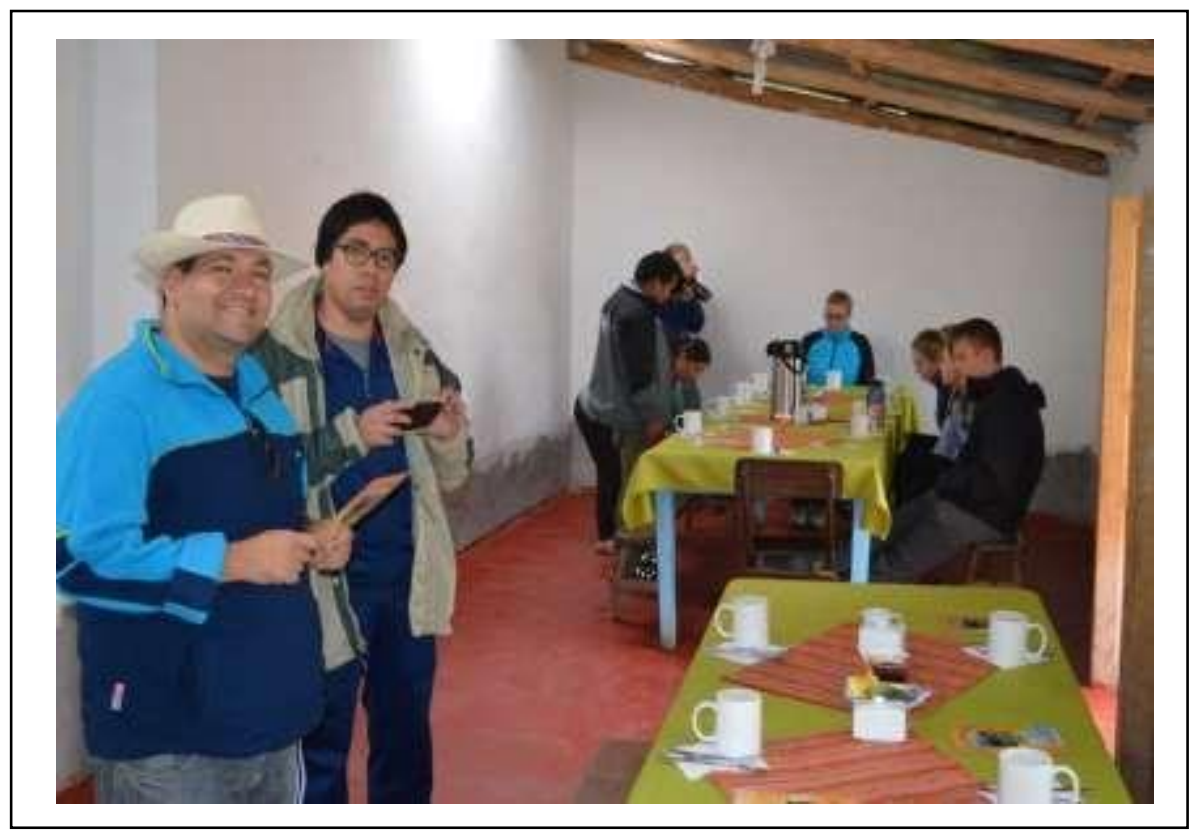

Figura 6. Comedor del interior del restaurante Don Julio. 
Existen otros grupos de restaurantes con menor participación de mercado que vendrian a ser casas, donde en temporada alta reciben grupos de turistas y acondicionan ambientes para recibirlos, como por ejemplo el restaurante Apu Salkantay, que se encuentra al costado de la carretera a Soraypampa y pertence a una familia de mollepatinos que acondicionaron su vivienda para recibir a los turistas. Además del restaurant, también funciona una polleria para los pobladores de Mollepata y una tienda de abarrotes. El motivo de la baja participacion de mercado se debe a lo improvisado de las instalaciones y la falta de preparación del personal.

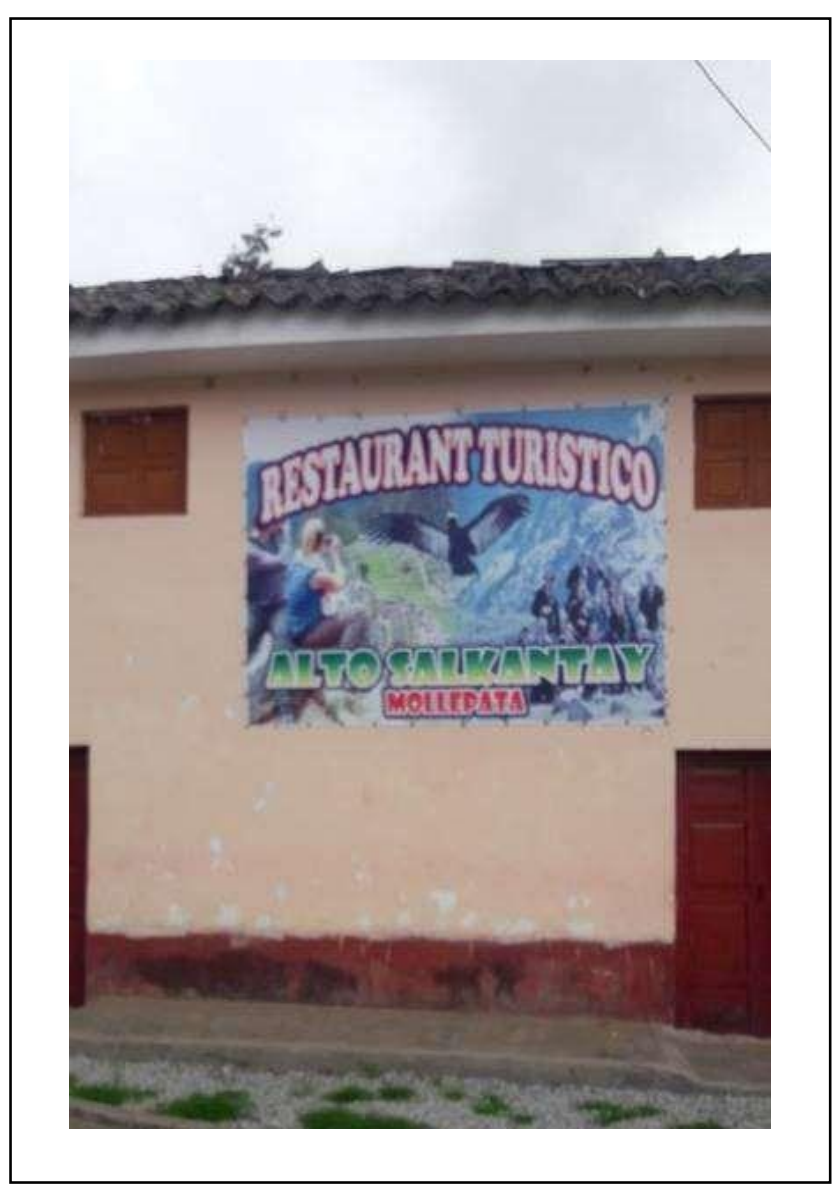

Figura 7. Fachada del restaurante Alto Salkantay. 
Como se dijo anteriormente, el plan de negocio será nuevo e innovador en la zona, encontrando varias diferencias con relación a los restaurantes que operan en la zona, por ejemplo:

- Precio del menú.

- Hora punta de atención en las mañanas.

- Cantidad de platos.

- Cantidad de la infraestructura.

- Cantidad de personal a cargo para la atención al cliente.

- Servicios complementarios al restaurante.

Tabla 6

Empresas que ofrecen el mismo producto

\begin{tabular}{|c|c|c|c|c|c|}
\hline Criterio & Restaurante La Herradura & $\begin{array}{c}\text { Restaurante } \\
\text { Sumac Terminal }\end{array}$ & $\begin{array}{c}\text { Restaurante } \\
\text { Don Julio }\end{array}$ & $\begin{array}{r}\text { Restaurante } \\
\text { Humantay }\end{array}$ & $\begin{array}{c}\text { Otros } \\
\text { restaurantes }\end{array}$ \\
\hline Ubicación & Plaza de Armas S/N & $\begin{array}{c}\text { Terminal } \\
\text { terrestre } \mathrm{S} / \mathrm{N}\end{array}$ & $\begin{array}{c}\text { Calle } \\
\text { Ayacucho N } \\
321\end{array}$ & $\begin{array}{c}\text { Calle Ayacucho } \\
\text { N } 333\end{array}$ & Varios \\
\hline Cantidad de empleos & 5 & 5 & 5 & 4 & 3 \\
\hline Horarios de atencion & 5:30 a 10:00 horas & $\begin{array}{l}\text { 5:30 a 09:30 } \\
\quad \text { horas }\end{array}$ & $\begin{array}{l}\text { 6:00 a 10:00 } \\
\text { horas }\end{array}$ & $\begin{array}{l}\text { 6:00 a 09:00 } \\
\text { horas }\end{array}$ & $\begin{array}{l}\text { 6:00 a 09:00 } \\
\text { horas }\end{array}$ \\
\hline \multicolumn{6}{|l|}{$\begin{array}{l}\text { Volumen de Ventas en } \\
\text { numero de desayunos }\end{array}$} \\
\hline $\begin{array}{l}\text { Temporada BAJA } \\
\text { (Enero - Febrero) }\end{array}$ & 4 & 3 & 2 & 2 & 2 \\
\hline \multicolumn{6}{|l|}{ Temporada MEDIA } \\
\hline \multicolumn{6}{|l|}{ Noviembre - DIciembre) } \\
\hline $\begin{array}{c}\text { Temporada ALTA } \\
\text { (Abril a Octubre) }\end{array}$ & 35 & 23 & 19 & 14 & 14 \\
\hline $\begin{array}{l}\text { Cantidad de mesas y } \\
\text { sillas }\end{array}$ & 10 & 10 & 8 & 8 & 6 \\
\hline \multirow[t]{2}{*}{ Precio del Menú } & $20-18$ soles & $19-15$ soles & $20-15$ soles & $20-15$ soles & $18-15$ soles \\
\hline & -Servicio Higiénicos. & $\begin{array}{l}\text {-Servicio } \\
\text { Higiénicos. }\end{array}$ & $\begin{array}{l}\text {-Servicio } \\
\text { Higiénicos. }\end{array}$ & $\begin{array}{l}\text {-Servicio } \\
\text { Higiénicos. }\end{array}$ & $\begin{array}{l}\text {-Servicio } \\
\text { Higiénicos. }\end{array}$ \\
\hline \multirow{4}{*}{$\begin{array}{c}\text { Servicios } \\
\text { Complementarios }\end{array}$} & & -Energía & -Energía & -Energía & -Energía \\
\hline & Energía Eléctrica. & Eléctrica. & Eléctrica. & Eléctrica. & Eléctrica. \\
\hline & -Agua y Desagüe & -Agua y & -Agua y & -Agua y & -Agua y \\
\hline & & Desagüe & Desagüe & Desagüe & Desagüe \\
\hline
\end{tabular}


En el caso de la atención de los turistas en las mañanas u hora punta, se debe recordar que estos establecimientos de restaurantes operan solo en las mañanas, aunque esporádicamente también atienden por las tardes y noches, ya que, al no tener una clientela segmentada, atienden indistintamente a lugareños y visitantes, por tal motivo, sólo se tomará en cuenta el rango de atención de mañana, dado que la mayoría de grupos y viajeros que van a iniciar el tour al circuito de Salkantay, se encuentran en Mollepata desde las 06:00 am hasta las 11:00 am.

2.4.2. Participación de mercado de cada uno de ellos.

Con el objetivo de conocer el porcentaje de participación de mercado de los restaurantes previamente señalados, se consideraron las encuestas que se realizaron a los propietarios de los restaurantes turísticos de Mollepata (ver anexo 7), debiendo mencionar también que los reportes de ingresos de turistas al pueblo de Mollepata (según puesto de control del terminal terrestre) el cual ascendió a 28,331 visitantes el año 2016 sirvieron para escatimar un aproximado de la participación de mercado de cada uno de ellos.

Al preguntar al encuestado (propietario del restaurant turístico) sobre su volumen de ventas aproximado, se fijaron tres tipos de volumen de ventas según las de temporadas de afluencia turística, las cuales son muy conocidas por los operadores de turismo en el Cusco y a su vez son reconocidas por los propietarios de los restaurantes de turismo en Mollepata. Generalmente son temporadas bajas o de bajo número de clientes, aquellos meses donde más llueve y son enero y febrero, después de esa fecha, el turismo empieza a subir en marzo y abril y se les conoce como temporadas medias, mientras que los meses de mayo a octubre son los mejores meses donde llegan más turistas y se le conoce como la temporada alta y finalmente para noviembre y diciembre baja ligeramente y se reconoce 
como temporada media. En la siguiente tabla se muestran los resultados de la afluencia de turistas de cada restaurant según las encuestas a los propietarios y con su respectiva proyección por temporada.

Tabla 7

Participación de mercado

\begin{tabular}{|c|c|c|c|c|c|c|c|c|c|c|}
\hline \multirow{2}{*}{$\begin{array}{c}\text { Restaurantes } \\
\text { Temporada de afluencia }\end{array}$} & \multicolumn{2}{|c|}{ La Herradura } & \multicolumn{2}{|c|}{ Sumaq Terminal } & \multicolumn{2}{|c|}{ Don Julio } & \multicolumn{2}{|c|}{ Humantay } & \multicolumn{2}{|r|}{ Otros } \\
\hline & $\begin{array}{l}\text { Prom. } \\
\text { Diario } \\
\end{array}$ & $\begin{array}{l}\text { Prom. } \\
\text { Temp. }\end{array}$ & $\begin{array}{l}\text { Prom. } \\
\text { Diario }\end{array}$ & $\begin{array}{l}\text { Prom. } \\
\text { Temp. }\end{array}$ & $\begin{array}{l}\text { Prom. } \\
\text { Diario T }\end{array}$ & $\begin{array}{l}\text { Prom. } \\
\text { emp. D }\end{array}$ & $\begin{array}{l}\text { Prom. } \\
\text { iario T }\end{array}$ & $\begin{array}{l}\text { Prom. } \\
\text { mp. Di }\end{array}$ & $\begin{array}{l}\text { Prom } \\
\text { iario T }\end{array}$ & $\begin{array}{l}\text { n. Prom. } \\
\text { Cemp. }\end{array}$ \\
\hline Baja (enero y febrero) & 5 & 300 & 4 & 240 & 2 & 240 & 1 & 60 & 0 & 0 \\
\hline $\begin{array}{l}\text { Media (marzo, abril, } \\
\text { noviembre, diciembre) }\end{array}$ & 20 & 2,400 & 15 & 1,800 & 12 & 1,440 & 10 & 1,200 & 3 & 360 \\
\hline $\begin{array}{l}\text { Alta (mayo, junio, julio, } \\
\text { agosto, seiembre, } \\
\text { octubre) }\end{array}$ & 42 & 7,560 & 35 & 6,300 & 20 & 3,600 & 10 & 1,800 & 7 & 1,260 \\
\hline Total & & 260 & & 340 & & 280 & & 060 & & 1,620 \\
\hline \% de participación & & $\%$ & & $\%$ & & $8 \%$ & & $1 \%$ & & $6 \%$ \\
\hline
\end{tabular}

En la tabla se puede apreciar que son cuatro los restaurantes de mayor participación de mercado, los del grupo de otros, son solo casas que esporádicamente reciben turistas sobre todo en temporada alta.

Asimismo, los meses de enero y febrero son los más bajos del año, siendo febrero el mes en que algunos restaurantes llegan a cerrar el negocio y aprovechan para darse de vacaciones, puesto que la lluvia cubre el paso por el nevado de Salkantay y por tal motivo las agencias tampoco operan la ruta.

El turismo se empieza a recuperar desde marzo y es en mayo donde ya empieza a consolidarse la temporada alta, restaurantes como La Herradura y Sumaq Terminal deben contratar personal extra para el servicio porque hay días donde venden más de cinco grupos diarios, lo cual significa más de 50 turistas diarios. 
Según el cálculo elaborado, la sumatoria de toda la afluencia de turistas de los restaurantes da un total de 28,560 turistas al año, cifra que guarda relación con el reporte oficial del municipio distrital de Mollepata; del total de esa cifra, los restaurantes la Herradura y Sumaq Terminal representan mayor dominio del mercado con el $36 \%$ y $39 \%$ respectivamente, mientras que Don Julio y Humantay tienen $18 \%$ y $11 \%$ respectivamente.

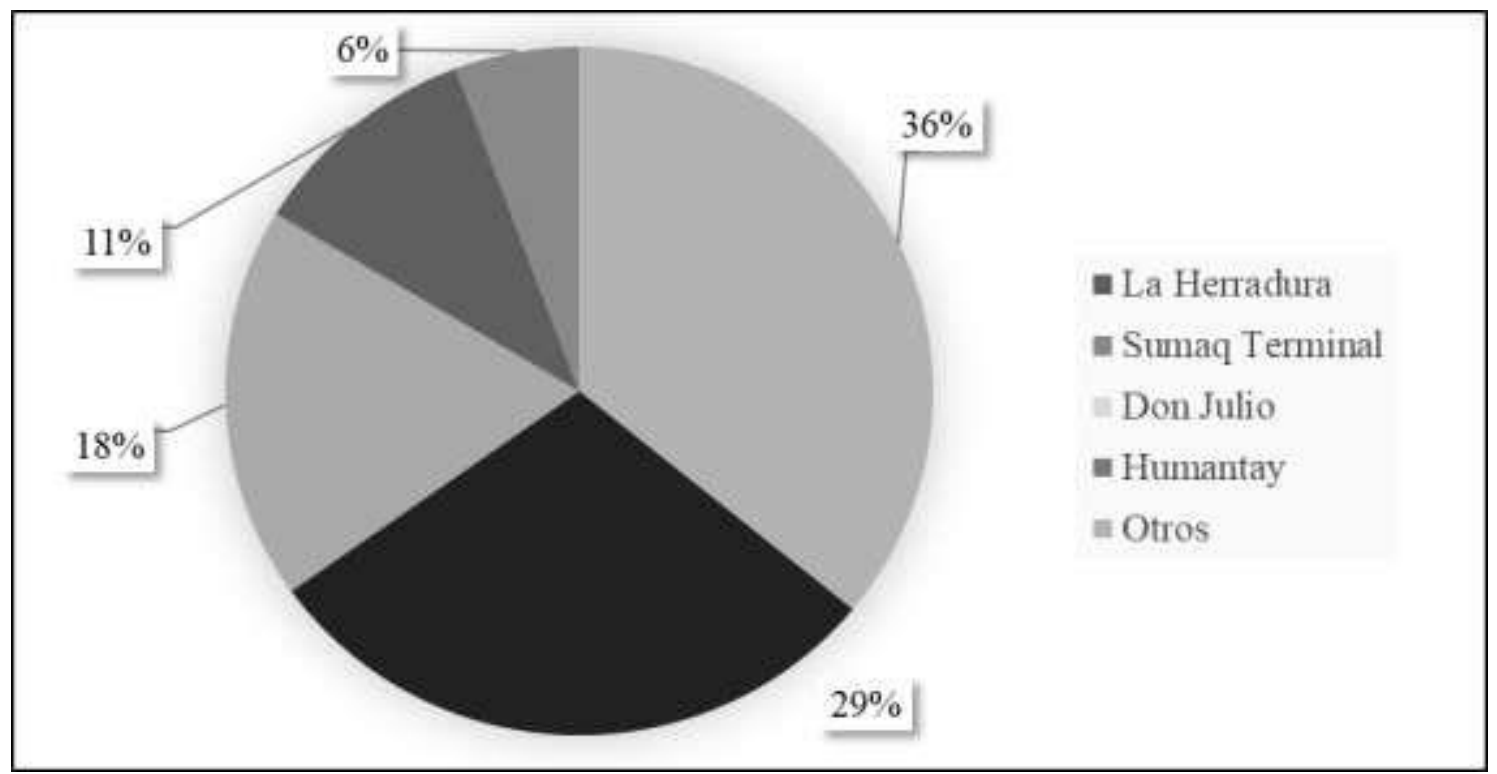

Figura 8. Participación de Mercado.

Con el objetivo de calcular la participación de mercado para el primer año, en el proyecto se estima abarcar una demanda menor al $28 \%$ de Suma Terminal (8,340 turistas al año), pero mayor al $18 \%$ (5,280 turistas al año) que recibe Don Julio. Esto teniendo en cuenta que se trata de una propuesta nueva y realista. 
2.4.3. Matriz De Perfil Competitivo.

La Matriz de Perfil Competitivo señala a aquellos competidores con características internas y externas sólidas. De esta manera, la matriz incorpora factores de éxito tanto externos como internos, señalando fortalezas y debilidades; donde cuatro es la fortaleza principal, tres es la menor, dos es la debilidad menor y uno es la debilidad principal. En conclusión, esta matriz señala información estratégica interna valiosa (David, 2013).

Para conocer el comportamiento competitivo en la propuesta de negocio se establecieron factores de éxito en la industria, los cuales se basan en los resultados de la investigación de mercado realizada. Estos mismos son validados mediante la observación a la competencia, las encuestas aplicadas a los competidores, entrevistas a expertos en turismo de aventura en la Región Cusco y a la tendencia de la industria, en torno al sector turístico y al sector de restaurantes. De esta forma, los factores críticos son:

- Calidad y buen gusto de platos

- Insumos orgánicos y Oriundos

- Calidad de servicio

- Presentación de productos

- Instalación e infraestructura

- Precio justo

- Alimentos con adecuado aporte nutricional

- Variedad de opciones

- Atención bilingüe

- Personal oriundo de la zona

- Higiene y salubridad

- Servicios turísticos complementarios 
Tabla 8

Matriz de Perfil Competitivo

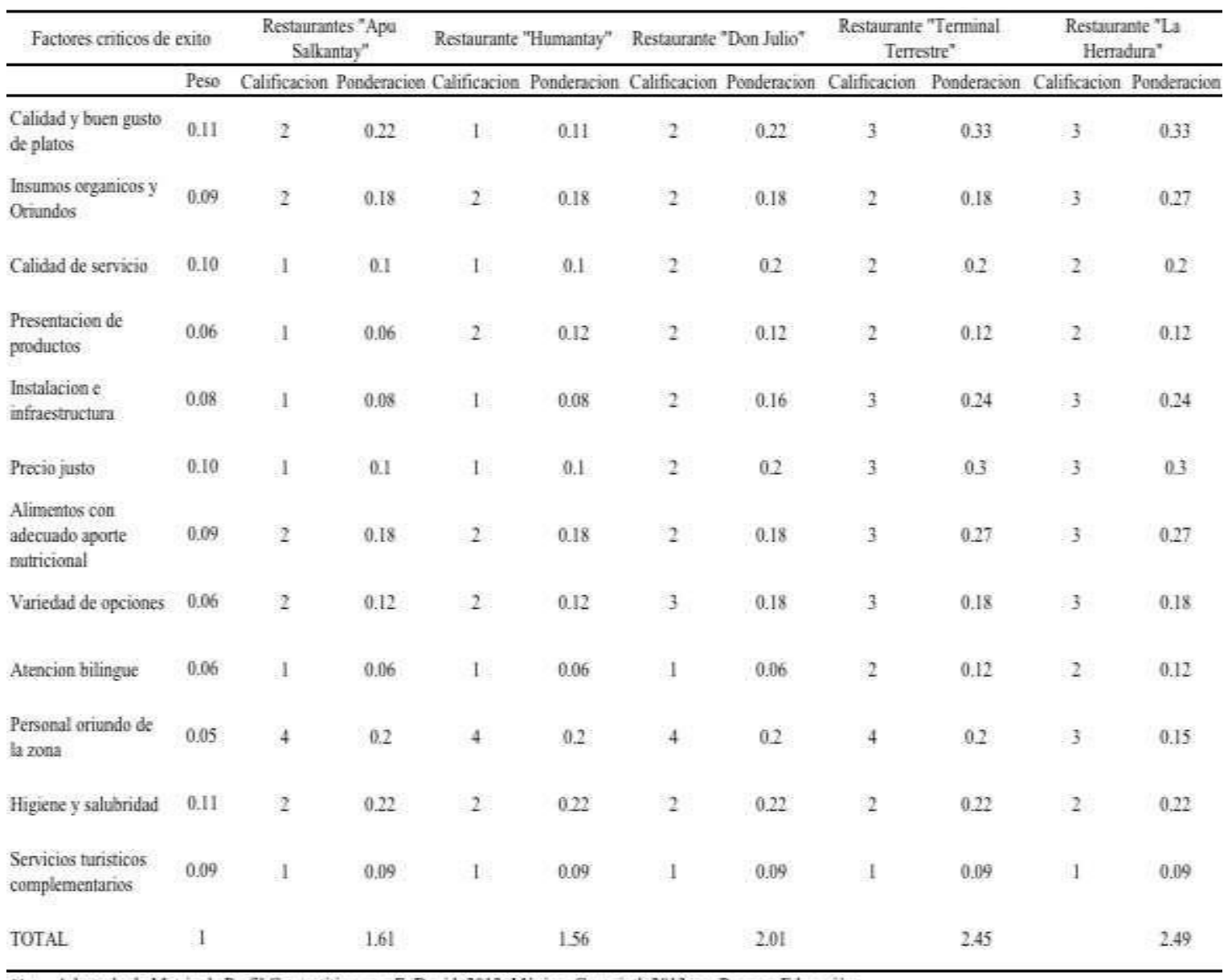

Noda. Adaptado de Matriz de Perfil Competitive, por F. David, 2013, Mexico, Copyngth 2013 por Pearson Educaciòn.

De acuerdo con la tabla, la competencia más fuerte sería el restaurante La Herradura, debido a la calidad de la comida que es bien apreciada por los clientes según estudio de mercado, y también porque la infraestructura con la que cuenta, tiene áreas verdes (los otros restaurantes no cuentan con áreas verdes). Aunque la diferencia en el puntaje con la propuesta de negocio es casi un punto decimal, es posible inferir que la alta capacidad competitiva que tiene la propuesta de negocio, marcará la diferencia. 


\subsection{Análisis del Contexto Actual y Esperado}

De acuerdo con Kotler y Keller (2012), observar y analizar el ámbito en el que se encuentra una empresa, es fundamental a fin de lograr identificar oportunidades y amenazas; asimismo, indican que para este propósito existen seis fuerzas, los cuales deben ser estudiadas para ingresar a un mercado.

Este análisis permitirá conocer de manera más clara el entorno que rodea a la investigación y también ayudará a hacer una valoración a largo plazo del desarrollo esperado a futuro.

2.5.1. Análisis Político - Gubernamental.

Según Kotler y Keller (2012) al analizar el entorno, el cual acoge a la empresa, se debe poner especial énfasis en los aspectos políticos, grupos de presión y otros más que atañen al espacio gubernamental e involucren directa o indirectamente a la empresa, con el objetivo de detectar nuevas oportunidades.

Según estudio del semanario Latín Business Chronicle, la nación posee el mejor ambiente macroeconómico de América Latina y es el tercer mejor país para hacer negocios, precedidos por Chile y Panamá. El índice Latín Business Index mide el ambiente para realizar negocios en 19 países de Latinoamérica, entre los factores evaluados están el ambiente macroeconómico, corporativo y político, la situación de cada país en cuanto a globalización y competitividad y el nivel tecnológico (Gestión, 2017).

Para la región Cusco el gobierno central tiene planificado grandes proyectos a corto, mediano y largo plazo que permitirán un desarrollo sostenido principalmente en el rubro turístico, entre estos proyectos menciona el mejoramiento para la accesibilidad de la ciudadela de Choquequirao. 
Choquequirao es una ciudad construida sobre los 3,000 m.s.n.m. a fines del imperio Inca y es considerada como la hermana de Machupicchu por la gran similitud estructural.

A fines del 2016 la guía de turismo Lonely Planet, nombró a la ciudadela inca Choquequirao como la mejor región para visitar el 2017 de acuerdo con el ranking Best in Travel 2017, también destacaron que fue el último refugio inca que resistió a los conquistadores, y cada vez son más los viajeros que quieren visitarlo (Castro, 2017).

En este sentido el viceministro de Turismo, Roger Valencia ha indicado que se iniciarán los proyectos para el mejoramiento de la accesibilidad a Choquequirao, entre los que se incluirán construcción de anillos viales, teleféricos complementarios y otros que sean necesarios (Castro, 2017).

Unos de los grandes problemas que debe enfrentar el gobierno del país es el acceso ferroviario a la ciudadela de Machupicchu ya que las dos empresas que actualmente operan los servicios de transporte no se abastecen para la gran cantidad de turistas que desean llegar a los restos arqueológicos, los cuales son maltratados por el ineficiente manejo de estos servicios. Es necesario que el gobierno central tome cartas en el asunto, dado que cada vez este problema se hace más caótico.

En el tema internacional una de las coyunturas que más afectará al país es la nueva presidencia de Donald Trump, debido principalmente a la cantidad de medidas en contra de Latinoamérica que propuso en la campaña política.

En esta línea, se puede identificar cinco problemas que Perú podría enfrentar ante el gobierno de Trump. En primer lugar, la posible modificación o eliminación del Tratado de Libre Comercio como una medida proteccionista, esto sería grave para Perú debido a que afectaría significativamente a la industria textil y agraria, ya que el $18 \%$ de las exportaciones peruanas son hacia Estados Unidos. Ante esta medida la visita de Pedro Pablo Kuczynski a China fue acertada como medida de contraparte. Otra posible medida sería la eliminación de las visas como una especie de medida de aislamiento. Un tercer 
problema que tendría que enfrentar Perú, sería el mayor costo de financiamiento con una progresiva alza de las tasas de interés. Otro efecto negativo podría ser la posible alza del dólar, que conllevará a un alza en general de los precios. Un posible efecto positivo sería el incremento del precio del oro pues ante una incertidumbre de los inversionistas haría que refugien sus fondos en este metal (Reyes, 2016).

Con respecto a la seguridad ciudadana en Cusco, el resguardo en el centro histórico del Cusco, como en los puntos de concentración turística es importante, al ser una ciudad cuya economía se sustenta en gran medida del flujo turístico de la zona. Actualmente, la Provincia de Anta ocupa el cuarto puesto en número de delitos dentro de la región del Cusco, la mayoría de estos, tipificados por violencia familiar (Gobierno Regional del Cusco, 2017). El distrito de Mollepata no cuenta con seguridad ciudadana en la zona, ya que, al ser un poblado de escaso movimiento económico y de actividad principalmente agrícola, de contexto rural y localizado a una gran distancia de la urbe regional como el Cusco, no presenta grandes índices de delincuencia en la zona.

El índice de confianza del inversionista en el país aún sigue siendo atractivo para atraer inversiones y capitales extranjeros al Perú, así lo demuestra el Riesgo País del Perú, que cerró la sesión del día 18 de mayo del 2017 con 1.39 puntos porcentuales, permaneciendo igual en relación a la sesión anterior. De esta forma, Perú se mantiene entre los países con menor riesgo país dentro de la región, seguido de México con 1.97 puntos porcentuales y Colombia con 2.04 puntos porcentuales, representando un mercado atractivo para la inversión y para el desarrollo de servicios y experiencias hacia el consumidor extranjero y nacional (Gestión, 2017). 
La política de promoción de la inversión en el Perú, empieza a obtener resultados favorables después de 16 meses de caída, aplicando un agresivo impulso a la inversión pública para desarrollar, consecuentemente, una masiva inversión privada en los próximos meses, esto a cargo de la Agencia de Promoción de la Inversión Privada ProInversion. De esta manera, se pretende alcanzar un crecimiento económico por encima del $4 \%$ o $5 \%$ y reactivar la economía del país (El Peruano 2017)

Cabe señalar de igual forma, que el Centro de Desarrollo Empresarial del Ministerio de la Producción, es el brazo de esta política de promoción de inversión privada del gobierno peruano para el desarrollo de micro y pequeñas empresas, con capacitaciones gratuitas para la formación y formalización de empresas nacientes, así como un permanente asesoramiento en el desarrollo y crecimiento de las mismas.

\subsubsection{Análisis Económico.}

En este aspecto Kotler y Keller (2012) señalan que es necesario conocer los factores que influyen en el poder adquisitivo del mercado que acoge a la empresa, analizando y estudiando factores interrelacionados como: capacidad de endeudamiento, ahorros, precios, facilidades de crédito, entre otros. Señalan, también, que las tendencias que impactan el poder adquisitivo inciden fuertemente tanto en empresas con mercados objetivos de adquisición baja y empresas con mayor susceptibilidad al precio.

Según el Fondo Monetario Internacional (FMI), la economía peruana tuvo en el 2016 un crecimiento del $3.7 \%$, frente a un $3.3 \%$ alcanzado en el 2015 y espera que para el 2017 se alcance el $2.7 \%$, debido a paralizaciones y cancelaciones de proyectos, como el aeropuerto internacional de Chinchero, el Gaseoducto Sur Andino y fenómenos naturales como E Niño que significó el estancamiento de las inversiones en el norte y centro del país. 
Sin embargo, se estima que la economía peruana en un período entre el 2018 al 2021 tenga un crecimiento de $4.0 \%$ en torno al potencial que posee, debido a un aumento de la demanda externa, y al fortalecimiento por la salida de la recesión de América Latina; de igual manera, Brasil y Argentina que representan el $40 \%$ del PBI de América latina crecerán $1.0 \%$ y $1.8 \%$ el 2018 respectivamente, dentro de un contexto de estabilización de precios de materias primas y ciclo político por cambio de administración. La consolidación del crecimiento económico de los Estados Unidos, de la Zona Europea y la aceleración de la actividad económica del grupo de economías emergentes, como Asia, también influirán en esta demanda y consecuentemente en el crecimiento económico peruano [Ministerio de Economía y Finanzas (MEF), 2017].

El profesor de Harvard University y líder de opinión sobre institucionalidad a nivel mundial, Dani Rodrik, destacó el crecimiento del Perú y señaló que es impresionante alcanzar una tasa de expansión superior a $3 \%$ en el actual contexto económico mundial.

El Producto Bruto Interno (PBI) creció $6.04 \%$ en febrero del 2016, registrando 79 meses de resultados positivos (INEI, 2016). Sin embargo, se espera que para el 2017 el PBI crezca solo un $2.8 \%$ por causas explicadas en el primer párrafo de este análisis. (El Comercio, 2017).

Para el 2018, las proyecciones indican que el PBI peruano crecerá en un $4.0 \%$, esto debido a la recuperación gradual de la inversión privada debido a un dinamismo mayor de la demanda interna, al aumento gradual del precio de los metales, al avance de proyectos de infraestructura y políticas para promover la inversión minera (MEF, 2017).

Según el INEI (2017), tomando como base la Encuesta Nacional de Hogares (ENAHO) en el ámbito del Cusco, la Población Económicamente Activa (PEA) es de 757 mil 400 habitantes; de los cuales, 24 mil 500 están desempleados. 
Según Salcedo (2016), el promedio salarial que reciben tanto trabajadores del sector público como el privado es de S/ 1,081, esta cifra representa una menor cantidad frente al costo de la Canasta Básica Familiar que asciende a S/ 1,515 (INEI, 2017).

En adición, se prevé que la tasa de crecimiento laboral se incremente en los próximos años al mismo ritmo que la fuerza laboral (MEF, 2017).

La inflación de agosto del 2017 fue de $0.67 \%$, con respecto al $0.20 \%$ del mes anterior julio; dicho registro, se debe al incremento en los precios de los ocho grandes grupos de consumo: alquiler de vivienda, combustibles, electricidad, alimentos y bebidas, muebles, enseres y mantenimiento de viviendas, otros bienes de servicio, vestido y calzados. Entre estos, el reajuste de las tarifas de agua potable doméstica y las tarifas de electricidad residencial son las principales causas de este incremento. Con respecto a la variación acumulada, la inflación acumulada en agosto fue de $1.90 \%$, representando una ligera disminución con respecto al similar mes el año anterior $1.96 \%$ (Gestión, 2017); y la tasa de inflación anual que se proyecto fue del 2 \% del 2017 al 2022 (MEF, 2017).

El tipo de cambio en el 2017, ha ido cayendo entre enero y setiembre, teniendo en cuenta que el anterior año 2016, el tipo de cambio con respecto a la divisa norteamericana fue de S/ 3.35 y el 2017 el dólar se encuentra en S/ 3.26. El Banco Central de Reserva tuvo que intervenir en varias ocasiones para comprar dólares y así evitar que la devaluación de este aumente, perjudicando el flujo financiero del conglomerado de empresas peruanas.

Las causas de la reducción del tipo de cambio del dólar americano, son las actuales políticas gubernamentales de Donald Trump, la incertidumbre que genera y las dudas que surgen con respecto a si el presidente norteamericano podrá cumplir con las reformas económicas trazadas por su gobierno. El segundo gran factor es la subida de los metales, como el oro, el cobre y zinc (El Comercio, 2017). 
Es necesario tener en cuenta que la proyección estimada del tipo de cambio para el 2021 es de S/ 3.42, en respuesta a la participación de moneda extranjera en la deuda pública y que poco a poco el MEF ira mitigando (MEF, 2017).

\subsubsection{Análisis Legal}

Según Kotler y Keller (2012) con este análisis, se busca identificar a las asociaciones que tengan la potestad de aplicar presión al sector donde se desarrolla la empresa, así como también entender las leyes que someten a la industria.

En primer lugar, se debe contar con Registros Sanitarios de Alimentos, para poder comerciar con los alimentos, de esta manera se cumple con una de las normativas fundamentales para poder operar el negocio.

Es necesario tener en cuenta la normatividad respecto a los lineamientos sanitarios que se deberán tener en cuenta (Resolución Ministerial №363-2005 Ministerio de Salud) cumplir con estas normas evitarán tener problemas con las licencias de funcionamiento. Es importante también considerar la legislación vigente para la apertura de negocios de cualquier índole en zonas rurales, para lo cual es necesario acogerse a todo lo dispuesto por la Municipalidad de Mollepata.

El régimen especial de impuesto a la renta es un sistema especial de tributación dirigida a empresas y/o negocios medianos y pequeños como es el caso del presente proyecto, que será explicado a mayor detalle en el capítulo seis de aspectos organizacionales.

Con respecto a la jornada laboral en Mollepata, es necesario precisar que, por tratarse de negocios familiares e incluso personales, y de una municipalidad con escaso control; no es posible llevar un registro o seguimiento de las jornadas laborables de estos negocios; sin embargo, según exploración visual propia, los negocios atienden entre cuatro a cinco 
horas diarias, con personal que labora en ese horario, sin percibir ningún beneficio de ley, como seguros, o Compensación por Tiempo de Servicios (CTS).

\subsubsection{Análisis Cultural}

De acuerdo con Kotler y Keller (2012) el análisis cultural hace referencia al estudio de las interrelaciones que se establecen entre las personas, las organizaciones, la naturaleza, entre otros.

En vista de la importancia que dan los visitantes a la cultura y tradiciones locales, el turismo rural debe tener un papel fundamental en la preservación, conservación y recuperación a largo plazo de la gastronomía, artesanía, folklore, costumbres, actividades tradicionales, etc.; sin ninguna imposición, por el contrario, concertación con las comunidades (MINCETUR, 2006).

Para Pacora (2012), Mollepata no solo posee una esplendorosa producción agrícola sino también un circuito turístico que ofrece al visitante una variedad de experiencias, desde la más íntima y sosegada hasta la más intensa y avezada. Si bien este distrito recibe alrededor de 27 mil turistas al año (según la Dirección Regional de Cultura, 2015), la mayoría solo permanece uno o dos días en el lugar ya que su objetivo es llegar a MachuPicchu.

Son pocos los afortunados que se detienen a apreciar lo que se está convirtiendo en una nueva ruta de turismo vivencial, ya sea si se quiere llegar hasta la ciudadela inca o simplemente adentrarse en los valles de aire limpio con aroma a eucalipto. En el primer caso, el visitante puede ir recorriendo uno a uno los poblados que conducen hasta MachuPicchu, para lo cual es necesario bordear el nevado Salkantay. Esta ruta, ideal para los amantes del trekking, se presenta como una espléndida alternativa al Camino Inca, ya que en su recorrido se encuentran con paisajes inefables, lagunas como espejos gigantes, los imponentes nevados Humantay y Salkantay ; pero lo más interesante de esta antigua 
ruta quechua es la progresión de los diversos pisos ecológicos, que va desde la cadena de montañas andinas donde se pueden aprovechar algunas fuentes de aguas termales, hasta la ceja de selva, plena de abundante vegetación tropical y fauna diversa y ruidosa, propia de estos bosques húmedos.

Lo más llamativo de todas estas experiencias es la convivencia con los lugareños, quienes están preparando una infraestructura más acorde para poder alojar a los turistas que llegan hasta esa zona y compartir con ellos las distintas costumbres que van desde la agricultura hasta la ganadería.

El perfil del turista que realiza la ruta trekking Mollepata - Salkantay, se enmarca dentro del Perfil del Turista de Aventura en Trekking en el Perú, entre ellos destacan personas solteras en su mayoría entre 25 a 34 años de edad, que viajan entre amigos, familiares y que no poseen alguna responsabilidad filial. Mayormente, prefieren hospedajes categorizados de tres estrellas, y el gasto promedio es de $\$ 1,750$ y la mayoría proviene de Estado Unidos (PROMPERU, 2017).

\subsubsection{Análisis Tecnológico}

Según Kotler y Keller (2012) saber de la existencia de oportunidades y tomar acciones para afrontar amenazas, todo esto como resultado de una política de adaptación rápida frente al cambio y aprovechando oportunidades de innovación, es parte del estudio tecnológico aplicado a la empresa.

Con el uso de las tecnologías de la información para el turismo, se ha logrado obtener muchos beneficios como, por ejemplo, conocer las necesidades de los clientes que conlleva a brindar un mejor servicio, llegar a una mayor cantidad de clientes y optimizar los recursos logrando aumentar la eficiencia. Se concluye que las tecnologías de 
información bien manejadas se traducen a una mejor interacción entre las empresas dedicadas al rubro turístico con sus posibles consumidores (Paito, 2013).

El sector turístico es muy atractivo para el desarrollo de tecnologías de información: el turismo es una actividad ínter territorial que ofrece y comercializa actividades lejos del lugar donde está el cliente. Por otra parte, al formar parte de una relacionada con el ocio y entretenimiento, se requiere promoción basada en medios audiovisuales que resalten atractivos (Paito, 2013).

A diferencia de otros medios, el internet y la interacción que lleva consigo ayuda a las personas a ubicar información con rapidez y exactitud sobre cualquier destino o actividad que les gustaría conocer o realizar. Los clientes desean obtener información instantánea y, cada vez más, la posibilidad de utilizar internet para crear o adaptar a su beneficio el producto turístico que buscan y pagarlo en línea (Paito 2013).

Una inversión en tecnologías de la información debe ser una prioridad dentro del negocio, por la relación e interacción con los clientes y porque también facilitará tareas de distribución y gestión; dado que se podrá mejorar también las labores administrativas, contables, financieras, también para la investigación y la planificación de marketing, además de gestión, ingresos, nominas, compras, etc (Paito 2013).

Dentro del negocio será necesario utilizar la tecnología aplicada para la gestión del día a día, desde la implementación de un sistema de vigilancia web, una red wifi y un sistema para la cobranza y facturación que incluye el uso del POS. Para una mayor relevancia estratégica, se diseñará un sitio web desde el que se podrá interactuar con el futuro cliente; es imprescindible elaborarla manteniendo el equilibrio entre una estética innovadora, animaciones impactantes y una utilización fácil y cómoda para el usuario. Asimismo, el manejo adecuado de redes sociales conducidas a la promoción y comunicación del producto, permitirán obtener los resultados esperados (Paito 2013). 
En la actualidad, la mayoría de restaurantes en Mollepata, no poseen herramientas tecnológicas que ayuden en el proceso de producción, atención al cliente, tributación, entre otros; debido a que estos negocios están orientados al consumidor local y adaptados con improvisación para la atención de un usuario cada vez más exigente como el turista extranjero o nacional. En este sentido, se puede mencionar al restaurante de La Herradura el cual posee desde hace seis meses un sistema de POS para el cobro de servicios a los comensales.

\subsubsection{Análisis Ecológico.}

Como Kotler y Keller (2012) establecen, estar actualizado respecto a las normativas y regulaciones con relación al medio ambiente, demostró una fuerte incidencia en algunas empresas del sector.

Para el Viceministerio de Turismo de la Dirección Nacional de Desarrollo de Producto Turístico en el 2006, el entorno natural es un aspecto clave para la actividad de turismo rural, especialmente en aquellas localidades donde se está empezando a desarrollar la actividad turística. Con el fin de garantizar el uso sostenible del medio ambiente, es esencial establecer un marco legislativo apropiado y adecuado para estas zonas, llevar a cabo una planificación equilibrada y seguir mejorando la gestión de las empresas, además de desarrollar políticas de responsabilidad social y medio ambiental.

Por otro lado, intensifica la conciencia ambiental de las comunidades cuando éstas observan el interés de los visitantes por la conservación y preservación del medio ambiente. Es impresionante la cantidad de productos que se pueden cosechar en los valles del Cusco como: papas y maíz, naranjas, tomates cherry, paltas hass, col de bruselas, holantao, berenjenas, kiwicha, quinua, aguaymanto, sachatomate, uva y hasta algarrobo. 
Todo el valle posee cerca de 32 microclimas, gracias a la alta tecnología agrícola que desarrollaron las culturas prehispánicas que habitaron esta zona; desde canales de regadío hasta un imponente sistema de andenes, todo el valle es aprovechado al máximo a través de esta herencia milenaria. Solo en Mollepata existen 15 pisos climáticos, es decir se puede producir de todo (Pacora, 2012).

El impacto de la unidad de negocio planteada en el presente proyecto será mínimo, ya que, al estar implementado en una casa típica dentro del poblado de Mollepata, no impactará ni perderá el concepto de la arquitectura ni el paisaje urbanístico de la zona.

Con respecto a los insumos utilizados en la preparación de la oferta culinaria, serán adquiridos a productores de la zona, igualmente la mano de obra estará conformada por personal de la zona.

Los desechos serán, puntualmente, depositados y entregados a los recolectores de basura municipal de Mollepata.

\subsection{Oportunidades y Amenazas}

En base al análisis realizado, como oportunidades, el sector Político - Gubernamental garantiza un adecuado ambiente de desarrollo y crecimiento para las empresas emergentes, facilitando condiciones para la creación y sostenibilidad de nuevos proyectos a través del tiempo, con reglas claras y generando políticas que contribuyan a garantizar demanda, tales como seguridad ciudadana en centros turísticos, una baja calificación de Riesgo país, entre otros. Con respecto al sector económico, se resalta un mercado económico sólido y estable, el cual asegura la captación y permanencia de inversiones y crecimiento continuo de la competitividad que solo busca el mejor servicio para el consumidor, debido a un ambiente macroeconómico favorable, la menor tasa de inflación de Sur América y una estabilidad económica, garantizada por instituciones financieras gubernamentales sólidas. 
En el aspecto legal, según la descripción previa, reglas y normas que fomentan la creación y permanencia de nuevos proyectos, con regímenes tributarios especiales y el aprovechamiento de vacíos legales, en cuanto a normas de fiscalización de negocios y establecimientos en una municipalidad tan alejada del Cusco, como Mollepata, estructuran un ambiente legislativo único y propicio para el proyecto.

En cuanto al entorno cultural, el hecho de hacer partícipe al poblador local de Mollepata en nuevos proyectos, como este, que se sienta importante durante el proceso de ofrecer un servicio de calidad y recibir una retribución por esta labor, sin sentirse excluido y evitando un resentimiento por parte de él, significará una oportunidad de desarrollo y capacitación a las habilidades del mismo, además de contribuir a planes posteriores de Responsabilidad Social con la comunidad.

El internet al ser una herramienta de información global, con cobertura a nivel nacional, representa una oportunidad única para llegar al cliente final y a las agencias de viajes, con estrategias de publicidad y marketing; también, al servicio de procesos internos, como facturación electrónica y utilización de POS. En el entorno Ecológico, se menciona la sensibilidad que podrá adquirir el poblador local frente al medio ambiente al estar en contacto con el visitante y el interés que tiene por la conservación.

Entre las amenazas que se detectaron para el proyecto se tienen los cambios y/o anulaciones de los tratados de libre comercio firmado por el Perú con otras naciones, cuya realización significaría una desestabilidad política económica en el país, obligando al estado a emitir leyes y reformas de emergencia, desestabilizando el ambiente político del País.

También se identifica una amenaza latente en el sector económico, como la cancelación de mega proyectos en la región Cusco, que significaría el alejamiento de inversiones, como es el caso del proyecto del Aeropuerto Internacional de Chinchero y/o catástrofes naturales, que impedirían el acceso o desarrollo turístico en Cusco. Amenazas en el contexto legal como normas más estrictas en el aspecto de registro sanitario en zonas rurales o establecimiento de 
normas de control para establecimientos de servicios turísticos en la Municipalidad de

Mollepata, representarían reformulaciones en el diseño de estrategias.

En el aspecto cultural, el poblador local, al no ver una retribución de negocios de capital ajeno implantados en su localidad, generaría protestas sociales y bloqueos en las principales vías de comunicación en Mollepata. En el aspecto tecnológico, se puede mencionar que al ser Mollepata una localidad alejada del foco económico del Cusco, podría presentar conectividad baja del internet, ya que se encuentra en una zona rural. Por último, factores ambientales y/o climatológicos que puedan llegar a afectar los productos base de los insumos utilizados por el restaurante, también representan una amenaza, además, de la falta de una adecuada política de tratamiento y reciclaje de residuos que generará la actividad y que causará un impacto al medio ambiente. A continuación, se presenta la Matriz de Factores Externos que influyen en el desarrollo del presente proyecto.

\section{Tabla 9}

Matriz de Evaluación de Factores Externos (EFE)

\begin{tabular}{|c|c|c|c|c|}
\hline & Factores Externos Claves & Ponderacion & Calificacion & Total \\
\hline \multirow{5}{*}{$\begin{array}{l}\text { Analisis Politico - } \\
\text { Gubernamental }\end{array}$} & Oportunidades & & & \\
\hline & Adecuadas politicas sobre seguridad ciudadana en centros turisticos, mayor demanda. & 0.07 & 4 & 0.28 \\
\hline & Apoyo gubernamental para la creacion y gestion del negocio, negocios estables. & 0.04 & 4 & 0.16 \\
\hline & Resgo Pais bajo, mayor inversion externa. & 0.05 & 2 & 0.1 \\
\hline & Ambiente macroeconomico ideal para hacer negocios, mayor inversion. & 0.06 & 2 & 0.12 \\
\hline \multirow[t]{2}{*}{ Analisis Economico } & Estabilidad economica gracias a instituciones financieras solidas. & 0.05 & 2 & 0.1 \\
\hline & Inflacion baja, mercado turistico estable. & 0.02 & 4 & 0.08 \\
\hline \multirow{3}{*}{ Analisis Legal } & Regimes legales del gobierno central que favorecen al desarrollo del negocio & 0.05 & 3 & 0.15 \\
\hline & Escasas normas municipales de control y fiscalizacion de negocios & 0.04 & 3 & 0.12 \\
\hline & Participacion de pobladores de la comunidad en la oferta turistica, personal tecnico. & 0.07 & 2 & 0.14 \\
\hline \multirow[t]{2}{*}{ Analisis Cultural } & Minima Competencia local como unidades de negocio propias. & 0.02 & 4 & 0.08 \\
\hline & Actividades de Responsabilidad Social para la misma Comunidad. & 0.03 & 2 & 0.06 \\
\hline \multirow{2}{*}{ Analisis Tecnologico } & Tecnologias de la informacion que faciliten procesos internos de atención y cobranzas. & 0.05 & 2 & 0.1 \\
\hline & Internet y redes sociales como uso para la publicidad y marketing & 0.01 & 4 & 0.04 \\
\hline \multirow[t]{3}{*}{ Analisis Ecologico } & Fomento de Conciencia ambiental en el poblador local. & 0.03 & 4 & 0.12 \\
\hline & & & & 1.65 \\
\hline & Amenazas & & & \\
\hline \multirow{2}{*}{$\begin{array}{l}\text { Analisis Politico - } \\
\text { Gubernamental }\end{array}$} & Cambios en los acuerdo comerciales firmados con EE UU y otras potencias. & 0.02 & 2 & 0.04 \\
\hline & Creación de severas politicas de recaudacion de impuestos. & 0.05 & 2 & 0.1 \\
\hline \multirow{2}{*}{ Analisis Economico } & Incumplimiento de contratos publico - privados como Chinchero, gaseoducto del sur. & 0.06 & 3 & 0.18 \\
\hline & Estancamiento de inversion y crecimiento por desastres naturales. & 0.02 & 2 & 0.04 \\
\hline \multirow{2}{*}{ Analisis Legal } & Normas de regularizacion de negocios por parte del municipio local. & 0.01 & 4 & 0.04 \\
\hline & Registro sanitario de alimentos mas estrictos. & 0.02 & 2 & 0.04 \\
\hline \multirow{2}{*}{ Analisis Cultural } & Escasez de mano de obra local calificada & 0.07 & 4 & 0.28 \\
\hline & Huelgas y protestas sociales que impiden la llegada de visitantes & 0.08 & 4 & 0.32 \\
\hline Analisis Tecnologico & Escasa y/o pobre conectividad de internet en la zona. & 0.05 & 4 & 0.2 \\
\hline \multirow[t]{2}{*}{ Analisis Ecologico } & Falta de plantas de procesamiento de residuos o desechos en la zona. & 0.03 & 2 & 0.06 \\
\hline & Total & 1.00 & & $\begin{array}{r}1.3 \\
2.95\end{array}$ \\
\hline
\end{tabular}


Al obtener un promedio ponderado de 2.95 como resultado del análisis, se concluye que el proyecto se desarrollará un ambiente externo favorable para el crecimiento del mismo. 


\section{Capítulo III. Estudio de Mercado}

\subsection{Descripción del Servicio o Producto}

El proyecto consiste en la creación de un Centro de Servicios Turísticos en el pueblo de Mollepata el cual contará con un restaurante en el que se elaborarán desayunos para los turistas que hagan la ruta de trekking Salkantay - Machupicchu, y además para darle más valor al restaurante se ofrecerán otros servicios como el de un Centro de Interpretación con servicios higiénicos para los turistas.

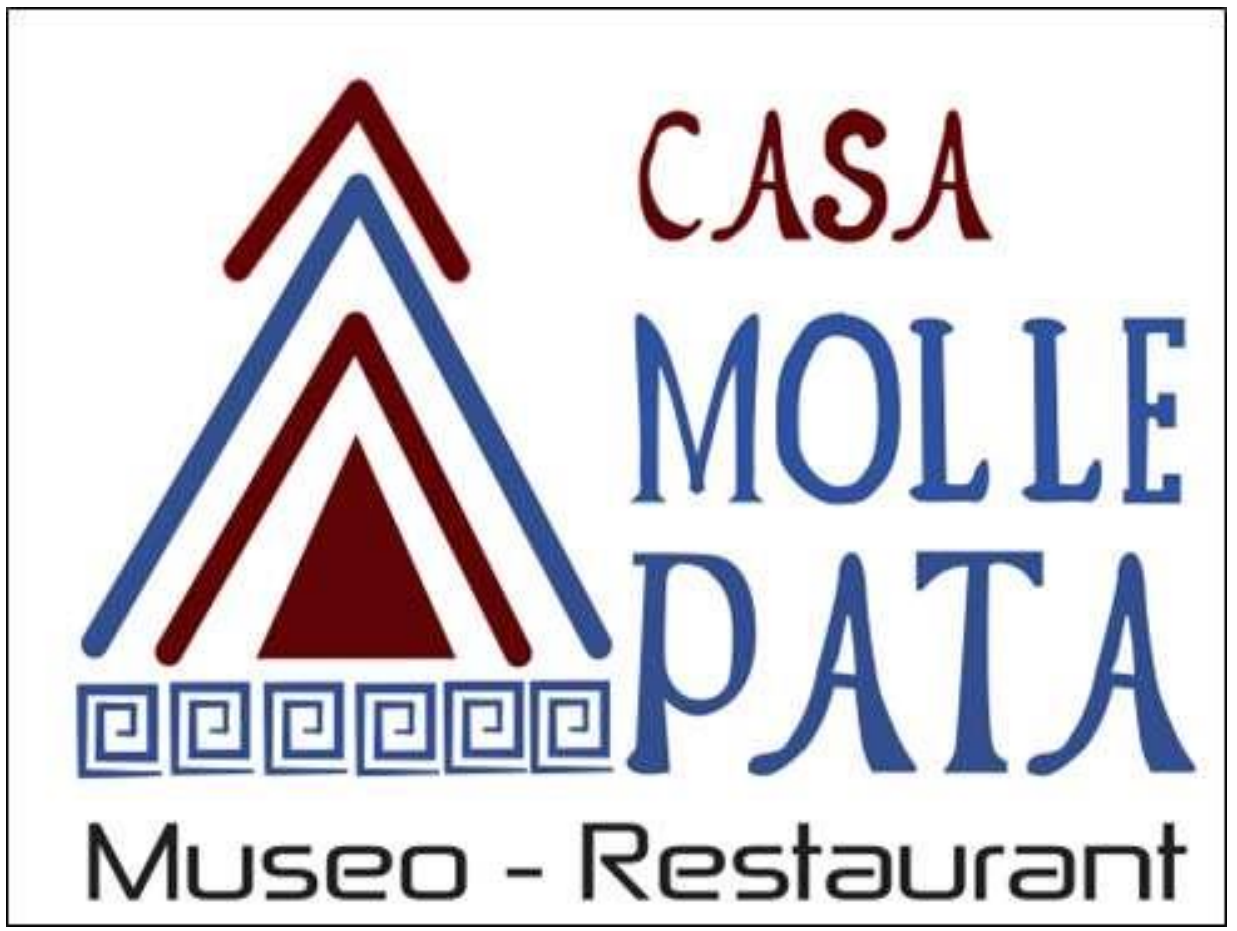

Figura 9. Logo del Centro de Servicios Turísticos - Casa Mollepata. 
Un Centro de Servicios Turísticos viene a ser un lugar donde se ofrecen un conjunto de actividades perfectamente diferenciadas entre sí, pero íntimamente relacionadas, que funcionan en forma armónica y coordinada con el objeto de responder a las exigencias de servicio planteadas por la composición socioeconómica de una determinada corriente turística. Dentro de los servicios se incluyen a los restaurantes, hoteles, oficinas de información turística, museos, centros de interpretación, miradores, servicios de embarques, transportes, entre otros (Ramírez, 2012).

Las agencias de viajes llegan con los turistas diariamente al pueblo de Mollepata, estos aprovechan el lugar para desayunar, tomar un breve descanso y empezar luego con la caminata del primer día. En ese sentido para la elaboración de la propuesta de servicios a ofrecer se realiza la siguiente investigación:

Para determinar los servicios que se ofrecerán en la propuesta de negocio, se realiza investigación exploratoria, primero con entrevistas a expertos en la ruta en estudio y luego se hace el desarrollo de cuestionarios a los empresarios que tienen mayor participación de mercado en la ruta Mollepata - Salkantay - Machupicchu

Para determinar las características de la propuesta gastronómica se realizaron entrevistas a renombrados empresarios gastronómicos, esto gracias a la participación de uno de los miembros en un evento gastronómico en el hotel Inkaterra hacienda del Valle Sagrado de los Incas en Cusco.

Para determinar la propuesta del centro de interpretación se entrevistó y se realizó investigación exploratoria a expertos en centros de interpretación exitosos en Cusco, asi como se analizó la opinión de varios empresarios que trabajan con turistas en la ruta en estudio.

Los servicios a ofrecer en la propuesta de negocio son: 
El restaurante para desayunos, que viene a ser la principal razón por la que las agencias de viajes hacen una parada obligatoria por el período de una hora aproximadamente para que los turistas puedan consumir los desayunos. El objetivo de este servicio turístico será ofrecer el desayuno para las decenas de viajeros que diariamente llegan a Mollepata para iniciar con el trekking. Para la elaboración de la propuesta gastronómica del restaurante se tuvo en cuenta la apreciación y sugerencia de expertos en la materia, gracias a la oportunidad que tuvo parte del equipo investigador asistiendo al Encuentro Multidisciplinario de Expertos en Cocina que se realizó en febrero del 2017 y tuvo como sede el Valle Sagrado de los Incas en Cusco (momentomater.com, 2017). En este evento se pudo realizar entrevistas a connotadas personalidades y expertos del rubro gastronómico como Gastón Acurio, Virgilio Martínez, entre otros (ver anexo 5).

La propuesta del restaurante turístico tendrá las siguientes características:

\section{a) Alto contenido energético}

Los turistas que harán la ruta de trekking necesitan alimentarse bien, de una forma balanceada y nutritiva para poder abastecerse de la energía suficiente y así tener un óptimo rendimiento en el primer día de trekking. Para elaborar la propuesta nutricional del desayuno que se ofrecerá en el restaurante, se tomó en cuenta la recomendación de Pia Sorensen, PhD biofísica molecular de la Universidad de Harvard, a quien se le entrevisto en el evento de expertos en cocina (ver anexo 5), fue afortunada su opinión para la investigación porque además de ser una reconocida experta de talla mundial en temas nutricionales, la PhD. Sorensen, realizó la ruta trekking de Mollepata - Salkantay - Machupicchu en agosto del 2016 y recordaba perfectamente su experiencia con el desayuno en Mollepata el primer día del trekking. La recomendación de la $\mathrm{PhD}$ fue, que un viajero que va a realizar una ruta de trekking de alta montaña necesita entre tres mil y cinco mil calorías por día, las cuales se 
obtienen con un desayuno con grasas en un $20 \%$, proteínas en un $20 \%$ y carbohidratos en un $60 \%$, siendo estos últimos los más importantes para los viajeros porque se digieren fácilmente a diferencia de las grasas que son difíciles de convertir en energía cuando se está en alta montaña y además, los carbohidratos requieren poco oxígeno y agua para ser transformados en energía. Finalmente recomendó que los desayunos deberían ofrecer abundante agua en especial las infusiones de hierbas.

La elaboración de la carta se hará en base a productos orgánicos que cumplirán con el objetivo de abastecer el combustible suficiente que el cuerpo necesita y permitir una fácil digestión para evitar molestias estomacales.

Tabla 10

Contenido energético de los ingredientes

\begin{tabular}{cc}
\hline \multicolumn{2}{c}{ Contenido energético de los ingredientes } \\
\hline Palta & $390 \mathrm{kcal} / 100 \mathrm{~g}$ \\
Papa & $350 \mathrm{kcal} / 100 \mathrm{~g}$ \\
Margarina & $350 \mathrm{kcal} / 100 \mathrm{~g}$ \\
Mermelada & $700 \mathrm{kcal} / 100 \mathrm{~g}$ \\
Jamón serrano & $250 \mathrm{kcal} / 100 \mathrm{~g}$ \\
Queso & $500 \mathrm{kcal} / 100 \mathrm{~g}$ \\
Harina & $400 \mathrm{kcal} / 100 \mathrm{~g}$ \\
Hojuelas de avena & $370 \mathrm{kcal} / 100 \mathrm{~g}$ \\
Arroz & $400 \mathrm{kcal} / 100 \mathrm{~g}$ \\
Leche en polvo & $370 \mathrm{kcal} / 100 \mathrm{~g}$ \\
Frutas & $500 \mathrm{kcal} / 100 \mathrm{~g}$ \\
Panqueque de quinua & $250 \mathrm{kcal} / 100 \mathrm{~g}$ \\
Azúcar & $600 \mathrm{kcal} / 100 \mathrm{~g}$ \\
Café & $400 \mathrm{kcal} / 100 \mathrm{~g}$ \\
\hline
\end{tabular}

b) Ingredientes locales

En el mencionado evento de Expertos Culinarios del Perú y el Mundo, se obtuvieron las sugerencias de expertos sobre los ingredientes que debería tener el menú del desayuno que se pretende ofrecer, Virgilio Martínez y Gastón Acurio coincidieron en que la carta de 
desayunos debería incluir productos agrícolas locales, en especial si es que la zona tiene características agrícolas particulares y en este caso Mollepata pertenece al valle del Apurímac, caracterizado por el buen clima y tierras fértiles que en la década de los setenta, tuvo un importante auge económico gracias a la producción agrícola de las haciendas.

En base a su experiencia como cocinero y empresario gastronómico, Gastón Acurio indicó que los turistas están buscando experiencias gastronómicas nuevas, basadas en alimentos 100 \% naturales, por otro lado Virgilio Martínez comentó que los turistas de hoy respetan mucho los cereales andinos y productos agrícolas propios del ande, sugiriendo que su incorporación a una dieta de desayuno para turistas que van a empezar con el trekking sería muy ventajosa, sobre todo teniendo en cuenta las propiedades proteicas de la kiwicha, la quinua, el tardío, la papa y otros. Como se indicó, Mollepata es un lugar conocido por sus tierras fértiles, en la década de los setenta, Mollepata fue un importante punto de producción agrícola de la región y a la actualidad algunas de sus comunidades campesinas intentan recuperar este estatus, por lo que vienen trabajando varios productos agrícolas de buena calidad que incluso ya fueron reconocidos por la prensa nacional (República, 2012). En ese entender la carta del restaurant se hará con la utilización de estos productos como los tomates y espinacas de Marcahuasi, quinua y kiwicha de Bellavista, papa y el maíz de Marcahuaylla, entre otros. De esta manera, se logrará innovar la propuesta con productos locales y a la vez apoyar a las comunidades del distrito de Mollepata.

\section{c) Variedad de opciones}

Para la elaboración de la carta de los desayunos se tomará en cuenta la economía del turista, la cantidad o variedad de alimentos y las dietas vegetarianas que puedan tener; y con esto se logrará satisfacer los distintos gustos y preferencias del cliente. Respecto a la propuesta de carta de desayunos para el presente proyecto, se propone una carta basada en un balance nutricional para el viajero de montaña, incluyendo los productos producidos por los 
campesinos de Mollepata los cuales creativamente son incorporados a una carta de menú; que si bien es cierto se busca la innovación, pero no transgrede la esencia de un desayuno cotidiano al que los viajeros están acostumbrados.

A continuación, se presenta el contenido que tendrá cada una de las tres variedades de desayunos:

- Desayuno Light Continental Andino

- Jugo con frutas del valle del Apurímac: naranja, papaya, o piña.

- Ensalada con frutas del valle del Apurímac con miel de abeja.

- Pan de Mollepata o Tostadas elaborado en horno de leña.

- Mermelada de membrillo (producida por los campesinos de Marcahuasi).

- Mantequilla.

- Bebida caliente (infusiones, café o leche).

- Desayuno Americano Andino

- Jugo con frutas del valle del Apurímac: naranja, papaya, piña o fresa.

- Ensalada con frutas del valle del Apurímac con miel de abeja.

- Pan o Tostadas.

- Mermelada de membrillo.

- Mantequilla.

- Bebida caliente (infusión o café o leche).

- Huevos, que pueden ser: Huevos fritos con jamón serrano más papas nativas y cebollín de Marcahuasi; o también dos huevos revueltos con tomate cherry de Marcahuasi y 
hashbrown de papitas andinas; otra opción son los omelletes con queso andino, hongos, cebolla, espinacas y salsa de palta; o, por último, omelletes vegetarianos.

- Desayuno Mollepatino Mejorado

- Jugo con frutas del valle del Apurímac: naranja, papaya, piña o fresa.

- Ensalada con frutas del valle del Apurímac con miel de abeja.

- Yogurt natural con granola andina.

- Panqueques de quinua.

- Pan o Tostadas.

- Mermelada de membrillo.

- Mantequilla.

- Bebida caliente (infusión o café o leche).

- Huevos, que pueden ser: Huevos fritos con jamón serrano más papas nativas y cebollín de Marcahuasi; o también dos huevos revueltos con tomate cherry de Marcahuasi y hashbrown de papitas andinas; o, por último, omelletes con queso andino, hongos, cebolla, espinacas.

d) Concepto y ambientación natural

El restaurante tendrá las características de una casa rural campestre y gran cantidad de áreas verdes. En el lugar ya existe una casa de adobe construida en la década de los ochenta, en la que algunos ambientes serán acondicionados para la cocina y almacén, y los demás ambientes de la casa servirán como parte de la decoración y el concepto que se pretende mostrar. Por ejemplo, se mejorarán los balcones y se pondrán en exhibición las cosas antiguas de la casa como monturas de caballos, ollas de barro antiguas, espejos antiguos entre otros. 
La parte del comedor será en una construcción rústica elaborada con troncos de eucalipto y estará bordeado por gran cantidad de áreas verdes donde habrá césped, arbustos nativos como el molle, plantas aromáticas como el romero y gran variedad de flores como el jazmín (rastreta), consiguiendo así la conservación del paisaje natural de la zona.

e) Higiene y calidad de servicio

Con el objetivo de brindar un nivel estandarizado de higiene, se tomará en cuenta las normas de Análisis de Riesgos y de Puntos Críticos de Control (HACCP), que es un sistema de gestión de la inocuidad de los alimentos basado en el control de los puntos críticos en la manipulación de los alimentos [Dirección General de Salud Ambiental (DIGESA), 2015], lo cual permitirá que todos los procesos de manipulación de alimentos sean correctos.

En cuanto al servicio de atención al cliente, el objetivo es lograr una atención cordial y proactiva a los turistas por lo que se cumplirán con todos los procesos de estandarización y capacitación para lograr un buen servicio. Teniendo en cuenta que la mano de obra operativa será local (poblador de Mollepata), existirá un riguroso plan de acción para el cumplimiento de este objetivo.

Asimismo, se contará con un Centro de Interpretación, es necesario precisar que estos establecimientos son parte de los servicios turísticos que ayudarán a dar más importancia y diferenciación a la propuesta. Los Centros de Interpretación son reconocidos como espacios de comunicación diseñados para mejorar la calidad de la experiencia recreativa del visitante, y para inspirar, de una forma agradable, un mayor aprecio por el recurso patrimonial o natural (Rideout-Civitarese, 2008). Si bien muchos la consideran también como una nueva versión de museos, un Centro de Interpretación no siempre debe guardar piezas de valor patrimonial, sino se suelen exponer representaciones de la realidad y es en la interpretación donde se fundamenta la existencia de estos equipamientos o representaciones. 
Dentro de la terminología que usa el Perú en materia de turismo, un Centro de Interpretación vendría a ser parte una instalación turística, porque son las instalaciones físicas que se relacionan directamente con el recurso o atractivo turístico y se utilizan para realizar la visita turística (MINCETUR, 2009). Bajo esta definición el propósito del plan de negocios es crear un lugar donde se muestre de manera innovadora y didáctica los principales valores de la ruta Mollepata - Salkantay - Machupicchu y que generen interés en la demanda.

De acuerdo con los datos obtenidos en la encuesta y entrevista a expertos los atractivos que más valoran los turistas sobre la ruta son: cruzar las altas montañas, el misticismo de las cumbres nevadas, lo variedad de flora y fauna y las formas de vida de los campesinos de la zona. En ese entender el Centro de Interpretación será un conjunto de ambientes donde se harán exposiciones fotográficas, escultóricas, y escritas sobre todos estos aspectos que son valorados por los turistas, y servirá para que lo guías de turismo puedan hacer una introducción de todo aquello que disfrutarán en el viaje.

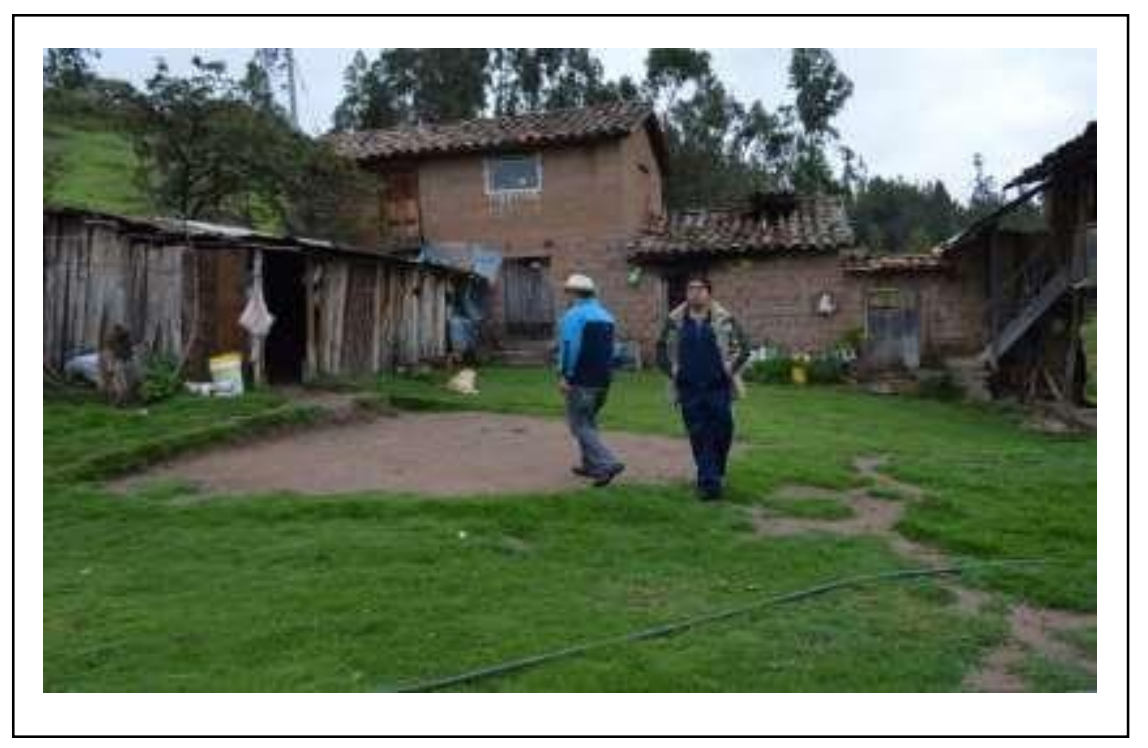

Figura 10. Área para el comedor turístico. 


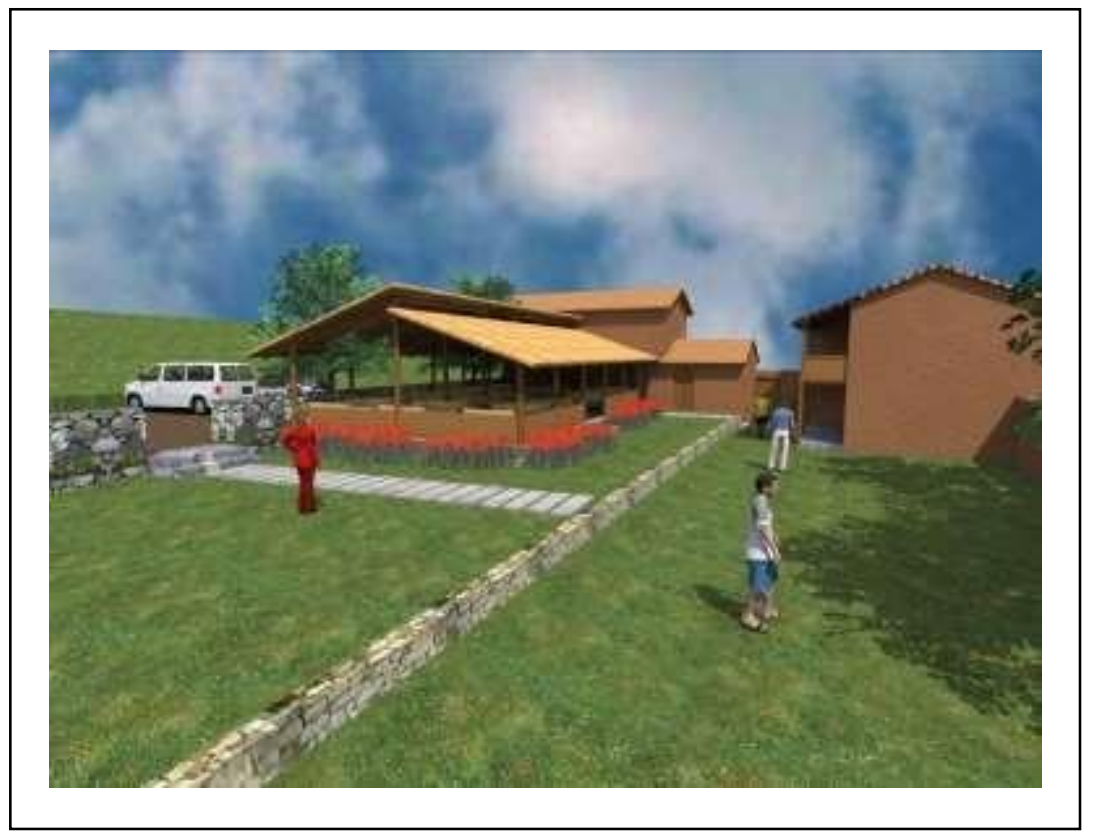

Figura 11. Vista panorámica del Restaurante en maqueta.

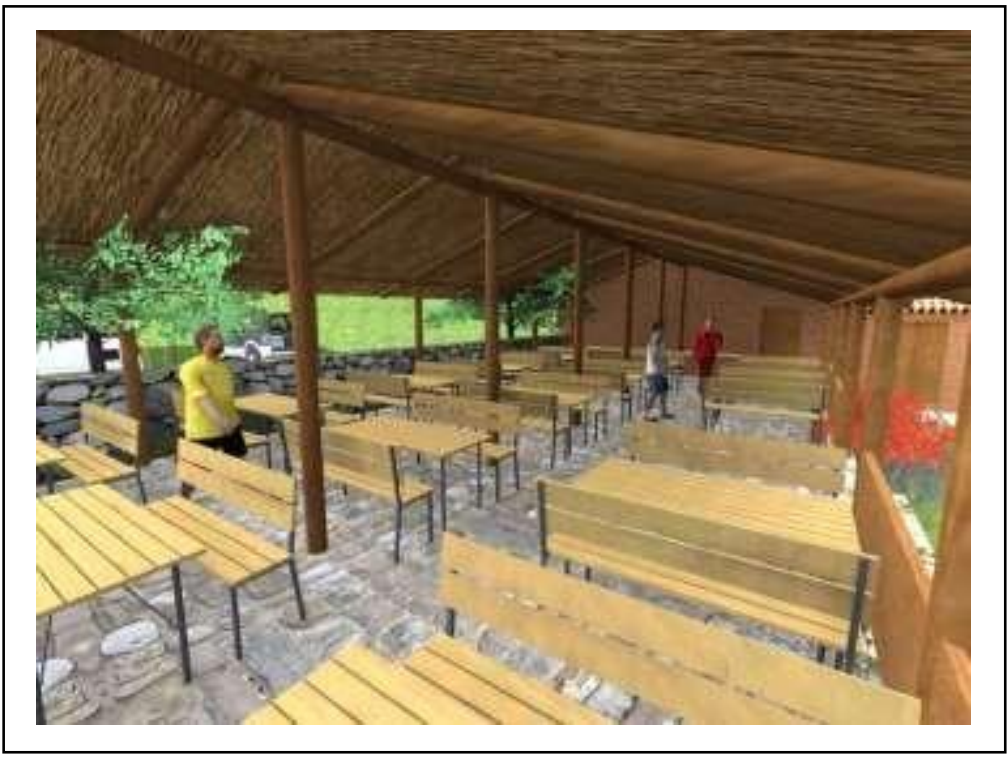

Figura 12. Interior del Restaurante en maqueta. 


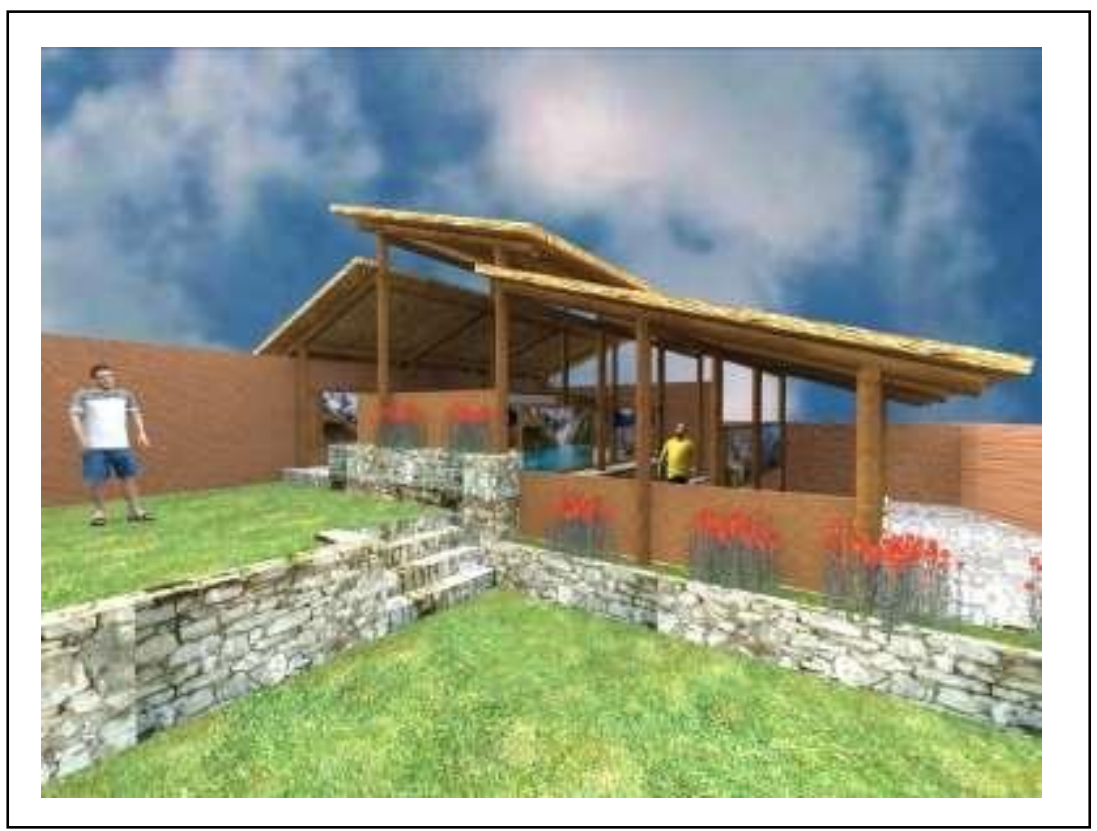

Figura 13. Vista panorámica del centro de interpretación en maqueta.

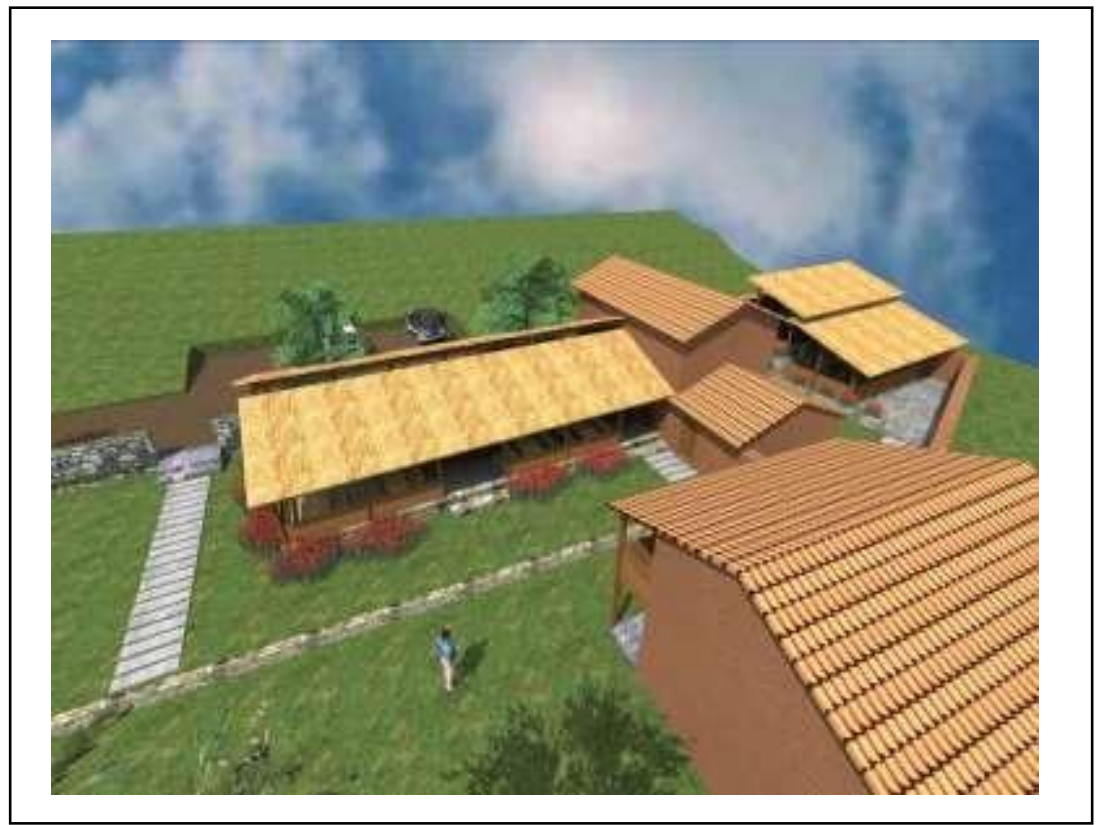

Figura 14. Vista panorámica del centro de servicios turísticos en maqueta. 


\subsection{Selección del Segmento de Mercado}

En el caso de los clientes industriales (B2B) los esfuerzos de la segmentación se ha centrado en características como el tamaño, la industria y la ubicación, correspondientes a las variables demográficas de estos clientes empresa; y que tal como en el caso de los mercados de consumo, también puede aplicarse las variables de segmentación psicográficas y personalidad, por ejemplo, unas empresas se caracterizan por ser más innovadoras que otras, convirtiéndose en usuarios líderes (Lehmann, 2007).

El segmento del mercado para el plan de negocios está formado por las agencias de viajes que demandan restaurantes en el distrito de Mollepata para realizar la ruta de trekking Salkantay - Machupicchu, motivo por el cual la forma de negociar será entre el restaurante a crear y las agencias de viajes, existiendo así una relación empresa - empresa o también conocido como B2B que son modelos de negocio en los que las transacciones de bienes o la prestación de servicios se producen entre dos empresa (www.humanlevel.com, 2016).

Las agencias de viajes y turismo son empresas que se encargan de la intermediación, organización y venta de productos e itinerarios turísticos. Estas pueden vender destinos turísticos de diversa ubicación geográfica como los destinos de sol y playa en Can Cun, México o los de cultura como las pirámides de Guiza en Egipto, las agencias de turismo pueden realizar actividades específicas en un destino como excursiones a museos, o escaladas de montañas, así también pueden recibir clientes de una determinada edad como adultos, otras solo a jóvenes y algunas también las subdividen por nacionalidades.

Para tipificar los segmentos de mercado en el plan de negocio se tomará como base las variables de segmentación para clientes B2B propuesta por Lemman D. en su libro Administración del Producto, de donde plantea la siguiente segmentación: (a) segmentación según distribución, (b) segmentación según ubicación geográfica, (c) segmentación según actividad y (d) segmentación según tamaño. 
A continuación, se detallan los criterios de segmentación que se realizó para segmentar la demanda que son las agencias de viajes.

\section{a) Segmentación según distribución}

Los canales de distribución en este caso son todos los procesos y acciones que hacen las agencias de viajes al relacionarse con los clientes. De todos estos procesos surgen varias tipificaciones, desde las agencias de viajes que necesitan intermediarios para la realización de los servicios turísticos (vinculación indirecta) y los que todos los procesos de relación con el cliente lo hacen de forma directa. En la segmentación por distribución se toma en cuenta lo estipulado por el Reglamento de Agencias de Viajes y Turismo vigente en el Perú, en el que las agencias se dividen en tres tipos: agencias mayoristas, agencias minoristas y agencias tour operadoras (MINCETUR, 2013).

- Agencias mayoristas o wholesaler

Son aquellas que organizan servicios y paquetes turísticos para ser ofrecidos por otras agencias (vinculación indirecta); debido a su gran tamaño tienen la capacidad de abarcar varios mercados internacionales, pero en la mayoría de los casos necesitan de otras agencias para desarrollar el servicio (MINCETUR, 2013). Por ejemplo, las agencias de viajes mayoristas que ofertan en Perú elaboran sus paquetes turísticos incluyendo ofertas hoteleras y de aerolíneas en varios destinos de Sudamérica como Islas Galápagos en Ecuador, Cusco en Perú, Uyuni en Bolivia y Patagonia en Buenos Aires. Los paquetes que ofrecen las agencias mayoristas también son de diversa naturaleza, como la agencia Peak Adventure que ofrece paquetes como Camino Inca, Salkantay - Machupicchu en Perú, Safaris fotográficos en el norte de África o expediciones a la Antártica.

Cabe mencionar que solo pueden ofrecer y vender los paquetes turísticos, es decir que cuando ellos venden un tour a Mollepata - Salkantay - Machupicchu, necesitan 
contactarse con un tour operador o una agencia de viajes minorista porque no están autorizados de ejecutar los paquetes.

La principal fortaleza es que tienen la capacidad de vincularse con los clientes en el extranjero, por ejemplo, la agencia G Adventure tiene convenios con universidades en Estados Unidos, lo que le permite captar estudiantes interesados en hacer rutas de trekking en Perú.

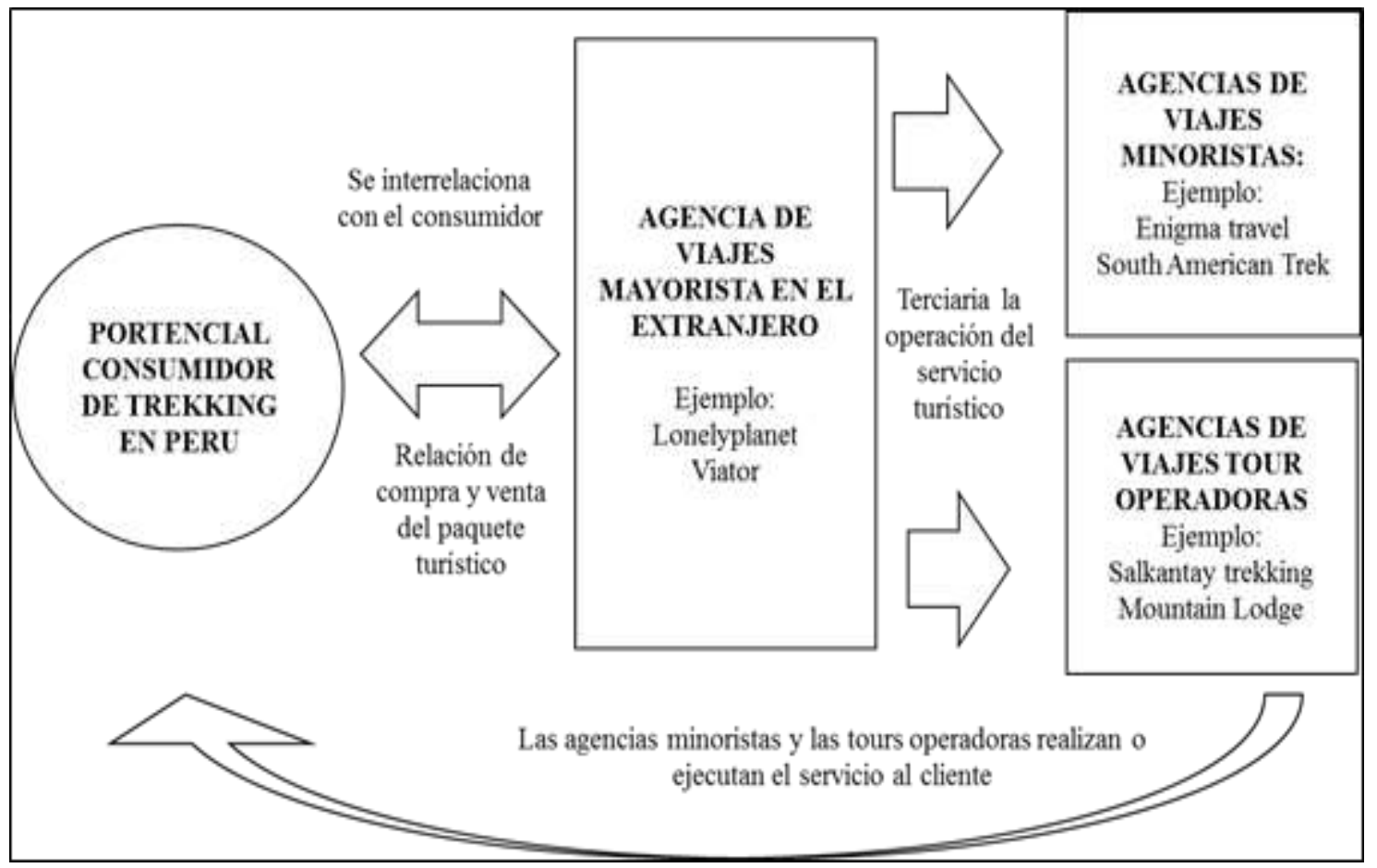

Figura 15. Operación de las agencias de viajes mayoristas según segmentación por distribución.

- Agencias minoristas o detallistas

Operan el producto de los mayoristas ejecutando el paquete turístico directamente al usuario. Así también proyectan, elaboran y organizan al turista toda clase de servicios y viajes combinados, no pudiendo ofrecer ni comercializar productos a través de otros 
servicios (MINCETUR, 2013). Estas agencias representan a las mayoristas en cada destino turístico, existiendo una mutua dependencia entre mayorista y minorista. Por ejemplo, en la ruta Mollepata - Salkantay - Machupicchu las agencias de viajes KB Tours y A rsa tours son agencias minoristas por excelencia, puesto que las agencias mayoristas, o toda aquella agencia de viajes que no tiene la capacidad de realizar la ejecución del tour de trekking por Salkantay debe endosar o terciar sus servicios a estas agencias. La ventaja de las agencias minoristas es que cuentan con la logística y los permisos respectivos para operar en el destino turístico.

Cabe mencionar que al día de hoy muchas agencias mayoristas en su afán de expansión se han fusionado o han creado agencias minoristas en los destinos turísticos donde más suelen vender paquetes turísticos, esto para poder tener un mejor control de su operación, y por ende incrementar las ganancias; por ejemplo, la agencia mayorista Internacional GAdventures contacta, vende y ahora también opera los tours de aventura en trekking al Camino Inca y a la ruta Salkantay - Machupicchu. Para poder operar un paquete turístico y ser una agencia minorista se debe contar con la autorización y licencia de funcionamiento emitida por el ente regulador del País (DIRCETUR).

- Agencias de viajes tour operadoras

Son aquellas que proyectan elaboran, diseñan y operan servicios turísticos dentro del territorio nacional, para ser ofrecidos y vendidos a través de las agencias de viajes mayoristas, aunque ellos también lo pueden ofrecer directamente al cliente (MINCETUR, 2013). Este tipo de agencia de viajes es muy parecido a la agencia de viajes minorista en el sentido de que también opera los paquetes turísticos que las agencias mayoristas no pueden ejecutar, con la diferencia de que los tour operadores pueden ofrecer y vender sus tours directamente a los clientes a través de sus oficinas comerciales o plataformas virtuales, lo cual sumado a su logística y permisos del ente regulador las convierte en las 
empresas que mayor demanda tienen en la ruta Salkantay - Machupicchu; tal es el caso de Salkantaytrek.com y Machupicchureservations.com, empresas que han desarrollado efectivos canales de venta online que les permite tener gran número de reservas llegando a tener más de cuatro mil ventas por año.

b) Segmentación por ubicación geográfica

Según Acerenza, dado que un viaje tiene geográficamente un punto de origen y un punto de destino, las agencias de viaje pueden tipificarse según se ubiquen en un lugar o en el otro, por lo que su forma de trabajar con el cliente será totalmente distinta. Pueden tipificarse en:

- Agencias emisoras (outgoing)

Son aquellas agencias cuya sede física se ubica en el lugar de origen de los viajeros. De este modo, su público es principalmente la población cercana a las mismas, que desea viajar a otros lugares. En este tipo de segmento se encuentran las agencias de viajes mayoristas con sus sedes internacionales.

En la siguiente tabla se aprecia a las principales agencias de viajes mayoristas emisivas de turistas a la ruta de trekking Mollepata - Salkantay - Machupicchu. 
Tabla 11

Agencias emisoras de turistas a la ruta Mollepata - Salkantay - Machupicchu

\begin{tabular}{lc}
\hline \multicolumn{1}{c}{ Agencia de viajes mayorista } & Nacionalidad del mercado \\
\hline Young Germany & Aleman estudiante \\
Student Outdoor & Amercicano estudiante \\
World Expeditions & Americano \\
South America Back Packer & Americano \\
National Geographic Expeditions & Americano \\
The guardian & Britanico \\
Wanderlust & Britanico \\
Tourism Concern & Europeo \\
Real Gap & Europeo \\
Macsa Adventure & Europeo \\
Wild land trekking & Mundial \\
Lonely Planet & Mundial \\
\hline Nota : Adaptado del Municipio Distrital de Mollepata: Registro \\
del arribo de turistas nacionales y extranjeros al distrito de \\
Mollepata, Boletín estadístico 2016.
\end{tabular}

La gran mayoría de estas agencias de viajes emisivas son grandes plataformas virtuales conocidos como meta buscadores, que funcionan en la web como globalizadores de oferta turística, algunas también son empresas internacionales que tienen convenios con estudiantes o programas educativos, lo cual les permite captar suficiente demanda y así luego endosar servicios a las agencias receptivas minoristas o tour operadoras. En el anterior cuadro se puede apreciar que la característica principal de estas empresas emisivas de turistas es captar demandas por nacionalidad y región geográfica; para reforzar el tema de mercados emisivos. A continuación, se muestran las estadísticas de los turistas que arribaron el 2016 a Mollepata según el país de procedencia. 
Tabla 12

Afluencia de turistas a Mollepata 2016, según nacionalidad

\begin{tabular}{|c|c|c|}
\hline Nacionalidad & $\mathrm{N}^{\circ}$ de visitantes & Porcentaje \\
\hline USA & 13,700 & $40.30 \%$ \\
\hline UK & 3,071 & $9.03 \%$ \\
\hline Alemania & 2,195 & $6.46 \%$ \\
\hline Canada & 1,971 & $5.80 \%$ \\
\hline Francia & 1,921 & $5.65 \%$ \\
\hline Brasil & 1,890 & $5.56 \%$ \\
\hline Australia & 1,880 & $5.53 \%$ \\
\hline España & 995 & $2.93 \%$ \\
\hline Holanda & 894 & $2.63 \%$ \\
\hline Belgica & 681 & $2.00 \%$ \\
\hline Argentina & 680 & $2.00 \%$ \\
\hline Irlanda & 635 & $1.87 \%$ \\
\hline Otros paises Europa & 1,768 & $5.20 \%$ \\
\hline Otros Paises Latinoamerica & 1,496 & $4.40 \%$ \\
\hline Paises Medio Oriente & 136 & $0.40 \%$ \\
\hline Paises Asia & 85 & $0.25 \%$ \\
\hline Total & 33997 & $100 \%$ \\
\hline
\end{tabular}

Nota : Adaptado del Municipio Distrital de Mollepata: Registro del arribo de turistas nacionales y extranjeros al distrito de Mollepata, Boletín estadístico 2016.

- Agencias receptoras (incoming)

En contraste con las agencias emisoras, estas sitúan físicamente su sede en los lugares a los cuales la gente desea viajar, y por tanto organizan viajes destinados a personas de otros lugares, a las cuales quieren atraer. El Cusco es un centro receptor donde se encuentran gran cantidad de agencias de viajes minoristas y tour operadoras que desarrollan paquetes turísticos para captar flujos turísticos del extranjero. 
Las agencias de viajes emisoras no pueden ejecutar directamente tours en un destino turístico por lo que necesitan de las agencias tour operadoras o las minoristas que si cuentan con logística y los permisos necesarios.

c) Segmentación según su actividad

Para segmentar a las agencias de viajes en base a su actividad es importante reconocer que estas empresas crean sus productos y paquetes turísticos basados en las motivaciones de los consumidores finales (turistas), a esto también se le puede reconocer como segmentación psicográfica, donde los grupos de empresas ofrecen determinados productos que provienen de los distintos hábitos y personalidades de los consumidores finales. (Lehmann, 2007). Las tipificaciones más importantes de acuerdo al medio turístico donde se desarrolla el proyecto son:

- Agencias de viajes para turismo Cultural

Son las que se especializan en actividades culturales como por ejemplo las que ofrecen tours a sitios arqueológicos, museos y otros lugares históricos.

- Agencias de viajes para el turismo rural comunitario

Estas agencias ofrecen a los turistas la experiencia poder convivir con las comunidades campesinas, siendo el caso de la Agencia Qantu Tours que trabaja con los campesinos de Umasbamba en Chinchero.

- Agencias de viajes para el turismo de naturaleza

Estas agencias ofrecen actividades en zonas de conservación natural como Reservas de la Biosfera, Parques Nacionales, Parques Naturales, el principal objetivo de realizar acciones de conservación y educación en estos espacios a través del turismo; por ejemplo, 
la agencia Manu Expeditions opera grupos en la biosfera de Manu y Tambopata, sus acciones van estrechamente ligadas a educar a los turistas sobre la conservación de especies de flora y fauna en esa zona.

- Agencias de viajes para el turismo de aventura

Este tipo de agencias de viajes ofrecen actividades donde los clientes realizan destrezas especiales o requieren de cierta exigencia física para la realización de la actividad, por lo que el desarrollo del tour, necesita determinado equipamiento, por ejemplo, las agencias de viajes que ofrecen river rafting necesitan botes, las que ofrecen ciclismo necesitan bicicletas, las que ofrecen escalada de montaña necesitan arneses y cuerdas especiales, etc. Actualmente en la ruta Mollepata - Salkantay - Machupicchu se realiza el turismo de aventura en la modalidad de trekking o senderismo de alta montaña. Muchas agencias en el Cusco ofrecen en vitrinas o plataformas virtuales los tours de trekking a Salkantay, Camino Inca o Lares, pero a la hora de operar al tour necesitan contactar con una agencia especialista en la ruta que tenga la logística adecuada para la realización del tour. A la fecha no existe un marco regulatorio que pueda inventariar las agencias autorizadas para ingresar a Mollepata, pero si el municipio distrital maneja estadísticas de las agencias de aventura que más ingresan a este pueblo anualmente. En el siguiente cuadro se detallan las principales agencias tour operadoras de aventura que ingresan a Mollepata y las actividades turísticas que ofrecen: 
Tabla 13

Agencias especializadas en actividad de aventura, ruta Mollepata - Salkantay -

Machupicchu

Agencias de viajede aventura

Actividades tuisticas especializadas

$\mathrm{Kb}$ tour

Machupicchureservations

Salkantay trekking

Alpaca expeditions

Arza tour

Mountain lodge peru

Salkantaybackpackers

Llama path

Extreme tourbulencia

Bambas

Sas travel

Wayky trek

South american trek

Bio andean

Chasky Peru Trek

Terra quechuas

Sam travel

Inca trailexpedition peru

Quechua expeditions
Camino Inca - Salkantay - Choquequirao

Camino Inca - Salkantay - Choquequirao - Huchuyqosqo

Salkantay - Camino Inka

Camino Inka - Lares - Salkantay

Camino Inka - Huchuyqosqo - Salkantay

Salkantay - Lares

Salkantay

Camino Inka - Lares - Salkantay

Camino Inca - Salkantay - Ausangate

Camino Inka - Salkantay - Inca Jungle

Camino Inca - Manu - Salkantay

Camino Inca - Inca Jungle - Salkantay

Camino Inca - Salkantay - Lares

Camino Inca - Inka Jungle - Lares trek - Salkantay

Camino Inka - Inka jungle - Salkantay - Huchuyqosqo

Camino lnca - Manu - Tambopata - Salkantay

Camino Inka - Salkantay - Lares

Camino Inka - Salkantay - Lares

Camino Inka - Salkantay - Manu - Ausangate

Nota : Adaptado del Municipio Distrital de Mollepata: Registro del arribo de turistas nacionales y extranjeros al distrito de Mollepata, Boletín estadístico 2016. 
d) Segmentación por tamaño

En este criterio de segmentación B2B, se suele tener en cuenta el tamaño del cliente (que puede medirse mediante factores como el volumen de ventas, la cantidad de empleados, número de plantas y de oficinas de ventas) y el tipo de la situación de compra. (Lehmann, 2007). Para la investigación la variable que se analizará será la cantidad de turistas que opera cada agencia de viajes en la ruta de Mollepata - Salkantay - Machupicchu, las mismas que son extraídas del conteo de turistas que realizo el municipio distrital de Mollepata durante el año 2016, de donde se encuentran las siguientes tipologías:

- Agencias de viajes de alta demanda

En este grupo están las agencias cuyo número de ingresos de turistas al pueblo de Mollepata es mayor a 850 turistas al año. En este grupo están las agencias de viajes que tienen mayor participación en la ruta Mollepata - Salkantay - Machupicchu, representando el $70.25 \%$ del mercado con 20,353 turistas al año. En este grupo se encuentran ocho agencias tour operadoras, las cuales son:

Tabla 14

Agencias de viajes tour operadoras de alta demanda

\begin{tabular}{llc}
\hline & \multicolumn{1}{c}{ Agencia tour Operadora } & Total de viajeros año 2016 \\
\hline 1 & KB tour & 6,285 \\
2 & Machupicchu Reservations & 5,668 \\
3 & Salkantay trekking & 4,810 \\
4 & Alpaca expeditions & 2,919 \\
5 & Arza tour & 1,491 \\
6 & Mountain lodge Perú & 1,098 \\
7 & Salkantay backpackers & 1,081 \\
8 & Llama path & 1,072 \\
& Total & 24,424 \\
\hline
\end{tabular}

Nota : Adaptado del Municipio Distrital de Mollepata: Registro del arribo de turistas nacionales y extranjeros al distrito de Mollepata, Boletín estadístico2016. 
- Agencias de viajes de regular demanda

En este grupo están las agencias cuyo número de ingresos de turistas al pueblo de Mollepata es menor a 800, pero mayor a 120 turistas al año. El promedio de llegada de estas agencias para hacer el trekking es de 2.35 días al año.

\section{Tabla 15}

Agencias de viajes tour operadoras de regular demanda

\begin{tabular}{llc}
\hline & Agencia tour Operadora & Total de viajeros al año \\
\hline 1 & Xtreme tourbulencia & 841 \\
2 & Bamba Experience & 709 \\
3 & Sas travel & 531 \\
4 & Wayky trek & 488 \\
5 & South american trek & 381 \\
6 & Bio andean & 371 \\
7 & Chasky & 308 \\
8 & Terra quechuas & 293 \\
9 & Sam travel & 290 \\
10 Inca trail expedition peru & 223 \\
11 Quechua expeditions & 223 \\
12 Amazonas explorer & 215 \\
13 Condor travel & 186 \\
14 Rasgos peru & 167 \\
15 Tierras vivas & 165 \\
16 Valencia travel & 158 \\
17 Nc travel peru & 152 \\
TOTAL & 5,703 \\
\hline
\end{tabular}

Nota : Adaptado del Municipio Distrital de Mollepata: Registro del arribo de turistas nacionales y extranjeros al distrito de Mollepata, Boletín estadístico 2016.

- Agencias de viajes de baja demanda

En este grupo están las agencias cuyo número de ingresos de turistas al pueblo de Mollepata es menor a 100, pero mayor a 20 turistas al año. El promedio de llegada de estas agencias para hacer el trekking es de 0.35 días al año. 
Tabla 16

Agencias de viajes tour operadoras de baja demanda

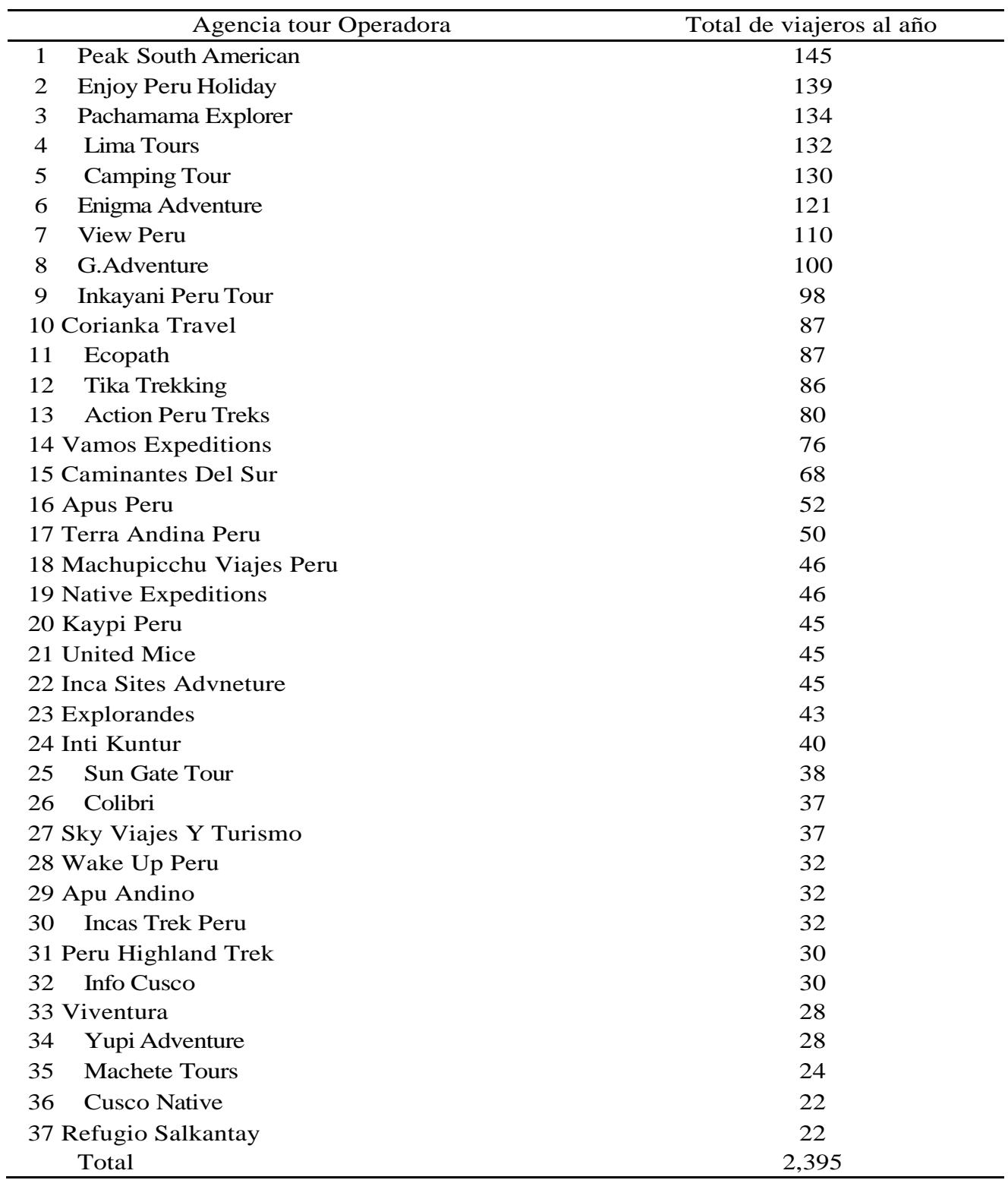

Nota : Adaptado del Municipio Distrital de Mollepata: Registro del arribo de turistas nacionales y extranjeros al distrito de Mollepata, Boletín estadístico 2016.

- Agencias de viajes de demanda esporádica

En este grupo se tiene un aproximado de 150 agencias de viajes a más, que esporádicamente operan turistas en el pueblo de Mollepata, en la cantidad menor a 20 turistas al año por agencia, pero todas en su conjunto llegan a más de 1,400 turistas al año. 
Tabla 17

Segmentación por tamaño de agencias de viajes

\begin{tabular}{lccc}
\hline \multicolumn{1}{c}{ Agencias de viaje } & Numrciouc & Ivumcto & Porcentaje \\
& agencias & Visitantes & \\
\hline Agencias de alta demanda & 8 & 24,424 & $71.84 \%$ \\
Agencias de regular demanda & 18 & 5,703 & $16.78 \%$ \\
Agencia de menor demanda & 36 & 2,395 & $7.05 \%$ \\
Agencia de demanda esporadica & 150 & 1,475 & $4.34 \%$ \\
$\quad$ Total & 212 & 33,997 & $100 \%$ \\
\hline
\end{tabular}

Nota:Adaptado del Municipio Distritalde Mollepata:Registro del arribo de turistas nacionales y extranjeros al distrito deMollepata, Boletín estadístico 2016.

A continuación, se presenta una gráfica según la demanda de las agencias de viaje.

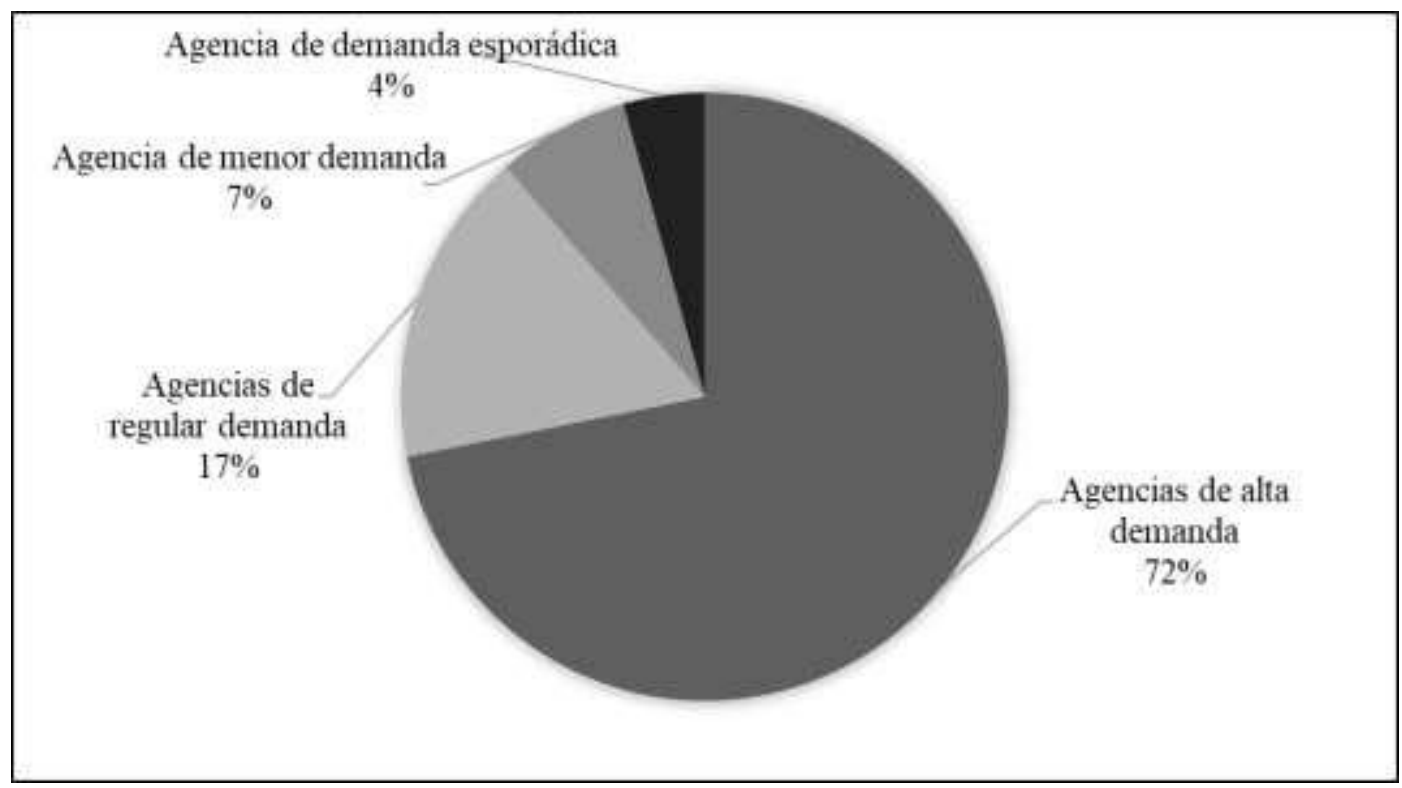

Figura 16. Registro del arribo de turistas nacionales y extranjeros al distrito de Mollepata, Adaptado del Municipio Distrital de Mollepata; Boletín estadístico, 2016. 
De todo lo expuesto, en conclusión, el centro de servicios turísticos estará dirigido al siguiente mercado:

Tabla 18

Segmentación de mercado

\begin{tabular}{lc}
\hline \multicolumn{1}{c}{ Criterio } & Segmento \\
\hline $\begin{array}{l}\text { Segmentación según } \\
\text { ubicación geográficas }\end{array}$ & $\begin{array}{r}\text { Agencias de viajes receptoras en el destino Cusco y que } \\
\text { operen paquetes turisticos en la ruta Mollepata Salkantay } \\
\text { Machupicchu }\end{array}$ \\
$\begin{array}{l}\text { Segmentación según } \\
\text { distribución }\end{array}$ & $\begin{array}{r}\text { Agencias de viajes minoristas y tour operadores que ejecutan u } \\
\text { operan la ruta Mollepata Salkantay Machupicchu }\end{array}$ \\
$\begin{array}{l}\text { Segmentación según su } \\
\text { actividad }\end{array}$ & $\begin{array}{c}\text { Agencias de viajes que expertas en actividades de aventura y } \\
\text { trekking en la ruta Mollepata Salkantay Machupicchu. }\end{array}$ \\
$\begin{array}{l}\text { Segmentación según } \\
\text { tamaño }\end{array}$ & Agencias de viajes que operaron la ruta Mollepata - Salkantay - \\
\end{tabular}

\subsection{Investigación Cualitativa}

Hair, Bush y Ortinau (2010) indican que la investigación cualitativa se encarga de encontrar data a través de reacciones, que faciliten comprender y analizar algunos factores que la investigación cuantitativa no puede esclarecer.

La investigación cualitativa produce datos descriptivos, formado por las propias palabras de las personas (habladas o escritas), aunque también se puede realizar observación de la conducta. Las técnicas más importantes de investigación cualitativa son las siguientes: 
Los focus groups, constituyen una de las formas de investigación cualitativa donde se reúne a un grupo de personas para indagar sobre actitudes y reacciones con respecto a un producto, un servicio, una marca, una pieza publicitaria, o una mezcla de todos. Las preguntas son respondidas por la interacción del grupo en una dinámica donde los participantes se sienten cómodos, libres de hablar y dar a conocer sus opiniones (Arango, 2011).

Las entrevistas en profundidad, son una técnica de investigación cualitativa que se aplica cuando no es posible conformar grupos debido a las especificidades del target investigado: líderes de opinión, empresarios, dirigentes políticos, profesionales, etc. (Arango, 2011). Los mini grupos funcionan de la misma forma que los focus groups, la diferencia radica en que el número de participantes es menor, de cuatro a seis personas (Arango, 2011).

Para fines de la investigación es de suma importancia conocer la percepción de los involucrados en el negocio para luego diseñar los instrumentos de investigación cuantitativa.

Al ser este un tipo de negocio business to business (B2B), los más involucrados en el estudio de mercado serán personas que dirigen negocios en turismo, o expertos en turismo de aventura, por lo que la técnica cualitativa a utilizar será la entrevista a profundidad.

\subsubsection{Proceso de Muestreo.}

El muestreo se hace reconociendo varios grupos de influencia para los objetivos del plan de negocio. En vista de que la propuesta de negocio se enfoca a ser un restaurant que ofrece desayunos para los turistas que llegan al poblado de Mollepata, el primer grupo de interés serán los potenciales clientes que decidirán contratar los servicios del restaurant, y son los administradores o gerentes de las agencias de viajes que operan la ruta Mollepata Salkantay - Machupicchu, En el anterior subtitulo se analizó los segmentos de mercado y se reconoció a las agencias tour operadoras en dicha ruta. 
La muestra será entrevistar a tres de estos gerentes o administradores, estando primero seguros que ellos son los que toman las decisiones para contratar un restaurant en Mollepata y tienen un amplio conocimiento de la realidad en la ruta turística.

El segundo grupo o muestra está formado por los expertos en la dirección o administración de Centros de Interpretación en la región del Cusco. La experiencia de ellos será importante para definir los objetivos y la temática del centro de interpretación; en la ciudad del Cusco existen un promedio de cinco centros de interpretación con características similares a la propuesta del presente plan de negocios, por lo que se entrevistará a tres personas que tengan experiencia en la dirección y administración de este tipo de empresas.

\subsubsection{Diseño de Instrumento.}

Los instrumentos de investigación cualitativa que se utilizaron son las entrevistas de profundidad, realizándose un total de cuatro entrevistas a distintos perfiles de expertos.

Para la primera entrevista a expertos en la ruta Mollepata - Salkantay - Machupicchu, el objetivo es entrevistar a los expertos que tienen amplia experiencia en la dirección y toma de decisiones en agencias de viajes que operan el circuito de turismo de aventura Mollepata - Salkantay - Machupicchu para así comprender la percepción y expectativas de quienes toman la decisión de contratar los servicios de restaurant en Mollepata. El resumen de la ficha técnica Nro. 1, se presenta a continuación en la siguiente tabla: 
Tabla 19

Resumen de ficha técnica entrevistas en profundidad

\begin{tabular}{ll}
\hline Naturaleza Metodologica & Investigacion Cualitativa \\
\hline Tecnica metodologica & Entrevista a profundidad \\
Tipo de pregunta & Preguntas semiestructuradas y preguntas de sondeo \\
Universo & $\begin{array}{l}\text { Expertos en Agencias de viajes tour operadoras de la ruta } \\
\text { de Trekking Mollepata - Salkantay - Machupicchu }\end{array}$ \\
Ambito Geografico & $\begin{array}{l}\text { Operadores Turisticos de la region Cusco } \\
\text { Elementos del Muestreo }\end{array}$ \\
Tamaño muestral & $\begin{array}{l}\text { Expertos de agencias de viajes que tengan poder de } \\
\text { Mollepata }\end{array}$ \\
\hline
\end{tabular}

A continuación, se presenta la guía de preguntas de la primera entrevista:

Guía De Entrevistas a Expertos en el Circuito De Trekking Mollepata - Salkantay Machupicchu:

Sobre la percepción del sector

- ¿Cómo ha evolucionado la actividad de trekking en el distrito de Mollepata y otros circuitos de aventura en la región del Cusco, hasta la actualidad?

- ¿Cuál es su percepción del futuro del turismo de trekking en el Cusco y en especial en el circuito Mollepata - Salkantay - Machupicchu teniendo en cuenta los cuellos de botella que enfrenta la región como capacidad de carga limite y problemas de accesibilidad a Machupicchu, transporte ferroviario, saturación del camino Inca, teleférico a Choquequirao, aeropuerto internacional de Chinchero entre otros)? Análisis de la oferta y demanda turística 
- ¿Cuál es el perfil del turista que viene a realizar trekking Mollepata - SalkantayMachupicchu?, por favor indíquenos las edades aproximadas, nacionalidades más comunes, hoteles en los que se hospedan, capacidad de gasto, gustos y preferencias en el servicio.

- ¿Cuáles considera que son los principales circuitos de trekking en el Cusco de mayor demanda? ¿Por qué? (Mencionar solo aquellos lugares donde el turista pernocta al menos una noche)

- ¿Cuáles son los atractivos turísticos que más disfruta el turista a la hora de hacer el circuito de trekking Mollepata - Salkantay - Machupicchu? Indique en orden de prioridades

Flujos de afluencia turística en Mollepata

- ¿Cuáles son los meses en los que se tiene más y menos afluencia de turistas en el circuito de trekking a Salkantay - Machupicchu?

- ¿Cuál es la cantidad aproximada de turistas que pasan diariamente o mensualmente por Mollepata tanto en temporada alta como baja?

- ¿Cuán perjudicial para su empresa es hoy la temporada baja en el circuito de trekking Mollepata - Salkantay - Machupicchu y cómo afronta o afrontó su empresa este tema?

Percepción de puntos críticos de la competencia

- ¿Cuáles considera que son las debilidades del circuito de trekking Mollepata Salkantay Machupicchu?

- Considera usted que los turistas salen satisfechos después de haber tomado su desayuno en el poblado de Mollepata, ¿sí o no? y ¿Por qué? 
- ¿Cuál es su diagnóstico de la realidad del servicio de los restaurantes que ofrecen desayunos a los turistas en el pueblo de Mollepata? Por favor analicemos punto por punto en cuanto a: ¿ubicación, variedad de la carta del menú, calidad de los alimentos, higiene, servicio al cliente, ambientación y decoración, temática o concepto del restaurant?

Análisis de la cadena de valor

- ¿Cómo su empresa elije el proveedor de desayunos para sus turistas en el poblado de Mollepata? y ¿cuál es el rol del guía de turismo a la hora de contactarse con los restaurantes turísticos de Mollepata?

- Como su empresa trabaja con los restaurantes del pueblo de Mollepata, explíquenos por favor los procesos de relación comercial con estos proveedores

Evaluación de la propuesta de negocio

- ¿Cómo cree usted que se podría mejorar la experiencia del turista a la hora de brindar el desayuno en el pueblo de Mollepata? (citar varios puntos en cuanto a ubicación, variedad de la carta del menú, calidad de los alimentos, servicio al cliente, ambientación y decoración, temática o concepto del restaurant)?

- Teniendo en cuenta que Mollepata es un punto importante en el circuito de trekking, al ser el punto de partida, ¿qué servicios turísticos considera usted que se debería implementar o mejorar en este poblado para hacer más positiva la experiencia de los turistas. (entiéndase por servicios turísticos como museos, centros de interpretaciones, restaurantes, abarrotes, farmacias, servicios higiénicos, o algún otro servicio útil para los turistas.)? 
- ¿Cree usted que la creación de un centro de interpretación en el poblado de Mollepata que permita al turista tener una previa conexión creativa y educativa sobre los valores más importantes del Circuito Mollepata - Salkantay - Machupicchu pueda ser valorado positivamente por los turistas? Si o no y ¿por qué?

- ¿Qué características y temática de concepto cree usted que debería tener un centro de interpretación en el circuito Mollepata - Salkantay - Machupicchu?

- ¿Estaría de acuerdo usted con la creación de un centro de interpretación en el distrito de Mollepata que además ofrezca otros servicios a los turistas como los de restaurant para desayunos, abarrotes, servicios higiénicos, etc.? Si o no y ¿por qué?

- ¿Cuánto tiempo como máximo estaría usted dispuesto a que sus turistas se queden en el poblado de Mollepata, y cuando como máximo podría pagar por el desayuno de un turista?

Para la segunda entrevista a expertos en centros de Interpretación Turística en el Cusco, el objetivo de la segunda ficha es conocer la percepción de expertos que tienen amplia experiencia y/o conocimiento sobre centros de interpretación turística en la región Cusco, con el objetivo de tener una visión clara de las experiencias reales de centros de interpretación en la zona en estudio. El resumen de la ficha técnica número dos, se presenta a continuación en la siguiente tabla: 
Tabla 20

Investigación Cualitativa

\begin{tabular}{ll}
\hline Naturaleza Metodologica & Investigacion Cualitativa \\
\hline Tecnica metodologica & Entrevista a profundidad \\
Tipo de pregunta & Preguntas semiestructuradas y preguntas de sondeo \\
Universo & Expertos en Centros de interpretacion turistica \\
Ambito Geografico & Region Cusco \\
Elementos del Muestreo & $\begin{array}{l}\text { Expertos en Centros de interptretacion con vocacion } \\
\text { para que los turistas puedan visitarlos }\end{array}$ \\
Tamaño muestral & Tres Unidades muestrales
\end{tabular}

Guía de Entrevistas en Centros de Interpretación a expertos en Centros de Interpretación En La Región Del Cusco

Información general de la oferta y demanda de centros de interpretación

- ¿Cuáles son los objetivos de un centro de interpretación cultural y natural?

- ¿Cómo se ha ido desarrollando la oferta de centros de interpretación en el Perú y en especial en nuestra región Cusco?

- ¿Por qué cree usted que son importantes los centros de interpretación en nuestros destinos turísticos?

- ¿Qué es lo que más disfrutan los turistas de los centros de interpretación en la región Cusco? 
Puntos críticos en los centros de Interpretación

- ¿Por qué cree usted que varios de los centros de interpretación creados por el estado en el punto de inicio de los atractivos turísticos no han tenido éxito?

- Desde su experiencia ¿cuáles son las debilidades de muchos centros de interpretación privados, en la región Cusco?

- ¿Coméntenos cuáles son ventajas competitivas que tiene el centro de interpretación que usted dirige o dirigió?

- ¿Cuántos turistas aproximadamente visitan mensualmente su centro de interpretación tanto en temporada alta como baja?

Análisis del producto y evaluación de la propuesta

- ¿Cuál consideran que debería ser la temática para un centro de interpretación donde los visitantes son turistas que están a punto de realizar la ruta de trekking Salkantay Machupicchu?

- Además de la interpretación educativa, que otros servicios turísticos cree usted que sea provechoso ofrecer en un centro de interpretación que está ubicado en una zona rural (entiéndase por servicios turísticos como, restaurantes, abarrotes, farmacias, servicios higiénicos, o algún otro servicio útil para los turistas)

- ¿Conocen algún centro de interpretación que brinde otros servicios turísticos a los clientes? y ¿está de acuerdo con la existencia de estos? Sí, no y ¿por qué?

- ¿Cuáles deberían ser los canales de promoción y publicidad para un centro de interpretación en la región del Cusco?

- ¿De quién depende la asistencia de clientes al centro de interpretación, del guía turístico o del mismo cliente? y ¿por qué? 
- ¿Qué acciones realiza su negocio para fidelizar a los guías de turismo con el centro de interpretación?

- ¿Cuál es su apreciación sobre la creación de un restaurante, que permita que a los comensales visitar gratuitamente un centro de interpretación el cual este ubicado en el poblado de Mollepata, siendo este un punto de inicio para la ruta de trekking Salkantay - Machupicchu?

\subsubsection{Análisis y Procesamiento de Datos.}

Las entrevistas a expertos fueron grabadas y transcritas posteriormente para su ser analizados divididos en dos grupos, para empezar, se desarrollan a continuación las entrevistas a expertos operadores turísticos en la ruta de trekking Mollepata - Salkantay Machupicchu:

Se toma en cuenta a empresarios de agencia de viaje de notable participación en el turismo de aventura y que sobre todo conocen la realidad de campo, es decir conocen ampliamente la zona en estudio (ver anexo 3).

Todos los entrevistados reconocen la importancia que tiene la ruta del camino Inca tradicional en el mercado de aventura y trekking del Cusco, al ser esta la más demandada de todas, pero por unanimidad todos los entrevistados señalaron que es preocupante la saturación de esta ruta por la capacidad limitada, y que el mercado necesita que se potencien nuevas rutas turísticas de aventura en el Cusco.

Los entrevistados señalaron que ante la saturación de cupos en la ruta Camino Inca tradicional a Machupicchu, los turistas prefieren la ruta de Salkantay e Inca Jungle (en ese orden) como la mejor opción para realizar trekking de aventura. Finalmente, las que menos se visitan son la ruta de trekking de Lares y Choquequirao. 
Los entrevistados señalaron que los mejores atractivos de esta ruta son los paisajes, ambientes naturales, el nevado Salkantay y la emoción de llegar caminando a Machupicchu.

Sobre el perfil del turista que hace la ruta de Mollepata - Salkantay - Machupicchu, los entrevistados señalaron que generalmente los viajeros son jóvenes entre 18 a 40 años, de nacionalidad norteamericana y europea. Sobre su comportamiento todos son de instinto aventurero y deportivos, tienes el objetivo de cruzar las montañas y llegar a Machupicchu, es como dicen en Europa, Life Changing Experience, es decir, una experiencia singular en la vida. Finalmente, cuando se les pregunto sobre el nivel económico, el representante de la agencia de viajes Valencia Travel, indico que su público es mayormente de hoteles 3 estrellas mientras que el de Pachamama Explorer indico que su público es de Hostels o algún tipo de hospedaje barato, esto se debe a que cada agencia se dirige a un segmento distinto según el nivel económico.

Cuando se les pregunto a los expertos sobre la incidencia de la temporada baja, todos señalaron que, si es una constante para los negocios, porque las lluvias dificultan la experiencia. Los meses de enero, febrero y marzo son los más bajos, pero por ejemplo agencias como Salkantay Trek indicaron que si o si todos los días del 2016 vendieron tours al Salkantay a pesar de la temporada de lluvias; la estrategia que usaron fue dar promociones y descuentos. Lo mismo sucede con Orellana tours que para vender en temporada baja debe dar promociones dirigiéndose al mercado de latinos.

Sobre las debilidades de la ruta hubo opiniones diferentes, algunos señalaron que la falta de mantenimiento a la ruta es un factor negativo, puesto que el estado no invierte en mejorar la accesibilidad del camino. Otro punto fue la infraestructura de servicios en Mollepata, considerando a los servicios higiénicos, paradores turísticos en la ruta, señalización turística, entre otros. 
Sobre la situación de los restaurantes turísticos de Mollepata, los entrevistados señalaron que estos necesitan mejorar pues los turistas salen insatisfechos ante la mala calidad, aunque también indicaron que ellos saben que probar servicios deficientes es parte de la aventura de trekking. Otros entrevistados señalaron que la atención es también un poco fría y que la infraestructura del restaurant es muy básica porque simplemente son habitaciones antiguas acomodadas como un comedor.

Al preguntar sobre cómo era el nexo de contacto con los restaurantes, algunos señalaron que existían una especie de convenios entre la agencia y el restaurant para hacer reservas previas, pero en otros casos era a protestad del guía la elección del restaurant.

Los entrevistados señalaron que el servicio más urgente a implementar serían unos adecuados servicios higiénicos para el turista, un lugar para donde los turistas puedan comprarse snack o alimentos de última hora previa a la caminata.

Al hacer la pregunta sobre el centro de interpretación todos los entrevistados mostraron su aceptación con la idea, indicando que los mejores temas a mostrar deberían ser educar al viajero sobre la conservación de la ruta, un resumen didáctico sobre los puntos importantes de la ruta y mostrar la importancia del pueblo de Mollepata.

Finalmente, al preguntar sobre el tiempo de permanencia en el restaurant de Mollepata y el costo del desayuno, en su mayoría los entrevistados señalaron que el tiempo oscila entre 45 a 90 minutos como máximo y el precio justo para el desayuno es entre S/ 15.00 y S/ 25.00 según el tipo de desayuno.

Por otro lado, también se desarrollaron entrevistas a expertos en centros de interpretación, cuyo análisis se desarrolla a continuación:

Dichas entrevistas se realizaron a personalidades muy importantes para los objetivos de la investigación en el sentido que son empresarios exitosos en el Cusco al haber creado Centros de Interpretación turística que gracias a la innovación han impactado positivamente en el sector y no tienen por el momento competidores cercanos (ver anexo 
3). Es el caso del Museo de la Coca, un lugar donde el turista a través de una visita guiada puede conocer más aspectos sobre la milenaria hoja de la coca. De igual forma sucede en el Museo del Chocolate, lugar donde el turista además de conocer detalles sobre el chocolate por medio de una serie de paneles informativos, puede degustar productos de cacao y tomarse un café elaborado por ellos mismos.

Asimismo, se desarrollaron entrevista a los expertos en Centros de Interpretación y el análisis se presenta a continuación:

Ante la necesidad de conocer más sobre el concepto y objetivos de estos establecimientos, las primeras preguntas se orientaron a saber más sobre la esencia de los Centros de Interpretación turística privados. En ambas entrevistas los invitados respondieron que el concepto de un Centro de Interpretación turística es brindar información y hacer que las personas puedan adquirir nuevos conocimientos de forma didáctica. Cuando se les hablo sobre el objetivo ambos entrevistados respondieron enfáticamente que la rentabilidad económica es secundaria y dejaron claro que siempre debe primar la rentabilidad social cuando se hace un Centro de Interpretación.

Sobre la evolución de los centros de interpretación en el Perú, las representantes del Museo de la Coca indicaron que su tío (dueño del negocio) creó ese lugar para resolver las preguntas de forma didáctica que muchos se hacían sobre los poderes reales de la coca y que no eran muy explícitos en los libros, mientras que en el Museo del Chocolate indican que la evolución de los Centros de Interpretación va por no solo dar información tal y como fuera un libro, sino ofrecer al visitante una experiencia y en el caso de ellos, es hacer que el visitante experimente la idea de cacao, que pruebe y lo lleve a compartir con su seres queridos. En ambos lugares se busca que el visitante no reciba carga informativa teórica y aburrida, más por el contrario, que la experiencia sea didáctica y dinámica. 
Cuando se les preguntó sobre el porqué del fracaso de los Centros de Interpretación turística del estado, los entrevistados respondieron que esto se debe primero a que el Estado solo busca lucrar con el cobro de entradas a estos lugares, segundo porque muchos de estos son muy informativos y no hay nada de experiencia y tercero porque PROMPERU no realiza una buena promoción de estos lugares.

Sobre los factores de éxito de un centro de interpretación los entrevistados señalaron que necesariamente es crear una idea bastante especial, es decir un tema de interpretación de interés genuino para los visitantes. Otro factor de éxito importante es no cobrar entrada a los visitantes, los turistas muchas veces vienen con el presupuesto limitado para los tours y no se arriesgan a invertir en lugares que tienen la mala fama de ser meramente informativos.

Al preguntar sobre los conceptos que debería tener un Centro de Interpretación en el inicio de la caminata de alta montaña, los entrevistados señalaron que el concepto debe ir por el tema de flora, fauna, geología, clima, costumbres y cultura local. Al tocar el tema de complementar el centro de interpretación con otros servicios turísticos como abarrotes o farmacias los entrevistados recomendaron no desviar el concepto de centro de interpretación con una propuesta meramente comercial. El entrevistado de Museo del Chocolate nos habló de camuflar propuestas comerciales con acciones sociales, por ejemplo si deseas vender una barra energética al turista, en vez de comprar cereal en el Marquet, seria trabajar con campesinos de la zona y usar sus cereales para elaborar barras energéticas y venderla al turista haciéndole entender la cadena de valor y la contribución real que hace el turista al comprar dicha barra energética producida por campesinos, de este modo no solo gana la empresa, sino también el campesino de la zona.

Cuando se preguntó sobre la mejor forma de captar clientes, la respuesta fue bien clara, en el mercado turístico cusqueño, la recomendación del guía de turismo es muy 
importante, los turistas se fían de ellos, es por eso que las acciones de marketing muchas veces están dirigidas a captar su atención y se les incentiva con comisiones y descuentos.

Finalmente, cuando se les comento sobre la propuesta para crear un centro de interpretación en Mollepata, los entrevistados resaltaron la importancia de crear un lugar que brinde conocimientos a los turistas, siendo necesarios temas como la conservación, la importancia del Apu y los caminos incas.

\subsection{Investigación Cuantitativa}

Hair et al. (2012) el principal objetivo de la investigación cuantitativa es cuantificar los resultados obtenidos por parte del estudio cualitativo. De esta manera se obtiene información exacta y acertada sobre la actualidad de la industria.

Comúnmente las investigaciones cuantitativas se realizan mediante encuestas, que consisten en la recolección sistemática de información necesarios en una muestra de personas y mediante un cuestionario pre-elaborado. Las encuestas se aplican cuando se pretende obtener resultados proyectados a un determinado mercado objetivo o target, por ejemplo, estudiantes de universidades públicas que residen en Cusco y que solo almuerzan en el comedor universitario.

La técnica de investigación cuantitativa que se realiza en la presente investigación son las entrevistas personales.

\subsubsection{Proceso de Muestreo.}

Según Hair et al. (2012), se identifica el tipo de muestreo no probabilístico para este proceso, además de muestreo aleatorio como el más adecuado para el proyecto, tal como se explicó en párrafos anteriores. 
Universo: Para el proceso de muestreo se hizo una segmentación por actividad y tamaño de la empresa (B2B), en la descripción del segmento de mercado se reconoció que existen 62 agencias de viajes de turismo que regularmente ingresan a Mollepata (más de veinte turistas al año).

Tipo de muestreo: No probabilístico, intencional o de conveniencia. En este caso se selecciona directamente o intencionadamente los individuos de la población, se toma en cuenta a las agencias de viajes tour operadoras que mayor volumen de ventas y participación del mercado tienen en el área de estudio. La razón de elegir el método no probabilístico es porque la segmentación de la demanda indica que los clientes están agrupados y son reconocidos por su volumen de ventas, así que el objetivo es analizar directa e intencionalmente a las agencias de viajes con mayor participación de turistas en la ruta de trekking Mollepata - Salkantay - Machupicchu, de otro modo no se lograra los objetivos de mercado.

Muestra: está formado por 25 agencias elegidas por conveniencia para los objetivos del plan de negocio, estas son las que tienen más del $88.62 \%$ del mercado con 30,127 turistas al año (entre 6,880 a 165 turistas al año). Con las 25 encuestas se determinará el target.

\subsubsection{Diseño de Instrumento.}

De acuerdo a Hair et al. (2012) el instrumento elaborado para este proyecto es el cuestionario, el cual contienen interrogantes en relación a variables que se espera medir.

En consecuencia, se desarrollaron nueve cuestionarios individuales con 23 preguntas edificadas en función a lo que se quiere medir. El objetivo de realizar el cuestionario es evaluar el grado de aceptación en el mercado para un nuevo restaurant turístico y centro de interpretación en el pueblo de Mollepata, a partir de la indagación sobre la percepción de 
la realidad del mercado, expectativas, preferencias, necesidades y la posibilidad de lanzar productos nuevos y/o diferenciados (Ver Anexo 6).

Tabla 21

Ficha Técnica del Cuestionario

\begin{tabular}{lc}
\hline \multicolumn{1}{c}{ Naturaleza Metodológica } & Investigación Cuantitativa \\
\hline $\begin{array}{l}\text { Técnica Metodológica } \\
\text { Tipo de Pregunta }\end{array}$ & $\begin{array}{c}\text { Encuesta personal } \\
\text { Preguntas estructuradas }\end{array}$ \\
Universo & $\begin{array}{c}\text { Representantes de agencias de viajes tour } \\
\text { operadoras en la Ruta Mollepata - Salkantay - } \\
\text { Machupicchu }\end{array}$ \\
Ámbito geográfico & Agencias de viajes de aventura en la región Cusco \\
& Representantes de agencias de viajes tour \\
operadoras en la Ruta Mollepata - Salkantay - & Machupicchu que tengan una afluencia de turistas \\
mayor a 850 turistas anuales
\end{tabular}

3.4.3. Análisis y Procesamiento de Datos.

Se realizó una gráfica de todas las respuestas obtenidas en relación a los 25 cuestionarios aplicados. De las 25 encuestas aplicadas todas están divididas en cuatro grupos, relacionados por su volumen de ventas anual, el cual se infirió de los datos estadísticos provistos por el municipio y cuando se hizo la pregunta general para escatimar volumen de ventas. Cabe recalcar que se tomó este grupo de agencias por ser las que 
tienen mayor participación de mercado en la ruta en estudio. Los grupos de las agencias de viajes encuestadas son:

Tabla 22

Agrupación de agencias de viajes según ventas

\begin{tabular}{|c|c|}
\hline Categorización por número de viajeros & Agencia de viajes \\
\hline $\begin{array}{c}\text { Tres Agencias de } 7000 \text { a } 5000 \\
\text { viajeros al año }\end{array}$ & $\begin{array}{l}1 \text { KB tour } \\
2 \text { Machupicchu Reservations } \\
3 \text { Salkantay trekking }\end{array}$ \\
\hline $\begin{array}{c}\text { Cinco agencias de } 3000 \text { a } 1500 \\
\text { viajeros al año }\end{array}$ & $\begin{array}{l}4 \text { Alpaca expeditions } \\
5 \text { Arza tour } \\
6 \text { Mountain lodge Perú } \\
7 \text { Salkantay backpackers } \\
8 \text { Llama path }\end{array}$ \\
\hline $\begin{array}{l}\text { Nueve agencias de } 1000 \text { a } 300 \\
\text { viajeros al año }\end{array}$ & $\begin{array}{l}9 \text { Xtreme tourbulencia } \\
10 \text { Bamba Experience } \\
11 \text { Sas travel } \\
12 \text { Wayky trek } \\
13 \text { South american trek } \\
14 \text { Bio andean } \\
15 \text { Chasky } \\
16 \text { Terra quechuas } \\
17 \text { Sam travel }\end{array}$ \\
\hline $\begin{array}{l}\text { Ocho agencias de } 250 \text { a } 180 \text { viajeros } \\
\text { al año }\end{array}$ & $\begin{array}{l}18 \text { Inca trail expedition peru } \\
19 \text { Quechua expeditions } \\
20 \text { Amazonas explorer } \\
21 \text { Condor travel } \\
22 \text { Rasgos peru } \\
23 \text { Tierras vivas } \\
24 \text { Valencia travel } \\
25 \text { Nc travel peru }\end{array}$ \\
\hline
\end{tabular}

Se estableció esta agrupación de agencias de viajes de acuerdo a la participación que tienen en la demanda de turistas, las agencias del primer grupo tienen una presencia casi diaria en Mollepata, las del segundo y tercer grupo entre cuatro a ocho veces por mes, 
mientras que las del último grupo una presencia al mes aproximadamente en temporada alta.

Los resultados del análisis de datos fueron los siguientes:

Las preguntas $\mathrm{N} 1-\mathrm{N} 2-\mathrm{N} 3$, son preguntas para obtener datos personales como nombres, empresa a la que representan y cargo en la empresa.

Pregunta N4. Cuantos pasajeros aproximadamente envía su agencia de viajes a la ruta Mollepata - Salkantay - Machupicchu en los meses de temporada alta (de mayo a octubre). Por favor indíquenos un promedio mensual aproximado.

Pregunta N5. Cuantos pasajeros aproximadamente envía su agencia de viajes a la ruta Mollepata - Salkantay - Machupicchu en los meses de temporada media (marzo, abril, noviembre y diciembre) y la temporada baja (de enero y febrero). Por favor indíquenos un promedio mensual aproximado.

Tabla 23

Participación mensual de la agencia por temporadas

\begin{tabular}{lccc} 
Agencias de viajes & $\begin{array}{c}\text { Temporada baja } \\
\text { (ene. a feb.) }\end{array}$ & $\begin{array}{r}\text { Temporada media } \\
\text { (mar.-abr.-oct.-nov.) }\end{array}$ & $\begin{array}{c}\text { Temporada Alta } \\
\text { (may. a oct.) }\end{array}$ \\
\hline
\end{tabular}

Tres Agencias de 7000 a 5000 viajeros al año

Cinco agencias de $3000 \mathrm{a}$ 1500 viajeros al año

60

150

36

300 viajeros al año

4


A continuación, se presenta un gráfico que muestra la participación mensual de las agencias por temporadas:

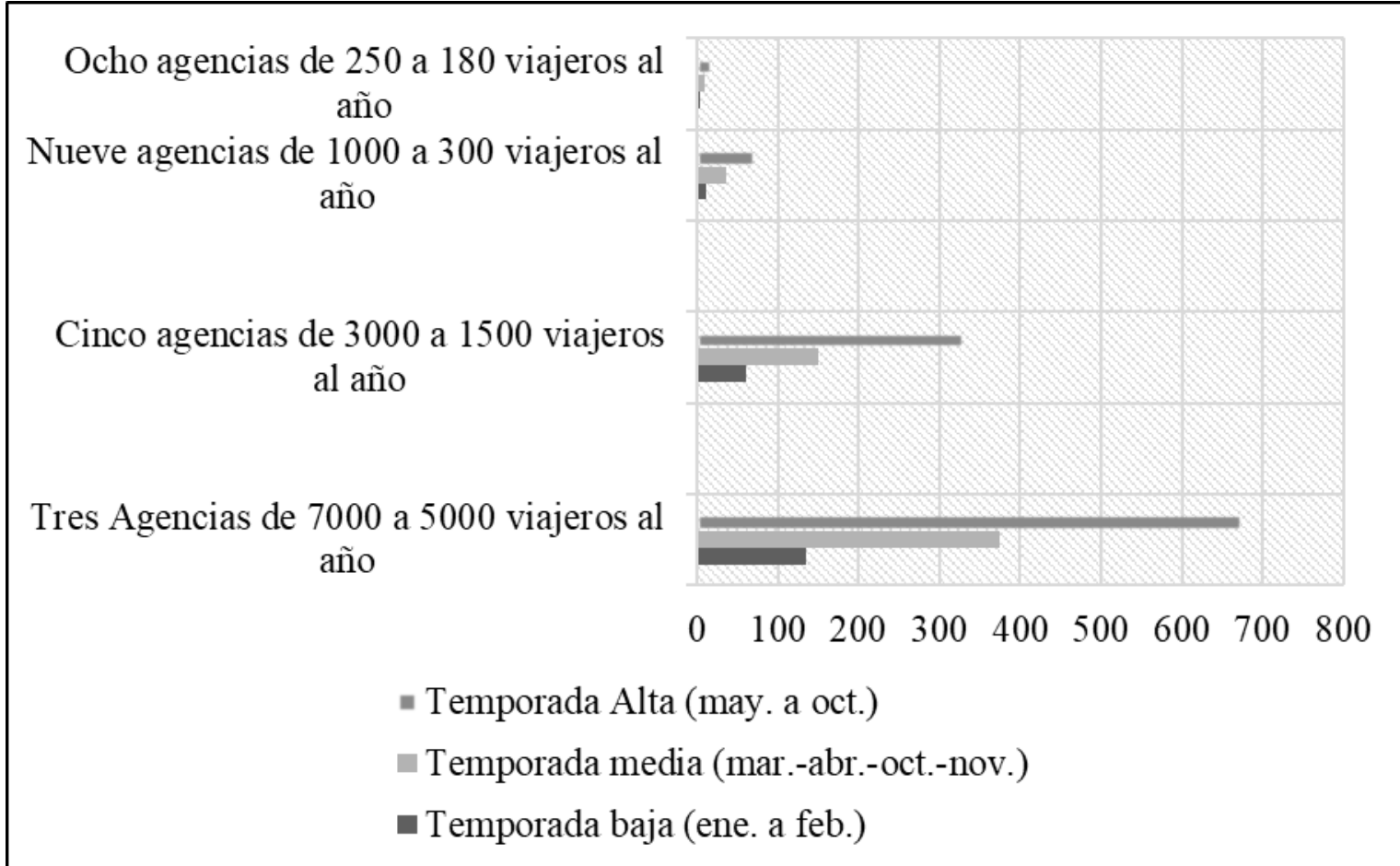

Figura 17. Participación mensual de las agencias por temporadas.

En esta primera pregunta se indaga sobre cuál es promedio de ventas aproximado que tiene cada agencia de manera mensual. En el desarrollo de la actividad turística de Salkantay se ve que está claramente marcado por las tres temporadas siendo los meses de lluvia de enero y febrero los más bajos, de ahí el turismo crece desde marzo y se le conoce como temporada media, en mayo ya logra su plenitud máxima hasta octubre a lo que se conoce como temporada alta, luego en noviembre y diciembre vuelve a bajar, cumpliendo así el ciclo.

Al hacer esta pregunta reconociendo las tres estaciones los empresarios pudieron calcular con mayor exactitud su volumen de demanda aproximado, de donde se sacan las siguientes conclusiones: 
Solo tres agencias de viajes pueden llegar a operar un promedio de 20 turistas diarios por los seis meses de temporada alta, lo cual puede representar más del $60 \%$ del flujo de demanda anual de viajeros que visitan el Salkantay. Estas agencias (KB tours, Salkantay trek y Salkantay group), indicaron que el 2016 trabajaron todos los días del año, aunque algunas veces en menor cantidad, pero trabajaron diario.

Los empresarios al hacer el cálculo indicaban que el flujo diario no es constante, sino que varía drásticamente unos días y otros, por ejemplo, en un buen día de temporada alta pueden llegar a operar hasta 50 turistas diarios, pero otro día esa misma agencia puede vender solo 10 turistas. Esto depende de la ocasión de la reserva.

Los grupos que las agencias de viajes operan tienen un máximo de 12 personas más guía de turismo, excepto la agencia $\mathrm{Kb}$ tours que opera grupos de hasta 25 personas con un solo guía de turismo.

La actividad turística baja considerablemente los meses de lluvias (enero y febrero), esto porque no hay buen acceso para cruzar el nevado. El grupo de las mejores agencias puede vender entre dos a cinco tours diarios en temporada baja, siendo febrero el mes más crítico.

Las agencias del grupo tres y cuatro en temporada baja simplemente ya no ofrecen sus servicios porque su participación de mercado es nula especialmente en febrero.

Pregunta N6. La mayoría de sus consumidores finales y/o visitantes que realizan el circuito de trekking Salkantay - Mollepata - Machupicchu, se hospedan en: (Vale máximo dos respuestas). 
Tabla 24

Hoteles de donde provienen los clientes de las agencias de viajes

\begin{tabular}{lccc}
\hline \multicolumn{1}{c}{ Agencias de viajes } & $\begin{array}{c}\text { Hoteles de 4 } \\
\text { y 5 estrellas }\end{array}$ & $\begin{array}{c}\text { hoteles de 1 a } \\
\text { 3 estrellas }\end{array}$ & $\begin{array}{c}\text { Hostales o } \\
\text { Hostel }\end{array}$ \\
\hline $\begin{array}{l}\text { Tres Agencias de 7000 a } \\
5000 \text { viajeros al año }\end{array}$ & $56 \%$ & $44 \%$ \\
$\begin{array}{l}\text { Cinco agencias de 3000 a } \\
1500 \text { viajeros al año }\end{array}$ & $19 \%$ & $44 \%$ & $38 \%$ \\
$\begin{array}{l}\text { Nueve agencias de } 1000 \text { a } \\
300 \text { viajeros al año }\end{array}$ & $52 \%$ & $48 \%$ \\
$\begin{array}{l}\text { Ocho agencias de } 250 \text { a } 180 \\
\text { viajeros al año }\end{array}$ & & \\
\hline
\end{tabular}

Nota. Participación mensual de agencias por temporadas. Análisis cuantitativo

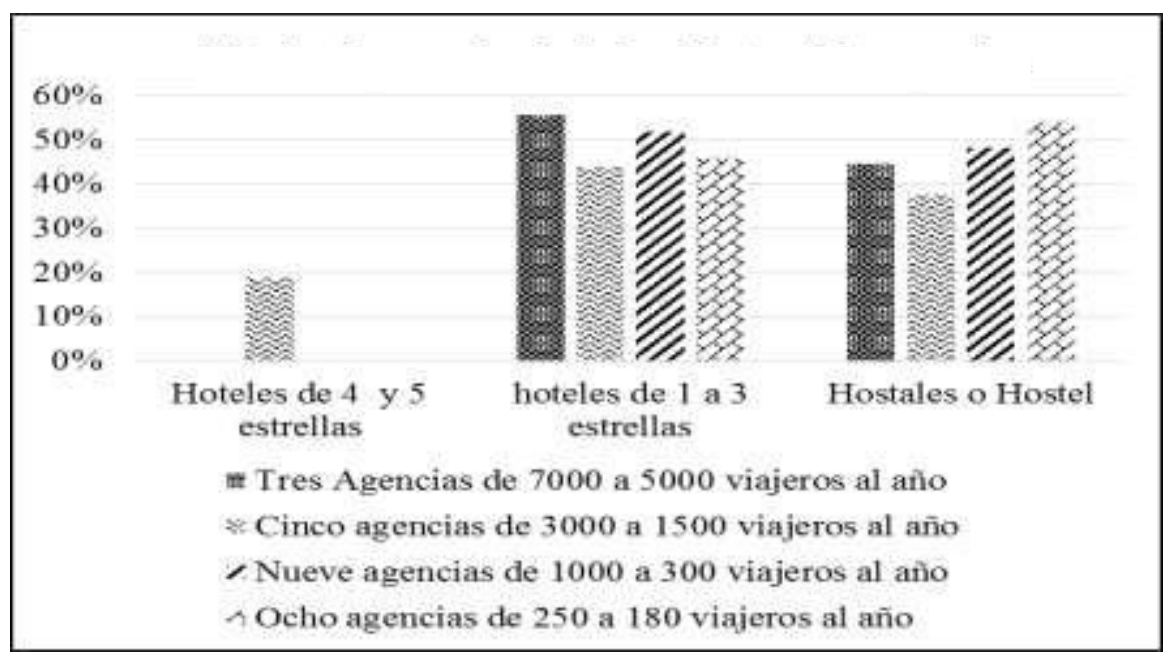

Figura 18. Hoteles de procedencia de las agencias de viaje. 
Las conclusiones que se obtuvieron al hacer esta pregunta son:

La mayoría de turistas que vienen a realiza esta actividad provienen de hoteles de tres estrellas y Hostels, los cuales son establecimientos de hospedaje ideales para jóvenes, esto porque como se analizó en el capítulo dos, generalmente los jóvenes son quienes desean aventuras del tipo de trekking Salkantay o Camino Inca.

Así también las encuestas arrojaron que en el grupo uno de las agencias que más venden los turistas provienen en un 56\% de hoteles tres estrellas (agencia Salkantay trek y Salkantay group), mientras que en el segundo grupo las agencias Mountain Lodge y Alpaca Expeditions trabajan con un tipo de turismo más selecto y sus clientes provienen de hoteles cuatro y cinco estrellas.

Pregunta filtro, F1. ¿Dónde programa el desayuno para sus viajeros el primer día del trekking Mollepata Salkantay?

Tabla 25

Hoteles de donde provienen los clientes de las agencias de viajes

\begin{tabular}{lccc}
\hline \multicolumn{1}{c}{ Agencias de viajes } & $\begin{array}{c}\text { Desayunan en } \\
\text { restaurantes de } \\
\text { Mollepata }\end{array}$ & $\begin{array}{c}\text { Llevan sus } \\
\text { propios } \\
\text { cocineros }\end{array}$ & $\begin{array}{c}\text { Cuentan con } \\
\text { restaurant } \\
\text { propio }\end{array}$ \\
\hline $\begin{array}{l}\text { Tres Agencias de 7000 a } \\
5000 \text { viajeros al año }\end{array}$ & 3 & 0 & 0 \\
$\begin{array}{l}\text { Cinco agencias de 3000 a } \\
1500 \text { viajeros al año }\end{array}$ & 3 & 1 & 1 \\
$\begin{array}{l}\text { Nueve agencias de } 1000 \text { a } \\
300 \text { viajeros al año }\end{array}$ & 9 & 0 & 0 \\
$\begin{array}{l}\text { Ocho agencias de 250 a 180 } \\
\text { viajeros al año }\end{array}$ & 8 & 0 & 0 \\
\multicolumn{1}{c}{ Total } & 23 & 1 & 1 \\
\hline
\end{tabular}

Nota. Participación mensual de agencias por temporadas. Análisis cuantitativo 


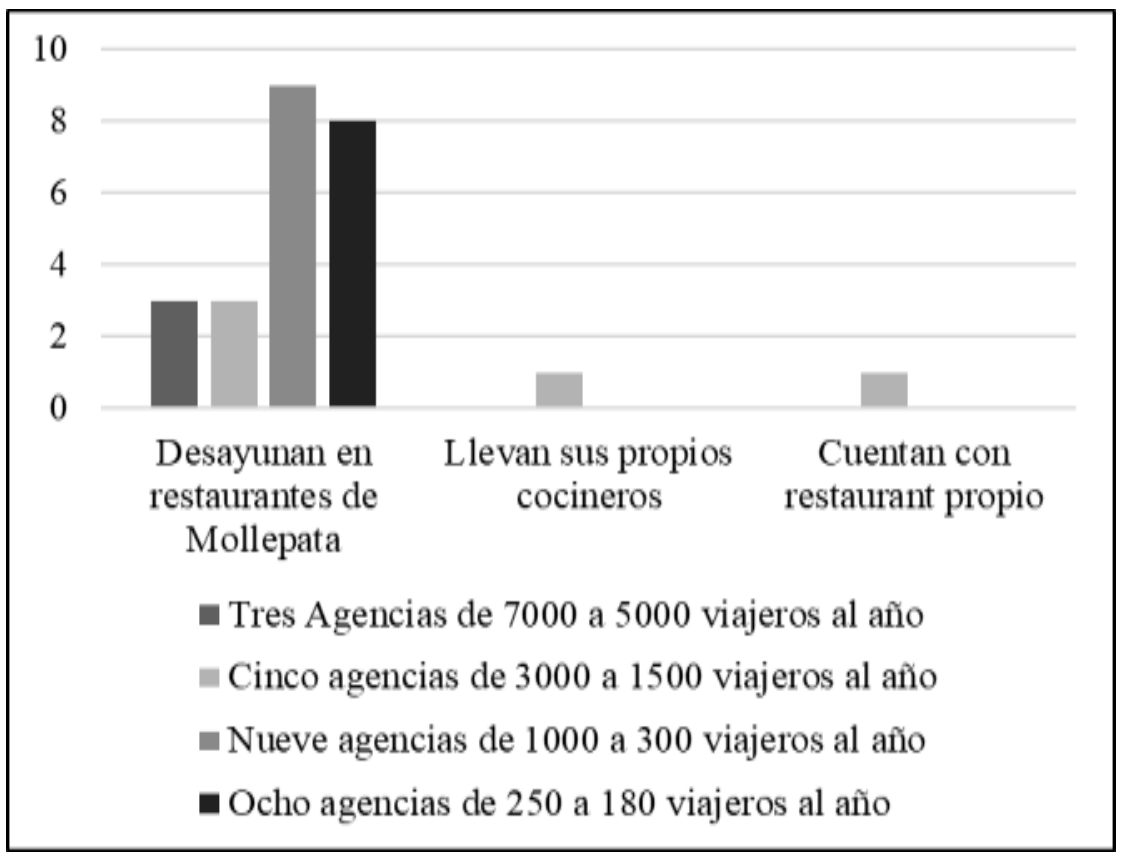

Figura 19. Lugar donde desayunan los viajeros, análisis cuantitativo

Los resultados del análisis de esta pregunta son los siguientes:

Esta pregunta sirvió para determinar el mercado disponible del plan de negocio, haciendo un filtro para determinar que agencias de viajes desayunan en los restaurantes de Mollepata, y se obtuvo que las agencias Alpaca Expeditions y MountaingLodge del grupo dos de ventas son lo que tienen su propia producción de desayunos, esto según respuesta de los administradores porque la calidad de servicios que brindan los restaurantes de Mollepata no es buena y prefieren hacerlo por su cuenta.

En el caso de Mountain Lodge tiene su restaurant propio llamado el Pedregal y la agencia Alpaca Expeditions lleva cocineros quienes elaboran el desayuno al aire libre a 35 minutos del pueblo de Mollepata, pero necesariamente tienen que usar los servicios higiénicos de algún restaurant en el pueblo de Mollepata, cuando pasan por este. 
P1. ¿El paquete turístico de Mollepata Salkantay Machupicchu que su agencia de viajes ofrece, incluye el costo del desayuno el día 1 ? Si su respuesta es NO, indique ¿por qué?

Tabla 26

Agencias de viajes que incluyen el desayuno en su tarifa

\begin{tabular}{lcc}
\multicolumn{1}{c}{ Agencias de viajes } & Si incluye & No incluye \\
\hline $\begin{array}{l}\text { Tres Agencias de 7000 a } \\
5000 \text { viajeros al año }\end{array}$ & 0 & 1 \\
$\begin{array}{l}\text { Tres agencias de } 3000 \text { a } \\
1500 \text { viajeros al año }\end{array}$ & 0 & 1 \\
$\begin{array}{l}\text { Nueve agencias de } 1000 \text { a } \\
300 \text { viajeros al año }\end{array}$ & 0 & 1 \\
$\begin{array}{l}\text { Ocho agencias de } 250 \text { a } 180 \\
\text { viajeros al año }\end{array}$ & 0 & 1 \\
Total & 0 & 4 \\
\hline $\begin{array}{l}\text { Nota. Participación mensual de agencias por temporadas. Análisis } \\
\text { cuantitativo }\end{array}$ &
\end{tabular}

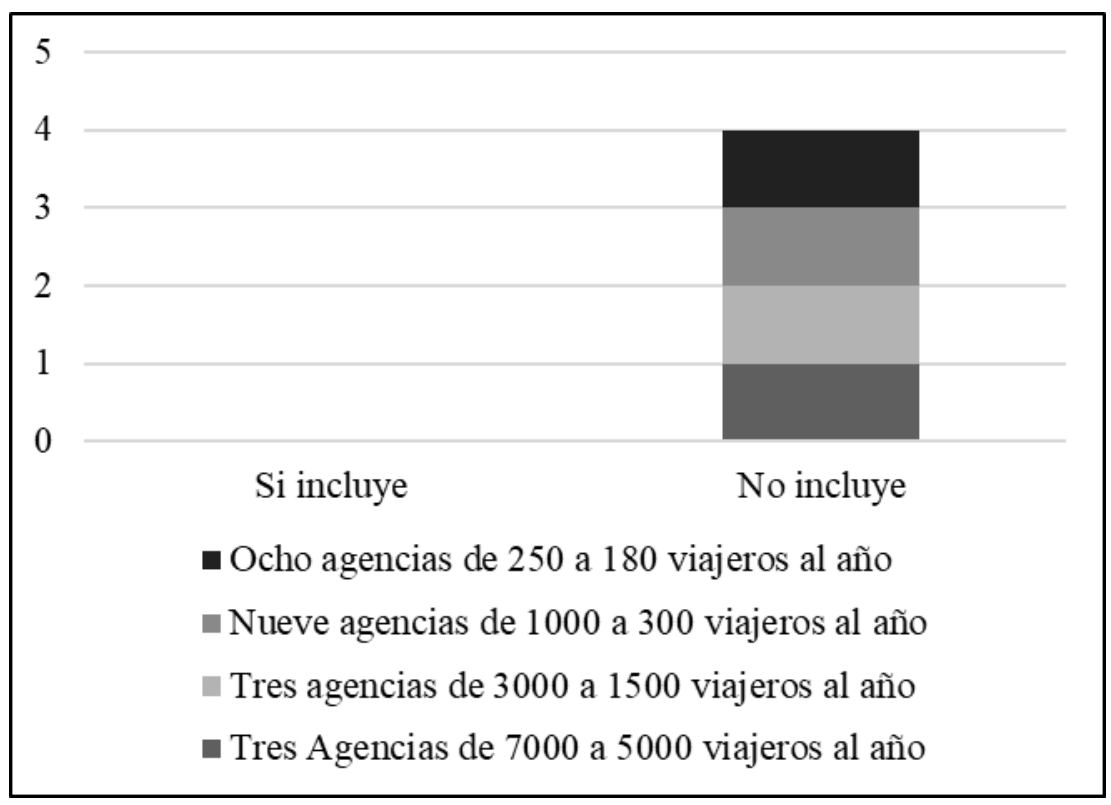

Figura 20. Agencias que incluyen el desayuno en su tarifa, análisis cuantitativo. 
A partir de la pregunta P1 a la P12, solo se dirigieron a 23 agencias, exceptuando a las agencias Alpaca Expeditions y Montain Lodge porque estas no desayunan en los restaurantes de Mollepata, sino tienen su propia producción de desayunos.

De la anterior pregunta, la conclusión es que ninguna de las agencias encuestadas decide incluir el costo del desayuno dentro del paquete, por una simple razón, y es que prefieren que el turista desayune a su libre elección y no comprometen la calidad del servicio si la comida no fue del gusto del cliente, pero si las agencias deciden en que restaurant el bus de pasajeros desayunara.

P2. De cada 10 turistas que llegan al pueblo de Mollepata por intermedio de su agencia de viajes, ¿cuántos cree usted que deciden tomar desayuno en el pueblo de Mollepata?

Tabla 27

Proporción de diez viajeros que desayunan en Mollepata

\begin{tabular}{lcc}
\hline \multicolumn{1}{c}{ Agencias de viajes } & $\begin{array}{c}\text { Nueve } \\
\text { viajeros }\end{array}$ & Diez viajeros \\
\hline $\begin{array}{l}\text { Tres Agencias de 7000 a } \\
5000 \text { viajeros al año }\end{array}$ & 1 & 2 \\
$\begin{array}{l}\text { tres agencias de 3000 a 1500 } \\
\text { viajeros al año }\end{array}$ & 1 & 2 \\
$\begin{array}{l}\text { Nueve agencias de 1000 a } \\
300 \text { viajeros al año }\end{array}$ & 5 & 4 \\
$\begin{array}{l}\text { Ocho agencias de 250 a 180 } \\
\text { viajeros al año }\end{array}$ & 4 & 4 \\
$\quad$ Total & 11 & 12 \\
\hline
\end{tabular}

Nota. Participación mensual de agencias por temporadas. Análisis cuantitativo 


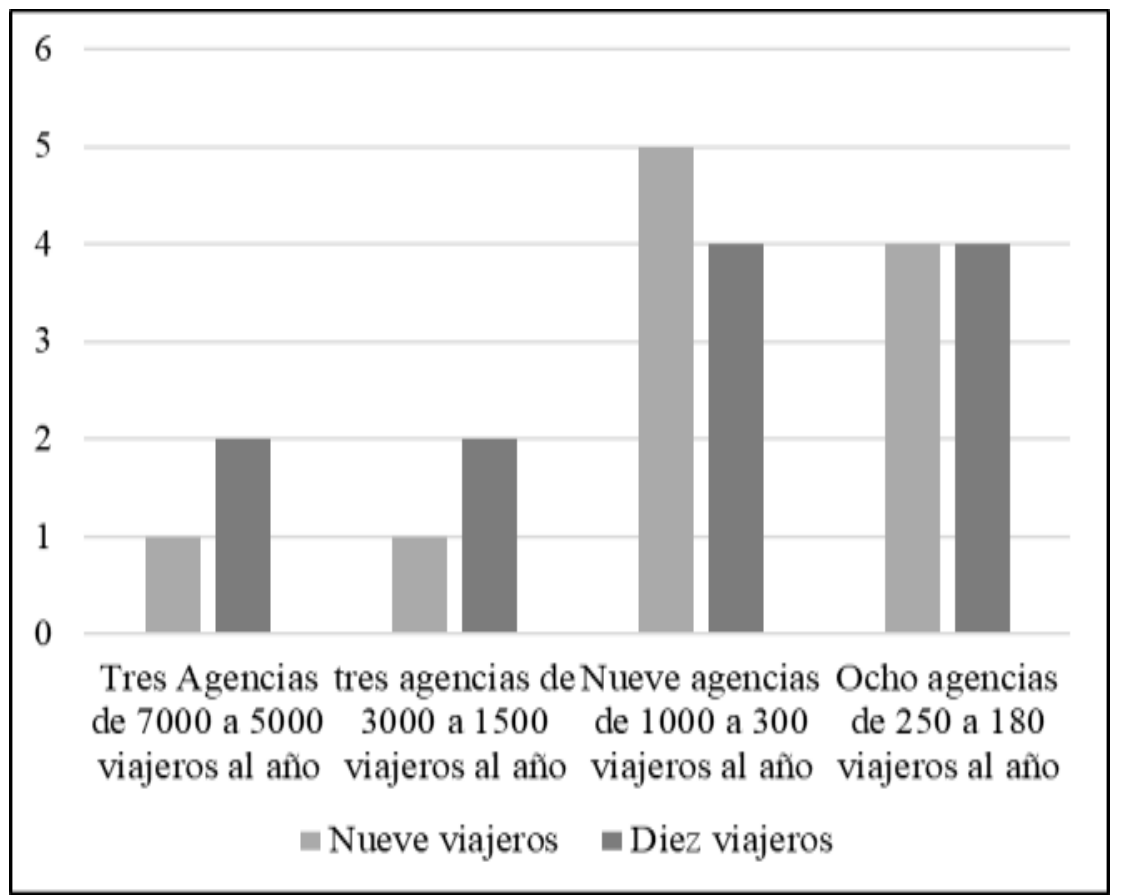

Figura 21. Proporción de cada diez viajeros que desayunan en Mollepata

Al realizar esta pregunta, los agentes de viajeros señalaron que casi en su totalidad todos desayunan en Mollepata, y de cada 1 viajeros, el 95\% decide desayunar. Cuando se les pregunto porque algunos no desayunan en Mollepata indicaron que estas excepciones ocurren cuando los viajeros se sienten mal de salud o cuando prefieren elaborarse sus propios refrigerios, pero como se reitera es mínimo.

P3. ¿Cuánto es el gasto promedio del turista que desayuna el primer día en el poblado de Mollepata? 
Tabla 28

Proporción de diez viajeros que desayunan en Mollepata

\begin{tabular}{lccc}
\hline Agencias de viajes & $\begin{array}{c}\text { De 15 a 20 } \\
\text { soles }\end{array}$ & $\begin{array}{c}\text { De 20 a 25 } \\
\text { soles }\end{array}$ & $\begin{array}{c}\text { Más de 25 } \\
\text { soles }\end{array}$ \\
\hline $\begin{array}{l}\text { Tres Agencias de 7000 a } \\
\begin{array}{l}5000 \text { viajeros al año } \\
\text { Tres agencias de 3000 a }\end{array}\end{array}$ & $37 \%$ & $43 \%$ & $20 \%$ \\
$\begin{array}{l}1500 \text { viajeros al año } \\
\text { Nueve agencias de 1000 a }\end{array}$ & $40 \%$ & $50 \%$ & $10 \%$ \\
$\begin{array}{l}300 \text { viajeros al año } \\
\text { Ocho agencias de 250 a 180 } \\
\text { viajeros al año }\end{array}$ & $45 \%$ & $52 \%$ & $9 \%$ \\
$\quad$ Total & $40 \%$ & $48 \%$ & $12 \%$ \\
\hline
\end{tabular}

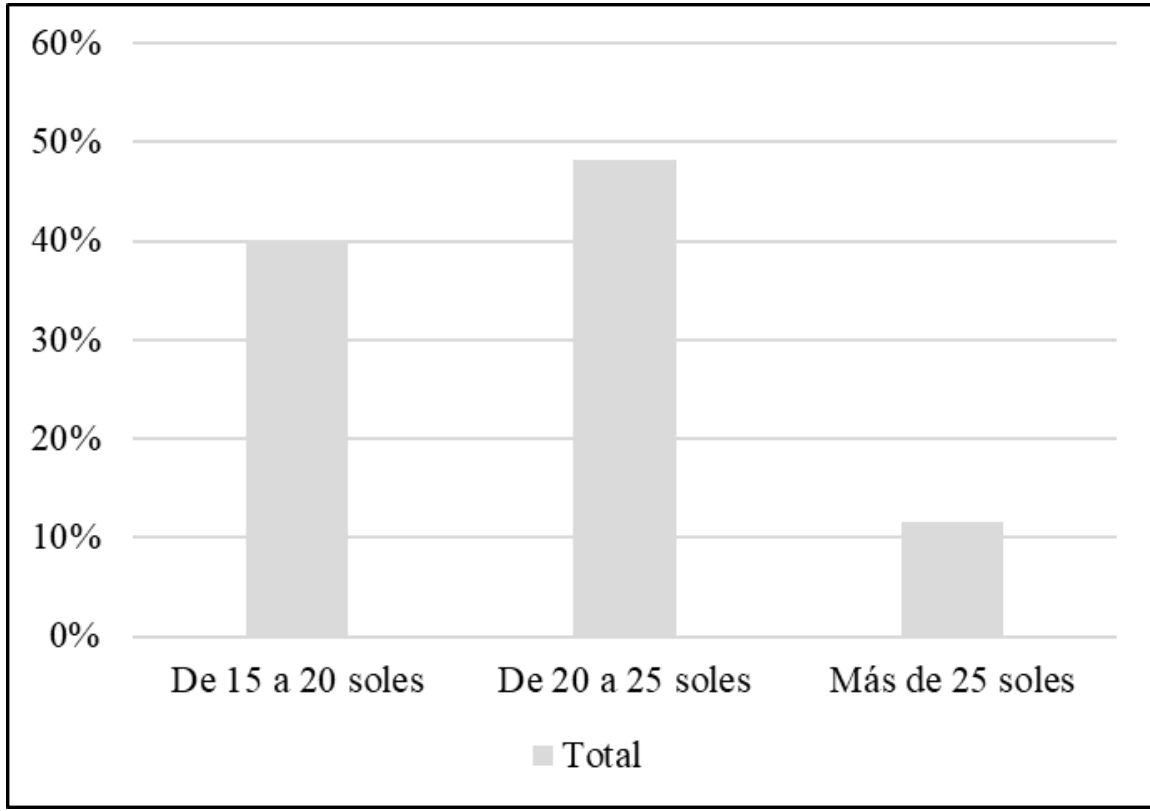

Figura 22. Gasto promedio de viajeros en el desayuno, análisis cuantitativo 
El objetivo de hacer esta preguntar es conocer cuánto es que gasta aproximadamente un viajero en los restaurantes de Mollepata. La conclusión es que casi el 50\% de los viajeros consumen entre 155 y 25 soles en desayunos sin incluir los gastos extras que tienen comprar suvenires. Otro $20 \%$ de viajeros gasta más de 25 soles, y esto sería por que compran desayunos más costos.

P4. ¿Cómo su empresa elige un restaurant para que los turistas desayunen en el poblado de Mollepata?

Tabla 29

Decisión para la elección del restaurante

\begin{tabular}{lcc}
\hline Agencias de viajes & $\begin{array}{c}\text { La agencia lo } \\
\text { reserva con } \\
\text { anticipacion }\end{array}$ & $\begin{array}{c}\text { El guia o } \\
\text { chofer lo } \\
\text { eligen }\end{array}$ \\
\hline $\begin{array}{l}\text { Tres Agencias de 7000 a 5000 } \\
\text { viajeros al año } \\
\text { tres agencias de 3000 a 1500 } \\
\text { viajeros al año }\end{array}$ & 3 & 0 \\
$\begin{array}{l}\text { Nueve agencias de 1000 a 300 } \\
\text { viajeros al año } \\
\begin{array}{l}\text { Ocho agencias de 250 a 180 } \\
\text { viajeros al año }\end{array}\end{array}$ & 9 & 0 \\
Total & 7 & 0 \\
\hline
\end{tabular}

El objetivo de esta pregunta es determinar quién es el encargado de elegir el restaurant donde los viajeros desayunaran en Mollepata. La respuesta fue contundente pues de las 23 agencias encuestadas 22 indicaron que la gerencia es quien hace el acuerdo comercial con los restaurantes para que los viajeros desayunen en un restaurant específico.

Mientras que solo una agencia del último grupo en ventas índico que a veces dejan que el guía o el chofer del bus decidan en que restaurant del pueblo desayunaran. 
P5. ¿Qué otros servicios le ofrecen los restaurantes de Mollepata además de brindar desayunos para los viajeros?

En el capítulo dos se tocó el tema que muchos restaurantes brindan soporte con el tema de arrieros a las agencias de viaje, en medida de que el restaurant al estar cerca de los arrieros puede contactarse con el sindicato de arrieros y reservar caballos de carga para equipaje de viajeros. Con esta pregunta de la encuesta confirmamos la información, aunque las encuestan también demostraron que solo algunas agencias buscan a los restaurantes para estos servicios.

P6. ¿Cómo califica usted a los restaurantes donde actualmente sus turistas desayunan en el pueblo de Mollepata? Indique su grado de satisfacción con los siguientes enunciados.

Tabla 30

Análisis de atributos de los restaurantes de Mollepata

\begin{tabular}{|c|c|c|c|c|c|}
\hline Agencias de viajes & $\begin{array}{c}\text { Calidad y } \\
\text { sabor de la } \\
\text { comida }\end{array}$ & $\begin{array}{l}\text { Higiene y } \\
\text { salubridad }\end{array}$ & $\begin{array}{l}\text { Calidad de } \\
\text { atencion al } \\
\text { cliente }\end{array}$ & $\begin{array}{l}\text { Ambiente y } \\
\text { decoracion }\end{array}$ & $\begin{array}{l}\text { Precio justo con } \\
\text { la calidad }\end{array}$ \\
\hline $\begin{array}{l}\text { Tres Agencias de } 7000 \text { a } \\
5000 \text { viajeros al año }\end{array}$ & 3.33 & 3.00 & 2.67 & 2.33 & 4.00 \\
\hline $\begin{array}{l}\text { Cinco agencias de } 3000 \text { a } \\
1500 \text { viajeros al año }\end{array}$ & 3.00 & 2.00 & 2.33 & 2.00 & 3.67 \\
\hline $\begin{array}{l}\text { Nueve agencias de } 1000 \text { a } \\
300 \text { viajeros al año }\end{array}$ & 2.89 & 2.44 & 3.22 & 2.11 & 4.11 \\
\hline $\begin{array}{l}\text { Ocho agencias de } 250 \text { a } 180 \\
\text { viajeros al año }\end{array}$ & 3.13 & 2.38 & 3.25 & 2.25 & 3.63 \\
\hline Promedio & 3.09 & 2.45 & 2.87 & 2.17 & 3.85 \\
\hline
\end{tabular}

A partir de la pregunta seis lo que se hace es analizar la calidad de los servicios de los actuales restaurantes de Mollepata, bajo la lógica que la puntuación de cinco es muy buena y un punto es pésimo. Por lo tanto, se obtiene los siguientes resultados:

Todas las agencias en su mayoría presentan un índice de satisfacción que oscila entre dos y tres puntos, lo que vendría a ser un estado de regular a malo, temas como higiene, 
salubridad y ambientación fueron los más bajos, y el precio justo fue el que más valoraron llegando a casi cuatro puntos de calificación lo que significa conformidad.

Las agencias de viajes más disconformes fueron las que tienen más volumen de ventas, ellos indicaron enfáticamente que el sector empresarial de Mollepata no se preocupa por mejorar estos atributos tan importantes que marcan la diferencia en un negocio competitivo.

P7. Si existe algún otro factor que le agrade o le desagrade sobre el restaurant turístico el cual sus turistas visitan en el pueblo de Mollepata, por favor indíquenos:

Al hacer esta pregunta la mayoría de encuestados se refirió a la amabilidad de los dueños como un factor positivo, varios encuestados también señalaron que el desayuno del restaurant La Herradura es muy agradable en especial las tortillas de huevos.

Con respecto a lo que más desagrada a los encuestados fue el tema de la falta de innovación para temas turísticos y el pésimo acondicionamiento de los comedores, porque son viviendas familiares acomodadas con ligereza para atender a los turistas.

P8. ¿Cuál es su satisfacción con la oferta de restaurantes turísticos en el poblado de Mollepata?

Tabla 31

Satisfacción de los turistas con los restaurantes de Mollepata

\begin{tabular}{|c|c|c|c|c|c|}
\hline Agencias de viajes & $\begin{array}{l}\text { Estoy muy } \\
\text { insatisfecho }\end{array}$ & $\begin{array}{c}\text { Estoy } \\
\text { insatisfecho }\end{array}$ & $\begin{array}{c}\text { Estoy } \\
\text { regularmente } \\
\text { satisfecho }\end{array}$ & Estoy satisfecho & $\begin{array}{l}\text { Estoy muy } \\
\text { satisfecho }\end{array}$ \\
\hline $\begin{array}{l}\text { Tres Agencias de } 7000 \text { a } \\
5000 \text { viajeros al año }\end{array}$ & & 0 & 2 & 1 & 0 \\
\hline $\begin{array}{l}\text { Tres agencias de } 3000 \text { a } \\
1500 \text { viajeros al año }\end{array}$ & & 0 & 2 & 1 & 0 \\
\hline $\begin{array}{l}\text { Nueve agencias de } 1000 \text { a } \\
300 \text { viajeros al año }\end{array}$ & & 3 & 6 & & 0 \\
\hline $\begin{array}{l}\text { Ocho agencias de } 250 \text { a } 180 \\
\text { viajeros al año }\end{array}$ & & 2 & 5 & 1 & 0 \\
\hline Total Satisfacción & & $22 \%$ & $65 \%$ & $13 \%$ & $0 \%$ \\
\hline
\end{tabular}




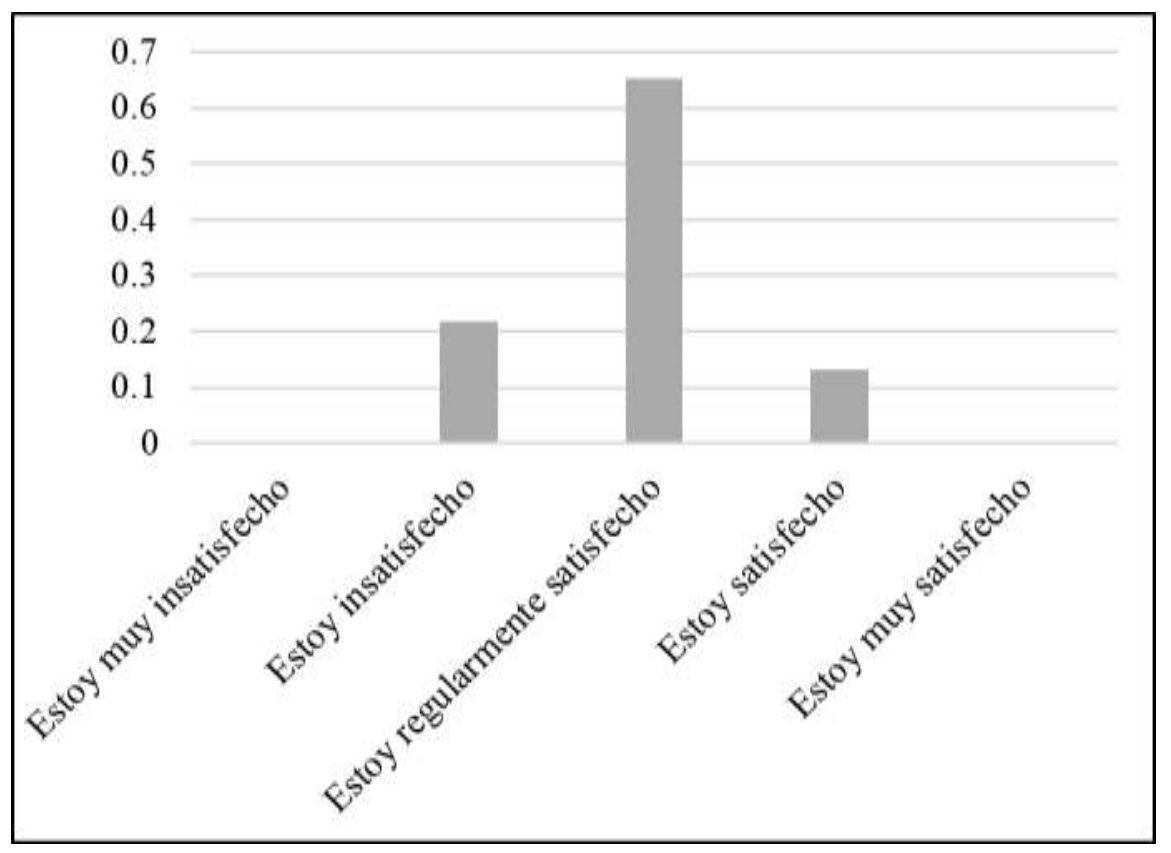

Figura 23. Total, satisfacción con los restaurantes

La respuesta a esta pregunta fue bastante clara, la mayoría de los encuestados señalo que estaban regularmente satisfechos hasta en un $65 \%$, los que mostraban más su malestar son las agencias que tienen volumen de ventas altos, pues ante la ausencia de buenos restaurantes se ven forzados a recomendar estos restaurantes.

Las empresas que muestran simpatía a los restaurantes de Mollepata, rescatan que la sazón del restaurant la Herradura y Don Julio son muy buenas.

La gerente de la agencia Kb Tours fue la única agencia que estaba contenta con el desempeño de los restaurantes de Mollepata, al preguntarle el por qué, que le daban un buen precio (barato) y eso hace que sus pasajeros estén felices. Con este dato nos convencimos de que $\mathrm{Kb}$ Tours está orientado al mercado de turistas más barato, es por eso que tiene muy buen volumen de ventas anuales.

P9. Desde su criterio, ¿cuáles son los aspectos más importantes que debe tener el restaurant donde sus turistas van a desayunar en el pueblo de Mollepata? 
Tabla 32

Atributos que el turista más valora en un restaurante en Mollepata

\begin{tabular}{|c|c|c|c|c|c|c|c|c|c|}
\hline Agencias de viajes & $\begin{array}{c}\text { Variedad } \\
\mathrm{e} \\
\text { innovacion } \\
\text { en la carta } \\
\end{array}$ & $\begin{array}{l}\text { Calidad y } \\
\text { salubridad } \\
\text { de } \\
\text { alimentos }\end{array}$ & $\begin{array}{l}\text { Calidad } \\
\text { de } \\
\text { atencion } \\
\text { al viajero }\end{array}$ & $\begin{array}{l}\text { Servicios } \\
\text { higienicos } \\
\text { en perfectas } \mathrm{p} \\
\text { condiciones }\end{array}$ & $\begin{array}{l}\text { Ubicación } \\
\text { cerca a la } \\
\text { plaza de } \\
\text { Armari } \\
\end{array}$ & $\begin{array}{l}\text { Decoracion } \\
\text { rustica con }{ }^{\mathrm{n}}{ }^{2} \\
\text { iada flora }\end{array}$ & $\begin{array}{l}\text { Apoyo del } \\
\text { estaurant a } \\
\text { sencias } \\
\text { de viajes } \\
\end{array}$ & $\begin{array}{l}\text { Servicios } \\
\text { turisticns } \\
\text { entarios del }\end{array}$ & $\begin{array}{l}\quad \text { Precio } \\
\text { economico } \\
\text { sayuno } \\
\end{array}$ \\
\hline $\begin{array}{l}\text { Tres Agencias de } 7000 \text { a } \\
5000 \text { viajeros al año }\end{array}$ & 6.67 & 10.00 & 8.00 & 10.00 & 4.33 & 8.67 & 6.33 & 7.67 & 7.33 \\
\hline $\begin{array}{l}\text { Cinco agencias de } 3000 \\
\text { a } 1500 \text { viajeros al año }\end{array}$ & 6.33 & 10.00 & 8.00 & 10.00 & 5.00 & 9.00 & 8.00 & 7.33 & 7.33 \\
\hline $\begin{array}{l}\text { Nueve agencias de } 1000 \\
\text { a } 300 \text { viajeros al año }\end{array}$ & 6.33 & 9.89 & 7.67 & 10.00 & 5.22 & 9.11 & 8.56 & 7.00 & 5.56 \\
\hline $\begin{array}{l}\text { Ocho agencias de } 250 \text { a } \\
180 \text { viajeros al año }\end{array}$ & 5.88 & 9.88 & 7.63 & 10.00 & 4.88 & 8.88 & 8.25 & 8.50 & 5.63 \\
\hline Promedio total & 6.30 & 9.94 & 7.82 & 10.00 & 4.86 & 8.91 & 7.78 & 7.63 & 6.46 \\
\hline
\end{tabular}

El objetivo de esta pregunta es conocer los factores más y menos determinantes que debería tener un restaurant en Mollepata según los empresarios y gerentes de agencias de viajes en turismo. Las conclusiones son las siguientes:

Los puntos que son valorados como necesarios y determinantes para un restaurant en Mollepata son los servicios higiénicos en perfectas condiciones seguido de la calidad y salubridad de los alimentos, ambos obtienen la puntuación de "factor muy importante".

En un segundo grupo, de los factores necesarios destaca primero la decoración rustica con variada flora, el buen trato al cliente y que se puedan crear nuevos servicios complementarios a los turistas.

Finalmente, en el último grupo están los factores que para el encuestado no son muy determinantes para un restaurant en Mollepata y son: precio barato del desayuno, innovación de la carta y en último lugar la cercanía del restaurant a la plaza de Armas del pueblo.

P10. De total de turistas que desayunan en el pueblo de Mollepata, ¿cuál es el desayuno que ellos más eligen? 
Tabla 33

Tipo de desayuno que más consumen los turistas

\begin{tabular}{|c|c|c|c|}
\hline Agencias de viajes & $\begin{array}{c}\text { Desayuno } \\
\text { simple o } \\
\text { continental }\end{array}$ & $\begin{array}{l}\text { Desayuno } \\
\text { Americano }\end{array}$ & $\begin{array}{c}\text { Desayuno } \\
\text { Especial }\end{array}$ \\
\hline $\begin{array}{l}\text { Tres Agencias de } 7000 \text { a } \\
5000 \text { viajeros al año }\end{array}$ & $33 \%$ & $67 \%$ & $0 \%$ \\
\hline $\begin{array}{l}\text { Tres agencias de } 3000 \text { a } \\
1500 \text { viajeros al año }\end{array}$ & $0 \%$ & $100 \%$ & $0 \%$ \\
\hline $\begin{array}{l}\text { Nueve agencias de } 1000 \text { a } \\
300 \text { viajeros al año }\end{array}$ & $33 \%$ & $56 \%$ & $11 \%$ \\
\hline $\begin{array}{l}\text { Ocho agencias de } 250 \text { a } 180 \\
\text { viajeros al año }\end{array}$ & $25 \%$ & $63 \%$ & $13 \%$ \\
\hline Promedio total & $23 \%$ & $71 \%$ & $6 \%$ \\
\hline
\end{tabular}

Esta pregunta tiene por objetivo marcar una tendencia sobre cuál es el producto que más consumen los viajeros. Los resultados son los siguientes:

El 65\% de los viajeros señalaron que el desayuno que más consumen es el americano, esto tal vez porque la mayoría de los visitantes son norteamericanos y los huevos juegan un papel preponderante en su dieta alimenticia.

El que ocupo segundo lugar en la encuesta es el desayuno continental con un $26 \%$, el motivo de esta elección puede ser por el costo barato en comparación al americano (unos soles menos), o en todo caso porque los viajeros creen que haciendo dieta podrán resistir más una caminata de varias horas en alta montaña, como se demostró en el capítulo 3.1, esto es erróneo.

Finalmente, el 9\% de los encuestados señalo que el desayuno mejorado que algunos restaurantes ofrecen con panqueques o sándwich es la menos favorita de los viajeros, tal vez por el mito de que comer poco es mejor para hacer caminatas de alta montaña o porque el desayuno mejorado tiene el precio es más alto del menú.

P11. ¿Cuánto tiempo como máximo destina usted para que el turista desayune en el pueblo de Mollepata? 
Esta pregunta fue realizada de forma abierta y solo se corroboro la información que ya se tenía como antecedente sobre el tiempo que demora un turista en Mollepata. Los encuestados indicaron que entre 45 minutos a una hora es tiempo suficiente para desayunar.

Sobre los horarios en el que los turistas llegan a Mollepata, los encuestados indicaron que este varía por el tipo de tour, por ejemplo, lo que hacen un tour de cuatro días y tres noches deberán llegar a Mollepata más temprano en comparación a los que tienen cinco días y cuatro noches que recién llegan a Mollepata a partir de las nueve de la mañana.

P12. Según su experiencia ¿Cuáles son aquellos productos que adquiere el turista en una compra de último minuto (abarrotes o suvenir)?

Esta otra pregunta tiene por objetivo conocer cuáles son los productos extras que más compran los viajeros luego de desayunar, y así se tomen decisiones en el presento proyecto a la hora de armar el producto de suvenir y abarrotes para los viajeros.

Los encuestados señalaron que todo turista si no hizo sus compras en Cusco se ve obligado a comprar en Mollepata, aguas, bebidas energizantes, hojas de coca, bastones, poncho para lluvia, memorias de cámara y algún snack para la caminata.

Así también los encuestados señalaron que muchas veces las tiendas de abarrotes o restaurantes no tienen variedad de productos en cuanto a las necesidades de os viajeros, sobre todo en snacks y alimentos de bolsillo, por lo que varios recomendaron al encuestador tomar en cuenta esta necesidad de los viajeros.

Preguntas de testeo de negocio: T1. De la lista que le presentamos a continuación califique usted cuál de estas propuestas tienen mayor grado de importancia para que la propuesta de restaurant sea más atractiva para usted. (Siendo puntuación de uno menos atractiva y diez muy atractiva) 
En esta pregunta se analizaron 20 variables para determinar la opinión del encuestador con respecto al producto a crear, las variables fueron agrupadas de la siguiente manera, y se obtuvieron los siguientes resultados.

Tabla 34

Testeo del producto

Analisis propuesta de producto

\begin{tabular}{lccc}
\hline \multicolumn{4}{c}{ Analisis propuesta de producto } \\
\hline Agencias de viajes & $\begin{array}{c}\text { Carta } \\
\text { Balanceada } \\
\text { en proteínas }\end{array}$ & $\begin{array}{c}\text { Productos } \\
\text { agrícolas } \\
\text { locales }\end{array}$ & $\begin{array}{c}\text { Tres opciones } \\
\text { de desayunos }\end{array}$ \\
$\begin{array}{l}\text { Tres Agencias de 7000 a } \\
5000 \text { viajeros al año }\end{array}$ & 8.00 & 8.33 & 9.00 \\
$\begin{array}{l}\text { Cinco agencias de 3000 a } \\
1500 \text { viajeros al año }\end{array}$ & 7.33 & 9.67 & 8.33 \\
$\begin{array}{l}\text { Nueve agencias de 1000 a } \\
300 \text { viajeros al año }\end{array}$ & 7.00 & 7.33 & 8.56 \\
$\begin{array}{l}\text { Ocho agencias de 250 a 180 } \\
\text { viajeros al año }\end{array}$ & 7.38 & 8.00 & 8.50 \\
\hline \multicolumn{1}{c}{ Promedio total } & 7.43 & 8.33 & 8.60 \\
\hline
\end{tabular}

Al preguntar al encuestado sobre lo que más valoran del producto del desayuno, ellos indicaron que la variedad de opciones y el uso de productos agrícolas de la zona son los más relevantes, y un poco más abajo con $7.43 \%$ está el tema de que el desayuno sea con alto valor nutritivo, aunque no es muy apreciado para el empresario o agente de viajes. 
Tabla 35

Testeo de ubicación y diseño

Propuesta de ubicación y diseño

\begin{tabular}{|c|c|c|c|c|}
\hline Agencias de viajes & $\begin{array}{c}\text { Restaurant al } \\
\text { airelibresin } \\
\text { muros }\end{array}$ & $\begin{array}{c}\text { Infraestructura } \\
\text { conmateriales de } \\
\text { la zona }\end{array}$ & $\begin{array}{l}\text { Servicios } \\
\text { higiénicos } \\
\text { modernos }\end{array}$ & $\begin{array}{c}\text { Ubicado a } 7 \\
\text { minutos de laplaza } \\
\text { de Mollepata }\end{array}$ \\
\hline $\begin{array}{l}\text { Tres Agencias de } 7000 \text { a } \\
5000 \text { viajeros al año }\end{array}$ & 9.67 & 7.00 & 10.00 & 6.33 \\
\hline $\begin{array}{l}\text { Cinco agencias de } 3000 \text { a } \\
1500 \text { viajeros al año }\end{array}$ & 9.33 & 5.00 & 9.67 & 8.00 \\
\hline $\begin{array}{l}\text { Nueve agencias de } 1000 \text { a } \\
300 \text { viajeros al año }\end{array}$ & 8.78 & 8.22 & 10.00 & 5.33 \\
\hline $\begin{array}{l}\text { Ocho agencias de } 250 \text { a } 180 \\
\text { viajeros al año }\end{array}$ & 9.00 & 8.25 & 9.88 & 5.88 \\
\hline Promedio total & 9.19 & 7.12 & 9.89 & 6.39 \\
\hline
\end{tabular}

Los resultados del análisis de esta pregunta demuestran una vez más que los servicios higiénicos son muy importantes y el turista valora que la propuesta de negocio le ponga bastante énfasis en crear adecuados servicios higiénicos. Así también el tema de que el restaurant sea al aire libre en armonía con la naturaleza fue un factor que valoraron los encuestados de forma unánime.

Los factores que obtuvieron bajo puntaje y por ende no fueron muy interesantes para el encuestados fueron la construcción del restaurant con materiales de la zona y que el restaurant este a siete minutos de la plaza de armas. 
Tabla 36

Testeo centro de interpretación

Propuesta del centro de interpretación

\begin{tabular}{lcccc} 
Agencias de viajes & $\begin{array}{c}\text { Exposiciones } \\
\text { fotográficas de } \\
\text { flora y fauna }\end{array}$ & $\begin{array}{c}\text { Historia del } \\
\text { poblador de } \\
\text { Mollepata }\end{array}$ & $\begin{array}{c}\text { Exposición del } \\
\text { nuevo proyecto } \\
\text { Choquequirao }\end{array}$ & $\begin{array}{c}\text { religiosidad } \\
\text { andina y el } \\
\text { Apu }\end{array}$ \\
\hline $\begin{array}{l}\text { Tres Agencias de 7000 a } \\
\text { 5000 viajeros al año }\end{array}$ & 3.67 & 9.00 & 5.67 & 10.00 \\
$\begin{array}{l}\text { Cinco agencias de 3000 a } \\
\begin{array}{l}1500 \text { viajeros al año } \\
\text { Nueve agencias de 1000 a }\end{array}\end{array} \quad 6.67$ & 8.67 & 6.00 & 9.33 \\
$\begin{array}{l}\text { 300 viajeros al año } \\
\text { Ocho agencias de 250 a 180 }\end{array}$ & 3.22 & 8.89 & 6.11 & 9.44 \\
viajeros al año & 4.50 & 8.13 & 5.75 & 8.75 \\
Promedio total & 4.51 & 8.67 & 5.88 & 9.38 \\
\hline
\end{tabular}

En este punto, se trata de conocer la opinión y aceptación del tema que tendrá el centro de interpretación para turistas, los encuestados al ser conocedores de la ruta y los principales atractivos que más gustan a los turistas recomendaron que la temática del centro de interpretación sea la religiosidad andina y el Apu seguido de la historia del poblador de Mollepata.

Los otros temas como de flora y fauna no fueron bien recibidos aduciendo que mostrar flores en paneles sería contraproducente para un turista que los siguientes días convivirá con la misma flora de manera in situ. Así mismo el tema de una exposición fotográfica sobre la ruta a Choquequirao seria desvirtuar los valores que ofrece la ruta a Salkantay.

Cuando se analizó la propuesta de precio los encuestados no se mostraron muy contentos con que el precio del desayuno llegue a los 27 soles, aduciendo que esto puede hacer ahuyentar a los jóvenes de presupuesto algo limitado, por lo que los encuestados recomendaron que el desayuno americano no suba más de 25 soles. 
Por otro lado, la totalidad de los encuestados se mostró muy contento con que el centro de interpretación sea de libre acceso incluso para aquellos que ni desayunaron en el restaurant del proyecto.

Tabla 37

Testeo promoción

Porpuesta de Promoción

\begin{tabular}{lccc}
\hline Agencias de viajes & $\begin{array}{c}\text { Hacer fam trips para } \\
\text { invitar a guías y } \\
\text { operadores }\end{array}$ & $\begin{array}{c}\text { Mostrar materia } \\
\text { multimedia y } \\
\text { papelería }\end{array}$ & $\begin{array}{c}\text { Utilizar canales } \\
\text { digitales para } \\
\text { promoción }\end{array}$ \\
\hline $\begin{array}{l}\text { Tres Agencias de } 7000 \text { a } \\
5000 \text { viajeros al año }\end{array}$ & 8.00 & 6.67 & 10.00 \\
$\begin{array}{l}\text { Cinco agencias de 3000 a } \\
1500 \text { viajeros al año }\end{array}$ & 7.67 & 7.67 & 10.00 \\
$\begin{array}{l}\text { Nueve agencias de } 1000 \text { a } \\
300 \text { viajeros al año }\end{array}$ & 7.11 & 9.00 & 9.67 \\
$\begin{array}{l}\text { Ocho agencias de 250 a 180 } \\
\text { viajeros al año }\end{array}$ & 6.38 & 8.75 & 9.88 \\
$\quad$ Promedio total & 7.29 & 8.02 & 9.89 \\
\hline
\end{tabular}

El objetivo de esta sección es conocer cuál es el medio de promoción más adecuado que al encuestado le gustaría recibir información sobre el proyecto, los resultados fueron:

Los medios digitales como redes sociales, youtube o una página fueron los favoritos seguido de material multimedia. Con menos puntaje fue valorada fue la promoción mediante papelería.

Con respecto a la realización de fam trips (eventos donde operadores de turismo conocen un negocio y hacen uso de los servicios), los encuestados señalaron que debido a la operatividad del turismo es muy difícil poder estar presente en este tipo de eventos. 
Tabla 38

Testeo Marca

\begin{tabular}{lccc}
\multicolumn{4}{c}{ Propuesta de Marca } \\
\hline Agencias de viajes & $\begin{array}{c}\text { Testo } \\
\text { nombre } \\
\text { Mollepata } \\
\text { land }\end{array}$ & $\begin{array}{c}\text { Testeo } \\
\text { Nombre } \\
\text { Museo } \\
\text { Salkantay }\end{array}$ & $\begin{array}{c}\text { Testeo } \\
\text { Nombre } \\
\text { Casa } \\
\text { Mollepata }\end{array}$ \\
\hline $\begin{array}{l}\text { Tres Agencias de 7000 a } \\
5000 \text { viajeros al año }\end{array}$ & 7.33 & 6.00 & 6.67 \\
$\begin{array}{l}\text { Cinco agencias de 3000 a } \\
1500 \text { viajeros al año }\end{array}$ & 7.33 & 6.33 & 7.67 \\
$\begin{array}{l}\text { Nueve agencias de 1000 a } \\
\text { 300 viajeros al año }\end{array}$ & 5.33 & 7.00 & 6.89 \\
$\begin{array}{l}\text { Ocho agencias de 250 a 180 } \\
\text { viajeros al año }\end{array}$ & 7.25 & 6.50 & 6.88 \\
\begin{tabular}{l} 
Promedio total \\
\hline
\end{tabular} & 6.81 & 6.46 & 7.02 \\
\hline
\end{tabular}

La última parte de esta sección estaba formada por el testeo para elegir el nombre de la empresa, los resultados fueron:

Los encuestados mostraron su apreciación y critica por los tres nombres y de todos el que ligeramente más gusto fue "Casa Mollepata" porque consideran que el nombre "Mollepata" como destino turístico Mollepata debería potenciarse como un lugar independiente al nevado Salkantay.

T2. De todas las ideas que se han mencionado en el nuevo concepto, cuáles son las que más le gustaron y las que menos le gustaron. Mencione hasta tres ideas de cada una

Esta fue una pregunta abierta para conocer opiniones. Dentro de lo que más les gusto a los encuestados es sin duda el tema dar valor con la propuesta gastronómica y crear un centro de interpretación que sería provechoso para los turistas y útil para los guías de turismo que necesitan ilustrar sus explicaciones.

T3. ¿Cambiaría su restaurant habitual o forma de dar desayunos a sus turistas en Mollepata por esta nueva propuesta? 
Tabla 39

Decisión de cambio a la propuesta de negocio

\begin{tabular}{|c|c|c|c|}
\hline Aoenciac de viaie & $\begin{array}{c}\text { Definitivamente si } \\
\text { cambiaria }\end{array}$ & $\begin{array}{c}\text { Posiblemente } \\
\text { cambiaria }\end{array}$ & $\begin{array}{c}\text { No se si } \\
\text { cambiaria }\end{array}$ \\
\hline KB tour & & & 1 \\
\hline Machupicchu Reservations & 1 & & \\
\hline Salkantay trekking & 1 & & \\
\hline Alpaca expeditions & \multicolumn{3}{|c|}{ no desayunan en Mollepata } \\
\hline Arza tour & \multicolumn{3}{|l|}{1} \\
\hline Mountain lodge Perú & \multicolumn{3}{|c|}{ no desayunan en Mollepata } \\
\hline Salkantay backpackers & \multicolumn{3}{|c|}{1} \\
\hline Llama path & 1 & & \\
\hline Xtreme tourbulencia & 1 & & \\
\hline Bamba Experience & 1 & & \\
\hline Sas travel & 1 & & \\
\hline Wayky trek & 1 & & \\
\hline South american trek & 1 & & \\
\hline Bio andean & 1 & & \\
\hline Chasky & 1 & & \\
\hline Terra quechuas & 1 & & \\
\hline Sam travel & 1 & & \\
\hline Inca trail expedition peru & & 1 & \\
\hline Quechua expeditions & 1 & & \\
\hline Amazonas explorer & 1 & & \\
\hline Condor travel & 1 & & \\
\hline Rasgos peru & 1 & & \\
\hline Tierras vivas & 1 & & \\
\hline Valencia travel & 1 & & \\
\hline Nc travel peru & & & 1 \\
\hline Total & 19 & 2 & 2 \\
\hline
\end{tabular}




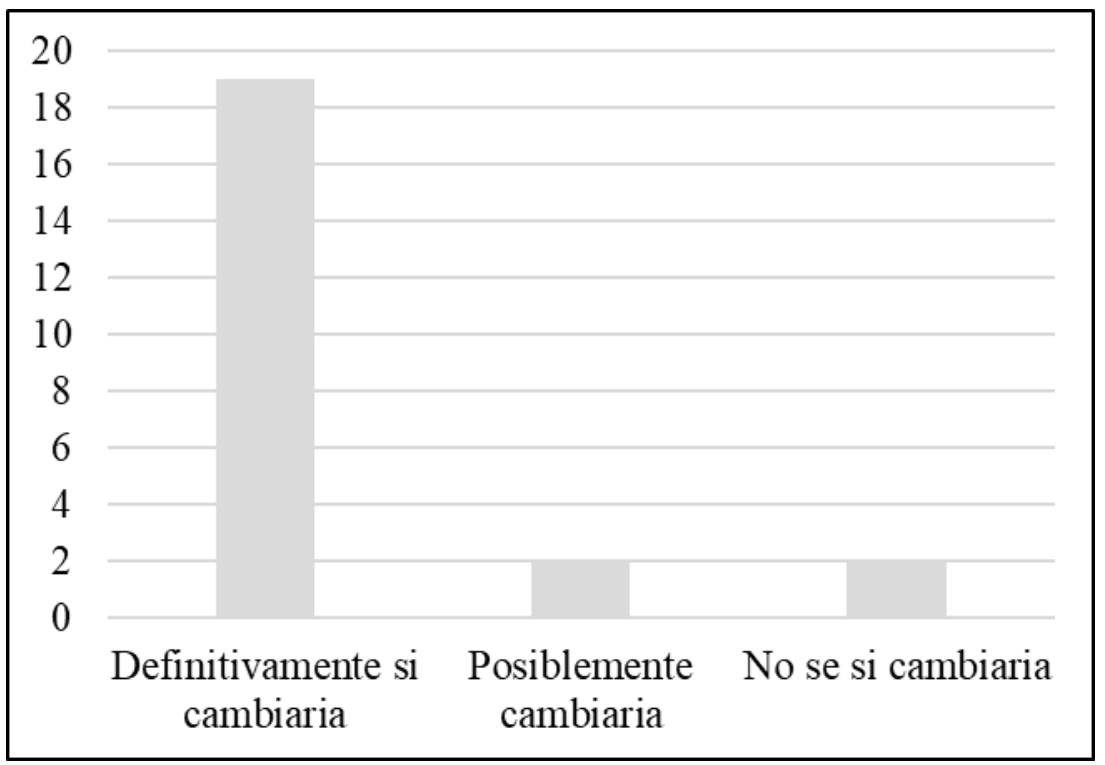

Figura 24. Decisión de cambio con la propuesta de negocio

Finalmente, esta última pregunta sirve para saber quiénes son los interesados en comprar nuestra propuesta y determinar con mayor exactitud nuestro mercado efectivo.

De las 23 agencias encuestadas 19 señalaron que definitivamente si vendrían al nuevo restaurant, y cuatro agencias señalaron que posiblemente, o no cambiarían de restaurant. $\mathrm{Al}$ parecer esto sucede porque las agencias Kb tours y Salkantay Backpaker se sienten cómodos con los precios bajos de su productor de desayunos en Mollepata, y no se fijan mucho en temas como calidad de servicio. 


\subsection{Conclusiones y Recomendaciones del Estudio Cualitativo y Cuantitativo}

\subsubsection{Estudio Cualitativo.}

Los expertos más indicados para analizar los aspectos de la ruta turística en el nevado de Salkantay son los empresarios de turismo y no necesariamente los pobladores de la zona o autoridades, esto debido a que el poblador de Mollepata tiene un escaso conocimiento de la actividad turística.

Los empresarios en turismo reconocen que el futuro del turismo estará en descubrir nuevos accesos de aventura y naturaleza para llegar a Machupicchu, los destinos tradicionales como los sitios arqueológicos de la ciudad ya no son muy atractivos para los empresarios.

Agregar una propuesta de valor a un restaurant como la creación de un museo de sitio, es sin duda muy apreciado por los expertos, el turismo es un sector que marca la diferencia con valores agregados para mejorar la experiencia del cliente.

\subsubsection{Estudio Cuantitativo.}

La ruta de Mollepata Salkantay Machupicchu es la segunda mejor ruta de trekking en el Cusco, después de la de Camino Inca, y tiene posibilidades de crecer mucho más con el desarrollo que tiene el turismo de aventura para los siguientes años.

Existe una demanda aproximada mayor a 30 mil viajeros al año que pasan por Mollepata y desayunan el primer día en un aproximado de cuatro a seis restaurantes ubicados en el pueblo mismo. 
La demanda de turistas llega a Mollepata a través de las agencias de viajes, y estas agencias recomiendan a los viajeros el lugar donde desayunaran en Mollepata (generalmente la elección se debe a un convenio previo entre la agencia y el restaurant).

Existen agencias de viajes que se especializan en varios segmentos del mercado de turistas, de los cuales el que más sobresale es la segmentación económica, donde hay agencias que operan turistas de capacidad económica media regular (turistas provenientes de hoteles 3 estrellas) y los de capacidad económica baja (turistas jóvenes que provienen de hostels o establecimientos de hospedaje para "mochileros")

Existen un promedio de 65 agencias de viajes que regularmente llegan a Mollepata durante el año con turistas para hacer la ruta de trekking, pero de ellos solo ocho agencias de viajes tienen el 71.84\% de participación del mercado, y las 17 siguientes una participación del $16 \%$.

\subsection{Perfil del Consumidor Tipo y sus Variantes}

El consumidor de nuestro producto serán las agencias de viajes tour operadoras de la ruta Salkantay - Machupicchu, que apuestan por un servicio diferenciado a la hora de escoger un restaurant para que los viajeros desayunen, en caso de las agencias tour operadoras que solo buscan desayunos económicos, también se realizaran estrategias para convencerlos.

\subsubsection{Perfil del turista de aventura}

Para fortalecer el tema del perfil del consumidor y sus variantes se usa como referencia la publicación sobre estudios del perfil de turistas de aventura, realizada por Prom-Peru, el año 2014, donde se muestran las características principales de los turistas que vienen a realizar turismo de aventura en nuestro país, y son: 
Su principal interés se centra en la naturaleza, y en ese sentido, tienden a preferir actividades de aventura que le permitan estar en contacto con la naturaleza, apreciar paisajes agradables, y a la vez conocer otras culturas.

Buscan estar bien informados, por lo que recurren antes del viaje a fuentes especializadas y a personas con experiencia en actividades de aventura.

Prefieren organizar sus viajes de turismo de aventura con el apoyo de una agencia de viajes.

Muestran un menor interés por experimentar aventura extrema prefiriendo así actividades de menor riesgo, como son las caminatas en montaña (trekking)

Mayormente oscilan entre los 19 a 35 años de edad.

Generalmente los turistas que realizan turismo de aventura en el Perú, son de nacionalidad norteamericana, seguida de turistas de procedencia europea de países como Alemania, Francia y Países bajos.

\subsubsection{Investigación al consumidor final}

Para poder conocer si la propuesta de negocio a crear será atractiva para los consumidores finales, se realizó una encuesta simple donde se contrasta la experiencia del desayuno que tuvieron en Mollepata con la propuesta de negocio (Ver anexo 9).

En los resultados de la encuesta por gran mayoría se vio la aceptación de los encuestados con la propuesta de negocio, así mismo se vio su insatisfacción con el desayuno que recibieron en el pueblo de Mollepata, casi el 70\% marco que tuvo una experiencia entre regular y mala y los que decían que era buena, señalaron que no tenían muchas expectativas de lo que recibirían el primer día de desayuno. En temas como testeo de producto, incorporación de ingredientes nutritivos y locales, aprovechamiento de paisajes naturales, decoración rustica 
fueron las más valoradas por los viajeros, llegando a tener en algunos hasta $100 \%$ de valoración.

Temas como precio de 20 a 25 soles y el nombre a proponer del local, fueron los puntos donde no se logró unánime aceptación, aunque la mayoría de los viajeros indico que le gustaría que el nombre sea Casa Mollepata, para conocer más sobre el pueblo donde esta ubicado el restaurant, así mismo otro grupo de personas mostro su interés con que también lleve el nombre de museo. Finalmente, los viajeros mostraron su agrado con que el centro de interpretación trate sobre temas de como el nevado influye en las formas de vida del poblador local. 


\section{Capítulo IV: Proyección del Mercado Objetivo}

\subsection{El Ámbito de la Proyección}

El ámbito de la proyección de la demanda se realizó teniendo como soporte la información de tipo secundaria, la misma que se obtuvo del municipio distrital de Mollepata, y se tomó como factor de influencia para la investigación el volumen de turistas con la que cada agencia tour operadora ingresa a realizar el trekking Mollepata - Salkantay - Machupicchu.

La información resultante es representativa y significativa del target, son extrapolables y proyectarles del universo.

\subsection{Selección del Método de Proyección}

De acuerdo con Sapag (2011) el método de regresión lineal es la más adecuada para el proyecto, ya que al utilizarla se obtendrá una recta que representa la tendencia de dos variables, que significará una referencia de partida para la proyección de tendencias posteriores.

Teniendo en cuenta el incremento de la demanda de turistas que realizan el trekking en la ruta Mollepata - Salkantay - Machupicchu, y sobre este punto, realizar una adecuada proyección, se tomó en cuenta los datos obtenidos del municipio distrital de Mollepata, que tiene una caseta de control en el ingreso al distrito donde registra todos los días del año, el número de turistas y las agencias de viajes que llegan para realizar turismo. 
Tabla 40

Ingreso anual de turistas a Mollepata

\begin{tabular}{ccc}
\hline Año & $\begin{array}{c}\text { Ingreso de turistas a } \\
\text { Mollepata }\end{array}$ & Crecimiento \\
\hline 2012 & 17,652 & 1.20 \\
2013 & 21,210 & 1.20 \\
2014 & 25,351 & 0.90 \\
2015 & 28,265 & 0.90 \\
2016 & 33,997 & 1.20 \\
\hline
\end{tabular}

Nota: Adaptado del Municipio Distrital de Mollepata: Registro del arribo de turistas nacionales y extranjeros al distrito de Mollepata, Boletín estadístico 2016.

En base a la información de la tabla anterior, se puede apreciar que la tasa de crecimiento en los últimos cinco años en promedio es de $1.08 \%$.

La fórmula que se aplicó para determinar la regresión lineal es la siguiente:

$$
y=a+b x
$$

Donde:

y = Función de proyección o línea de tendencia

$\mathrm{a}=$ Comportamiento no explicado de la variable por la variable $\mathrm{x}$

$\mathrm{b}=$ Comportamiento explicado por la variable 
Tabla 41

Datos para la regresión lineal

\begin{tabular}{ccc}
\hline Años & X & Y \\
\hline 2012 & -2 & 8 \\
2013 & -1 & 41,878 \\
2014 & 0 & 0 \\
2015 & 1 & 0 \\
2016 & 2 & 0 \\
Sumatorias & & 41,886 \\
\hline
\end{tabular}

Nota : Adaptado de calculo de variables de la ecuacion

por N. Sapag, 2011, Proyectos de Inversion, p.92

Copyrigth 2011 por Pearson Educación

A partir de esos datos se desarrolla la siguiente tabla a fin de tener los valores de las variables para reemplazar en la fórmula de regresión lineal.

Tabla 42

Determinación de los valores de las variables

\begin{tabular}{ccccc}
\hline Años & $\mathrm{X}$ & $\mathrm{Y}$ & $\mathrm{XY}$ & $\mathrm{X}^{2}$ \\
\hline 2012 & -2 & 17,652 & $-35,304$ & 4 \\
2013 & -1 & 21,210 & $-21,210$ & 1 \\
2014 & 0 & 25,351 & 0 & 0 \\
2015 & 1 & 28,265 & 28,265 & 1 \\
2016 & 2 & 33,997 & 67,994 & 4 \\
\multicolumn{2}{c}{ Sumatorias } & 126,475 & 39,745 & 10 \\
\hline
\end{tabular}

Nota: Adaptado de calculo de variables de la ecuacion por N.

Sapag, 2011, Proyectos de Inversion, p.92 Copyrigth 2011 por 
Para determinar los valores de a y b, se utiliza las siguientes fórmulas:

$$
\begin{aligned}
& \mathrm{b}=\frac{\mathrm{n}\left(\sum \mathrm{xy}\right)-\left(\sum \mathrm{y}\right)\left(\sum \mathrm{x}\right)}{\mathrm{n}\left(\sum \mathrm{x}^{2}\right)-\left(\sum \mathrm{x}\right)^{2}} \\
& \mathrm{a}=\overline{\mathrm{y}}-\mathrm{b}(\overline{\mathrm{x}})
\end{aligned}
$$

Por último, se tiene $a=25,295$; mientras que $b=3,974.50$, y la línea de tendencia sería:

$$
y=25,295+3,974.50 x
$$

En base a la línea de tendencia, se reemplaza en la fórmula la variable x para poder tener la proyección de la demanda anual de turistas al distrito de Mollepata, tal y como se muestra en la siguiente tabla.

Tabla 43

Proyección del ingreso de turistas a Mollepata

\begin{tabular}{ccc}
\hline Años & $\mathrm{x}$ & $\begin{array}{c}\text { Ingreso de turistas a } \\
\text { Mollepata }\end{array}$ \\
\hline 2017 & 3 & 37,219 \\
2018 & 4 & 41,193 \\
2019 & 5 & 45,168 \\
2020 & 6 & 49,142 \\
2021 & 7 & 53,117 \\
2022 & 8 & 57,091 \\
\hline
\end{tabular}

Nota : Adaptado de calculo de variables de la ecuacion por N. Sapag, 2011, Proyectos de Inversion, p.92 Copyrigth 2011 por Pearson Educación 


\subsubsection{Mercado Potencial.}

Según Kotler y Keller (2012), todo mercado potencial es la representación del grupo de consumidores que puede tener interés por la oferta que se está ofreciendo en el mercado. Cabe recalcar que el grado de interés del consumidor no es suficiente para poder precisar el mercado especifico.

Teniendo en cuenta la forma de negocio del plan, business to business (B2B), se identifica a las agencias de viajes tour operadoras a Salkantay con poder de determinación parar generar demanda direccionada al plan de negocio. De acuerdo al reporte estadístico obtenido por el municipio distrital de Mollepata se tienen 212 agencias de viajes tour operadoras que ingresaron a Mollepata cada año. El 2016 ingresaron 33,997 viajeros de los cuales el primer grupo (agencias de alta demanda) son ocho agencias que tienen un dominio del $71.84 \%$ del total de viajeros que ingresan a Mollepata, y un segundo grupo (agencias de regular demanda) tiene una participación con el $16.78 \%$, para fines de esta investigación se toma como mercado potencial a ambos grupos teniendo así el $88.62 \%$ del total de viajeros a Mollepata lo cual significa 32,983 viajeros para el año 2017.

Tabla 44

Selección del mercado potencial

\begin{tabular}{lccc}
\hline \multicolumn{1}{c}{ Captación de mercado } & $\begin{array}{c}\text { Participación } \\
\text { Porcentual }\end{array}$ & $\begin{array}{c}\text { Total de } \\
\text { Agencias de } \\
\text { Viajes }\end{array}$ & $\begin{array}{c}\text { Total de } \\
\text { viajeros al 2017 }\end{array}$ \\
\hline Agencias tour operadoras en la ruta & $100 \%$ & 212 & 37,219 \\
Salkantay & $71.84 \%$ & 8 & 26,738 \\
Agencias de alta demanda & $16.78 \%$ & 17 & 6,244 \\
Agencias de regular demanda & $88.62 \%$ & 25 & 32,983 \\
Mercado Potencial &
\end{tabular}


Las agencias que componen el mercado potencial están enumeradas en base al volumen de ingresos que producen en la ruta en estudio, en la siguiente tabla se muestra que existe un dominio preponderante del mercado por parte de las primeras ocho agencias tour operadoras, y al final de la lista están agencias que operan más de 100 viajeros al año, si bien es cierto su participación porcentual individual es menor al 1\%, pero en su conjunto forman el $16.78 \%$.

Tabla 45

Lista de agencias que conforman el mercado potencial

\begin{tabular}{lcc}
\hline Agencia tour Operadora & Total viajeros 2017 & $\begin{array}{c}\text { Participación } \\
\text { porcentual }\end{array}$ \\
\hline 1 KB tour & 6,880 & $18.49 \%$ \\
2 Machupicchu Reservations & 6,205 & $16.67 \%$ \\
3 Salkantay trekking & 5,266 & $14.15 \%$ \\
4 Alpaca expeditions & 3,196 & $8.59 \%$ \\
5 Arza tour & 1,633 & $4.39 \%$ \\
6 Mountain lodge Perú & 1,202 & $3.23 \%$ \\
7 Salkantay backpackers & 1,183 & $3.18 \%$ \\
8 Llama path & 1,173 & $3.15 \%$ \\
9 Xtreme tourbulencia & 921 & $2.47 \%$ \\
10 Bamba Experience & 777 & $2.09 \%$ \\
11 Sas travel & 581 & $1.56 \%$ \\
12 Wayky trek & 535 & $1.44 \%$ \\
13 South american trek & 417 & $1.12 \%$ \\
14 Bio andean & 407 & $1.09 \%$ \\
15 Chasky & 338 & $0.91 \%$ \\
16 Terra quechuas & 321 & $0.86 \%$ \\
17 Sam travel & 317 & $0.85 \%$ \\
18 Inca trail expedition Perú & 244 & $0.66 \%$ \\
19 Quechua expeditions & 244 & $0.66 \%$ \\
20 Amazonas Explorer & 236 & $0.63 \%$ \\
21 Cóndor travel & 203 & $0.55 \%$ \\
22 Rasgos Perú & 183 & $0.49 \%$ \\
23 Tierras vivas & 181 & $0.49 \%$ \\
24 Valencia travel & 173 & $0.46 \%$ \\
25 Nc travel Perú & 167 & $0.45 \%$ \\
& 32,327 & $88.62 \%$ \\
\hline & &
\end{tabular}


Al hacer la proyección se tomó como referencia la información del año 2016, y se realizó una proyección de cinco años a desde el 2017 al 2021, por lo que se tiene lo siguiente:

Tabla 46

Proyección del mercado potencial

\begin{tabular}{lccccc}
\hline \multicolumn{1}{c}{ Detalle } & 2017 & 2018 & 2019 & 2020 & 2021 \\
\hline $\begin{array}{l}\text { Mercado Total } \\
\text { Turistas a Mollepata }\end{array}$ & 37,219 & 41,193 & 45,168 & 49,152 & 53,117 \\
$\begin{array}{l}\text { Mercado Potencial } \\
\quad \text { Agencias de alta/regular demanda }\end{array}$ & $88.62 \%$ & $88.62 \%$ & $88.62 \%$ & $88.62 \%$ & $88.62 \%$ \\
$\quad$ Subtotal 1 & 32,983 & 36,505 & 40,028 & 43,559 & 47,072 \\
\hline
\end{tabular}

De la tabla anterior se aprecia que el mercado potencial tiene un progresivo crecimiento en el número total de viajeros para los cinco años, pero se considera constante el crecimiento del número de agencias; el supuesto es que las agencias de viajes que ya están posicionadas dentro de las 25 mejores en volumen de ventas solo incrementaran su participación de mercado para los siguientes años, y el escenario es que no existan nuevas agencias con ese volumen de participación de mercado.

\subsubsection{Mercado Disponible.}

Según Kotler \& Keller, el mercado disponible está aquel que está compuesto por un grupo de consumidores que poseen interés y cuentan con ingresos para poder acceder a una oferta en particular en el mercado; es decir están calificados para adquirir dicha oferta.

Para estimar el total del mercado disponible se realiza el trabajo en base al mercado potencial ya determinado, con la aplicación de filtros que son las preguntas elaboradas en el cuestionario (estudio cuantitativo), las cuales fueron: 
F1. ¿Dónde programa el desayuno para sus viajeros el primer día del trekking Mollepata - Salkantay?

a) Desayunan en los restaurantes turísticos del pueblo de Mollepata. (Se eligió esta respuesta).

b) Mis cocineros de la agencia de viajes prefieren preparar un desayuno a las afueras del pueblo de Mollepata. Si respondieron esto preguntar ¿por qué no desayunan en el pueblo de Mollepata? - pasar a preguntas de testeo.

c) Prefiero que desayunen en el hotel por su cuenta y ya no paramos hasta el almuerzo. Si respondieron esto preguntar ¿por qué no desayunan en el pueblo de Mollepata? - pasar a preguntas de testeo.

A través de dichas preguntas se identificó que, de las 25 agencias encuestadas, dos agencias indicaron que no desayunan en Mollepata, Alpaca Expeditions indico que prefiere llevar sus propios cocineros a la ruta, por un tema de dar mejorar calidad de su servicio, y la agencia Mountain Lodge tiene un local privado a 30 minutos de Mollepata donde sus viajeros tienen una especie de brunch al mediodía. En conclusión, el $86.67 \%$ del mercado potencial es el mercado disponible.

Tabla 47

Proyección del mercado disponible

\begin{tabular}{lccccc}
\hline \multicolumn{1}{c}{ Detalle } & 2017 & 2018 & 2019 & 2020 & 2021 \\
\hline Subtotal 1 & 32,983 & 36,505 & 40,028 & 43,559 & 47,072 \\
Mercado Disponible & & & & & \\
$\quad$ Agencias que desayunan en Mollepata & $86.67 \%$ & $86.67 \%$ & $86.67 \%$ & $86.67 \%$ & $86.67 \%$ \\
Subtotal 2 & 28,587 & 31,639 & 34,692 & 37,752 & 40,798 \\
\hline
\end{tabular}




\subsubsection{Mercado Efectivo.}

Según Kotler \& Keller el mercado efectivo está formado por el grupo de consumidores que va a adquirir el producto que oferta una empresa.

Para calcular el mercado efectivo, se procedió a aplicar la encuesta respectiva para marginar a aquellas agencias de viajes que estarían dispuestas a formar o realizar una alianza estratégica con los negocios de restaurante turístico y centro de interpretación en Mollepata.

Dentro de la encuesta, los resultados a las preguntas hechas allí, arrojaron la siguiente información de carácter concluyente:

P15. ¿Cambiaría su restaurant habitual o forma de dar desayunos a sus turistas en Mollepata por esta nueva propuesta?

- Definitivamente si la cambiaria

- Posiblemente la cambiaria

- No sé si cambiaria

- Posiblemente No Cambiaria

- Definitivamente No Cambiaria

Los resultados para medir la intención de cambio en las agencias tour operadoras son los siguientes: 
Tabla 48

Pregunta de filtro

Cambiaría su restaurant habitual o forma de dar desayunos a sus turistas en Mollepata por esta nueva propuesta

Número de agencias de viaje

Definitivamente si

19

Probablemente si

2

No se si cambiaria

2

Posiblemente no cambiaria

0

Definitivamente no cambiaria

Total
0

23

Según el criterio de (Pope, 2012) cuando se realiza la evaluación de compra de un nuevo producto o servicio, las escalas de clasificación utilizadas deben ser castigadas de la siguiente manera:

- Definitivamente si: $75 \%$

- Probablemente sí: $25 \%$

- No sé si cambiaria: $10 \%$

- No cambiaria: $2 \%$

En este caso el análisis debe ser individualmente agencia por agencia para así calcular el mercado efectivo que cada agencia podría aportar a la propuesta de negocio. Las agencias de viajes que señalaron que "definitivamente si cambiarían a la nueva propuesta de negocio" son en total 19, las que señalaron "posiblemente si" son un total de dos, y las que señalaron "no sé si cambiaria" fue también dos agencias de viaje. Para determinar el número de mercado efectivo se multiplica la participación de mercado de las 19 agencias por el 0.75 de castigo, la participación de mercado de las otras dos agencias por el 0.25 de 
castigo y la agencias que marcaron "no sé si cambiaria" se multiplica por el $0.10 \mathrm{de}$ castigo. A continuación, se presentan los resultados:

Tabla 49

Determinación de mercado efectivo según criterio Pope

\begin{tabular}{|c|c|c|c|c|c|}
\hline Agencias tour operadoras & $\begin{array}{l}\text { Mercado } \\
\text { dicnnnihle }\end{array}$ & $\begin{array}{l}\text { Participacion } \\
\text { de marnadn }\end{array}$ & $\begin{array}{c}\text { efinitivamente si } \\
\text { (criterio Pope } \\
75 \% \text { ) }\end{array}$ & $\begin{array}{c}\text { Posiblemente si } \\
\text { (criterio Pope } \\
25 \% \text { ) }\end{array}$ & $\begin{array}{l}\text { No se si cambiaría } \\
\text { (criterio Pope } 10 \% \text { ) }\end{array}$ \\
\hline $1 \mathrm{~KB}$ tour & 6,880 & $24.07 \%$ & & & $2.41 \%$ \\
\hline 2 Machupicchu Reservations & 6,205 & $21.71 \%$ & $16.28 \%$ & & \\
\hline 3 Salkantay trekking & 5,266 & $18.42 \%$ & $13.82 \%$ & & \\
\hline 4 Arza Tours & 1,633 & $5.71 \%$ & $4.28 \%$ & & \\
\hline 5 Salkantay backpackers & 1,183 & $4.14 \%$ & & $1.03 \%$ & \\
\hline 6 Llama path & 1,173 & $4.10 \%$ & $3.08 \%$ & & \\
\hline 7 Xtreme tourbulencia & 921 & $3.22 \%$ & $2.42 \%$ & & \\
\hline 8 Bamba Experience & 777 & $2.72 \%$ & $2.04 \%$ & & \\
\hline 9 Sas travel & 581 & $2.03 \%$ & $1.53 \%$ & & \\
\hline 10 Wayky trek & 535 & $1.87 \%$ & $1.40 \%$ & & \\
\hline 11 South american trek & 417 & $1.46 \%$ & $1.09 \%$ & & \\
\hline 12 Bio andean & 407 & $1.42 \%$ & $1.07 \%$ & & \\
\hline 13 Chasky & 338 & $1.18 \%$ & $0.89 \%$ & & \\
\hline 14 Terra quechuas & 321 & $1.12 \%$ & $0.84 \%$ & & \\
\hline 15 Sam travel & 317 & $1.11 \%$ & $0.83 \%$ & & \\
\hline 16 Inca trail expedition Perú & 244 & $0.85 \%$ & & $0.21 \%$ & \\
\hline 17 Quechua expeditions & 244 & $0.85 \%$ & $0.64 \%$ & & \\
\hline 18 Amazonas Explorer & 236 & $0.83 \%$ & $0.62 \%$ & & \\
\hline 19 Cóndor travel & 203 & $0.71 \%$ & $0.53 \%$ & & \\
\hline 20 Rasgos Perú & 183 & $0.64 \%$ & $0.48 \%$ & & \\
\hline 21 Tierras vivas & 181 & $0.63 \%$ & $0.47 \%$ & & \\
\hline 22 Valencia travel & 173 & $0.60 \%$ & $0.45 \%$ & & \\
\hline 23 Nc travel Perú & 167 & $0.58 \%$ & & & $0.06 \%$ \\
\hline Total & 28,584 & $100.00 \%$ & $52.8 \%$ & $1.25 \%$ & $2.47 \%$ \\
\hline
\end{tabular}

En la tabla se aprecia que las 23 agencias de viajes tienen un porcentaje de participación de mercado, donde agencias como KB Tour y Machupicchu Reservations poseen el $24.07 \%$ y el $21.71 \%$; aplicando el criterio Pope se multiplica la participación de mercado de la primera agencia que es $24.07 \%$ por el 0.10 de castigo y se convierte en un 2.41\%, lo mismo se hace con la participación de mercado de la Agencia Machupicchu Reservations, pero como ellos marcaron que definitivamente si comprarían, entonces $21.71 \%$ se multiplica por el 0.75 de castigo y el resultado se convierte en un $16.28 \%$ de 
participación de mercado, esto se realiza con las 23 agencias de viajes. Finalmente se procede con las sumatorias de los porcentajes, pero se excluirán los que señalaron que “posiblemente si comprarían el producto", esto porque lo más realista es que no compren el producto y no se quiere crear falsas expectativas. El resultado de las sumatorias se hace entonces tomando en cuenta los que definitivamente si comprarían el producto y equivale al $52.77 \%$, lo cual equivale a 15,083 turistas al año, siendo este resultado el mercado efectivo para el año 2017 (escenario prudente). A continuación, se detalla la proyección de mercado efectivo para los siguientes años:

Tabla 50

Proyección del mercado efectivo

\begin{tabular}{lrrrrc}
\hline Detalle & 2017 & 2018 & 2019 & 2020 & 2021 \\
\hline Subtotal 2 & & & & & \\
Mercado Efectivo & 28,584 & 31,637 & 34,689 & 37,742 & 40,794 \\
Agencias que definitivamente & & & & & \\
comprarian & $52.77 \%$ & $52.77 \%$ & $52.77 \%$ & $52.77 \%$ & $52.77 \%$ \\
Subtotal 3 & 15,083 & 16,693 & 18,304 & 19,914 & 21,525 \\
\hline
\end{tabular}

\subsubsection{Mercado Objetivo.}

Según Kotler y Keller el mercado objetivo está formado por el grupo de consumidores a los que una empresa se va a enfocar y dirigir con su producto.

Para segmentar, se tomaron en cuenta tres factores primordiales como, el volumen de demanda que cada agencia de viajes tiene en Mollepata (Clientes heavys), la capacidad de atención del restaurante o capacidad instalada y la participación de mercado, que como se concluyó en el capítulo II, la propuesta de negocio intenta posicionarse para el primer año el tercer lugar en volumen de ventas de los cuatro restaurantes que existen en Mollepata. Según estudio cualitativo se determinó que aproximadamente en el 2016 el segundo 
restaurant en ventas, "Sumaq Terminal” vende 8340 desayunos anuales y el tercer restaurant que es "Don Julio" vende 5280 desayunos anuales. Por lo que en un escenario positivo pero conservador, la propuesta de negocio pretende superar a Don Julio para el primer año de ventas.

Por ende, se ha considerado pertinente captar el $37 \%$ del mercado efectivo, lo cual vendría a ser 10 agencias de viajes con un aproximado de 5,561 clientes al año, con un crecimiento conservador para los siguientes cinco años:

Tabla 51

Proyección del mercado objetivo

\begin{tabular}{lrrrrr}
\hline Detalle & 2017 & 2018 & 2019 & 2020 & 2021 \\
\hline Subtotal 3 & & & & & \\
Mercado Objetivo & 15,083 & 16,693 & 18,304 & 19,914 & 21,525 \\
proyeccion de consumidores & $37 \%$ & $54 \%$ & $58 \%$ & $74 \%$ & $79 \%$ \\
Subtotal 4 & 5561 & 8979 & 10686 & 14814 & 16947 \\
\hline
\end{tabular}

\subsection{Pronóstico de Ventas}

Según Kotler y Keller en una empresa el pronóstico de las ventas es el resultado de dos variables, primeramente, son las ventas y luego es un plan donde están actividades de marketing.

Luego de haber determinado el mercado objetivo o meta, ahora es necesario proyectar esa misma variable, pero en unidades monetarias, para la proyección de ventas se tomó en cuenta las siguientes variables:

El mercado objetivo anual, es decir el total de viajeros aproximado que llegará al restaurante del proyecto es un escenario muy conservador son 5,561 clientes el primer año. 
El precio de venta promedio del desayuno será de S/. 22.00 sin impuestos, el mismo que se estableció de acuerdo a los resultados del estudio cuantitativo, cuando se realizó la pregunta a los representantes de las agencias de viajes sobre cuánto es el costo promedio que tiene el viajero cuando desayuna en Mollepata, y sobre cuanto estiman que los viajeros podrían pagar por una oferta de desayunos mejorada.

Se realizará una proyección anual, pero también se realizará una proyección de ventas mensual, porque el negocio estará profundamente marcado por la estacionalidad de la afluencia turística, existiendo una temporada alta y otra temporada baja. A continuación, la proyección de ventas anual:

Tabla 52

Pronóstico de ventas

\begin{tabular}{lccccc}
\hline Detalle & 2017 & 2018 & 2019 & 2220 & 2021 \\
\hline Ventas anuales & S/.122,342.00 & S/.197,520.79 & S/.235,070.68 & S/.325,884.76 & S/.372,797.24 \\
Desayunos diarios (L-D 360 días) & 15 & 25 & 29 & 41 & 46 \\
\hline
\end{tabular}

\subsection{Aspectos Críticos que impactan el Pronóstico de Ventas}

Para poder estimar cuáles son los aspectos críticos que podrían impactar al presente proyecto, se tomó en cuenta la información recogida en el capítulo sobre el análisis del contexto actual, y algunas preguntas en la entrevista a expertos y encuesta a operadores de turismo. A continuación, se presenta un resumen de las conclusiones:

El contexto actual y futuro de la ruta es bastante positivo, sobre todo porque la ruta de Mollepata - Salkantay se perfila a ser una de las mejores de aventura de trekking gracias a su conectividad con Machupicchu. Los operadores turísticos y empresarios concordaron en que invertir en Mollepata para el turismo será muy provechoso para los siguientes años. 
Las actividades turísticas de aventura de un día están siendo muy demandadas por los turistas en Cusco, es el caso de los viajeros que van a diario a la montaña de Vinicunca o “montaña de los siete colores" quienes en grandes cantidades diariamente salen de Cusco, deseosos de llegar a la cima de las montañas andinas. Caso similar es el de Mollepata, pues se empieza a observar que las agencias de viajes intentando vender caminatas de un día al nevado de Salkantay con almuerzo en Mollepata y retorno al Cusco el mismo día, esto podría ser una oportunidad para ampliar la cartera de productos e incorporar el almuerzo como una opción nueva al mediano plazo.

El municipio distrital de Mollepata viene trabajando intensamente por finiquitar la carretera de acceso al complejo arqueológico de Choquequirao, con este nuevo proyecto se llegará al centro arqueológico en tan solo dos días y no en cinco como es actualmente, la ubicación del restaurant esta exactamente al costado del futuro acceso a Choquequirao, lo cual en un mediano plazo beneficiara positivamente a las ventas del negocio.

Es necesario precisar que los inversionistas que estén interesados en apostar en esta propuesta tienen que considerar los siguientes riesgos a los que se podrían enfrentar y como mitigarlos, los cuales se detallan a continuación:

En primer lugar, la dificultada de poder adecuar las instalaciones con los servicios que se pretenden ofrecer, dado que la zona tiene un único acceso para seguir la ruta del trekking. Este riesgo se puede mitigar en vista que el proyecto no representa una infraestructura muy elaborada por querer mantener la esencia rustica del lugar.

Como todo proyecto nuevo es susceptible a generar competencia directa, para lo cual se tienen diseñadas estrategias en el capítulo siente que permitan que el negocio no pierda el atractivo característico para el visitante.

Todo negocio del sector turístico está sujeto a la estacionalidad, como se mencionó en el capítulo dos (temporada alta y regular), este riesgo no implica que no exista clientela, por el contrario, en ambas temporadas se recibirán visitantes. 
Por la naturaleza de la zona en temporada de lluvias se suscitan derrumbes que impiden el acceso al poblado, sin embargo, el municipio cuenta con planes de contingencia para superar estos inconvenientes en un plazo de un par de horas. 


\section{Capítulo V: Ingeniería del Proyecto}

\subsection{Estudio de Ingeniería}

\subsubsection{Modelamiento y Selección de Procesos Productivos.}

Según David (2013), la cadena de valor es un proceso en el que una empresa establece el costo de todas las actividades en las que una organización incurre desde el momento en el que se obtiene la materia prima hasta la comercialización que es proceso final. De acuerdo a Porter la mejor manera de describir una empresa es a través de una cadena de valor, en la que todos los ingresos menos los costos de todas las actividades producen valor. Mediante este análisis también podemos identificar de mejor manera todas las ventajas y desventajas

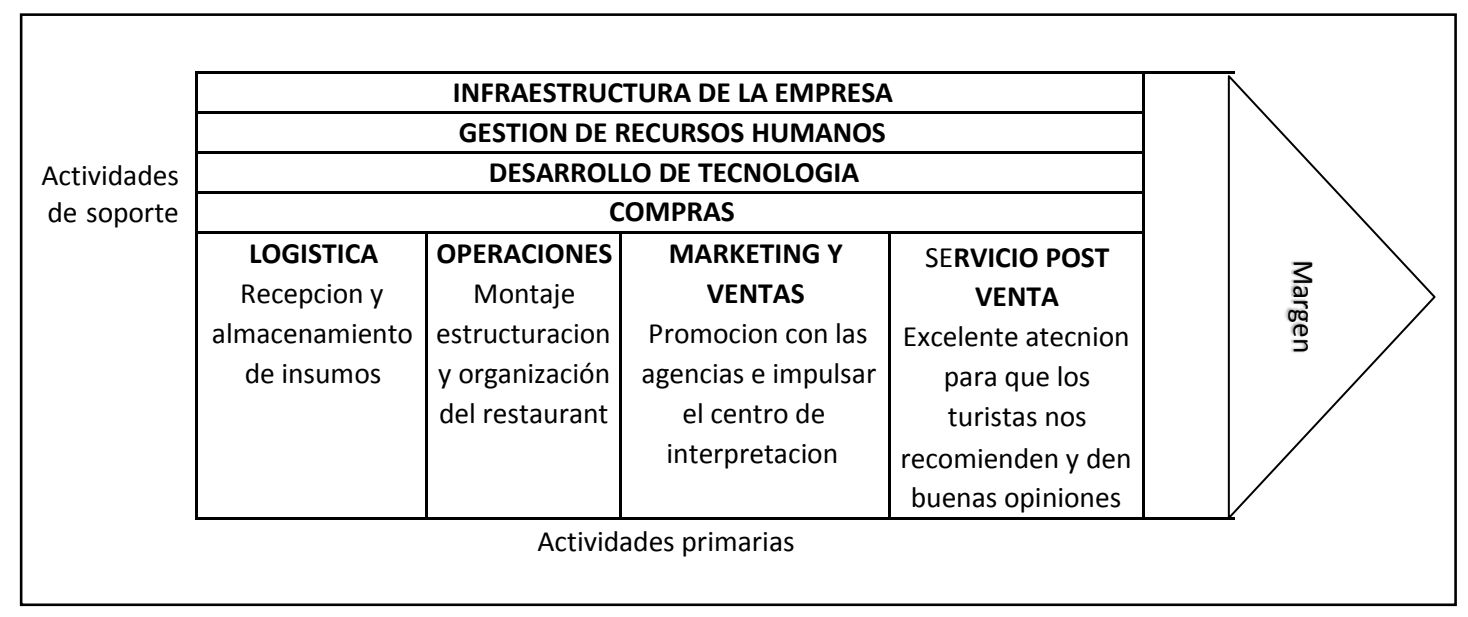

Figura 25. Actividades de la cadena de valor, Adaptado de Administración Estratégica (p. 270), por A. A. Thompson, M. A. Peteral, J. E. Gamble y A. J. Strickland, 2012, México:

Editorial Mc Graw Hill Companies, Inc. Copyright 2012. 
Según Stamato (2012) una empresa desarrolla diversas actividades como puede ser marketing, recursos humanos, logística, etc., estas a su vez dan una base para formular las estrategias que harán la diferencia, y ayudarán a un mayor y mejor posicionamiento de ventajas en costos.

Las actividades o acciones de valor que están dentro de esta mencionada cadena son aquellas que se desempeñan en un negocio para tener un producto con ventajas para el consumidor (Stamato, 2012)

Dentro de la cadena de valor las dos actividades principales son las primarias (que hacen referencia a todo el proceso desde el ingreso de los insumos hasta la comercialización del producto) y de soporte, que como su nombre indica, son el respaldo de todas las actividades de la cadena (Stamato, 2012).

A continuación, se presenta el desarrollo de las actividades primarias de la cadena de valor con sus respectivas actividades:

\section{a) Logística Interna}

Se refiere a las actividades de ingreso, recepción y almacén de los productos necesarios para el desarrollo de las actividades, la programación de llegada de los proveedores, teniendo en cuenta que el proyecto no se encuentra en una zona de común llegada de proveedores, sin embargo, muchos de los insumos que se usarán para la elaboración de los desayunos, serán adquiridos de la zona como frutas, vegetales y otros productos agrícolas. 
b) Operaciones

Obtención del servicio final de restaurante que incluye facilitar y ofrecer el servicio del centro de interpretación y orientación turística a los turistas.

\section{c) Marketing y Ventas}

Actividades que ayudaran para que el cliente consuma el producto, en este punto cobra gran fuerza el centro de interpretación ya que será un gran atractivo complemento que será de interés antes o después de que los clientes consuman sus alimentos, se debe tener en cuenta en la mayoría de los clientes llegaran por medio de las agencias de viaje, quienes ofrecerán desde un inicio como parte del paquete el producto.

\section{d) Servicio Post venta}

Según Stamato (2012), el servicio de post venta son un conjunto de acciones realizadas para mantener la fidelización de los clientes, ofreciéndoles garantías, beneficios, entre otros.

A continuación, se presenta el desarrollo de las actividades de soporte de la cadena de valor con sus respectivas actividades:

\section{a) Compras}

Como indica Stamato (2012), las compras se refieren a la función de abastecer insumos que se utilizarán en la producción de materias primas, así como la adquisición de los activos como maquinaria, equipo de laboratorio, equipo de oficina y edificios.

La mayoría de productos serán adquiridos en el valle de Limatambo y la zona de Mollepata que tienen importantes valles agrícolas como el de Marcahuasi, Huamanpata y Cotocamarca, sin embargo, aquellos productos industrializados serán traídos desde Cusco 
Un punto importante para mayor realce de nuestra carta es describir los productos orgánicos y saludables que se ofrecerán dentro de los desayunos y realzar que provienen del sector y que son cultivados de la manera más natural posible.

b) Desarrollo de Tecnología

Stamato (2012) considera al desarrollo de la tecnología como la actividad importante en la cadena, asimismo, se considera dentro de esta actividad el uso de redes, ingeniería de proceso, equipos, etc. El desarrollo de la tecnología es importante porque puede ser una condición clave para la generación de ventajas competitivas, pero en algunos sectores no.

El conocimiento implica el manejo de los servicios y los gustos de los habituales consumidores. Por otro lado, los procesos serán estandarizados tanto los de atención al cliente como los de manipulación de alimentos.

Será importante también el manejo de plataformas digitales tanto para la promoción como distribución de información como canal de venta, al ser este un negocio en área rural el trabajo logístico tendrá un soporte informático de nivel usuario básico.

c) Administración de Recursos Humanos

Se refiere al manejo del personal idóneo para los diferentes puestos, esto implica la capacitación necesaria. Dicha actividad resulta ser clave para la cadena.

Tiene influencia directamente las ventajas competitivas de acuerdo al grado de motivación y liderazgo que se consiga por medio de la concientización de los objetivos. Para el proceso continuo de la empresa se debe contar como mínimo con el siguiente personal. 
Tabla 53

Personal para el negocio

\begin{tabular}{lc}
\hline \multicolumn{1}{c}{ Ítem } & Inversión (S/.) \\
\hline Administrador & 1,200 \\
Asistente & 400 \\
Cocinero (chef) & 850 \\
Mozo & 400 \\
Ayudante de cocina & 400 \\
Mozo & 400 \\
\hline Total & 3,650 \\
\hline
\end{tabular}

d) Infraestructura de la Empresa

Incluye toda la parte contable financiera, legal, gubernamental y todo lo que implique en correcto manejo de la empresa.

Stamato (2012), indica que la cadena de valor no es solamente un conjunto de actividades independientes, sino estas también se pueden desarrollar como un sistema de varias actividades interdependientes. Las actividades de valor se relacionan por eslabones dentro de la cadena. Éstos eslabones determinan la forma en que se desarrolla una actividad y cómo tiene un impacto en el costo o desempeño de otra. Por ejemplo, en la elaboración de alimentos en un restaurant, los tiempos en que el mozo lleva a la comida al comensal influyen en la calidad.

A continuación, se presenta gráficamente el diagrama de flujo tanto de la atención del establecimiento, así como del flujo de la cocina, a fin de tener una mayor comprensión del proceso de servicios. 


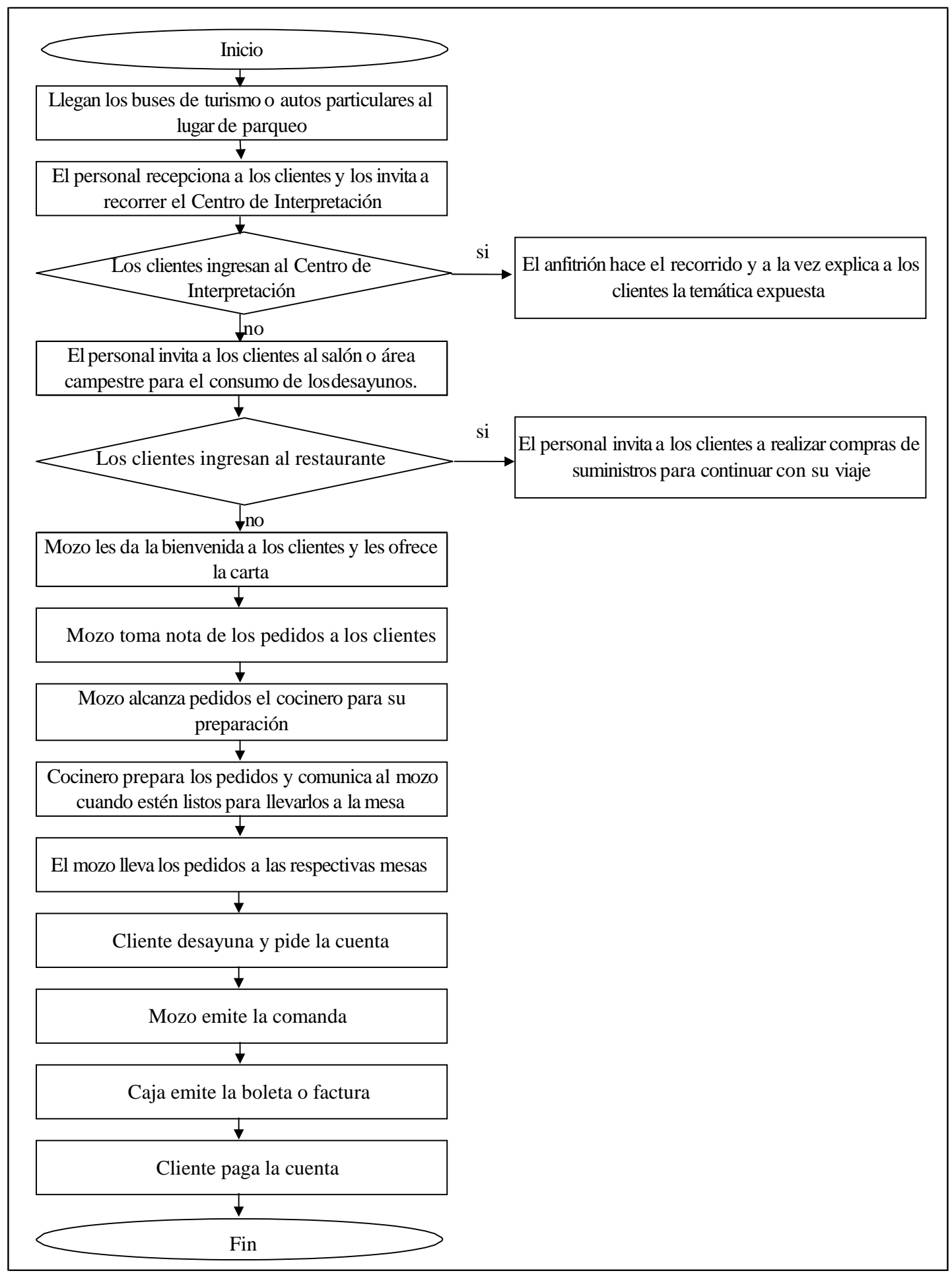

Figura 26. Diagrama de Flujo de Atención. 


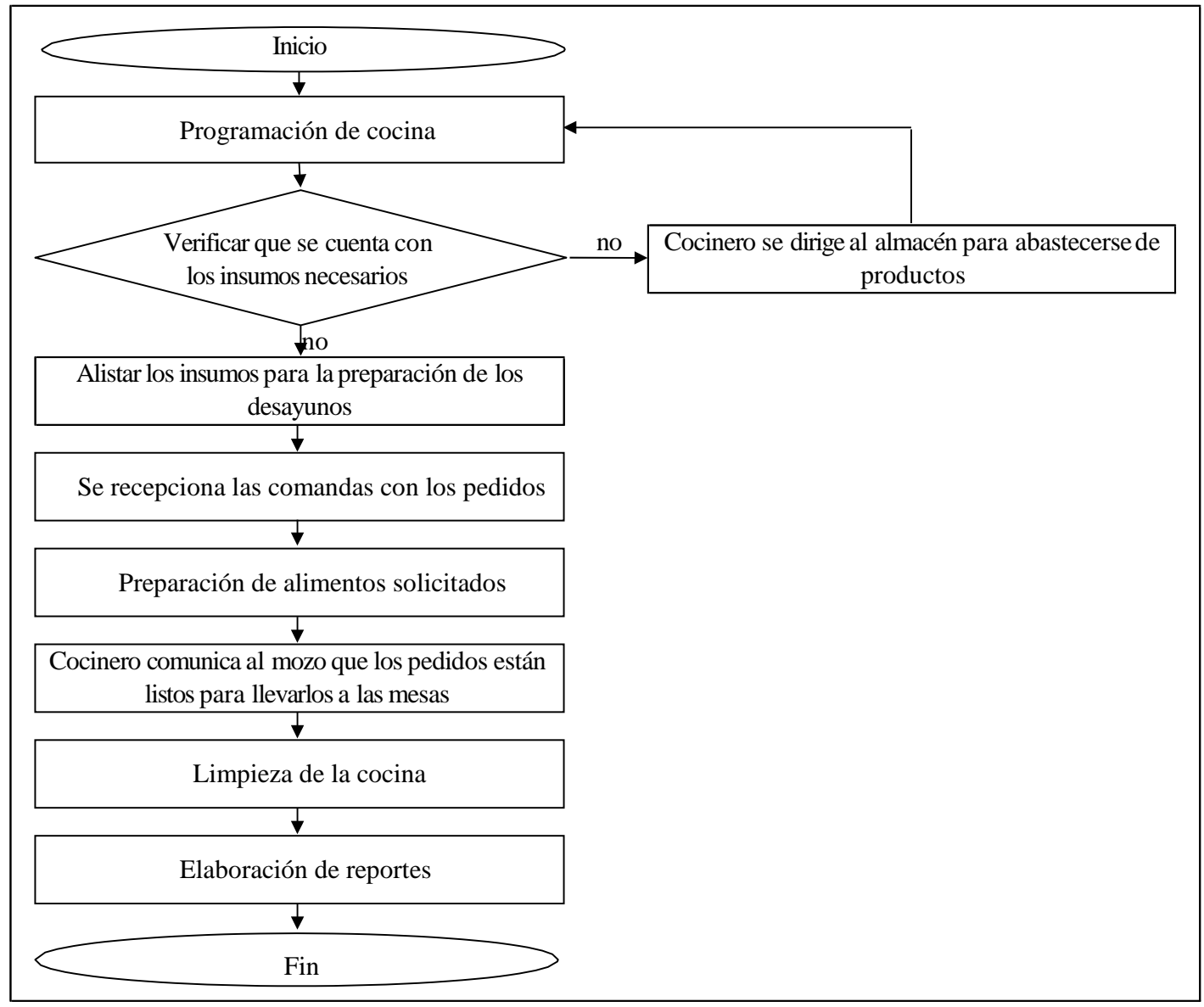

Figura 27. Diagrama de Flujo de la Cocina.

\subsubsection{Selección del Equipamiento.}

Sapag (2011) recomienda que para todo proyecto nuevo es mejor utilizar balances al momento de la selección de los equipamientos, estos balances son unos formularios que ayudaran para hacer un trabajo más eficaz.

En ese entender, para el primer balance se tomó en cuenta cinco puntos claves: 
Tabla 54

Balance de implementos para la administración

\begin{tabular}{llccc}
\hline \multicolumn{1}{c}{ Ítem } & \multicolumn{1}{c}{ Especificaciones } & Cantruad & Costo unitario & Costo total \\
& & unidades & $(\mathrm{S} /)$ & $(\mathrm{S} /)$ \\
\hline Escritorio & De madera de 1,5 por 0,7 & 1 & 250 & 250 \\
Teléfono & Básico para oficina & 1 & 65 & 65 \\
Laptop & Core I5 Windows 10 de 500gb & 1 & 1,500 & 1,500 \\
Smartphone & Memoria de 16 g de 1 gb rm & 1 & 500 & 500 \\
Silla giratoria & Regulable con espaldar & 1 & 90 & 90 \\
Silla de escritorio & madera & 2 & 50 & 100 \\
Impresora fotocopiadora & Bandeja de 30 hojas multifuncional & 1 & 590 & 590 \\
Estante & 3 niveles de melamina & 1 & 140 & 140 \\
Archivador & Metálico de 3 cajones & 1 & 150 & 150 \\
& Total & & & 3,385 \\
\hline
\end{tabular}

Tabla 55

Balance de implementos para la cocina

\begin{tabular}{lcccc}
\hline \multicolumn{1}{c}{ Ítem } & \multirow{2}{*}{ Especificaciones } & $\begin{array}{c}\text { Cantidad } \\
\text { unidades }\end{array}$ & $\begin{array}{c}\text { Costo unitario } \\
(\mathrm{S} /)\end{array}$ & $\begin{array}{c}\text { Costo total } \\
(\mathrm{S} /)\end{array}$ \\
\hline Congeladora & De 440 litros, 2 puertas & 1 & 1,300 & 1,300 \\
Estante para alimentos & De madera de 3 niveles & 1 & 130 & 130 \\
Estante para menajeria y mantelería \\
$\begin{array}{l}\text { Total } \\
\text { Toladera de 3 niveles }\end{array}$ & 2 & 130 & 260 \\
& & & & 1,690 \\
\hline
\end{tabular}


Tabla 56

Balance de equipos para el proceso de producción

\begin{tabular}{|c|c|c|c|c|}
\hline Ítem & Especificaciones & $\begin{array}{l}\text { Cantidad } \\
\text { unidades }\end{array}$ & $\begin{array}{c}\text { Costo unitario } \\
(\mathrm{S} /)\end{array}$ & $\begin{array}{c}\text { Costo total } \\
(\mathrm{S} /) \\
\end{array}$ \\
\hline Cocina de 4 hornillas & $\begin{array}{l}\text { Cocina } 3 \text { hornillas de acero } \\
\text { inoxidableconbaranda tubular } \\
\text { con piloto para cada hornilla }\end{array}$ & 1 & 1,200 & 1,200 \\
\hline $\begin{array}{l}\text { Mesa de madera para } \\
\text { preparado }\end{array}$ & $\begin{array}{l}\text { De } 1,6 \text { de largo por } 0,8 \text { de } \\
\text { ancho }\end{array}$ & 1 & $15 n$ & $15 n$ \\
\hline Refrigeradora & Dos puertas (530 a 700 litros) & 1 & 1,000 & 1,000 \\
\hline Tabla de picar & De 45 por 30 & 2 & 45 & 90 \\
\hline Olla & 5 litros & 1 & 300 & 300 \\
\hline Sartèn & De cerámica anti adherente & 2 & 84 & 168 \\
\hline Calentadora & 5 litros & 2 & 70 & 140 \\
\hline Termo & 3 litros & 2 & 150 & 300 \\
\hline Licuadora semi industrial & 3 velocidades & 2 & 148 & 296 \\
\hline Tostadora & 4 rebanada & 2 & 150 & 300 \\
\hline Juego de utensilios & & 2 & 350 & 700 \\
\hline Cuchillos & $\begin{array}{l}\text { Set de } 5 \text { cuchillos de acero } \\
\text { inoxidable }\end{array}$ & 1 & 60 & 60 \\
\hline Extintor & Polvo químico & 1 & 70 & 70 \\
\hline Estantes de madera & $\begin{array}{l}\text { Metálico de } 80 \text { por } 30 \text { por } \\
2,40\end{array}$ & 2 & 90 & 180 \\
\hline Horno microondas & $\begin{array}{l}\text { de } 1,4 \mathrm{CU} \\
\text { Total }\end{array}$ & 1 & 390 & $\begin{array}{c}390 \\
5,344\end{array}$ \\
\hline
\end{tabular}


Tabla 57

Balance de implementos para salón principal

\begin{tabular}{|c|c|c|c|c|}
\hline Ítem & Especificaciones & $\begin{array}{l}\text { Cantidad } \\
\text { unidades }\end{array}$ & $\begin{array}{c}\text { Costo } \\
\text { unitario }(\mathrm{S} /)\end{array}$ & $\begin{array}{c}\text { Costo total } \\
(\mathrm{S} /)\end{array}$ \\
\hline Mesas & $\begin{array}{l}\text { Rusticas de pino (150 por } \\
0,70)\end{array}$ & 10 & 150 & 1,500 \\
\hline Banca & Madera pino & 20 & 40 & 800 \\
\hline Juegos de vajilla & $\begin{array}{l}\text { Loza blanca hotelera (plato } \\
\text { grande, plato pequeño, } \\
\text { bowl, taza) }\end{array}$ & 45 & 31 & 1,395 \\
\hline Servilletero & Cerámica artesanal & 13 & 11 & 143 \\
\hline Azucarero & Cerámica artesanal & 13 & 15 & 195 \\
\hline Juego de saleros & Cerámica artesanal & 13 & 15 & 195 \\
\hline Equipo de música & $\begin{array}{l}\text { Minicomponente con salida } \\
\text { de } 5 \text { vatios USB }\end{array}$ & 3 & 260 & 780 \\
\hline Termo & 2,2 litros sifón air pump & 3 & 120 & 360 \\
\hline Adorno de mesa & Floreros de cerámica & 13 & 11 & 143 \\
\hline Jarras de $2 \mathrm{~L}$ & Cristal & 5 & 20 & 100 \\
\hline Mermelero mantequillero & De cerámica & 13 & 8 & 104 \\
\hline Vasos & Vidrios & 45 & 2 & 90 \\
\hline Individuales & tela andina & 45 & 3 & 135 \\
\hline Barra para caja & Madera de 2 por 0,60 & 1 & 300 & 300 \\
\hline Decoración & Cuadros, mascaras andinas & 1 & 500 & 500 \\
\hline Extintor & Polvo quimico & 1 & 700 & 700 \\
\hline \multirow[t]{2}{*}{ Juegos de cubiertos } & $\begin{array}{l}\text { Acero inoxidable (cuchara, } \\
\text { cucharilla, tenedor. } \\
\text { Cuchillo) }\end{array}$ & 45 & 25 & 1,125 \\
\hline & Total & & & 8,565 \\
\hline
\end{tabular}

Tabla 58

Balance de equipos para el Centro de Interpretación

\begin{tabular}{|c|c|c|c|}
\hline Ítem & $\begin{array}{l}\text { Cantidad } \\
\text { unidades }\end{array}$ & $\begin{array}{c}\text { Costo unitario } \\
(\mathrm{S} /)\end{array}$ & $\begin{array}{c}\text { Costo total } \\
(\mathrm{S} /)\end{array}$ \\
\hline Iluminación & 8 & 60 & 480 \\
\hline Cartel interactivo & 8 & 200 & 1,600 \\
\hline Vitrinas & 8 & 500 & 4,000 \\
\hline Total & & & 6,080 \\
\hline
\end{tabular}


5.1.3. Lay Out.

El lay out es una palabra en ingles que significa diseño o plan, para la administración significa la forma de disponer, o sectorizar los productos y servicios.

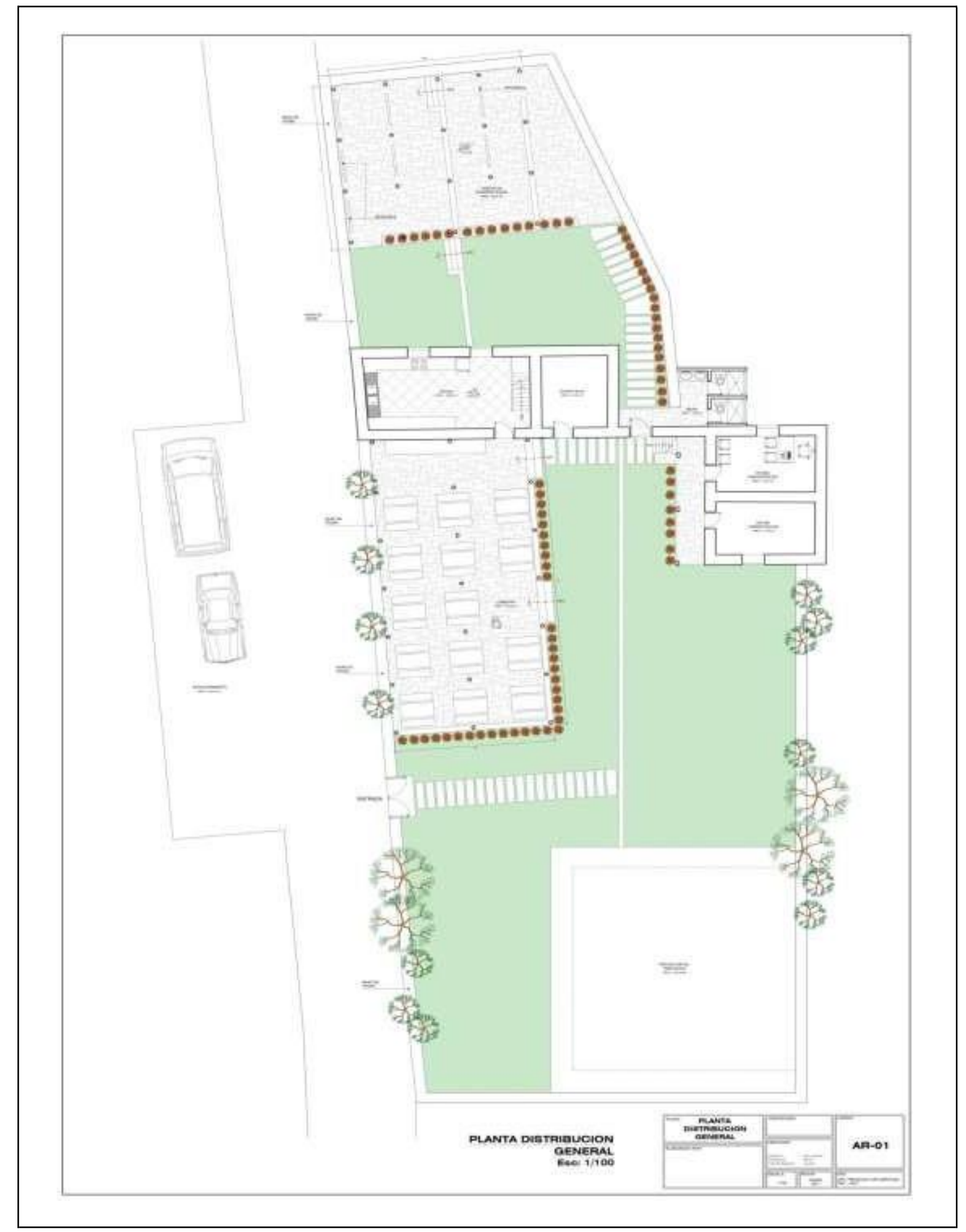

Figura 28. Lay out. 
5.1.4. Distribución de Equipos y Maquinarias.

En el área de cocción se ubicará la cocina, el microondas, entre otros equipos a fin de atender los pedidos.

En el almacén estará ubicada la congeladora que se encuentra cerca de la cocina para tener un acceso directo dentro del área.

El área de administración que será el espacio donde el administrador podrá desarrollar las actividades respectivas y en caso de ser necesario, atender a los clientes. Esta área contará con un teléfono fijo, una laptop, y una impresora fotocopiadora.

En el salón principal se ubicará todo el mobiliario para que los clientes puedan consumir sus alimentos, dígase; mesas y sillas. Este ambiente también contara con un equipo de música.

En el área del centro de interpretación se contará con vitrinas para exhibir las distintas manifestaciones culturales de la zona. Este ambiente también contara con iluminación especial a fin de resaltar lo expuesto.

Es necesario indicar que todos los ambientes cuentan con un extintor en caso de presentarse cualquier emergencia.

\subsection{Determinación del Tamaño}

Sapag (2011) recomienda que para definir el tamaño de un proyecto se debe estimar el monto de inversiones y el nivel de operación, los factores que se relacionan para esta estimación son como acceso a insumos, ubicación, demanda esperada, entre otros. 
Se ha determinado maximizar el área construida ya existente además de aprovechar las áreas de jardín como zona campestre para la implementación de más mesas para la atención de los comensales, también se considerará el área de parking para todos los buses de turismo que lleguen hasta el negocio.

\subsubsection{Proyección de Crecimiento}

En la proyección de crecimiento figuran las siguientes ofertas:

- Implementación de una tienda de suvenires, será planificada a mediano plazo

- En función al incremento de los turistas en la zona se evalúa la implementación de un hospedaje a largo plazo, ya que cada vez son más el número de visitantes que desean pernoctar en Mollepata, debido a que es el punto de partida para los distintos recorridos.

Todas estas proyecciones cuentan con el respaldo de ser terreno propio de los miembros del proyecto teniendo a disposición con nueve hectáreas.

\subsubsection{Recursos.}

El personal mínimo requerido se define de la siguiente manera: se contará con un administrador, quien también hará las funciones de guía en el centro de interpretación un asistente que apoyará con todas las áreas, principalmente en caja, un chef y un mozo; en cuanto a recursos materiales se contará con todos los equipamientos mencionados en el capítulo cinco, como son cocina, refrigeradora, congeladora, horno, licuadora vajilla, menaje, etc. 


\subsubsection{Tecnología.}

La tecnología utilizada será la necesaria para la conservación de alimentos además de la maquinaria para la preparación de los mismos como cocinas hornos entre otros equipos. También se contará con equipos audiovisuales para una mejor exposición del centro de interpretación, además de contar con computadora para la administración y necesariamente un sistema de pagos electrónicos.

\subsubsection{Flexibilidad.}

Sapag (2011), define a la flexibilidad dentro de la empresa como la capacidad que tiene una empresa para adecuarse con fácilmente a los cambios del entorno.

Considerando que la demanda de turistas que llegan a esta zona, cada vez es más grande se debe tener en cuenta la adaptabilidad que debe tener del negocio para poder aumentar la demanda, estoy implica tener la infraestructura idónea dependiendo a las necesidades del mercado.

\subsubsection{Selección Del Tamaño Ideal.}

Para seleccionar el tamaño del terreno, se revisó el área construida ya existente la cual será remodelada y acondicionada de acuerdo a las necesidades del proyecto. También se tomó en cuenta que se desea que el establecimiento cuente con amplios jardines para que los clientes desayunen en un lugar conectado con la naturaleza. 
El terreno cuenta con un área de aproximadamente 850 metros cuadrados los cuales se abarcan principalmente la sala principal de comedor donde se pueden instalar hasta 15 mesas y el área del centro de interpretación, en cual permitirá que las exhibiciones estén estratégicamente distribuidas.

El área de parking se encuentra al frente del establecimiento con capacidad de hasta 10 vehículos, que permitirá la llegada de los comensales sin ningún inconveniente.

\subsection{Estudio de Localización}

Según Sapag (2011) el estudio de localización permite al inversionista escoger teniendo en cuenta varios factores, el lugar donde se ubicará un proyecto, lo cual definirá el éxito, o caso contrario, el fracaso del proyecto.

El proyecto se desarrollará en un terreno propiedad de uno de los inversionistas, el cual se encuentra a las afueras de Mollepata donde inicia el recorrido para todas las personas que harán Camino Inca o los diferentes trekkings de la zona.

El terreno está ubicado estratégicamente al inicio del camino en medio de paisajes naturales que permiten explotar la belleza de la localidad.

\subsubsection{Definición de Factores Locacionales.}

De acuerdo a la teoría de Sapag (2011), la determinación de los factores Locacionales son básicamente ponderaciones de factores del 1 al 5, donde 1 es muy desfavorable y 5 muy favorable; lo cual indica que la zona 1 es la favorable para el desarrollo del proyecto.

Considerando que la zona donde se encuentra el terreno pre determinado se ubica a la salida del poblado, exactamente donde inicia la ruta para hacer trekking A continuación, se detallan los factores Locacionales considerados para el presente proyecto: 
a) Mercado que se desea atender

Son todos aquellos turistas interesados en conocer y recorrer el camino que parte del pueblo de Mollepata, al nevado Salkantay y la ciudad Inca de Machupicchu.

b) Punto medio del poblado

El establecimiento se encontrará en las afueras de Mollepata, aproximadamente a un kilómetro de la plaza de armas del pueblo, al inicio de la ruta rumbo a Soraypampa, que es el primer punto de campamento de la zona, lo cual facilita a los viajeros el acceso a la zona de recorrido.

c) Acceso al transporte

La carretera desde Cusco hasta Mollepata es asfaltada, sin embargo, un pequeño tramo hasta llegar a la ubicación final es trocha algo accidentada (200 metros aproximadamente).

d) Costo y disponibilidad de terrenos adecuados a las características del proyecto

Por las características del proyecto se necesita un terreno amplio con área campestre y en contacto con la naturaleza.

e) Acceso a productos oriundos de la zona

El clima de la zona y las tierras fértiles permiten el cultivo de una gran variedad de productos de calidad, los cuales se pueden adquirir a precios cómodos, esto favorece mucho al proyecto debido a que no será necesario gastar en trasporte para traerlos de la ciudad del Cusco. 
f) Apoyo gobierno local

El alcalde del poblado promueve la actividad turística, por tal motivo apoya e incentiva los proyectos que contribuyan al crecimiento económico de la localidad.

Después de determinar los principales factores de localización, se realizó la ponderación de los mismos y como se puede observar en la siguiente tabla, la zona A tiene un puntaje mayor en relación a las otras alternativas consideradas, es por eso que la mejor opción para desarrollar el proyecto es la Zona A.

- La zona A que está situada a inicio del camino donde comienza el trekking

- La zona B comprende los alrededores de la plaza principal del pueblo

- La zona C está determinada por las periferias donde se ingresa al pueblo de Mollepata.

Para determinar cuál es la zona optima se realizó la ponderación de las mismas, pudiendo concluir que la zona A tiene un puntaje mayor en relación a las otras alternativas consideradas, es por eso que la mejor opción para desarrollar el proyecto es la Zona A.

Se debe tener en cuenta que la zona A es terreno propio, se hizo el respectivo análisis con la intención de demostrar las bondades de dicho terreno.

Tabla 59

Factores Locacionales

\begin{tabular}{lccc}
\hline Factores locacionales & \multicolumn{3}{c}{ Zona A Zona B Zona C } \\
\hline Mercado que se desea atender & 5 & 5 & 5 \\
Punto medio del poblado & 4 & 5 & 3 \\
Acceso al transporte & 5 & 5 & 5 \\
Acceso a proveedores & 4 & 4 & 4 \\
Costo y disponibilidad de terrenos & 5 & 3 & 3 \\
Acceso a productos oriundos de la zona & 5 & 5 & 5 \\
Apoyo gobierno local & 5 & 4 & 4 \\
Total ponderado & 33 & 31 & 29 \\
\hline
\end{tabular}




\subsubsection{Consideraciones Legales.}

Toda empresa nueva que iniciará actividades debe tener todos sus papeles en reglas y realizar sus trámites ante entidades encargadas como los municipios o gobiernos locales, asimismo, se deben revisar los requisitos que soliciten las instituciones como:

- Instituto Nacional de Defensa Civil (INDECI). Una vez que se haya terminado todas las remodelaciones e instalaciones del local se deberá pasar una inspección técnica que evaluará si nuestro local cuenta con todos los requisitos para ser un establecimiento seguro y que cumpla con todos los parámetros que exigen dicha institución, para que posteriormente se nos otorgue la licencia de funcionamiento.

- Superintendencia Nacional de Registros Públicos (SUNARP). Después de crear la sociedad esta deberá ser registrada ante SUNARP

- Superintendencia Nacional de Aduanas y de Administración Tributaria (SUNAT). El primer paso que se debe realizar antes de iniciar cualquier trabajo, es solicitar ante la SUNAT el RUC de la empresa, esto permitirá realizar todos los registros contables desde un inicio, es decir llevar la contabilidad desde la implementación en general y la compra de activos fijos hasta que comiencen las operaciones para su posterior declaración de impuestos.

Ministerio de Trabajo. Ante esta entidad se deberá realizar todos los trámites relacionados al ámbito laboral como son la presentación de los respectivos contratos de trabajo de cada trabajador. 


\subsubsection{Identificación del Marco Legal.}

- Norma Sanitaria para el Funcionamiento de Restaurantes y Servicios Afines (Resolución Ministerial No 363-2005/MINSA).

- Ley MYPE (Decreto Legislativo $\mathrm{N}^{\circ}$ 1086), su reglamento (Decreto Supremo $\mathrm{N}^{\circ}$ 024-2009-PRODUCE).

- Reglamento sobre vigilancia y control sanitario de alimentos y bebidas (Decreto Supremo $N^{\circ}$ 007-98-SA).

- Reglamento de Restaurantes $N^{\circ}$ 025-2004/Ministerio de Comercio Exterior.

- Registros de sanidad DIGESA.

- Ley General de Sociedades $N^{\circ} 26887$.

\subsubsection{Ordenamiento Jurídico de la Empresa.}

Se constituirá una Sociedad de Anónima Cerrada (20 socios).

Además, se debe buscar el nombre en registros públicos y reservarlo. Asimismo, se debe redactar y elaborar la minuta de constitución; gestionar la licencia de funcionamiento en la municipalidad; e inscribir en SUNAT a la empresa.

De igual forma la empresa estará regida por la ley MYPE por contar con menos de 10 trabajadores, este punto es importante ya que las exigencias hacia los trabajadores no son las mismas que una empresa grande 


\subsection{Determinación de la Localización Óptima}

El proyecto se desarrollará en un terreno propio estratégicamente ubicado a las afueras del pueblo de Mollepata donde comienza el camino para llegar a la montaña de Salkantay y posteriormente a la ciudadela inca de Machupicchu. 


\section{Capítulo VI: Aspectos Organizacionales}

\subsection{Caracterización de la Cultura Organizacional deseada}

Según David Uno de los procesos que se desarrolla en un largo plazo, es la cultura organizacional y la filosofía que se quiere desarrollar en la empresa, durante este proceso, se van formando reglas, códigos y procedimientos que van a ir amoldando el accionar básico de la empresa y van a lograr características únicas y ventajosas frente a sus competidores localizados en el mismo sector. Se llega a decir que "el éxito o fracaso de las reformas corporativas" están íntimamente relacionadas con la cultura organizacional que se crea en las mismas, según Allaire y Firsirotu.

El restaurante turístico localizado en Mollepata es una organización que reconoce a sus colaboradores, como tal, gente que aporta su esfuerzo para el buen servir y atención al cliente, ayudando al desarrollo del negocio. El centro de Servicios Turísticos reconoce que para tener usuarios y/o clientes satisfechos, los colaboradores deben de experimentar el mismo grado de sensación. Por tal motivo, la cultura organizacional se establece apoyada en tres pilares fundamentales para su desarrollo, la misión, la visión y los valores. Estos tres ejes correctamente alineados a la razón de ser de la empresa, formarán un pilar rector del presente y del futuro de la organización. Bien sostiene David que las publicaciones de visión y misión óptimamente diseñadas son esenciales para formular, implementar y evaluar las estrategias" 


\subsubsection{Visión.}

Según David, la visión es la referencia o norte máximo que rige el rumbo de toda empresa en un largo plazo. Para lograr la visión, la organización debe de establecerse objetivos reales y alcanzables en el tiempo, es por eso que para su elaboración los miembros o líderes de las empresas deben preguntarse ¿En qué queremos convertirnos? y su repuesta debe de ser breve y en su conformación deben participar tantos directivos sea posible. Por lo tanto, la visión para el presente plan de negocios, se define de la siguiente manera:

“Ser el Centro de Servicios Turísticos líder entre los restaurantes y centros de interpretación de Mollepata en la ruta de trekking Salkantay para el 2020”

\subsubsection{Misión.}

Según Kotler la misión de una empresa representa el propósito de existencia de la misma y para su elaboración se debe responder a la siguiente pregunta ¿Cuál es nuestro negocio? Con el desarrollo de la misión será más fácil desarrollar objetivos y estrategias que estén alienados a la naturaleza de la empresa. Es meritorio mencionar que la misión puede estar direccionada hacia el mercado o el producto que ofrece la empresa, o también es el caso que puede direccionarse a ambas partes.

En tal razón de acuerdo a Thompson \& Strickland, una misión estratégicamente reveladora parte de las respuestas a tres preguntas claves; ¿qué se trata de satisfacer?, la respuesta a esta pregunta es conocer las necesidades del cliente o público objetivo. ¿A quién se quiere satisfacer?, la respuesta a esta pregunta es determinar los grupos de clientes que tendrá el proyecto o conocido también como mercado objetivo. Y finalmente, ¿cómo se pretende crear valor para satisfacerlos? 
De esta forma se desarrollará cada una de las tres preguntas propuestas por Thompson y Strickland para poder formular una adecuada misión.

Tabla 60

Análisis de la misión

Correlación de las preguntas de Thompson \& Strickland, con la misión actual de la empresa

¿Qué? La necesidad de una adecuada nutrición e información .

¿A quién? A los bvisitantes, viajeros y/o turistas de la ruta de trekking Mollepata - Salkantay - Machupicchu

¿Cómo? A través de una experiencia única e inigualable en gastronomía ycultura

Teniendo las respuestas claras a estas tres interrogantes, se procede a formular la misión del proyecto:

“Trasmitir una experiencia única al viajero que combine sabores, calidad, sustentabilidad e información exacta, mediante platos, variedades de desayunos y descripción clara de la zona a recorrer"

\subsubsection{Principios.}

Además de la misión y visión muchos autores como Hernandez, Gallarzo, \& Medin señalan que los principios dentro de una compañía son fundamentales, para estructurar las bases que permitan una mejor comprensión de cuáles son los factores motivacionales que tiene una compañía.

Estos, además son las líneas guía para todos los miembros de la organización, empresa y/o compañía a través de todos sus niveles jerárquicos. Estos principios deben ser transmitidos oportunamente y memorizados por el personal, además, estos deben ser 
interiorizados e inherentes a todas las actividades de la empresa, ya que serán los cimientos sobre los cuales se redactarán las declaraciones de misión y visión.

a) Existimos para servir

Principio principal del proyecto, y en ella se involucran valores como la pasión por servir de mejor forma a los clientes, la confianza reinante que debe existir en el ámbito laboral, la puntualidad tanto en las órdenes de entrega como en el cumplimiento de actividades y procesos.

b) Trabajo en equipo

Este principio se estructura sobre valores fundamentales como la confianza y el apoyo entre el personal, dado que, en un ambiente seguro y confiable, las ideas de innovación y las soluciones se gestarán más rápidamente.

c) Máximo compromiso de integridad en todo lo que se hace

La honestidad, integridad y nuevamente la confianza mueven a este principio. Estos tres valores motivarán el compromiso con lo que se hace en la empresa, viéndose reflejado en el producto final que esta desarrolla.

d) Compromiso con la sociedad local por la cultura y bienestar.

El servicio y la ética serán factores estructurales fundamentales para establecer real conciencia del compromiso que la empresa tiene para con la comunidad local que la acoge. Este principio es el segundo con mayor importancia dentro del proyecto. 
e) Mejora continua de la calidad

La pasión por el servicio, la confianza, la integridad que reine en el ámbito laboral, y la puntualidad en los servicios, serán claves para la mejora continua de los procesos y en el producto final que este genere.

Tabla 61

Correlación entre principios y valores institucionales

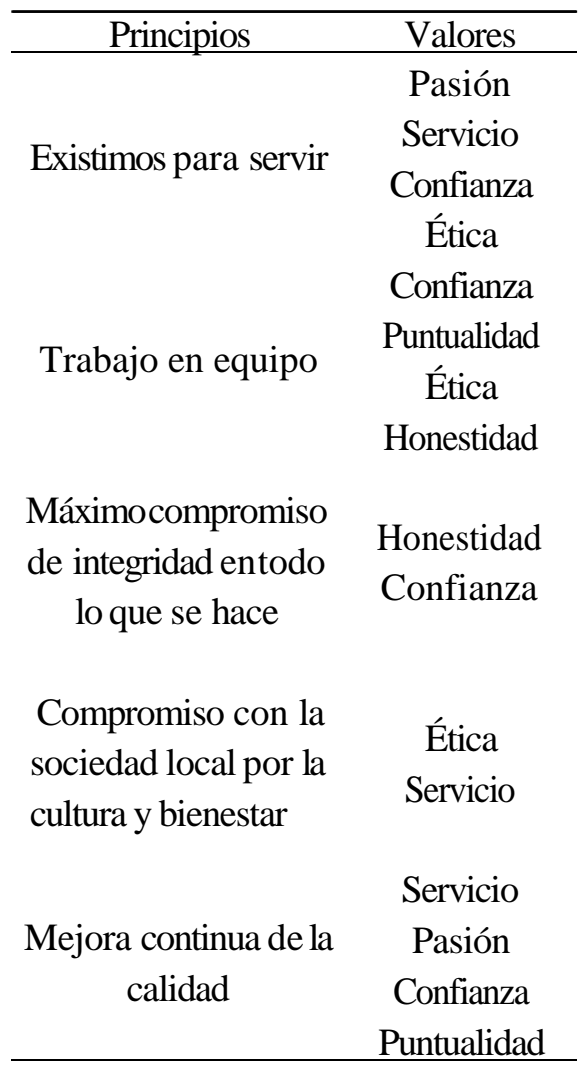

\subsection{Formulación de Estrategias del Negocio.}

Según David los factores hacen que una determinada empresa logre una ventaja competitiva en el mercado son las ya conocidas cinco estrategias específicas de Porter; con la adecuada aplicación de estas, una empresa puede llegar a obtener una ventaja competitiva en tres diferentes bases; liderazgo en costos, diferenciación y enfoque. Las dos primeras especialmente destinadas a empresas con gran tamaño y capacidad de producción, las dos 
últimas, operan en ambos casos, para empresas pequeñas. Liderazgo en costos comprende las dos primeras estrategias específicas de Porter, el tipo 1 o liderazgo en costos - bajo costo y el tipo 2 o liderazgo en costos - mejor valor. La diferenciación, es la estrategia genérica que es útil tanto para empresas grandes como para pequeñas y se establece sobre la estrategia específica tipo 3 o simplemente llamada diferenciación. El enfoque se estructura sobre las estrategias tipo 4, enfoque bajo coste y el tipo 5 o enfoque mejor valor.

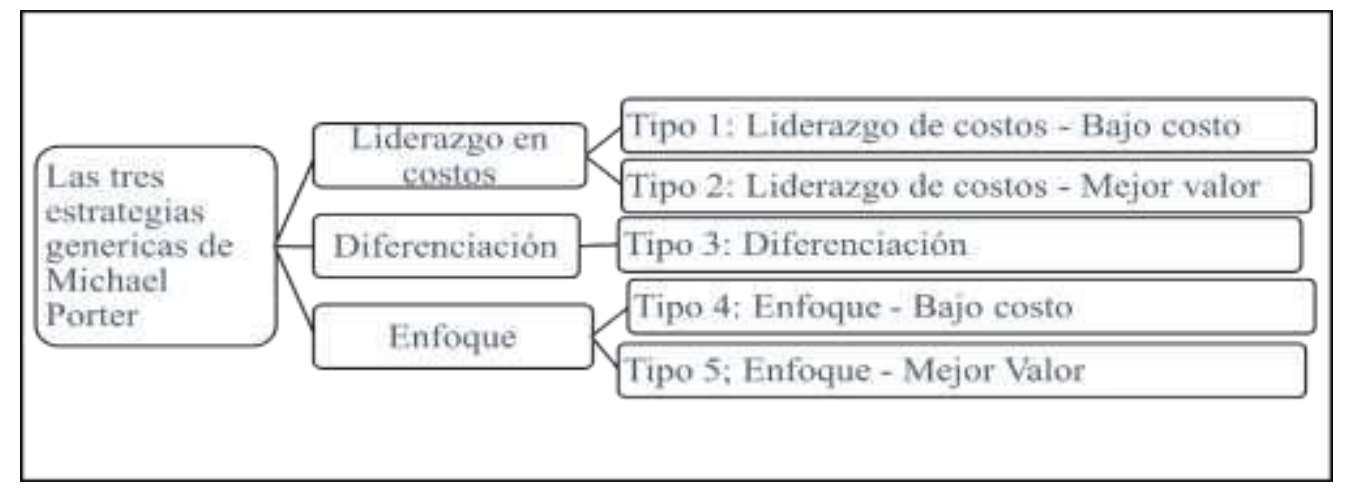

Figura 29. Las tres estrategias genéricas de Michael Porter.

Bajo este enfoque y siguiendo las indicaciones establecidas por Michael Porter, se ubica el ámbito en el cual se halla el proyecto, materia del plan de negocios; una empresa pequeña. Por lo tanto, las estrategias a tomar serán las de diferenciación de productos y/o servicios; ya que el valor agregado del proyecto serán los platillos en base a insumos orgánicos oriundos de la zona y con una adecuada base nutricional acorde a las futuras exigencias del organismo.

La segunda estrategia a desarrollar, será el de enfoque de mejor valor, ya que los productos serán enfocados a un pequeño segmento o una selecta variedad de clientes con la mejor relación valor-precio disponible en el mercado.

Teniendo en cuenta que esta estrategia es determinante en base a las ventajas competitivas que tiene el proyecto, ya que según la matriz VRIO, una de ellas es la característica del establecimiento y su excelente ubicación, ambiente rustico, cómodo y acogedor, es 
importante que no rompa la armonía del lugar y su excelente ubicación al inicio del trekking Mollepata - Salkantay - Machupicchu; características que hacen que el producto y servicio sean inimitables. Teniendo en cuenta que esto aunado a la calidad de los insumos, oriundos de la zona y el adecuado balance nutricional de los desayunos, significan un valor agregado único y diferencial en la mente de nuestro consumidor final y de nuestro mercado objetivo (las agencias de viajes).

Con respecto al producto, la preparación de una adecuada variedad de desayunos, de acuerdo a la calidad de insumos de la zona y el servicio proveído, al ofrecer estos platos al consumidor final, ya sea en el restaurante y en el centro de interpretación, significará otra característica de diferenciación, que el cliente podrá notar inmediatamente. Con respecto al precio, es levemente superior al resto y las actividades de responsabilidad social que desarrollará el proyecto reforzaran la idea de diferenciación en los clientes finales y el mercado objetivo.

\subsection{Determinación de las Ventajas Competitivas Críticas.}

Kotler \& Keller (2012), para lograr una ventaja comparativa critica, la propuesta de valor debe ser esencial para diferenciarse de la competencia y lograr una aventajarse de la competencia; entendiéndose propuesta de valor, como cantidad final de beneficios que la empresa promete dar a sus clientes.

De esta manera y de acuerdo a la información obtenida de las entrevistas a profundidad realizadas, conjuntamente con la recolección de datos y análisis de las tendencias en el sector, se obtiene las ventajas competitivas siguientes: 
Tabla 62

Matriz VRIO de ventajas competitivas criticas

\begin{tabular}{|c|c|c|c|c|c|}
\hline Ventajas competitivas & Valioso & Raro & Inimitable & $\begin{array}{c}\text { Organización } \\
\text { alineada al } \\
\text { recurso }\end{array}$ & Tipos \\
\hline Calidad de producto y servicio & $\mathrm{Si}$ & $\mathrm{Si}$ & No & & Ventaja competitiva temporal \\
\hline Insumos organicos oriundos de la zona & $\mathrm{Si}$ & No & & & Equidad competitiva \\
\hline Adecuado balance nutricional de cada platillo & $\mathrm{Si}$ & $\mathrm{Si}$ & No & & Ventaja competitiva Temporal \\
\hline Personal de la zona & $\mathrm{Si}$ & No & & & Equidad competitiva \\
\hline Reduccion del impacto medioambiental en la zona & $\mathrm{Si}$ & $\mathrm{Si}$ & No & & Ventaja competitiva temporal \\
\hline Ambiente rustico, comodo y acogedor. & $\mathrm{Si}$ & $\mathrm{Si}$ & $\mathrm{Si}$ & $\mathrm{Si}$ & Ventaja competitiva sostenible \\
\hline Gigantografias y mapas de la ruta Salkantay (Centro de interpretación) & $\mathrm{Si}$ & $\mathrm{Si}$ & No & & Ventaja competitiva temporal \\
\hline Actualizacion constante de informacion geografica de la zona & $\mathrm{Si}$ & $\mathrm{Si}$ & No & & Ventaja competitiva temporal \\
\hline Informacion y capacitacion para primeros auxilios & Si & $\mathrm{Si}$ & $\mathrm{Si}$ & $\mathrm{Si}$ & Ventaja competitiva sostenible \\
\hline
\end{tabular}

Las ventajas competitivas críticas descritas anteriormente, representan en su conjunto las dos estrategias genéricas de Porter, la diferenciación y el enfoque de valor-calidad en los productos.

Aplicando un análisis más profundo de cada ventaja competitiva, se encuentran aquellas que son temporales y se deberá trabajar en una mejora continua, innovando procesos de servicios, opciones nuevas de platos con adecuados balances nutricionales, nuevas técnicas de reciclaje e impacto medioambiental de la zona, actualización constante de la información brindada de geografía, flora y fauna de la zona mediante el Centro de Interpretación. Teniendo en cuenta que estas mejoras continuas no generarán gastos cuantificables considerables. innovando de esta manera se podrá cumplir la propuesta de valor planteada hacia el público objetivo y se logrará vigencia en el mercado.

\subsection{Diseño de la Estructura Organizacional Deseada}

Según recomienda David, en de las distintas estructuras organizacionales, la funcional es la más recomendada para pequeñas empresas, puesto que es muy práctico y no es causa de gasto, o de costo a la organización. 


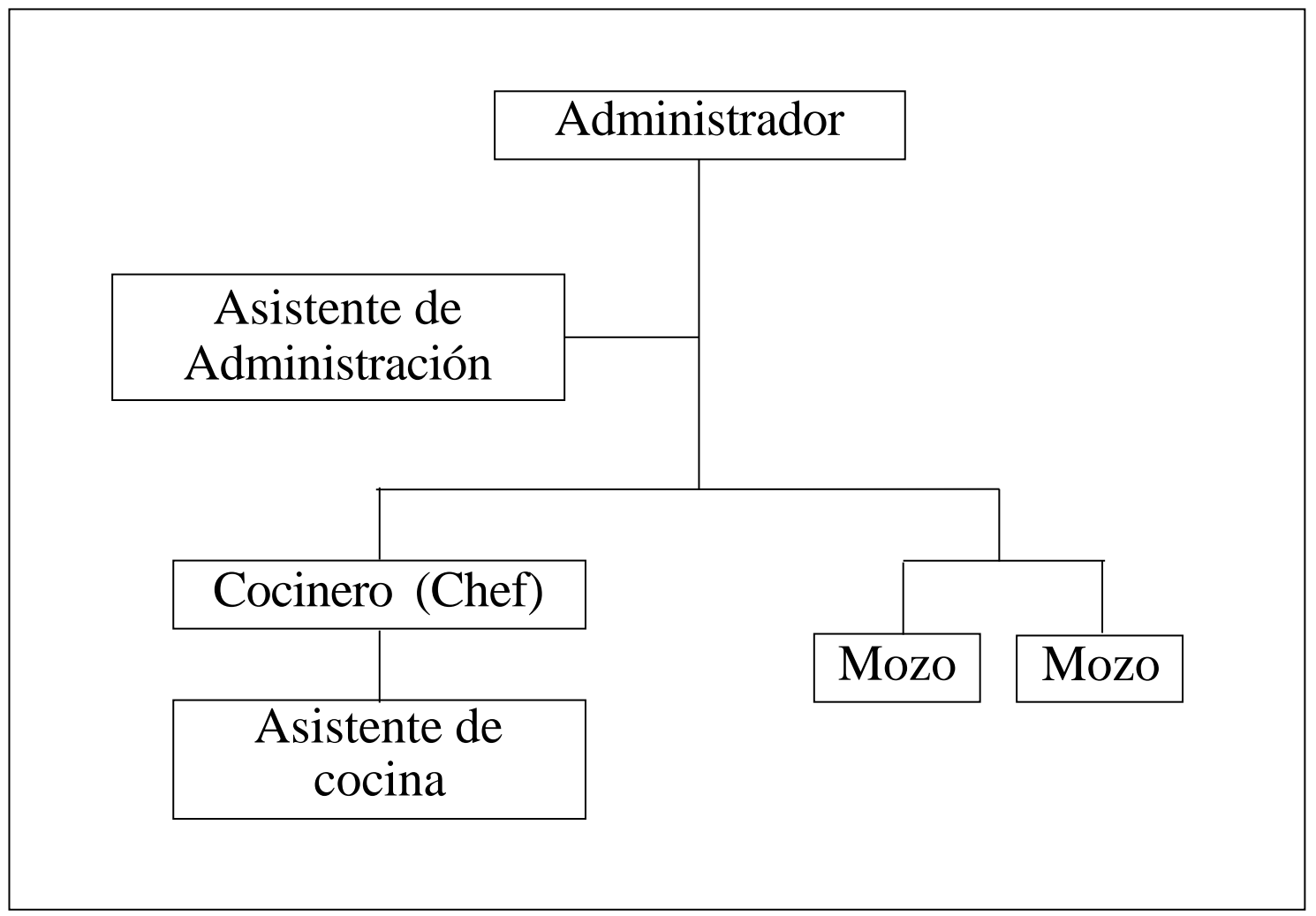

Figura 30. Estructura organizacional funcional.

En el nivel administrativo se basa en puestos de toma de decisiones y puestos de mando, los cuales se hallan descritos en el organigrama como el área de administración y el área de Asistente de Administración.

Está representado por las áreas de cocinero (chef), este a su vez tiene una sub área de asistente de cocina y los mozos que se encuentran en el área de atención directa del cliente.

Estas áreas representan la mano de obra directa que tiene contacto con el producto final.

\subsection{Diseño de los Perfiles de Puestos Clave}

Según define Álvarez (2006), el puesto de trabajo es el espacio establecido para que el trabajador cumpla una determinada función dentro de la cadena o procesos del trabajo, para lo cual se le provee de todos los instrumentos y tareas para el cumplimiento de sus funciones. 


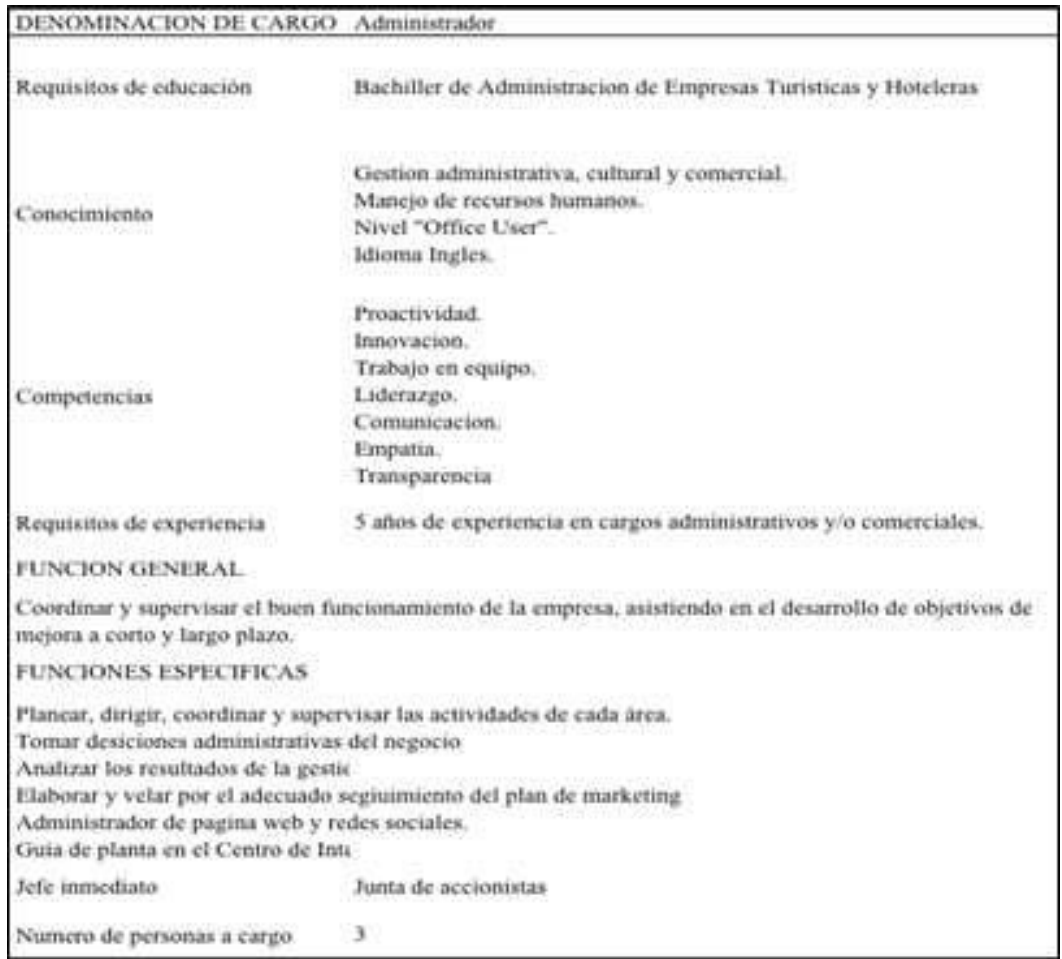

Figura 31. Descripción del puesto de Administrador.

A grandes rasgos se busca un administrativo con amplia experiencia, minino con un título de bachillerato en Administración de empresas hoteleras y turísticas, que tenga dominio intermedio de Ingles, ya que será el puesto clave dentro del proyecto.

En cuanto al asistente de administración, se necesita una persona joven proactiva, honesta, ordenada que tenga facilidad para seguir y cumplir procesos, además de ser el ayudante personal del administrador, estará involucrado en todas las áreas, reportando directamente al administrador las incidencias que se generen en cada una de ellas, e identificando oportunidades de mejora. 


\begin{tabular}{|ll|}
\hline DENOMINACION DE CARGO & Asistente Administrativo \\
\hline Requisitos de educación & Bachiller de Administracion de Empresas \\
& Turisticas y Hoteleras \\
& Estrategias de venta. \\
& Conocimiento de Ingles y Quechua. \\
& Nivel "Office User". \\
Conocimiento & Conocimiento de marketing en redes sociales. \\
& Procesos y logisitica de cocina. \\
& Atencion al cliente. \\
& Proactividad. \\
Competencias & Trabajo bajo presion. \\
& Ordenado. \\
Requisitos de experiencia & Honesto. \\
FUNCION GENERAL & 2 años de experiencia en cargos similares. \\
Brindar asistencia y apoyo de caracter administrativo para el correcto funcionamiento de todas las area \\
FUNCIONES ESPECIFICAS & \\
Realizar las ventas y cobranzas a los comensales. & \\
Control de reservas. & \\
Asitencia administrativa de planes de ventas, promoción y comerciales. \\
Apoyo logistico en cocina, cocinero y en servicio al cliente, mozos. \\
Administracion de redes sociales y apoyo en contenido en paginas web. \\
Jefe inmediato & Administrador \\
Numero de personas a cargo & 2 \\
\hline
\end{tabular}

Figura 32. Descripción del puesto de Asistente Administrativo.

El personal de cocina, cocinero es aquella persona que se encarga de elaborar los alimentos y platos ofrecido en la carta, es otro puesto clave además del Administrador, ya que su área es la central operativa del negocio. Reporta directamente al administrador. 


\begin{tabular}{|ll|}
\hline DENOMINACION DE CARGO & Cocinero \\
\hline Requisitos de educación & $\begin{array}{l}\text { Tecnico en gastronomia. } \\
\text { Bachller en cocina. }\end{array}$ \\
& \\
& Mantenimiento en el área de cocina. \\
Conocimiento & Logisitica e Inventario. \\
& Preparación de alimentos y platillos. \\
& Nutricion y dietetica. \\
& \\
Competencias & Trabajar bajo presión. \\
& Disciplinado. \\
Requisitos de experiencia & Ordenado. \\
FUNCION GENERAL & Determinación. \\
Elaboracion de desayunos, mediante la creacion de opciones alimenticias organicas y nutritivas. \\
FUNCIONES ESPECIFICAS & 3 años de experiencia en cargos similares. \\
Preparacion de desayunos de acuerdo a la carta. & \\
Administración de área de cocina. & \\
Control de alamacén e insumos y la rotación de estos. & \\
Inspeccionar el cumplimiento de higiene y seguridad. & \\
Seguimiento de las politicas diseñadas por administración. \\
Jefe inmediato & Administrador \\
Numero de personas a cargo & 1 \\
\hline
\end{tabular}

Figura 33. Descripción del puesto de Cocinero (Chef). 


\begin{tabular}{|c|c|}
\hline DENOMINACION DE CARGO & Asistente de Cocina \\
\hline Requisitos de educación & $\begin{array}{l}\text { Estudiante en gastronomia. } \\
\text { Tecnico de cocina. }\end{array}$ \\
\hline Conocimiento & $\begin{array}{l}\text { Conocimiento de productos oriundos de la } \\
\text { zona. } \\
\text { Preparación de alimentos y platillos. } \\
\text { Calidad de Servicio. }\end{array}$ \\
\hline Competencias & $\begin{array}{l}\text { Trabajar bajo presiòn. } \\
\text { Proactivo. } \\
\text { Atento. } \\
\text { Metodico. } \\
\text { Flexibilidad. }\end{array}$ \\
\hline Requisitos de experiencia & 1 año de experiencia en cargos similares. \\
\hline \multicolumn{2}{|l|}{ FUNCION GENERAL } \\
\hline \multicolumn{2}{|c|}{ Colaboracion y soporte en la preparacion de desayunos, bebidas $y$ atencion al cliente. } \\
\hline \multicolumn{2}{|l|}{ FUNCIONES ESPECIFICAS } \\
\hline \multicolumn{2}{|c|}{$\begin{array}{l}\text { Preparacion de desayunos de acuerdo a indicaciones del chef y/o cocinero. } \\
\text { Elaboracion de jugos y bebidas incluidas en la carta. } \\
\text { Soporte en la toma de pedidos y atencion al cliente. } \\
\text { Compras inmediatas y de ultimo minuto de insumos. } \\
\text { Seguimiento de las politicas diseñadas por administracion. }\end{array}$} \\
\hline Jefe inmediato & Cocinero y/o Chef \\
\hline
\end{tabular}

Figura 34. Descripción del puesto de Asistente de Cocina.

\begin{tabular}{|ll|}
\hline DENOMINACION DE CARGO & Mozo \\
\hline Requisitos de educación & $\begin{array}{l}\text { Tecnico en cocina. } \\
\text { Bachiller en turismo. } \\
\text { Secundaria completa. }\end{array}$ \\
Conocimiento & Atención al cliente. \\
& Tecnicas de servicio. \\
& Preparación de platos simples. \\
Competencias & Trabajar bajo presión. \\
& Transparente.. \\
Requisitos de experiencia & Proactivo. \\
FUNCION GENERAL. & Empatia. \\
Atención y servicio al comensal, atendiendo su pedido y velando por su satisfacción. \\
FUNCioNES ESPECIFICAS & Flexiblidad \\
Servicio de toma y entrega al comensal. & 1 año de experiencia en cargos similares. \\
Control de higiene y presentacion de comedor del restaurante. \\
Supervisión del bienestar del comensal.
\end{tabular}

Figura 35. Descripción del puesto de los mozos. 


\subsection{Remuneraciones, Compensaciones e Incentivos}

Chiavenato (2009) en sus publicaciones escribe que los trabajadores de una empresa reciben una remuneración salarial en base al tipo de jornada laboral que realizan, y estas pueden rutinarias, un proceso fijo y por lo general son funciones ya establecidas bajo un sueldo fijo En cambio la de remuneración variable pueden medirte son la productividad, desempeño o eficacia.

De esta forma el Administrador, cabeza de área Administrativo y el cocinero, cabeza de área Operativo serán los dos únicos integrantes que laborarán las ocho horas completas diarias, Los demás integrantes como el asistente administrativo y los mozos también recibirán remuneraciones fijas, pero solo laborando cuatro horas diarias, es decir en un rango de 06:00 am hasta las 10:00 am, horario en el cual se tiene mayor flujo de demanda en el distrito de Mollepata. Esta forma remunerativa, tanto como la cantidad de empleados del negocio obedece al régimen especial de impuesto a la renta, el cual el proyecto se quiere acoger.

El régimen especial de impuesto a la renta es un régimen tributario, dirigido a personas jurídicas, sociedades conyugales, sucesiones indivisas y personas naturales, domiciliadas en el país, que obtengan rentas de tercera categoría, proveniente de las actividades de comercio y/o industria y de servicios (SUNAT, 2008)

Los beneficios de pertenecer a este régimen especial son efectuar solamente el pago por impuesto a la renta en SUNAT, y no pagar impuestos de ganancias ocasionales que genere la misma. Además de no estar obligados a pagar el anticipo al impuesto a la renta del año siguiente. 
Las recompensas son utilizadas para reconocer el esfuerzo de un colaborador por el correcto desempeño de sus tareas y funciones. En cambio, los incentivos son las actividades que ayudan a alentar el desarrollo laborar de un trabajador (Hernández, Gallarzo, \& Medina, 2011).

Tabla 63

Planilla de remuneraciones y compensaciones

\begin{tabular}{|c|c|c|c|c|c|c|c|c|}
\hline Sneldne & Cantidad & $\begin{array}{c}\text { Remuneración Bruta } \\
\text { mensual (S/.) }\end{array}$ & Bruta Anual (S/.) & CTS & Gratificaciones & Total Anual S & Costc & aboral \\
\hline Administrador & 1 & 1,200 & 14,400 & & 2,400 & 16,800 & 180 & 16,980 \\
\hline Asistente Administrativo & 1 & 400 & 4,800 & & 800 & 5,600 & 180 & 5,780 \\
\hline Cocinero (Chef) (Part time) & 1 & 850 & 10,200 & & 1,700 & 11,900 & 180 & 12,080 \\
\hline Mozo (Part time) & 1 & 400 & 4,800 & & 800 & 5,600 & 180 & 5,780 \\
\hline Mozo (Part time) & 1 & 400 & 4,800 & & 800 & 5,600 & 180 & 5,780 \\
\hline Total & 5 & 3,250 & 39,000 & & 6,500 & 45,500 & 900 & 46,400 \\
\hline
\end{tabular}

En el caso objetivo del proyecto, las recompensas estarán descritas por los objetivos determinados cada mes y cumplidos de acuerdos a lineamientos implementados por administración. Esta recompensa se adjudicará solo en el nivel operativo.

\subsection{Política de Recursos Humanos}

La finalidad de las políticas de recurso humanos es seleccionar al personal idóneo para satisfacer las necesidades del negocio. Además, de gestionar, crear y planificar capacitaciones y entrenamiento para los nuevos colaboradores una vez seleccionados, de esta forma, se asegura un rápido crecimiento y adaptación del mismo a los procesos de la empresa, adaptabilidad y utilización de las nuevas tecnologías en el menor tiempo posible.

Los libros laborables obligatorios forman parte también de las políticas de recursos humanos. El libro de planillas sirve como un registro de las remuneraciones pagadas, además de otros derechos sociales. 
El proceso para registrar un libro de planillas en un registro de planillas, no debe pasar las 24 horas una vez se haya empezado a laboral y se conservan las mismas, junto con las boletas de pago, con respecto a este último tema, boletas de pago, los trabajadores también deberán recibir una copia del mismo para realizar trámites.

Las obligaciones del empleador de acuerdo a sus derechos y beneficios se detallan a continuación

a) Jornada de trabajo

Como se indicó anteriormente, todos los colaboradores del proyecto, reciben una remuneración fija, de los cuales solo el administrador y el cocinero cumplirán con jornadas laborables completas, y el asistente de administración trabajan media jornada laboral de 4:30 horas.

b) Horario de trabajo

El mayor flujo de demanda en Mollepata se realiza entre abril y noviembre de cada año. En las mañanas desde las 06:00 am hasta las 10:00 am el proyecto estará apto para el público, en consecuencia, el personal de medio tiempo como el asistente de administración y el mozo tendrán el rango de horas previamente mencionadas, como jornada laboral en el proyecto. Administrativo y chef cocinero si estarán bajo la jornada laboral empezando desde las 06:00am y terminando a las 14:00 pm, es decir ocho horas.

\section{c) Refrigerio}

El trabajador tiene entendido que pude utilizar como mínimo una hora, en su centro de trabajo, para poder alimentarse o descansar y que no afecta a su jornada laboral existente. 
d) Descanso semanal

Al estar el proyecto ubicado en el sector turístico, los fines de semana son los días en el que existe una mayor cantidad de viajeros. Por ende, el administrador planificará y controlará los días libres y/o francos de los colaboradores.

e) Vacaciones anuales

Se considerará vacaciones anuales a todos aquellos trabajadores que han pasado el primer año de labor, en este caso las vacaciones son remuneradas, y deben ser no menor a 30 días calendario.

\section{f) Gratificaciones}

Son los reconocimientos de la empresa para con los colaboradores, se otorgan en la quincena de julio y de diciembre.

g) Selección de colaboradores

Esta selección se realiza mediante la descripción de los puestos de trabajo, descritos líneas arriba. Estas entrevistas serán llevadas a cargo del administrador del proyecto. De esta manera, el administrador también se encargará de desarrollar y planificar adecuadas entrevistas de trabajo, en base a los perfiles de puestos y siguiendo los siguientes pasos:

- Oferta de trabajo, que es la primera información el cual es analizado por los participantes.

- Curriculum Vitae, es el dato valioso para la empresa, donde se detalla información personal, experiencia aboral, títulos profesionales y/o técnicos, idiomas, referencias entre otros. 
- Pruebas Psicométricas, que se realizan a los candidatos que van siendo seleccionados, donde se aplican unas pruebas psicológicas y psicométricas a profundidad.

- Entrevista, que es la fase final del proceso de selección, en el que se entabla una entrevista presencial con el empleador, generalmente el entrevistador es un personal idóneo, en este caso, será el Administrador. 


\section{Capítulo VII: Plan de Marketing}

\subsection{Estrategias de Marketing}

Como indica Kotler \& Armstrong (2008), el plan de marketing es el lineamiento y acciones realizadas por la gerencia para alcanzar los objetivos trazados por la empresa. Cabe resaltar que el plan de marketing varias según la naturaleza del negocio, pero la gran mayoría de autores considera que todo plan de Marketing debe contemplar cuatro estrategias conocidas como las 4 Pes, y son: Precio, Plaza, Producto y Promoción.

\subsubsection{Estrategia de Producto.}

En un restaurant se ofrecen productos, pero a su vez también existe un servicio, por lo que Lovelock \& Wirtz (2009) da una mejor definición para entender la estrategia de producto desde la naturaleza de los servicios de un restaurant. señalan do que una concepción de servicio, es la mezcla de un producto básico junto con una serie de servicios complementarios, que suman valor y lo diferencian de la competencia.

De acuerdo a la consulta que se hizo a los expertos el mejor nombre para el negocio es “Casa Mollepata Museo Restaurant”, originalmente se pensó que Museo o Casa Salkantay sería más comercial, pero lo cierto es que el nombre de Casa Mollepata intenta dar valor a lo que el distrito de Mollepata puede ofrecer, al margen del nevado de Salkantay. Para el diseño del logotipo se inspiró en las montañas nevadas de la cordillera del Vilcabamba que son imponentes paisajes. El color azul representa a las cumbres nevadas y el rojo al hombre andino además de que el rojo, según expertos también es un color que provoca hambre en los consumidores. Finalmente, el nombre de Museo Restaurante da a conocer 
los dos objetivos que tendrá la unidad de negocio como restaurante y Centro de Interpretación.

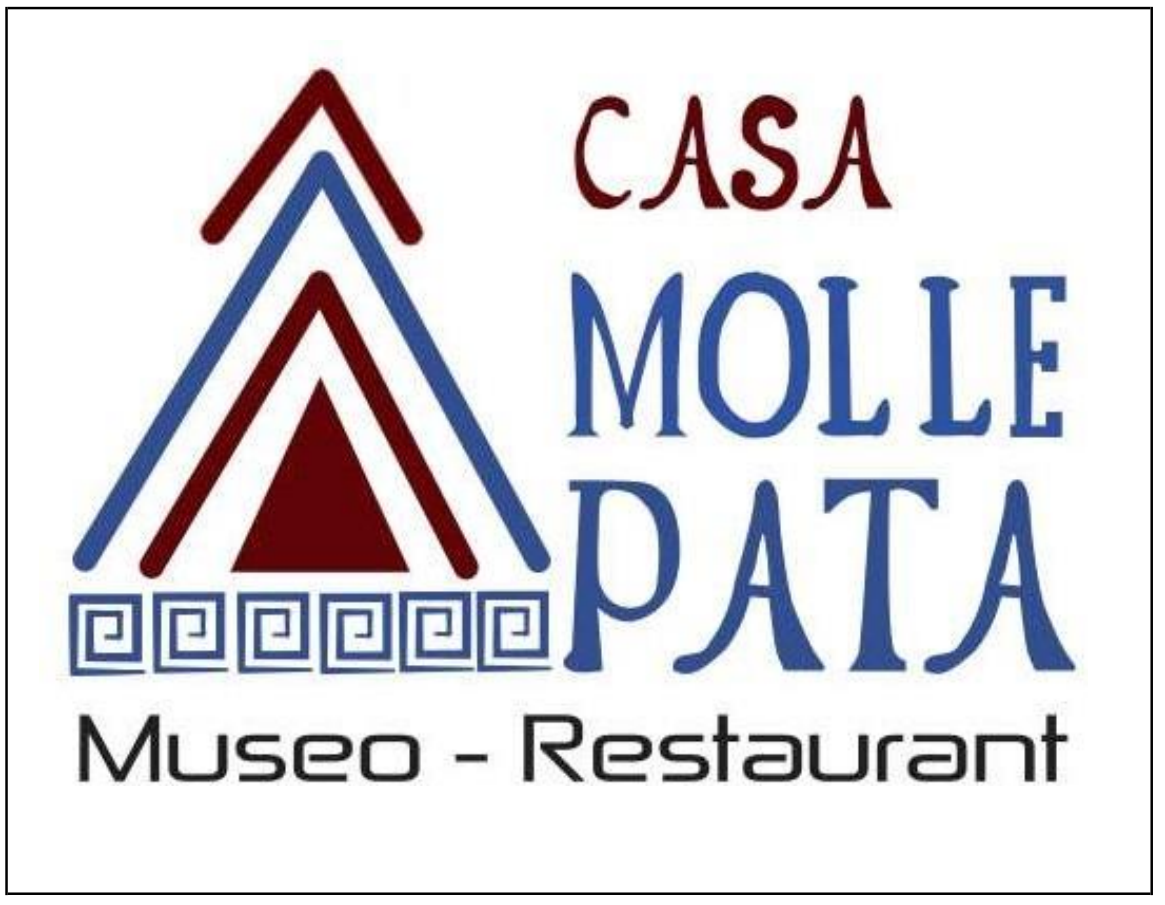

Figura 36. Logotipo de Centro de Servicios Turísticos - Casa Mollepata.

El presente proyecto es un Museo - Restaurant en el centro poblado de Mollepata, que combina sus productos, desayuno light continental andino, desayuno americano andino y desayuno buffet andino con servicios complementarios, como el recorrido por el centro de interpretación del circuito de trekking Mollepata - Salkantay - Machupicchu. De esta manera, estos tres tipos de producto estarán preparados en base a insumos orgánicos y naturales, esta característica representa una propuesta diferente dentro del mercado de restaurantes en el centro poblado. Una segunda característica del producto es el balance nutricional que presenta cada uno los platos descritos, y que aportan un alto valor energético para aquellas personas que están a punto de realizar actividades físicas que demanden un gasto de energía prolongado, más aún el primer día de exigencia física. 
Según Kotler \& Keller se analiza el producto del presente proyecto considerando los cinco niveles del producto.

Tabla 64

Los cinco niveles de producto de Kotler

\begin{tabular}{ll}
\hline Beneficio Básico & Nutrición en el restaurante y cultura en el Centro de Interpretación. \\
\hline Producto Genérico & $\begin{array}{l}\text { Restaurante que consta de sillas, mesas, vajillas, menaje, disponibilidad de las } \\
\text { opciones ofrecidas y baños. }\end{array}$ \\
Producto Esperado & $\begin{array}{l}\text { Infraestructura artesanal, en baños, donde se oferte productos de calidad de buen } \\
\text { sabor, saludables y acompañados de un buen servicio. }\end{array}$ \\
\hline Producto Ampliado & $\begin{array}{l}\text { Atención oportuna y personalizada en el restaurante y. excelente información } \\
\text { sobre la zona y los paisajes de la zona en el Centro de Interpretación. }\end{array}$ \\
\hline Producto Potencial & $\begin{array}{l}\text { Platos elaborados con altos estándares de calidad e higiene, insumos orgánicos y } \\
\text { con un balance nutricional adecuado. }\end{array}$ \\
\hline
\end{tabular}

En cuanto a los servicios complementarios, estos conforman ocho grupos que representan los pétalos de la flor de servicio, los cuales rodean al producto principal o básico. Estos a su vez, se dividen en dos grupos, los servicios de facilitación y los servicios de mejora (Lovelock \& Wirtz, 2009). 
A continuación, se describen los servicios de facilitación:

a) Información

Casa Mollepata, y sus áreas de restaurante y centro de interpretación garantizan la adecuada transmisión de información de horarios de atención al cliente, ubicación, promociones y descuentos, los insumos orgánicos que se utilizan, medios de pagos entre otros.

b) Pago

El proyecto acepta cualquier medio de pago, tarjetas de crédito o de débito, dinero en efectivo. No se aceptarán cheques de gerencia, créditos, cheques de viajeros

c) Toma de pedidos

La toma de pedido sigue estrictamente las políticas de atención al cliente diseñado por administración. Este empieza con el ingreso a la infraestructura de grupos de visitantes liderados por su guía, el mozo los ubica en una mesa a fin para ellos e inicia una pequeña presentación y bienvenida del proyecto, mientras reparte la carta, pasado unos tres minutos se apersona a la mesa para tomar el pedido.

d) Facturación

La facturación electrónica será operada en el restaurante, facilitando los procesos de facturación, claro está, manteniendo el proceso de realización de facturas físicas.

A continuación, se describe los servicios de mejora: 
a) Hospitalidad

El término hospitalidad, se refiere al nivel de confort que el cliente y/o visitante sienta al ingresar a la planta del proyecto, ya sea al restaurante o al centro de interpretación. El personal encargado de desarrollar esta sensación al cliente es el mozo y el asistente administrativo, como cajero, quienes estarán en contacto con él. Se propone capacitaciones y cursos de atención al cliente, cada 6 meses, en los cuales, implique manejo de emociones, cordialidad, paciencia, escucha, entre otros.

\section{b) Excepciones}

Parte importante dentro de los servicios de mejora, ya que son servicios que no se desarrollan frecuentemente en el proyecto, pero que necesitan un manual de procesos, para que, llegado el momento, se afronte de la forma más clara y rápida posible dicha situación, Para el presente proyecto se propone desarrollar estrategias y técnicas para afrontar los reclamos y la solución de problemas, contingencia común en restaurantes, estas estrategias y técnicas deben ser impartidas al administrador, asistente de administración y mozo, cada mes, realizando un debido conteo e inventario de estas situaciones al mes.

\section{c) Cuidado}

Las instalaciones del proyecto, tanto el restaurante como el centro de interpretación, deben brindar seguridad, parte del confort, a los visitantes. La infraestructura deberá contar con tres cámaras de seguridad instaladas en lugares estratégicos del restaurante, centro de interpretación y zona de parqueo. 
d) Consultas

El mozo será el encargado de mantener una permanente comunicación con los comensales en el restaurante, apersonándose a cada mesa cada 10 minutos, para conocer las consultas y opiniones del viajero, sobre el servicio del proyecto. Además de, resolver las inquietudes que tengan los comensales. El administrador, como guía local, realizara la misma función en el centro de interpretación.

\subsubsection{Estrategia de Precio.}

Según Kotler \& Keller (2012), el precio se denomina como el único con capacidad de generar ingresos dentro de mix de marketing, los demás generan costos. También, el precio comunica el posicionamiento del valor del producto al mercado.

Los datos recogidos a través del estudio cuantitativo, en la cual se realiza la pregunta sobre la capacidad de gasto del cliente para este tipo de comidas y/o desayunos y hasta cuanto estarían dispuestos a pagar, el $48 \%$ de entrevistados indican que estarían dispuestos a pagar un monto no menor a los S/ 20.00 y un máximo permitido de S/ 25.00.

Cabe indicar que este negocio es Bussines to Bussines y la pregunta fue formulada a las agencias de viajes, ya que el viajero y/o turista efectuará el pago mediante las agencias de viajes. 


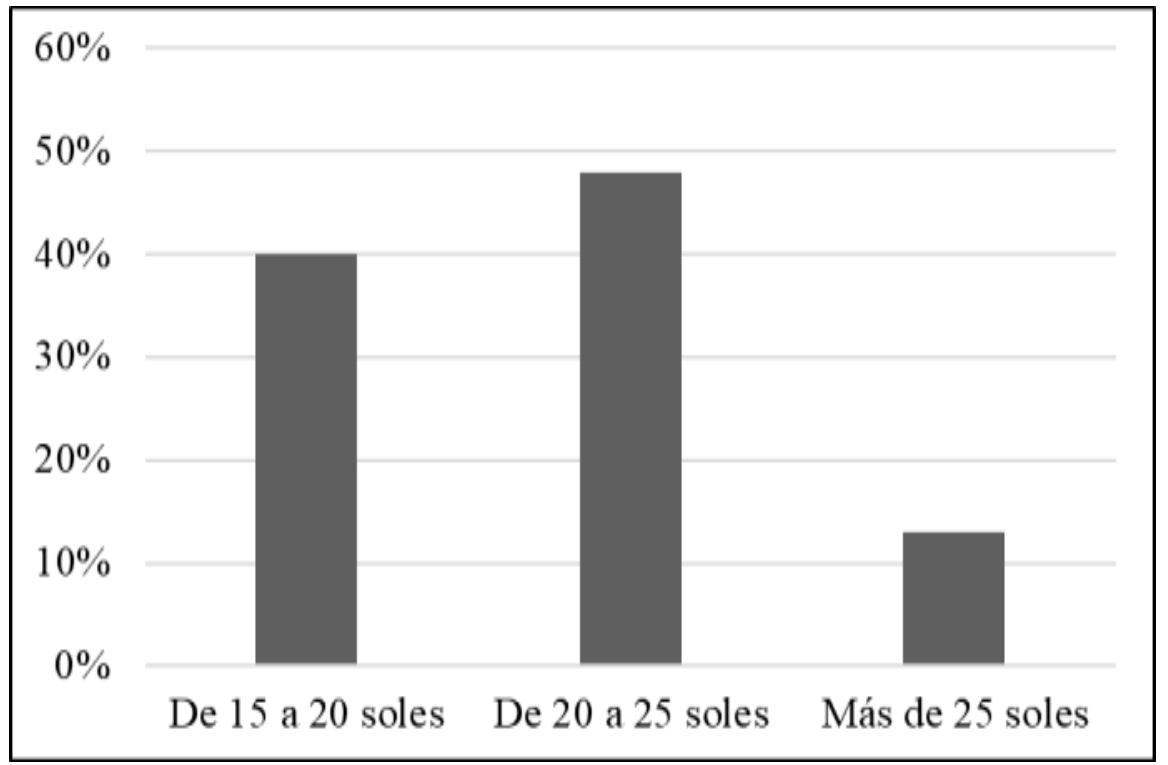

Figura 37. Gasto promedio de viajeros en restaurantes en Mollepata.

En este caso, el $48 \%$ del mercado, agencias de viajes, están dispuestas a pagar un precio por desayuno entre S/ 20.00 a S/ 25.00, fijando un límite mínimo y máximo para determinar un precio fijo, estableciendo de esta manera una estrategia de precio basada en la disposición de pago de dicha demanda.

En este entender, se define el precio de venta de la unidad a producir del proyecto, los desayunos, considerando la suma de costos fijos y variables mensuales más el margen de utilidad que se desea obtener, teniendo en consideración factores, claves como el punto de equilibrio, el promedio de comensales mensuales, la cantidad de desayunos a expender en el mes entre otros. El precio sugerido será de S/ 22.00, este precio cubre un margen de contribución variable con respecto a los precios fluctuantes de los insumos.

Cabe indicar que, el que efectúa el pago es el viajero por medio de las agencias de viajes y ellos están dispuestos a pagar esta cantidad con el fin de obtener un producto de calidad, aun no encontrado en la zona. 


\subsubsection{Estrategia de Distribución.}

Según Kotler \& Keller (2012), la estrategia de distribución permite a la empresa mostrar, vender y entregar un producto al cliente, pudiendo realizarse esta de manera directa o indirecta a través de los distribuidores.

En este caso, al ser un producto que está acompañado de estándares de servicio y que se provee in situ, el canal de distribución es directo, del productor al consumidor final, sin la intervención de intermediarios y en la misma plaza física donde se elabora el producto.

Los atributos del producto, por ser de naturaleza orgánica, necesitan de un lugar de almacenamiento cercano al lugar de cosecha, la ubicación del restaurante en el distrito de Mollepata, cercano a los lugares de cosecha y a la zona donde se ubica su mercado meta, representa una locación ideal para la recepción, almacenamiento de insumos y posterior transformación en el producto final que será expendido en la misma plaza física al consumidor final.

Cabe resaltar que, el almacén del restaurante está ubicado en la segunda planta del área de cocina del restaurante, de fácil acceso para el personal de cocina.

\subsubsection{Estrategia de Promoción y Publicidad.}

Según Kotler \& Keller (2012), las empresas con el transcurrir del tiempo y en respuesta a las fuerzas sociales desarrollaron, se adaptaron y respondieron estrategias para estas nuevas tendencias. Hoy en día la estrategia de publicidad y promoción puede ser manejada a través de plataformas digitales.

Considerando al mercado objetivo, a las agencias de viajes que operan la ruta Mollepata - Salkantay - Machupicchu, la estrategia de promoción y publicidad estará dirigida a ellas mediante el mensaje publicitario del tipo informativo, previa autorización 
del cliente, dando a conocer las opciones de desayunos, el horario de atención, los costos, así como la ventaja competitiva frente a los competidores de la zona, que es la utilización de elementos orgánicos y oriundos de la zona. Luego de este primer contacto, se enviará boletines informativos digitales sobre las mejoras y promociones del proyecto, trimestralmente. Así como también tarjetas de presentación y folletería del plan de negocio. El desarrollo de la página web, como el costo de tarjetas de presentación y folletería incurrirá un gasto de S/ 300.00.

El desarrollo de una página web, será fundamental para la información, gestión y atención al mercado objetivo y a clientes libres, adicionalmente el uso de redes sociales, tales como Facebook y Twitter serán canales de información directos para este tipo de clientes.

Además, aprovechando la afluencia de los comensales del restaurante, al centro de interpretación, se recolectará información, mediante pequeñas encuestas, de dos preguntas, para saber que páginas web de viajes, visitan constantemente y que intereses tienen al desear visitar ese lugar; toda esta data será importante para realizar un trabajo SEO o Webmaster especializado, es decir, la colocación de banner publicitarios en estas páginas, conectores y conexiones de Link Building con palabras claves de fácil recordación, referentes a términos de viajes, que representen un enlace directo hacia a la página web del proyecto. Además del posicionamiento en el principal motor de búsquedas como Google y en motores de búsqueda más especializados como el TripAdvisor.

A fin de entregar un valor agregado al servicio de restaurante, se incluirá una vista con guía totalmente gratis al centro de interpretación que estará ubicado a un costado del restaurante, mientras se preparan los alimentos, los comensales podrán obtener una información más detallada del circuito Mollepata - Salkantay - Machupicchu, con imágenes, banners informativos. 


\subsection{Estrategia de Ventas}

Según Kotler \& Keller (2012), las estrategias de ventas son las acciones que se realizarán para poder distribuir los productos o servicios a los consumidores.

Dado que el mercado objetivo es selecto y no representa un mercado disperso y amplio, la principal estrategia de ventas serán las reuniones con los gerentes generales, administradores y equipo de ventas y reservas de las agencias de viajes especializadas en la ruta Salkantay, mediante presentaciones dinámicas de manera mensual. De igual forma, se recolectará direcciones electrónicas, del Gerente General, del equipo de ventas y reservas para registrar una base de datos exclusiva a la cual se hará llegar trimestralmente nuestros boletines informativos y promociones. Esta acción representará gastos en movilidad y viáticos del Administrador, que representa un costo de S/ 150.00 mensual.

El Centro de Interpretación significa una fuente importante de estrategia de ventas, ya que, al representar un valor agregado al servicio de restaurante, se ofrecerá el mismo como un lugar de briefing e información al pasajero que consuma en el restaurante, teniendo en este un espacio dedicado a la información del lugar a visitar en todos sus aspectos, tanto geográfico, poblacional, natural y cultural.

Con respecto a cuentas internacionales y pasajeros libres, se utilizarán redes sociales como el Facebook, Twitter, Instagram y Tripadvisor, en el cual se irán publicando posts y artículos con contenido relevante a la situación de la ruta Salkantay y a los productos del restaurante, dicha información será actualizada mensualmente y con imágenes propias. Esta labor estará a 
cargo del Administrador y del Asistente de Administración y no representará mayor gasto, dado que esta función forma parte de las funciones de ellos.

\subsubsection{Plan de Ventas.}

En el desarrollo del plan de marketing Kotler \& Keller (2012), señalan que el plan de ventas es el factor más importante puesto que brinda dirección para el producto y es el punto de inicio para este análisis es el cliente.

De acuerdo al pronóstico de ventas estipulado en el capítulo IV y al análisis del punto de equilibrio descrito en el capítulo de evaluación planificación financiera del presente proyecto, se tiene como objetivo de ventas expender S/ 122,342 el primer año de funcionamiento, tomando como base los S/ 22.00 de precio de venta por desayuno, se obtiene una demanda estimada de 5,561 personas el primer año, esta cifra a su vez dividida en 360 días de atención calendario, arroja como resultado 15 desayunos diarios.

Para los años venideros, las ventas se incrementarán, de esta manera para el 2018, las ventas anuales esperan ser de S/ 197,520, para el 2019 una cantidad de S/ 235,070.68, y llegando al 2021 una cantidad de 372,797.24 Soles.

Para lograr estos pronósticos de ventas se realizará las siguientes acciones a tomar.

- Establecer reuniones con gerentes, administradores, equipo de ventas y de reservas de agencias de viajes.

- Concretar alianzas estratégicas con agencias de viajes operadoras de la ruta Salkantay.

- Implementar políticas especiales de trabajo y coordinación con las agencias de viajes de mayor demanda en el circuito Mollepata - Salkantay- Machupicchu. 
- Agendar reuniones trimestrales con las Agencias de viajes para conocer sus impresiones de la labor realizada en el restaurante y centro de interpretación.

- Desarrollar un plan de trabajo y posicionamiento web en el principal motor de búsqueda web.

- Publicación de post y artículos con relación a comida orgánica, turismo de aventura y actividades sociales en el distrito de Mollepata a través redes sociales y plataformas digitales.

- Ventas y realización de reservas a través de redes sociales y plataformas web.

\section{Plan de Brand Equity}

La intervención de esfuerzos, llámense estos procesos y programas de Marketing, cuyo resultado sea el desarrollo y progreso de la marca, es el resultante de su adecuado manejo para su equidad (Aaker, 2002)

Según el desarrollo de equidad de marca de David Aaker, para lograr generar valor en la marca, esta tiene que transmitir cuatro cualidades importantes, la primera refiere sobre la percepción del consumidor sobre la calidad del producto, la segunda es la asociación de la marca con una sensación, impresión en la mente del consumidor, la tercera cualidad representa la lealtad de la marca, en la cual el consumidor difícilmente realiza un cambio en su elección de compra ya que es fiel a la marca y la cuarta cualidad representa la conciencia de marca, la cual desarrolla cuan implantada esta la marca y su significado en la mente del consumidor. 


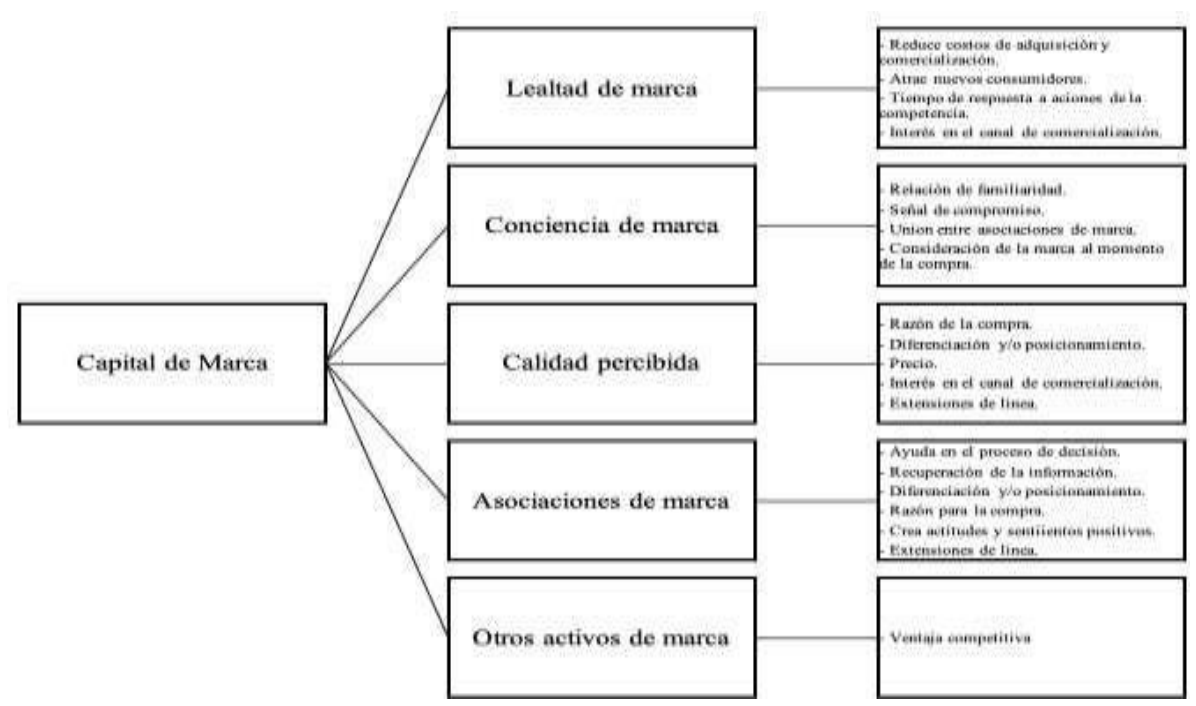

Figura 38, Modelo de construcciones de marcas, Adaptado de: Aaker, D. (2002). Construir marcas poderosas. 2a. ed. Barcelona: Gestión 2000. p. 9

\section{a) Calidad Percibida}

El producto central del proyecto, los tres tipo de desayunos, así como los ingredientes orgánicos que intervienen en su preparación y su adecuado balance nutricional representan una innovación dentro de la oferta en el mercado de restaurantes en Mollepata. Cabe indicar, que este producto, al ser proveído dentro de un mercado donde la oferta de restaurantes es precaria, en cuanto a elaboración de producto y servicio, entrega un valor adicional que se traduce a la calidad de servicio. Esta se halla reflejada en el trato del personal hacia el cliente final y en las visitas gratuitas informativas al centro de interpretación del proyecto, donde el cliente puede comprobar el valor adicional y competitivo de la oferta del proyecto, frente a la competencia actual de la zona.

El precio, al estar determinado mediante un promedio simple realizado en base a un rango de costos que el mercado objetivo, agencias de viajes, estarían dispuestos a pagar; teniendo en cuenta que ellos conocen bien la disposición de sus clientes finales para desembolsar la cantidad adecuada por un 
servicio de desayunos, es altamente atractivo, ya que, esta información es el resultado de la encuesta aplicada al mercado objetivo del proyecto.

Es de esta manera que un precio atractivo, aunado a ventajas competitivas descritas anteriormente y a estrategias de comunicación directa de la marca tanto al mercado objetivo, ya sea mediante reuniones periódicas con las agencias de viajes, presentaciones con sus equipos de ventas y reservas y la utilización del internet, páginas web y redes sociales para llegar al cliente final, construirán en un corto plazo la percepción deseada que el proyecto desea lograr en la mente du su mercado objetivo y del cliente final.

b) Asociación de la marca.

Como se indicó en la parte de estrategia de producto del plan de Marketing, se decidió el nombre de Casa Mollepata para poner relevancia y especial énfasis en el lugar donde se halla el presente proyecto, además de ser de particular recordación para los clientes finales, conocedores de la ruta y del punto de partida del mismo, Mollepata. Cabe indicar que las montañas trazadas en el logo del proyecto son de color azul, ya que se quiere representar los nevados que en él imperan como el Salkantay y el Umantay.

El hombre andino, que se halla cubierto por las montañas, está representado por el color rojo, ya que según estudios de neuro marketing, el rojo provoca hambre en la mente de los consumidores.

Es importante también señalar, que la asociación que la marca quiere lograr a través de su logotipo de montaña en líneas azules y del hombre andino en líneas rojas, es una sensación de protección y seguridad. Protección en base a la adecuada información del lugar, de sus obstáculos y de su geografía única impartidas en el centro de interpretación y que representan, para el cliente final, un aviso previo a los retos que experimentarán en la ruta y su posterior preparación para enfrentarlas. La sensación de seguridad pasa por la certeza de la calidad que se les ofrece a través de productos bien diseñados y servicios bien estructurados y que prometen un adecuado suministro de alimentos que les proporcionarán energía para la actividad física a desarrollar. 
c) Lealtad de marca.

La confianza es un activo que se logra a través del tiempo en base al mantenimiento de los estándares de calidad tanto del producto en sí como de los servicios adyacentes. Es de esta manera que el proyecto busca fidelizar a su mercado objetivo, entregando una precepción de preocupación y de mejora continua para con el cliente final y el mercado objetivo. De esta forma, la entrega de una pequeña encuesta finalizado la utilización de los servicios, subsanando falencias indicadas en las mismas, llevando un adecuado control de base de datos de los consumidores, entregando tarjetas de felicitación electrónica y pequeños descuentos ofrecidos hacia ellos, conllevará en un corto plazo, establecer cimientos para la creación de una lealtad de marca fuerte.

Es también necesario indicar que la integridad, es un comportamiento que llevará a generar mayor lealtad de marca en el consumidor, la promesa cumplida es algo que valora en especial el cliente final, una excelente nutrición e información para afrontar de mejor forma el reto que acaece el trekking Mollepata - Salkantay - Machupicchu es la promesa que el proyecto oferta a su cliente final y mercado objetivo, teniendo todas las capacidad para poder cumplirlo.

d) Conciencia de marca.

Según Aaker (2002), la conciencia de marca es la última, pero no menos importante, cualidad exigida para lograr un adecuado nivel de equidad. Esta se trabaja a largo plazo y suele ir edificada en base a los resultados de las 3 anteriores cualidades.

Tener a Casa Mollepata museo restaurant, implantada en la mente de nuestros consumidores finales y además estar ya establecida en las preferencias habituales del mercado objetivo, se logra en base a resaltar las ventajas competitivas del proyecto, que según matriz VRIO, son el adecuado balance nutricional, la calidad de servicio que rodea al producto, el museo de interpretación y la estratégica ubicación del proyecto, 
Una relación de familiaridad es también otra característica importante para lograr la conciencia de la marca, en el caso del presente proyecto, el uso de la página web y las redes sociales, mediante posts que guarden relación con la nutrición y las actividades al aire libre, pueden ser publicados dos veces por semana, de esta forma, se obtiene una recordación mayor, frente a nuestra competencia.

e) Otros Activos de Marca

Las ventajas competitivas, de acuerdo a la matriz VRIO, son el ambiente rustico, acogedor, cómodo que combinado a su excelente ubicación en el poblado de Mollepata, hacen que el expendio del servicio sea proveído en un lugar excepcional dentro de la zona.

\section{Plan de responsabilidad social empresarial}

\section{Antecedentes}

Los restaurants, como lugares de relación social, favorecen la interacción de distintos grupos de personas, algo que hemos podido ver últimamente más a menudo, sobre todo gracias a las redes sociales. Y aunque en los países de cultura mediterránea existe la tradición de fomentar la interacción entre los individuos, es en los Estados Unidos donde han aparecido los casos más novedosos.

En esta parte del proyecto plantearemos algunas acciones que se deberán implementar con la intención de que Casa Mollepata Museo Restaurant sea una empresa socialmente responsable y de esta manera pueda contribuir al crecimiento y desarrollo sostenible del todo el poblado. Para tal propósito se planteará implementar las siguientes acciones:

- Enseña idiomas a los empleados

Los restaurantes probablemente sean uno de los oficios donde podemos encontrar una población más diversa, fruto principalmente de la afluencia de turistas de todo el mundo principalmente que hablan inglés, con tal motivo, hay muchos empresarios 
que deciden enseñar el inglés u otros idiomas a sus empleados como forma práctica de integración, esto ayudará a los trabajadores a tener una mejor interacción con los visitantes además de ayudarlos en su crecimiento profesional

\section{- Promover la venta de productos de la zona}

Hay acciones que algunos restaurantes organizan para contribuir a la integración de colectivos en riesgo de exclusión social. La organización de mercados o mercadillos para comercializar determinados productos es una forma de ayudar a quien más lo necesita y además favorecen el intercambio de experiencias, lo que convierte a esta iniciativa en una alternativa muy aconsejable. Además, potencia de una forma muy positiva la imagen de marca del proyecto.

Debemos tener en cuenta que los días sábados se implementa un mercadillo en la plaza de Mollepata, este mercadillo podría ser potencializado e impulsar para que más productores se unan y puedan ofrecer sus productos.

\section{- Ofrece tus instalaciones como centro para reuniones}

En los últimos años, hay restaurantes que ofrecen su espacio para que determinadas asociaciones o agrupaciones de la comunidad hagan sus reuniones. No se cobra por ello, puesto que el objetivo simplemente es contribuir a mejorar la relación con el entorno.

Hay casos muy coherentes, como las asociaciones de los pobladores en defensa de los intereses de la comunidad que muchas veces no tienen donde reunirse o simplemente apoyar con prestar el local en horarios que no se dé servicio para que los distintos grupos del poblado puedan reunirse, sin que esto afecte la producción del negocio. 
- Colaborar con entidades benéficas

En algunos casos, los restaurantes cuentan con un excedente de comida que, si no se cede a entidades benéficas, se va a malgastar. Afortunadamente, la práctica de ceder aquellos alimentos que ya no se van a comercializar pero que están en perfectas condiciones para el consumo es cada vez más habitual.

En Estados Unidos, es común recurrir al Ejército de Salvación, siendo famosa la colaboración de empresas como McDonald’s. En España, los Bancos de Alimentos o Cáritas suelen ser las entidades que gestionan estos procesos.

- Ayuda desinteresada ante catástrofes

Toda la zona de Mollepata no está libre de fuerte lluvias que puedan producir derrumbes o deslizamientos los cuales puedan producir que hay damnificados, a los cuales se les puede ayudar de distintas maneras como brindándoles apoyo en recolección de alimentos vestimenta etc.

Por otro lado, también se debe tener en cuenta que por los derrumbes muchas veces el poblado se ha quedado incomunicado al estar bloqueado el acceso principal, para lo cual el restaurant podría estar preparado para ayudar en la organización necesaria para que la población solucione este imprevisto lo antes posible.

\subsubsection{Políticas de Servicios y Garantías.}

Kotler \& Keller (2012), señalan que las políticas de garantías y servicios permiten reducir el riesgo que percibe un comprador lo que resulta ser un beneficio muy útil para una empresa que no es reconocida en el mercado o cuando la calidad del producto del competidor es superior.

A continuación, se detallan las políticas y garantías del presente plan de negocios: 
- El proceso de reservas se realiza como mínimo un mes de anticipación de la llegada del grupo o pasajeros al restaurante.

- El medio de comunicación para reservas en este periodo, será mediante correo electrónico.

- Acuerdos y por menores de último minuto, sobre reservas hechas, se realizarán vía telefónica.

- El tiempo de respuesta a comentarios e redes sociales y pagina web será de un día, como máximo, en caso de fines de semana, el primer día hábil de la siguiente semana.

- El tiempo de espera de pedido es de 10 a 15 minutos.

- Las imágenes en la carta del menú son referenciales.

- Se aceptan pagos solamente en efectivo y mediante tarjeta de crédito Visa y MasterCard.

- Cualquier reclamo será atendido por el Asistente Administrativo. 


\section{Capítulo VIII: Planificación Financiera}

\subsection{La Inversión}

\subsubsection{Inversión Pre-Operativa}

Para la implementación del proyecto se determinó pre inversiones tanto en activos intangibles como tangibles. Ciertos precios han sido considerados en dólares, y para poder convertirlos a soles se usó el tipo de cambio oficial de la Superintendencia de Banca Seguros y AFP emitida el día 21 de febrero del 2017 que es de 3.247.

a) Activos Tangibles

Según Sapag (2011) se consideran activos tangibles todos aquellos bienes físicos que le pertenecen a la empresa, los cuales son requeridos para su funcionamiento.

Como se aprecia en la siguiente tabla, se consideran todos los activos tangibles mencionados en el capítulo cinco, y adicionalmente se considera el terreno del presente proyecto que tiene un valor de S/ 64,500, lo cual hace un monto total de S/ 99,634 que se utilizará para el equipamiento. 


\section{Tabla 65}

\section{Activos Tangibles}

\begin{tabular}{|c|c|c|c|c|c|}
\hline Ítem & $\begin{array}{l}\text { Cantidad } \\
\text { unidades }\end{array}$ & $\begin{array}{c}\text { Costo unitario } \\
(\mathrm{S} /)\end{array}$ & $\begin{array}{l}\text { Costo total } \\
(\mathrm{S} /)\end{array}$ & $\begin{array}{l}\text { Costo total } \\
\text { sin IGV }\end{array}$ & $\begin{array}{l}\text { Costo total } \\
\text { con IGV }\end{array}$ \\
\hline Equipo para oficina administrativa & & & 3785 & 3208 & 3785 \\
\hline Escritorio & 1 & 250 & 250 & 212 & 250 \\
\hline Teléfono & 1 & 65 & 65 & 55 & 65 \\
\hline Laptop & 1 & 1500 & 1500 & 1271 & 1500 \\
\hline Smartphone & 1 & 500 & 500 & 424 & 500 \\
\hline Silla giratoria & 1 & 90 & 90 & 76 & 90 \\
\hline Silla de escritorio & 2 & 50 & 100 & 85 & 100 \\
\hline Impresora fotocopiadora & 1 & 590 & 590 & 500 & 590 \\
\hline Uniforme para el personal & 4 & 100 & 400 & 339 & 400 \\
\hline Estante & 1 & 140 & 140 & 119 & 140 \\
\hline Archivador & 1 & 150 & 150 & 127 & 150 \\
\hline Equipo para Cocina & & & 5464 & 4631 & 5464 \\
\hline Cocina de 4 hornillas & 1 & 1200 & 1200 & 1017 & 1200 \\
\hline Mesa de madera para preparado & 1 & 150 & 150 & 127 & 150 \\
\hline Refrigeradora & 1 & 1000 & 1000 & 847 & 1000 \\
\hline Tabla de picar & 2 & 45 & 90 & 76 & 90 \\
\hline Olla & 1 & 300 & 300 & 254 & 300 \\
\hline Sartèn & 2 & 84 & 168 & 142 & 168 \\
\hline Calentadora & 2 & 70 & 140 & 119 & 140 \\
\hline Termo & 2 & 150 & 300 & 254 & 300 \\
\hline Licuadora semi industrial & 2 & 148 & 296 & 251 & 296 \\
\hline Tostadora & 2 & 150 & 300 & 254 & 300 \\
\hline Juego de utensilios & 2 & 350 & 700 & 593 & 700 \\
\hline Tachos de basura & 2 & 60 & 120 & 102 & 120 \\
\hline Extintor & 1 & 70 & 70 & 59 & 70 \\
\hline Cuchillos & 1 & 60 & 60 & 51 & 60 \\
\hline Estantes de madera & 2 & 90 & 180 & 153 & 180 \\
\hline Horno microondas & 1 & 390 & 390 & 331 & 390 \\
\hline Almacén & & & 1690 & 1432 & 1690 \\
\hline Congeladora & 1 & 1300 & 1300 & 1102 & 1300 \\
\hline Estante para alimentos & 1 & 130 & 130 & 110 & 130 \\
\hline Estante para menajeria y mantelería & 2 & 130 & 260 & 220 & 260 \\
\hline Implementación salón principal & & & 8115 & 6877 & 8115 \\
\hline Mesas & 10 & 150 & 1500 & 1271 & 1500 \\
\hline Banca & 20 & 40 & 800 & 678 & 800 \\
\hline Juegos de vajilla & 45 & 31 & 1395 & 1182 & 1395 \\
\hline Servilletero & 13 & 11 & 143 & 121 & 143 \\
\hline Azucarero & 13 & 15 & 195 & 165 & 195 \\
\hline juego de saleros & 13 & 15 & 195 & 165 & 195 \\
\hline Equipo de música & 3 & 260 & 780 & 661 & 780 \\
\hline Termo & 3 & 120 & 360 & 305 & 360 \\
\hline adorno de mesa & 13 & 11 & 143 & 121 & 143 \\
\hline Jarras de $2 \mathrm{~L}$ & 5 & 20 & 100 & 85 & 100 \\
\hline Mermelero mantequillero & 13 & 8 & 104 & 88 & 104 \\
\hline Vasos & 45 & 2 & 90 & 76 & 90 \\
\hline Individuales & 45 & 3 & 135 & 114 & 135 \\
\hline Barra para caja & 1 & 300 & 300 & 254 & 300 \\
\hline $\begin{array}{l}\text { Implementos de Seguridad } \\
\text { (Extintor,señaletica,botiquin,etc.) }\end{array}$ & 1 & 250 & 250 & 212 & 250 \\
\hline Decoración & 1 & 500 & 500 & 424 & 500 \\
\hline Juegos de cubiertos & 45 & 25 & 1125 & 953 & 1125 \\
\hline Implementación centro de interpretación & & & 6080 & 644 & 6080 \\
\hline Iluminación & 8 & 60 & 480 & 51 & 480 \\
\hline Cartel interactivo & 8 & 200 & 1600 & 169 & 1600 \\
\hline Vitrinas & 8 & 500 & 4000 & 424 & 4000 \\
\hline Total Inversión Pre-operativa & & 0 & 25134 & & 35434 \\
\hline Total activos tangibles & & & & & 35434 \\
\hline
\end{tabular}


b) Activos Intangibles

Estos activos están conformados por todos los bienes no materiales y derechos de propiedad de la empresa considerados para el funcionamiento (Sapag, 2011).

Se considerará para el proyecto S/ 10,000 en activos intangibles.

Tabla 66

Activos Intangibles

\begin{tabular}{lc}
\multicolumn{1}{c}{ Ítem } & $\begin{array}{c}\text { Costo total } \\
\text { sin IGV }\end{array}$ \\
\hline Constitución de la empresa & 4000 \\
Licencias de edificación & 1000 \\
Registro de marca & 500 \\
Licencia definitiva & 300 \\
Certificado de sanidad & 500 \\
Certificado de defensa civil & 500 \\
Desarrollo de pagina web & 1500 \\
Gastos de capacitacion y asesoramiento & \\
nutricional (insumos, materiales y servicios) & 800 \\
Campaña de marketing y publicidad inicial & 1000 \\
Legalización de libros contables y autorización de & \\
emisión de comprobantes de pago & 200 \\
\hline
\end{tabular}

\subsubsection{Inversión en Capital de Trabajo}

Esta herramienta de análisis, permite determinar el éxito o fracaso de la empresa, existen tres métodos para determinar el capital de trabajo y son el método contable, período de desfase y el método de déficit acumulado máximo, éste último es el más preciso para determinar la inversión (Sapag, 2011). 
Como se aprecia en la siguiente tabla, el capital de trabajo del presente proyecto se calculó mediante el método de déficit acumulado máximo con un total de S/ 7,215.

Las ventas mensuales se calcularon a partir de los resultados obtenidos de la proyección del capítulo cuatro, en el que se determinó un mercado objetivo inicial de 5,582 personas que se atenderán en el primer año y el precio promedio es de S/ 22.00; es así que a partir de esa información se consideran los ingresos mensuales para el capital de trabajo, teniendo en cuenta la estacionalidad del sector turístico de la zona.

En base al resultado obtenido del capital de trabajo, por el método de máximo déficit acumulado se tiene la variación anual que se muestra en la siguiente tabla. El detalle de la determinación del capital de trabajo se encuentra desarrollado en el capítulo nueve

\section{Tabla 67}

Variación anual del capital de trabajo

\begin{tabular}{lcccccc}
\hline & 0 & 1 & 2 & 3 & 4 & 5 \\
\hline Capital de trabajo & 7.164 & & & & & \\
Variación de capital trabajo & & 4408 & 2057 & 5293 & 2908 & 21830 \\
Total & 7.164 & 11.572 & 13.629 & 18.922 & 21.830 & 21.830 \\
\hline
\end{tabular}

Tabla 68

\begin{tabular}{lcccccccccccc}
\hline \multicolumn{1}{c}{ Meses } & Ene & Feb & Mar & Abr & May & Jun & Jul & Ago & Sep & Oct & Nov & Dic \\
\hline Ingresos & 2.424 & 1.032 & 4.642 & 7.303 & 15.915 & 14.264 & 13.368 & 13.053 & 16.865 & 14.992 & 9.839 & 5.305 \\
& & & & & & & & & & & & \\
Costo de ventas & 1.006 & 428 & 1.927 & 3.031 & 6.606 & 5.921 & 5.549 & 5.418 & 7.001 & 6.223 & 4.084 & 2.202 \\
G Administrativos & 2.072 & 2.072 & 2.072 & 2.072 & 2.072 & 2.072 & 2.072 & 2.072 & 2.072 & 2.072 & 2.072 & 2.072 \\
G. Ventas & 1.895 & 1.895 & 1.895 & 1.895 & 1.895 & 1.895 & 1.895 & 1.895 & 1.895 & 1.895 & 1.895 & 1.895 \\
& & & & & & & & & & & & \\
Saldos & -2.549 & -3.363 & -1.251 & 305 & 5.342 & 4.376 & 3.852 & 3.668 & 5.897 & 4.802 & 1.788 & -864 \\
Saldo acumulado & -2.549 & -5.913 & -7.164 & -6.859 & -1.518 & 2.859 & 6.711 & 10.379 & 16.276 & 21.078 & 22.866 & 22.002 \\
\hline
\end{tabular}

\section{Capital de Trabajo}




\subsubsection{Costo del Proyecto}

El costo del proyecto asciende a un total de S/ 103,648, como se puede observar en la siguiente tabla, en la que se incluye la inversión pre-operativa y la inversión en capital de trabajo.

Tabla 69

Costo del proyecto

\begin{tabular}{lc}
\hline \multicolumn{1}{c}{ Detalle } & Total (S/.) \\
\hline Activo tangible & 89.634 \\
Activo intangible & 10.300 \\
Inversion en Capital de trabajo & 7.164 \\
Total & 107.098 \\
\hline
\end{tabular}

\subsubsection{Inversiones Futuras}

En este análisis, serán necesario considerar a toso aquellos bienes y activos sujetos a depreciación, para ello se revisó información de SUNAT (2017), que indica vida útil de los mismos.

\section{Tabla 70}

Inversiones Futuras

\begin{tabular}{lcccrrrrr}
\hline Activos Fijos & Costo & $\begin{array}{c}\text { Vida } \\
\text { útil }\end{array}$ & $\begin{array}{c}\% \text { de } \\
\text { depreciacion }\end{array}$ & & & & & \\
& & & & \multicolumn{1}{c}{ Año 1 } & \multicolumn{1}{c}{ Año 2 } & \multicolumn{1}{c}{ Año 3 } & \multicolumn{1}{c}{ Año 4 } & Año 5 \\
\hline Maquinarias y equipos & 5.471 & 5 & $10 \%$ & 4.974 & 4.521 & 4.110 & 3.737 & 3.397 \\
Muebles y enseres & 17.073 & 5 & $10 \%$ & 15.521 & 14.110 & 12.827 & 11.661 & 10.601 \\
$\begin{array}{l}\text { Equipos de procesamiento de datos } \\
\text { Terreno y acondicionamiento del proyecto en }\end{array}$ & 2.590 & 5 & $25 \%$ & 2.072 & 1.884 & 1.712 & 1.557 & 1.415 \\
Mollepata & & & & & & & & \\
Total & 64.500 & 30 & $3 \%$ & 62.621 & 56.929 & 51.753 & 47.048 & 42.771 \\
& 89.634 & & & 85.188 & 77.444 & 70.403 & 64.003 & 58.184 \\
\hline
\end{tabular}




\subsection{Financiamiento}

\subsubsection{Endeudamiento y Condiciones}

El proyecto será financiado por capital propio de los accionistas, el cual tendrá la siguiente estructura.

Tabla 71

Financiamiento del proyecto

\begin{tabular}{lcc}
\hline Estructura de Financiamiento & Monto (S/.) & Porcentaje \\
\hline Aporte de los Accionistas & & \\
Terreno y acondicionamiento del proyecto en Mollepata & 64.500 & $60 \%$ \\
Dinerario (para capital trabajo) & 7.164 & $7 \%$ \\
Compra mobiliario & 35.434 & $33 \%$ \\
Total & 107.098 & $100 \%$ \\
\hline
\end{tabular}

\subsubsection{Capital y Costo de Oportunidad}

Es necesario determinar el costo de oportunidad que permitirá conocer las oportunidades que se tiene que sacrificar para disponer los recursos a otra alternativa mejor (Sapag, 2011).

Para el análisis del costo de oportunidad de los inversionistas se utilizó la siguiente información: 
Tabla 72

Datos para la tasa de descuento del accionista

\begin{tabular}{lccc}
\hline Aritmética Averigüe & Stocks & \multicolumn{2}{c}{ tocks - T.B tocks - T.Bonds } \\
\hline $1928-2016$ & $11,42 \%$ & $3,46 \%$ & $5,18 \%$ \\
$1967-2016$ & $11,45 \%$ & $4,88 \%$ & $7,08 \%$ \\
$2007-2016$ & $8,65 \%$ & $0,74 \%$ & $5,03 \%$ \\
\hline
\end{tabular}

Nota. Adaptado de Damodaran Online (2017)

Con esta información se trabajará en adelante, así como con la beta de 0.77 del sector.

Tabla 73

Beta del sector

\begin{tabular}{lccccr}
\hline Sector & $\begin{array}{c}\text { Nro. de } \\
\text { firmas }\end{array}$ & Beta & D/E Ratio & Tax rate & Unlevered Beta \\
\hline Restaurant/Dining & 86 & 0,77 & $35,01 \%$ & $16,47 \%$ & 0,59 \\
\hline Nota. Adaptado de demoraran Online (2017) & & & & &
\end{tabular}

Remplazando en la siguiente fórmula:

$$
K_{\text {ecorrEEUU }}=R_{f}+\beta\left[R_{m}-R_{f}\right]
$$

KecorrEEUU $=4.37+0.77(7.08)$

KecorrEEUU $=0.0982=9.82$

$K_{\text {ereal }} E E U U=\left[\left(1+K_{\text {ecorrEEUU }}\right) /\left(1+\inf _{\text {EEUU }}=\right)\right]-1$

$$
\begin{aligned}
& \text { KerealEEUU }=((1+0.0982) /(1+0.02801))-1 \\
& \text { KerealEEUU }=(1.0982 / 1.02801)-1 \\
& \text { KerealEEUU }=0.0683=6.83
\end{aligned}
$$




\section{$K_{\text {erealPeru }}=K_{\text {erealEEUU }}+$ RiesgoPais}

KerealPerú $=6.83+1.66$

KerealPerú $=8.49 \%$

KerealPerú $=18.49 \%$ (agregando $10 \%$ por tratarse de una propuesta)

\section{$K_{\text {ecorrPerú }}=\left(1+K_{\text {erealPeru }}\right)(1+\inf$ Peru $)-1$}

KecorrPerú $=(1+0.0849)(1+0.093)-1($ sin agregar $10 \%)$

KecorrPerú $=18.58 \%$ (agregando el 10\%)

KecorrPerú $=28.98 \%$

Una vez sustituidos los valores se tiene un costo de oportunidad del accionista (Ke) de $28.98 \%$.

8.2.3. Costo de Capital Promedio Ponderado

Dado que no existe financiamiento externo, el valor de esta tasa será igual al Ke de $28.98 \%$. 


\subsection{Presupuestos Base}

\subsubsection{Presupuesto de Ventas}

Este presupuesto es el punto de inicio para la planificación, ya que de este se partirá para todos los demás. En base a la información que se obtuvo de la demanda proyectada, el ingreso total de S/ 118,998 para el primer año, el cual tiene una tendencia de crecimiento como se puede ver en el cuadro siguiente.

Es necesario precisar que las cancelaciones se pueden dar por motivos netamente ajenos al negocio, en estos casos estas reservas ya estarán pagadas, por tanto, debido a que son de último momento, no son rembolsables.

Tabla 74

Presupuesto de Ventas

\begin{tabular}{lccccc}
\hline Detalle & Año 1 & Año 2 & Año 3 & Año 4 & Año 5 \\
\hline Clientes al año & 5.582 & 9.016 & 10.618 & 14.742 & 17.008 \\
$\begin{array}{l}\text { Precio } \\
\text { Ingresos por ventas (96\% pedidos }\end{array}$ & 22 & 22 & 22 & 22 & 22 \\
$\begin{array}{l}\text { Son entregados) } \\
\text { Ingresos por cancelaciones (4\% }\end{array}$ & 117.882 & 190.414 & 224.254 & 311.354 & 359.205 \\
pedidos son cancelados) & 1.116 & 1.803 & 2.124 & 2.948 & 3.402 \\
Ingresos totales & 118.998 & 192.217 & 226.378 & 314.302 & 362.606 \\
\hline
\end{tabular}

\subsubsection{Presupuesto de Costos de Producción}

Para este punto se consideran todos aquellos costos que entren en la producción del producto para poder satisfacer a demanda de los turistas y que se obtiene del presupuesto de ventas. Teniendo en cuenta la mano de obra directa, la materia prima y los gastos indirectos de fabricación, para el proyecto se considerará un presupuesto de S/ 51,316. 
Tabla 75

Presupuesto de Costos de Producción

\begin{tabular}{lccccc}
\hline Detalle & Año 1 & Año 2 & Año 3 & Año 4 & Año 5 \\
\hline $\begin{array}{l}\text { Materia Prima (Insumos) } \\
\text { Mano de Obra directa: }\end{array}$ & 28.094 & 45.380 & 53.444 & 74.202 & 85.606 \\
$\quad$ - Cocinero (Chef) (Part time) & 12.080 & 12.080 & 12.080 & 12.080 & 12.080 \\
CIF & & & & & \\
- Depreciación & 3.223 & 3.223 & 3.223 & 3.223 & 3.223 \\
- Servicios (Agua , Luz) & 4.800 & 4.800 & 4.800 & 4.800 & 4.800 \\
- Gas & 3.120 & 3.120 & 3.120 & 3.120 & 3.120 \\
- Material para limpieza & 6.000 & 6.000 & 6.000 & 6.000 & 6.000 \\
& & & & & \\
Costo de producción & 51.316 & 68.602 & 76.667 & 97.425 & 108.829 \\
\hline
\end{tabular}

8.3.3. Presupuesto de Compras

Para el presupuesto de compras se tomará en cuenta los costos de producción, de igual manera se indica cando de materia prima se necesita, cabe indicar que las compras tienen que ser al contado ya que los productos son perecibles.

Se determinó un presupuesto promedio de insumos en un desayuno, que es de S/ 5.03; de esta manera, para el primer año se tiene un presupuesto de compras de S/ 28,094.

Tabla 76

Promedio de Costo de Insumos

\begin{tabular}{lc}
\hline \multicolumn{1}{c}{ Desayuno } & $\begin{array}{c}\text { Costo insumos } \\
\text { para un desayuno }\end{array}$ \\
\hline Desayuno Ligth continental andino & 2,9 \\
Desayuno americano andino & 5,3 \\
Desayuno buffette andino & 6,9 \\
Promedio insumos por plato & 5,03 \\
\hline
\end{tabular}


Tabla 77

Presupuesto de Compras

\begin{tabular}{lccccc}
\hline Detalle & Año 1 & Año 2 & Año 3 & Año 4 & Año 5 \\
\hline Clientes al año & 5.582 & 9.016 & 10.618 & 14.742 & 17.008 \\
Insumos & 28.094 & 45.380 & 53.444 & 74.202 & 85.606 \\
Total & 28.094 & 45.380 & 53.444 & 74.202 & 85.606 \\
\hline
\end{tabular}

8.3.4. Presupuesto de Costo de Ventas

En base al presupuesto de compra de materiales directos, los gastos indirectos y mano de obra directa; se elabora este presupuesto. Tanto el inventario inicial como el inventario final estimado son combinados con esta data con la finalidad de determinar el costo de las ventas. Los costos de ventas para el primer año ascienden a S/ 50,144.

Tabla 78

Presupuesto de Costo de Ventas

\begin{tabular}{lccccc}
\hline Detalle & Año 1 & Año 2 & Año 3 & Año 4 & Año 5 \\
\hline Costo de producción & 51.316 & 68.602 & 76.667 & 97.425 & 108.829 \\
Inv Inicial de Productos Terminados & 0 & 0 & 0 & 0 & 0 \\
Inv Final de Productos Terminados & 1.124 & 1.815 & 2.138 & 2.968 & 3.424 \\
$\quad$ - Pedidos cancelados & 1.124 & 1.815 & 2.138 & 2.968 & 3.424 \\
Costo de ventas & 50.193 & 66.787 & 74.529 & 94.457 & 105.404 \\
\hline
\end{tabular}

\subsubsection{Presupuesto de Gastos Administrativos}

Los gastos admirativos son todos aquellos que nos permitan casar adelante el proyecto.

Para el primer año se requiere para los gastos administrativos la suma de S/ 24,861. 
Tabla 79

Presupuesto de Gastos Administrativos

\begin{tabular}{lccccc}
\hline Detalle & Año 1 & Año 2 & Año 3 & Año 4 & Año 5 \\
\hline Planilla & & & & & \\
$\quad$ - Administrador & 16.980 & 17.489 & 18.364 & 19.282 & 20.246 \\
Otros servicios & & & & & \\
$\quad$ - Servicio de contabilidad & 2.400 & 2.472 & 2.596 & 2.725 & 2.862 \\
- Servicio Legal & 2.400 & 2.472 & 2.596 & 2.725 & 2.862 \\
-Duo de telefono mas internet & 2.400 & 2.472 & 2.596 & 2.725 & 2.862 \\
Depreciación & 681 & 681 & 681 & 681 & 681 \\
Total & 24.861 & 25.587 & 26.832 & 28.140 & 29.512 \\
\hline
\end{tabular}

8.3.6. Presupuesto de Marketing y Ventas

El presupuesto de marketing y ventas está de acuerdo a la información del capítulo siete, que incluye publicidad a través de material de promisión impreso, redes sociales, página web, y por mail con la intención de dar a conocer el centro turístico. De igual manera se consideraron las entrevistas con distintas agencias de turismo para dar a conocer el producto y recopilar información de los visitantes. Es así que el presupuesto en el primer año suma $\mathrm{S} / 5,400$.

Tabla 80

Presupuesto de Marketing y Ventas

\begin{tabular}{lccccc}
\hline Detalle & Año 1 & Año 2 & Año 3 & Año 4 & Año 5 \\
\hline $\begin{array}{l}\text { Folleteria (volantes, tarjetas de } \\
\text { presentacion, etc) }\end{array}$ & 5.400 & 5.400 & 5.400 & 5.400 & 5.400 \\
Asistente Administrativo & 5.780 & 5.953 & 6.251 & 6.564 & 6.892 \\
Mozos (Part time) & 11.560 & 11.560 & 11.560 & 11.560 & 11.560 \\
$\begin{array}{l}\text { Depreciación } \\
\text { Total }\end{array}$ & 0 & 0 & 0 & 0 & 0 \\
\hline
\end{tabular}


8.3.7. Presupuesto de Gastos Financieros

Para este proyecto no se contará con financiamiento, sin embargo, te contará con una cuenta bancaria que generará gastos bancarios como mantenimiento de cuenta, ITF entre otros, el presupuesto anual será de S/ 480 para el primer año.

Tabla 81

Presupuesto de Gastos Financieros

\begin{tabular}{lccccc}
\hline Detalle & Año 1 & Año 2 & Año 3 & Año 4 & Año 5 \\
\hline Gastos bancarios & 480 & 504 & 529 & 556 & 583 \\
Total & 480 & 504 & 529 & 556 & 583 \\
\hline
\end{tabular}

\subsection{Presupuestos de Resultados}

8.4.1. Estado de Ganancias y Pérdidas Proyectado

Este estado financiero, plasma información respecto a la rentabilidad y la utilidad durante un período determinado (Stickney, Weil, Schipper \& Francis, 2012).

En el presente cuando se muestra el Estado de ganancias y pérdidas proyectado a cinco años. 
Tabla 82

Estado de Ganancias y Pérdidas Proyectado

\begin{tabular}{lccccc}
\hline Detalle & Año 1 & Año 2 & Año 3 & Año 4 & Año 5 \\
\hline Ventas totales & 118.998 & 192.217 & 226.378 & 314.302 & 362.606 \\
Costo de Ventas & 50.193 & 66.787 & 74.529 & 94.457 & 105.404 \\
$\quad$ Utilidad Bruta & 68.806 & 125.430 & 151.848 & 219.846 & 257.202 \\
G. Administrativos & 24.861 & 25.587 & 26.832 & 28.140 & 29.512 \\
G. Ventas & 22.740 & 22.913 & 23.211 & 23.524 & 23.852 \\
$\quad$ Utilidad Operativa & 21.204 & 76.930 & 101.805 & 168.183 & 203.838 \\
G. Financieros & 480 & 504 & 529 & 556 & 583 \\
$\quad$ Utilidad antes de Impuestos & 20.724 & 76.426 & 101.276 & 167.627 & 203.254 \\
Impuesto a la renta $(2.5 \%)$ & 2.975 & 4.805 & 5.659 & 7.858 & 9.065 \\
Utilidad Neta & 17.749 & 71.620 & 95.617 & 159.769 & 194.189 \\
\hline
\end{tabular}

8.4.2. Balance Proyectado

El Balance General muestra la situación financiera de una entidad en un periodo dado (Stickney, Weil, Schipper \& Francis, 2012).

Para el proyecto, el balance proyectado refleja un crecimiento, se debe tener en cuenta que como el financiamiento es propio, el pasivo será igual a cero. 
Tabla 83

Balance Proyectado

\begin{tabular}{lccccc}
\hline & Año 1 & Año 2 & Año 3 & Año 4 & Año 5 \\
\hline Activo & & & & & \\
Caja y bancos & 34.402 & 114.312 & 217.242 & 385.668 & 587.524 \\
Clientes & 0 & 0 & 0 & 0 & 0 \\
Existencias & 0 & 0 & 0 & 0 & 0 \\
Activo Corriente & 34.402 & 114.312 & 217.242 & 385.668 & 587.524 \\
Inmueble, maquinaria y equipo (neto) & 83.175 & 76.716 & 70.257 & 63.798 & 57.338 \\
$\quad$ edificios y otras construcciones & 64.500 & 64.500 & 64.500 & 64.500 & 64.500 \\
$\quad$ maquinaria y equipo & 11.544 & 11.544 & 11.544 & 11.544 & 11.544 \\
$\quad$ muebles y enseres & 13.590 & 13.590 & 13.590 & 13.590 & 13.590 \\
- depreciación acumulada & 6.459 & 12.918 & 19.377 & 25.836 & 32.296 \\
Intangibles & 10.300 & 10.300 & 10.300 & 10.300 & 10.300 \\
Activos diferidos & 0 & 0 & 0 & 0 & 0 \\
Activo No Corriente & 93.475 & 87.016 & 80.557 & 74.098 & 67.638 \\
& & & & & \\
Total Activo & 127.877 & 201.328 & 297.798 & 459.766 & 655.162 \\
& & & & & \\
Pasivo & & & & & \\
Tributos por pagar & 2.975 & 4.805 & 5.659 & 7.858 & 9.065 \\
Pasivo Corriente & 2975 & 4805 & 5659 & 7858 & 9065 \\
Pasivo No Corriente & 0 & 0 & 0 & 0 & 0 \\
Total Pasivo & 127.749 & 71.620 & 95.617 & 159.769 & 194.189 \\
Capital Social & & 196.522 & 292.139 & 451.908 & 646.097 \\
Resultados Acumulados & & & & & \\
Resultados del ejercicio & 107.152 & 107.152 & 107.152 & 107.152 & 107.152 \\
Total Patrimonio & & & & &
\end{tabular}


8.4.3. Flujo de Caja Proyectado

El Flujo de Caja muestra la información que nos ayudará a hacer un uso más eficiente del efectivo (Stickney, Weil, Schipper \& Francis, 2012).

A continuación, se puede observar un flujo de caja positivo con la siguiente estructura.

Tabla 84

Flujo de Caja Económico

\begin{tabular}{|c|c|c|c|c|c|c|}
\hline & & Año 1 & Año 2 & Año 3 & Año 4 & Año 5 \\
\hline Ingresos por ventas & & 118.998 & 192.217 & 226.378 & 314.302 & 362.606 \\
\hline Otras ventas & & 0 & 0 & 0 & 0 & 0 \\
\hline Ingresos totales & & 118.998 & 192.217 & 226.378 & 314.302 & 362.606 \\
\hline Costos Variables & & 28.094 & 45.380 & 53.444 & 74.202 & 85.606 \\
\hline Costos fijos (sin depreciación) & & 62.220 & 62.220 & 62.220 & 62.220 & 62.220 \\
\hline Amortización de intangibles & 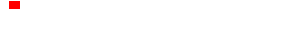 & 3.500 & 3.500 & 3.500 & 3.500 & 3.500 \\
\hline Egresos totales & & 93.814 & 111.100 & 119.164 & 139.922 & 151.326 \\
\hline Utilidad antes de impuestos & & 25.185 & 81.118 & 107.213 & 174.380 & 211.280 \\
\hline Impuestos & & 2.975 & 4.805 & 5.659 & 7.858 & 9.065 \\
\hline Utilidad neta & & 22.210 & 76.312 & 101.554 & 166.523 & 202.215 \\
\hline Depreciación & & 12.000 & 12.000 & 12.000 & 12.000 & 12.000 \\
\hline Inversión Inicial & -99.934 & & & & & \\
\hline Inversión Capital Trabajo & -7.218 & & & & & \\
\hline Variacion capital de trabajo & & 4.441 & 2.072 & 5.333 & 2.930 & 21.995 \\
\hline Valor residual & & & & & & 8.963 \\
\hline Flujo de Caja Económico & -107.152 & 29.768 & 86.240 & 108.221 & 175.593 & 245.174 \\
\hline
\end{tabular}

Tabla 85

Flujo de Caja Operativo

\begin{tabular}{|c|c|c|c|c|c|c|}
\hline & & Año 1 & Año 2 & Año 3 & Año 4 & Año 5 \\
\hline FLUJO DE CAJA OPERATIVO & & 37.710 & 91.812 & 117.054 & 182.023 & 217.715 \\
\hline Activo fijo & -89.634 & & & & & \\
\hline Activo intang. & -10.300 & & & & & \\
\hline Capital de Trabajo & -7.218 & -4.441 & -2.072 & -5.333 & -2.930 & \\
\hline Valor de Salvamento & & & & & & 82.690 \\
\hline Recup. Cap trab. & & & & & & 21.995 \\
\hline FLUJO DE CAJA DE LA INVERSIÒN & -107.152 & -4.441 & -2.072 & -5.333 & -2.930 & 104.685 \\
\hline FLUJO DE CAJA ECONOMICO & -107.152 & 33.268 & 89.740 & 111.721 & 179.093 & 322.400 \\
\hline
\end{tabular}




\section{Capítulo IX: Evaluación Económico Financiera}

\subsection{Evaluación Financiera}

\subsubsection{TIR}

Para Sapag (2011), la tasa interna de retorno (TIR) sirve para analizar la rentabilidad de un proyecto expresada en porcentaje; si la TIR es mayor que cero, como es el caso del proyecto que tiene un $70 \%$, significa que el proyecto es beneficioso y rentable.

\subsubsection{VAN}

Según Sapag (2011), el valor actual neto (VAN) ayuda a medir la rentabilidad del proyecto en unidades monetarias; si el VAN es mayor que cero, como es el caso del proyector que tiene un total de S/ 508,111; reflejará la rentabilidad del proyecto.

\subsubsection{ROE}

La ratio de Rentabilidad Neta del Patrimonio (ROE) facilita a las empresas verificar si son rentables en el tiempo (Stickney, Weil, Schipper \& Francis, 2012).

En este caso, el ratio de ROE es de $13.88 \%$ en el primer año y para el año siguiente $35.57 \%$. 


\subsubsection{Ratios}

Los ratios financieros se usan para evaluar proyectos y permiten medir a una empresa de acuerdo con su liquidez, endeudamiento, rentabilidad, y gestión (cuatro grupos de criterios de evaluación) (Stickney, Weil, Schipper \& Francis, 2012).

Se observa en la siguiente tabla que los índices de liquidez y de solvencia resultan cero, debido a que no se cuenta con financiamiento externo y el capital de trabajo es positivo.

El ratio de rotación de activo muestra una ganancia de S/ 0.93 y es ascendente en el tiempo. El ratio de rentabilidad de activos (ROA) es de $13.14 \%$ y de $34.37 \%$ en el primer y segundo año respectivamente.

Tabla 86

\section{Ratios}

\begin{tabular}{lccccc}
\hline Detalle & Año 1 & Año 2 & Año 3 & Año 4 & Año 5 \\
\hline Ratio de Liquidez & 0 & 0 & 0 & 0 & 0 \\
Prueba Acida & 0 & 0 & 0 & 0 & 0 \\
Capital de Trabajo & 31.427 & 109.506 & 211.582 & 377.811 & 578.459 \\
& & & & & \\
Dias Promedio Inventario & 0,00 & 0,00 & 0,00 & 0,00 & 0,00 \\
Dias Promedio de Cobro & 0,00 & 0,00 & 0,00 & 0,00 & 0,00 \\
Dias Promedio de Pago & 0,00 & 0,00 & 0,00 & 0,00 & 0,00 \\
Ciclo de Negocios & 0,00 & 0,00 & 0,00 & 0,00 & 0,00 \\
& & & & & \\
Cobertura de intereses & 0,02 & 0,01 & 0,01 & 0,00 & 0,00 \\
Apalacamiento & 0,02 & 0,02 & 0,02 & 0,02 & 0,01 \\
Rotación de Activo & 0,93 & 0,95 & 0,76 & 0,68 & 0,55 \\
Margen Neto & 0,15 & 0,37 & 0,42 & 0,51 & 0,54 \\
Multiplicador de Capital & 1,00 & 0,98 & 0,98 & 0,98 & 0,99 \\
ROA & $13,88 \%$ & $35,57 \%$ & $32,11 \%$ & $34,75 \%$ & $29,64 \%$ \\
ROE & $13,88 \%$ & $34,72 \%$ & $31,50 \%$ & $34,16 \%$ & $29,23 \%$ \\
\hline
\end{tabular}




\subsection{Análisis de Riesgo}

9.2.1. Análisis de Punto de Equilibrio

Según Sapag (2011) el punto de equilibrio es aquel en el cual no hay perdida ni ganancia.

Tabla 87

Costos y gastos mensuales (costos fijos y costos variables)

\begin{tabular}{lc}
\hline Costos y gastos mensuales & Costos fijos Costos Variables \\
\hline Administrador & 1.200 \\
Asistente Administrativo & 400 \\
Cocinero (Chef) (Part time) & 850 \\
Mozo (Part time) & 400 \\
Mozo (Part time) & 400 \\
Servicio contable - tributario & 200 \\
Servicio Legal & 100 \\
Energía eléctrica & 200 \\
Agua y desagüe & 200 \\
Teléfono e internet (trios) & 200 \\
Gas & 260 \\
Material de limpieza & 500 \\
Folleteria (volantes, tarjetas de presentacion, etc) & 450 \\
G. Ventas (visitas y charlas agencias) & 150 \\
G. Ventas (visitas y charlas empresas) & 150 \\
Mantenimiento cuenta corriente & 40 \\
Promedio de Insumos & \\
Total & 5.700 \\
\hline
\end{tabular}

De igual manera para Sapag (2011) la fórmula es la división de los costos fijos entre la diferencia del precio con los costos variables y se obtiene lo siguiente:

$$
\text { P.E. }=\frac{\text { C.F. }}{P-C . V .}
$$




$$
\text { P. E. V. (valores) }=\frac{\text { C.F. }}{1-\frac{\text { C.V.U. }}{\text { P.V }}}
$$

Tabla 88

Punto de Equilibrio

\begin{tabular}{lr}
\hline Punto de equilibrio & \\
\hline Costos fijos mensuales & 5.700 \\
Precio unitario & 22 \\
Promedio de clientes mensuales & 465 \\
Costo variable unitario & 10,27 \\
PE mensual (unidades) & 486 \\
PE diario (unidades) & 24 \\
PE mensual (en soles ) & $\mathrm{S} / .10 .694$ \\
PE diario (en soles ) & $\mathrm{S} / .535$ \\
\hline
\end{tabular}

Según los resultados, el proyecto llegará al punto de equilibrio cuando se vendan 24 desayunos por día o 488 al mes.

\subsubsection{Análisis de Sensibilidad}

Según Sapag (2011), el análisis de sensibilidad ayudará a evaluar la situación del proyecto en caso de que se vean afectadas las variables como precio, costo variable, costo fijo, entre otros; debido a diversos factores a fin de optar por la mejor decisión.

De acuerdo con la premisa anterior, se identificó que cuando el precio llegue a S/ 7.00, los costos fijos y variables lleguen a S/ 209,829 y S/ 18.68 respectivamente; el VAN tendrá un valor igual a cero. 
Tabla 89

Análisis de Sensibilidad

\begin{tabular}{lcl}
\hline \multicolumn{1}{c}{ Detalle } & VAN & TIR \\
\hline Precio +1 & 385,935 & $60 \%$ \\
Costo Variable Unitario +1 & 237,264 & $23 \%$ \\
Gasto Administrativo +10000 & 276,138 & $35 \%$ \\
\hline
\end{tabular}

Tabla 90

Análisis de punto crítico

\begin{tabular}{lc}
\hline \multicolumn{1}{c}{ Detalle } & Valor crítico \\
\hline Precio & 7.86 \\
Costo variable unitario & 10.23 \\
Costos fijos & 10,409 \\
\hline
\end{tabular}

9.2.3. Análisis de Escenarios

Este análisis, requiere la evaluación de tres escenarios; como son: optimista normal y pesimista; como se aprecia en la tabla.

Tabla 91

Análisis de Escenarios

\begin{tabular}{lcc}
\hline Escenarios & Ventas proyectadas & VAN \\
\hline Optimista & $10 \%$ & 569,656 \\
Normal & $0 \%$ & 488,721 \\
Pesimista & $-10 \%$ & 451,883 \\
\hline
\end{tabular}

Para el escenario optimista, el resultado del VAN llegaría a S/ 569,656, y en el pesimista llegaría a S/ 451,883. 


\section{Conclusiones y Recomendaciones}

\section{Conclusiones}

- Una vez realizado el estudio del proyecto se pudo comprobar la viabilidad del negocio.

- A través del análisis PESTE se determinó las condiciones externas favorables para desarrollo del proyecto.

- El análisis de competitividad demostró que el proyecto es atractivo para ingresar al mercado de restaurantes en Mollepata.

- Según las características del proyecto, la empresa será una Sociedad Anónima Cerrada.

- El público objetivo para el presente proyecto son agencias de viajes tour operadoras que tienen alta demanda en la ruta (Mollepata - Salkantay- Machupicchu), en especial las que tienen más de mil viajeros al año.

- De acuerdo a las recomendaciones de los expertos los desayunos deben contener tres características que son alto contenido nutritivo, insumos orgánicos de la zona y variedad de la carta.

- Actualmente los establecimientos existentes en la zona de influencia del proyecto ofrecen desayunos entre S/ 15.00 y S/ 20.00, según los resultados de la investigación cuantitativa, los turistas tienen un presupuesto de gasto entre S/ 20.00 a S/ 25.00.

- De acuerdo al análisis del contexto actual el distrito de Mollepata se proyecta a incrementar su demanda turística debido a la construcción a nueva ruta al complejo turístico de Choquequirao.

- También se puede concluir que el proyecto es rentable con un VAN de S/ 488,721 y una TIR de $66 \%$. 


\section{Recomendaciones}

- La ubicación del proyecto es óptima para el servicio que se desea brindar, sin embargo, se recomienda tener en el poblado la publicidad necesaria, además de la señalización adecuada para que los visitantes lleguen sin ningún problema.

- En vista que las temporadas son bien marcadas (alta de mayo a octubre y baja de diciembre a marzo), se recomienda mejor negociación con las agencias de viajes, con mejores promociones.

- Se recomienda hacer una evaluación directa a los consumidores finales, con la intención de conocer sus gustos y preferencias, esta evaluación se debe realizar en temporada alta para mejores resultados.

- Se recomienda aprovechar la infraestructura existente y restructurarla con las características necesarias que requiere el proyecto

- Se recomienda trabajar con la DIRCETUR y gobiernos locales con la intención de promocionar y mejorar el producto turístico en Mollepata

- También se recomienda tener e incentivar la responsabilidad social y medio ambiental, con el objetivo de proteger y preservar los atractivos de la zona.

- En base al estudio realizado se recomienda a mediano y largo plazo implementar nuevas unidades de negocio como hospedaje, mini Marquet y centro de catering.

- Finalmente, de recomienda la ejecución del proyecto ya que tiene un futuro prometedor. 
Anexos 
Anexo 1. Lista consolidada del total de agencias de viajes que ingresaron a Mollepata el año 2016

Total de agencias de viajes que ingresaron el año 2016

\begin{tabular}{|c|c|}
\hline 1 Total $\mathrm{Kb}$ Tour & 6,437 \\
\hline 2 Total Machupicchu Reservations & 5,806 \\
\hline 3 Total Salkantay Trekking & 4,927 \\
\hline 4 Total Alpaca Expeditions & 2,990 \\
\hline 5 Total Arza Tour & 1,527 \\
\hline 6 Total Inca Train Reservations & 1,136 \\
\hline 7 Total Llama Path & 1,098 \\
\hline 8 Total Extreme Tourbulencia & 862 \\
\hline 9 Total Bambas & 727 \\
\hline 10 Total Sas Travel & 544 \\
\hline 11 Toral Wayky Trek & 500 \\
\hline 12 Total South American Trek & 390 \\
\hline 13 Total Bio Andean & 380 \\
\hline 14 Total Chasky & 316 \\
\hline 15 Total Terra Quechuas & 301 \\
\hline 16 Total Sam Travel & 297 \\
\hline 17 Total Mountain Lodge Peru & 261 \\
\hline 18 Total Inca Trail Expedition Peru & 228 \\
\hline 19 Total Quechua Expeditions & 228 \\
\hline 20 Total Amazonas Explorer & 221 \\
\hline 21 Total Condor Travel & 190 \\
\hline 22 Total Rasgos Peru & 171 \\
\hline 23 Total Tierras Vivas & 169 \\
\hline 24 Total Valencia Travel & 162 \\
\hline 25 Total Nc Travel Peru & 156 \\
\hline 26 Total Peak South American & 148 \\
\hline 27 Total Enjoy Peru Holiday & 143 \\
\hline 28 Total Pachamama Explorer & 137 \\
\hline 29 Total Lima Tours & 135 \\
\hline 30 Total Camping Tour & 133 \\
\hline 31 Total Enigma Adventure & 124 \\
\hline 32 Total View Peru & 112 \\
\hline 33 Total G.Adventure & 103 \\
\hline 34 Total Inkayani Peru Tour & 101 \\
\hline 35 Total OrellanaTravel & 89 \\
\hline 36 Total Ecopath & 89 \\
\hline 37 Total Tika Trekking & 86 \\
\hline 38 Total Action Peru Treks & 86 \\
\hline 39 Total Vamos Expeditions & 78 \\
\hline 40 Total Caminantes Del Sur & 74 \\
\hline 41 Total Apus Peru & 63 \\
\hline 42 Total Terra Andina Peru & 51 \\
\hline 43 Total Machupicchu Viajes Peru & 48 \\
\hline 44 Total Native Expeditions & 48 \\
\hline 45 Total Kaypi Peru & 46 \\
\hline 46 Total United Mice & 46 \\
\hline 47 Total Salkantay Backpackers & 46 \\
\hline 48 Total Inca Sites Advneture & 46 \\
\hline 49 Total Explorandes & 44 \\
\hline 50 Total Inti Kuntur & 44 \\
\hline 51 Total Sun Gate Tour & 44 \\
\hline 52 Total Colibri & 38 \\
\hline 53 Total Sky Viajes Y Turismo & 38 \\
\hline 54 Total Wake Up Peru & 32 \\
\hline 55 Total Apu Andino & 32 \\
\hline 56 Total Incas Trek Peru & 32 \\
\hline 57 Total Peru Highland Trek & 30 \\
\hline 58 Total Info Cusco & 30 \\
\hline 59 Total Viventura & 30 \\
\hline 60 Total Yupi Adventure & 29 \\
\hline 61 Total Cusco Native & 23 \\
\hline 62 Total Refugio Salkantay & 23 \\
\hline Otras agencias de viajes & 1,475 \\
\hline Total & 33,997 \\
\hline
\end{tabular}


Anexo 2: Visitantes que arribaron a Mollepata según país de origen, año 2016.

Cuadro de visitantes a Mollepata según Nacionalidad año 2016

\begin{tabular}{lr}
\hline Nacionalidad & Numero de visitantes \\
USA & 13,700 \\
UK & 3,071 \\
Alemania & 2,195 \\
Canada & 1,971 \\
Francia & 1,921 \\
Brasil & 1,890 \\
Australia & 1,880 \\
España & 995 \\
Holanda & 894 \\
Belgica & 681 \\
Argentina & 680 \\
Irlanda & 635 \\
Otros paises Europa & 1,768 \\
Otros Paises Latinoamerica & 1,496 \\
Otros Paises Medio Oriente & 136 \\
Otros Paises Asia & 85 \\
Total & 33,997 \\
\hline Nota: Adaptad
\end{tabular}

Nota : Adaptado del Municipio Distrital de Mollepata:

Registro del arribo de turistas nacionales y extranjeros al distrito de Mollepata, Boletín estadístico 2016. 


\section{Anexo 3. Ficha Técnica de Investigación Cualitativa - Entrevista a Expertos en la ruta de trekking Mollepata - Salkantay - Machupicchu}

\section{Objetivo de la Investigación}

El objetivo es llevar a cabo la entrevista a los expertos que tienen amplia experiencia en la dirección y toma de decisiones en agencias de viajes que operan el circuito de turismo de aventura del lugar donde vamos a realizar la investigación para así lograr comprender la percepción y la necesidad que tienen estas personas expertas con respecto al área donde vamos a realizar el negocio.

Los objetivos específicos del mismo son:

1. Conocer la percepción real del experto con respecto al desarrollo de la oferta y la demanda para el turismo de aventura en la región del Cusco y en el Circuito de Trekking Mollepata - Salkantay - Machupicchu

2. Identificar cuáles son los nuevos retos que tiene la oferta turística pasa satisfacer a la creciente demanda en el circuito Mollepata -Salkantay - Machupicchu, sobre todo en lo que concierne al distrito de Mollepata

3. Conocer la apreciación del experto con respecto a la realidad de los restaurantes que brindan el servicio de desayuno en el pueblo de Mollepata

4. Conocer cómo se desarrolla la cadena de valor para proveer de alimentación a los turistas en todo el circuito Mollepata -Salkantay - Machupicchu, en especial lo que concierne al desayuno del primer día en el pueblo de Mollepata.

5. Conocer la percepción del experto con la propuesta de implementar un centro de interpretación en el Circuito Turístico Mollepata - Salkantay - Machupicchu 


\section{Contenido}

1. Evolución y proyección de la oferta en el Circuito Turístico Mollepata - Salkantay Machupicchu y los demás circuitos de aventura de la región Cusco.

2. Evolución y proyección de la demanda para el Circuito Turístico Mollepata - Salkantay Machupicchu y los demás circuitos de aventura de la región Cusco

3. Perfil y características del turista que visita el Circuito Turístico Mollepata - Salkantay Machupicchu y los demás circuitos de aventura de la región Cusco

4. Descripción de la realidad de los servicios de alimentación (desayuno) para turistas en para el Circuito Turístico Mollepata - Salkantay - Machupicchu y los demás circuitos de aventura de la región Cusco

5. Análisis de cómo deberían ser los servicios en los restaurantes que brindan alimentación para el Circuito Turístico Mollepata - Salkantay - Machupicchu y los demás circuitos de aventura de la región Cusco.

6. Análisis de todo lo que debería tener un centro de servicios turísticos en el inicio del Circuito Turístico Mollepata - Salkantay - Machupicchu y los demás circuitos de aventura de la región Cusco.

7. Importancia y características sobre la creación un centro de Interpretación en el Circuito Turístico Mollepata - Salkantay - Machupicchu y los demás circuitos de aventura de la región Cusco. 


\section{Perfil del Entrevistado}

Persona con más de 5 años de experiencia en la dirección, gerencia o administración de agencias de viajes que haya o esté operando el Circuito Turístico Mollepata - Salkantay Machupicchu. Que conozca a profundidad las características de dicho circuito, tanto a la oferta como a la demanda y en especial los servicios que proveen los restaurantes de Mollepata.

\section{Cuestionario}

\section{Sobre la percepción del sector}

- ¿Cómo ha evolucionado la actividad de trekking en el circuito Mollepata - SalkantayMachupicchu y otros circuitos de aventura en la región del Cusco, hasta la actualidad?

- ¿Cuál es su percepción del futuro del turismo de trekking en el Cusco y en especial en el circuito Mollepata - Salkantay - Machupicchu teniendo en cuenta los cuellos de botella que enfrenta la región como capacidad de carga limite y problemas de accesibilidad a Machupicchu, transporte ferroviario, saturación del camino Inca, teleférico a Choquequirao, aeropuerto internacional de Chinchero entre otros?

\section{Análisis de la oferta y demanda turística}

- ¿Cuál es el perfil del turista que viene a realizar trekking de varios días en la región del Cusco?, por favor indíquenos las edades aproximadas, nacionalidades más comunes, hoteles en los que se hospedan, capacidad de gasto, gustos y preferencias en el servicio.

- ¿Cuáles considera que son los principales circuitos de trekking en el Cusco de mayor demanda? ¿Por qué? (Mencionar solo aquellos lugares donde el turista pernocta al menos una noche). 
- Teniendo en cuenta que existen al menos cinco rutas de trekking consolidas para llegar a Machupicchu (Camino Inca Clásico, Lares Trek, Inca Jungle y Salkantay Trek y Ausangate trek). Como considera usted que es la distribución de turistas que visitan estos circuitos cada año, indique por favor en porcentajes del 1 al 100\%.

\section{Flujos de afluencia turística en Mollepata}

- De los cinco circuitos de trekking antes mencionados, ¿cuáles cree usted que tienen mayor proyección a crecer en afluencia turística y por qué?

- ¿Cuáles son los atractivos turísticos que más disfruta un turista que viene hacer trekking a nuestra región Cusco?

- ¿Cuán perjudicial para la economía de una empresa es hoy la temporada baja en los circuitos de trekking de la región Cusco, y que acciones están tomando las empresas para afrontar este tema?

\section{Percepción de puntos críticos de la competencia}

- Desde su percepción ¿Cuáles considera que son las debilidades del circuito de trekking Mollepata - Salkantay- Machupicchu?

Hablemos ahora de la oferta de restaurantes que se dan en los circuitos de trekking del Cusco y en especial en el trekking de Mollepata - Salkantay - Machupicchu

- Cuál es su diagnóstico del servicio que vienen ofreciendo los restaurantes para turistas en los distintos circuitos de trekking de la Región del Cusco, en especial los que brindan desayuno. Por favor, considerar en su respuesta las siguientes variables: ubicación, variedad de la carta del menú, calidad de los alimentos, higiene, servicio al cliente, ambientación y decoración, temática o concepto del restaurant).

- ¿Desde su perspectiva cuál cree que es el mejor restaurant que ofrece desayunos a los turistas en Mollepata? y ¿por qué? 
- Considera usted que los turistas salen satisfechos después de haber tomado su desayuno en el poblado de Mollepata, ¿sí o no? y ¿Por qué?

\section{Análisis de la cadena de valor}

- ¿Cómo su empresa elije el proveedor de desayunos para sus turistas en el poblado de Mollepata? y ¿cuál es el rol del guía de turismo a la hora de contactarse con los restaurantes turísticos de Mollepata?

- ¿Cómo cree usted que se podría mejorar la experiencia del turista a la hora de brindar el desayuno en el pueblo de Mollepata? (citar varios puntos en cuanto a ubicación, variedad de la carta del menú, calidad de los alimentos, servicio al cliente, ambientación y decoración, temática o concepto del restaurant)?

\section{Evaluación de la propuesta de negocio}

- Teniendo en cuenta que Mollepata es un punto importante en el circuito de trekking al ser el punto de partida, ¿qué servicios turísticos considera usted que se debería implementar o mejorar en este poblado para hacer más positiva la experiencia de los turistas. (entiéndase por servicios turísticos como museos, centros de interpretaciones, restaurantes, abarrotes, farmacias, servicios higiénicos, o algún otro servicio útil para los turistas.)?

- ¿Cree usted que la creación de un centro de interpretación en el poblado de Mollepata que permita al turista tener una previa conexión creativa y educativa sobre los valores más importantes del Circuito Mollepata - Salkantay - Machupicchu pueda ser valorado positivamente por los turistas? ¿Sí o no? y ¿por qué?

- Que características y temática de concepto cree usted que debería tener un centro de interpretación en el circuito Mollepata - Salkantay - Machupicchu.

- ¿Estaría de acuerdo usted con la creación de un centro de interpretación en el distrito de Mollepata que además ofrezca otros servicios a los turistas como los de restaurant para desayunos, abarrotes, servicios higiénicos, etc.? Si o no y ¿por qué? 
- ¿Cuánto tiempo como máximo estaría usted dispuesto a que sus turistas se queden en el poblado de Mollepata, y cuando como máximo podría pagar por el desayuno de un turista? 


\section{Entrevista de profundidad número 1 - Gerente propietario de la agencia de viajes en turismo Pachamama Explorer}

\section{Perfil del Participante número 1.}

- Experto del Sector: Lic. en Turismo Juan Orellana Concha

- Dueño de la agencia de viajes Pachamama Explorer. Agencia que tiene una demanda de más de 100 turistas al año en la ruta de trekking Mollepata Salkantay Machupicchu

- Conocimiento y experiencia en el sector de agencias de viajes de turismo ocupando cargos gerenciales sobre todo en agencia de turismo de aventura como G-Adventures y Peak.

- Referencia de éxito trabajando la ruta de trekking Mollepata - Salkantay - Machupicchu desde inicios del año 2000, lo cual le

- Profesional con raíces en el pueblo de Mollepata (Nieto de Mollepatinos), lo cual le permitió conocer el pueblo desde que era muy joven, motivo por el cual sus ideas, opiniones y valoraciones son relevantes para los objetivos de la investigación.

\section{Desarrollo de la entrevista a profundidad}

Buenas tardes, mi nombre es Joseph Bonnett soy estudiante de post grado de la Universidad San Ignacio de Loyola, en este momento estoy realizando un proyecto de investigación que tiene su desarrollo en el ámbito turístico, por tanto, me gustaría conocer su posición. Yo formularé algunas preguntas para conocer su opinión respecto al sector.

Por favor, siéntase libre de expresar su opinión e ideas con respecto a este tema, de forma abierta y sincera. Así mismo, le recordamos que la información producto de esta entrevista será utilizada con el único y exclusivo fin de enriquecer nuestra investigación, uniéndose a la opinión de otros expertos de forma anónima y confidencial. 
Su opinión será muy valiosa para esta investigación y con la finalidad de no perder ningún detalle de la misma tomando apuntes o escribiendo, esta entrevista será filmada, por lo cual solicitamos su apoyo y autorización.

Entrevistador: Gracias Sr. Orellana, por favor, siéntase libre de expresar su opinión, así mismo la opinión que usted nos va a proporcionar es totalmente confidencial y no vamos a develar su identidad para la investigación

Entrevistado: Claro, no hay problema.

Entrevistador: Perfecto, muchas gracias, bueno, empecemos con la primera pregunta, la primera pregunta es; Como ha evolucionado la actividad de trekking en el circuito Salkantay Machupicchu y otros circuitos de aventura en la región Cusco hasta la actualidad.

Entrevistado: Si hacemos una evaluación de los últimos 5 años la actividad turística ha crecido prácticamente al $80 \%$, esta es una ruta muy cotizada por clientes que quieres vista Machupicchu, y esto sumado a que la ruta a Machupicchu tiene una capacidad muy limitada de ingreso diario y muchos turistas hacen esta ruta para llegar a Machupicchu lo cual la hace muy cotizada.

Entrevistador: Correcto, muchas gracias y bueno, siguiendo entonces con esto, ¿Cuál es entonces su percepción del futuro del turismo de trekking en el Cusco y en especial en el circuito digamos Salkantay, Mollepata - Salkantay - Machupicchu? teniendo en cuenta los cuellos de botella que enfrenta la región como la capacidad de carga limite en lo que usted ha mencionado en el Camino Inca, problemas de accesibilidad a Machupicchu, el transporte ferroviario, saturación del Camino Inca, teleférico a Choquequirao, el Aeropuerto Internacional de Chinchero ¿Cuál es su percepción del futuro del turismo de trekking en el Cusco, teniendo en cuenta estos detalles?

Entrevistado: yo pienso que el turismo por el lado de Salkantay ha crecido, pero el manejo de la ruta por las instituciones protectoras del turismo, no están poniendo las reglas del juego, 
cada quien pone sus propias reglas, las agencias y otro, si esto sigue así con el tiempo se va a dañar el medio ambiente y el medio geográfico, las agencias vienen creando sus propias rutas, muchos suben a los nevados y los lagos, acampan donde les da la gana, no hay un control sobre la limpieza, botan la basura por los campos y con el tiempo se va a malograr todo. Choquequirao va a traer desarrollo incluso a muchas comunidades que aún no tienen turismo como Curahuasi y Limatambo, pero repito si es que no va a existir un control o una planificación esta ruta se va a ir deteriorando.

Entrevistador: Perfecto, muchas gracias. Y entonces ¿Cuál es el perfil del turista que viene a realizar trekking de varios días en la región del Cusco? si pudieras definirlo, digamos en su mayoría, en cuanto a edad, en cuanto a nacionalidad, en cuanto a, no sé, en qué tipo de hoteles se hospedan, cinco, cuatro, tres, ¿cuáles son más o menos sus gustos, preferencias en el servicio? ¿Qué tipo de nacionalidad, más o menos?

Entrevistado: El trekking a Salkantay es considerado como un turismo para turistas de economía baja. Esto es por el mismo servicio, los turistas empiezan a investigar el costo de vida, el servicio de las agencias y presupuestan todo exacto y limitado; los turistas jóvenes backpackers son los que reservan como jóvenes de Hostel y solo algunos de hoteles grandes. Finalmente, los que más viajan a Salkantay son americanos.

Entrevistador: Ahora, ¿Cuáles considera que son los principales circuitos de trekking en el Cusco, de mayor demanda? Si pudiese mencionarlo alguno y ¿Por qué, por qué son los principales?, usted cree.

Generalmente el tour de camino Inca es muy cotizado a nivel de Sudamérica, y hacen su reserva con meses de anticipación. Los que no planifican con meses y buscan opciones improvisadas de última hora viajan a Salkantay. Las rutas que más se venden es obviamente Camino Inca, pero las fechas son muy limitadas, por la disponibilidad, luego en el ranking de 
ventas creo que esta el Inca Jungle por el abra Málaga, junto a Salkantay por Mollepata y finalmente más al final esta Choquequirao y Lares.

Entrevistador: Perfecto, ahora, teniendo en cuenta que existen al menos cinco rutas de trekking consolidadas para llegar a Machupicchu, como, también usted muy bien lo ha indicado, Camino Inca, el clásico, Lares, el camino de Lares, Salkantay, incluso también el Ausangate, debe haber por ahí. ¿Cómo considera usted que es la distribución de turistas que visitan estos circuitos cada año? Si pudiese indicarlo en porcentajes, ya lo dijo, le puso un orden, pero, digamos le pudiese poner a la demanda, a la cantidad que hay de visitantes a estos circuitos por porcentajes ¿Cómo lo haría?

Camino inca, aunque limitado por que el ministerio ofrece un numero de tickets, luego esta Salkantay, Abra Málaga y finalmente Lares y Choquequirao Entrevistador: Perfecto, ahora, de los cinco circuitos de trekking antes mencionados ¿Cuál cree usted que tiene mayor proyección a crecer en afluencia turística? Y ¿Por qué?

Entrevistado: Pienso que Salkantay.

Entrevistador: ¿Por qué?

Entrevistado: Porque tiene, mira, el Salkantay Trek tiene lo que es belleza paisajística, que es un plus, el plus de ver el nevado, los paisajes típicos, gente de la zona, en trajes, en una vida diaria de campo, son factores que incrementan a la aventura de llegar y ver Machupicchu. Porque pienso que tiene para crecer bastante también, porque el cupo para llegar a Camino Inca ya está establecido, ósea, no vas a pasar, creo que son quinientos por día, no vas a pasar de quinientos cupos por día, ya hay un límite, pero no para Salkantay, Salkantay no tiene un límite establecido, ósea no es que te vendan la ruta, ósea el Gobierno Peruano no vende la ruta a Salkantay, lo que te vende es el Inca Trail, igual Lares, que tiene el tour en la ruta que nosotros ofrecíamos era con los baños termales más. Pero como que la gente iba más por ver 
el detalle del ande, Salkantay, el ande mismo, ver los nevados, de las comunidades y eso llamaba más.

Entrevistador: Claro, como usted lo ha dicho, belleza paisajística.

Entrevistado: Claro, tiene un plus.

Entrevistador: Un valor agregado.

Entrevistado: Claro, es un valor agregado, es otro "Reward", es otra recompensa ver caminata y lograr ver paisajes muy típicos nuestros que atraen tanto, entonces yo pienso que, dentro de las rutas alternas, llamémoslo así, Salkantay es la que definitivamente tiene más para crecer. Entrevistador: Ahora ¿Cuál son los atractivos turísticos que más disfruta un turista que viene a hacer trekking en nuestra región Cusco? Creo que ya usted lo mencionó, pero, si pudiese profundizarlos.

El atractivo que más disfruta es el paisaje porque se camina por montañas altas, ceja de selva y luego llegar a Machupicchu, el turista que más disfruta esta ruta es el amante del trekking. Entrevistador: Ahora, ha trabajado mucho tiempo en agencias de viajes, que ofrecía este tipo de servicio en turismo de aventura ¿Cuan perjudicial para la economía de una empresa es hoy la temporada baja en los circuitos de trekking en la región Cusco y que acciones están tomando las empresas para afrontar este tema o deberían tomar para afrontar este tema? Entrevistado: La estrategia puede ser trabajar con el turista latino, ofrecer tours a chilenos, argentinos, aunque el clima no nos favorece por las lluvias. En época de lluvias baja el turismo en la ruta de Mollepata Salkantay, incluso hasta más del 50\%. En el caso de la ruta Inca Jungle, ellos ofrecen actividades de aventura y eso les gusta a los turistas latinos de la temporada baja.

Entrevistador: Ya y digamos si había un equilibro en la demanda para los trekking en Salkantay u otra ruta ¿Qué se podría mejorar para que aumento un poco la demanda? 
Entrevistador: Perfecto, ahora, desde su percepción ¿Cuáles considera que son las debilidades del circuito de trekking Mollepata - Salkantay - Machupicchu, ósea, el circuito de trekking de Salkantay? Ya lo dijo una vez, la falta de infraestructura ¿Otras cosas? Incluso lo puede comparar con Camino Inca; esto tiene y Salkantay no lo tiene.

Entrevistado: las debilidades por parte de las empresas son los restaurantes, es por eso que no incluimos en nuestra tarifa, existen problemas de higiene, elaboración de alimentos y eso perjudica al viajero, comen en un restaurant X de Mollepata y se enferman, incluso hemos tenido problemas con viajeros enfermos, por eso a veces preferimos llevar a nuestros cocineros.

Entrevistador: Perfecto, ahora, hablemos de la oferta de restaurantes que se dan en los circuitos de trekking en Cusco y en especial en el trekking de Mollepata - Salkantay Machupicchu ¿Cuál es su diagnóstico del servicio que viene ofreciendo los restaurantes para turistas en los distintos circuitos de trekking en la región Cusco? en especial los que brindan desayuno, por favor, considerar en su respuesta las siguientes variables, la ubicación, la variedad de la carta del menú, la calidad de los alimentos, la higiene, servicios al cliente, la ambientación, decoración, temático o concepto del restaurante.

Entrevistado: También el servicio es un poco frio, creo que la atención debería ser mejor. La ambientación es mala, el espacio no es apropiado para un restaurant, la acomodación de las sillas no son las apropiadas para un restaurant. Y tampoco una temática. El pueblo no lo hace al propósito, pero lamentablemente nadie asesora y por eso se comente errores.

Entrevistador: La siguiente pregunta es; desde su perspectiva ¿Cuál cree que es el mejor restaurante que ofrece desayuno a los turistas en Mollepata? Y ¿Por qué?

No hay ninguno en mi opinión.

Entrevistador: Claro, y ¿Considera usted que los turistas salen satisfechos después de haber tomado desayuno en uno de esos restaurantes en Mollepata? 
Entrevistado: Definitivamente no.

Entrevistador: Claro, lo ha dicho bien, ahora ¿Cómo su empresa elige al proveedor de desayunos para sus turistas cuando hacen un trekking a Salkantay, en el poblado de Mollepata?

Entrevistado: En algunos casos nosotros ya tenemos contactos específicos, y lo que hacemos es llamarles por teléfono una o 2 horas antes del viaje, entonces ellos nos esperan listos, en nuestro caso el guía no elije sino nosotros en gerencia somos los que programamos, pero si sabemos que el restaurant se esfuerza por congraciarse con nuestros guías y les dan desayunos gratis. La gente local trata de engreír al guía.

Entrevistador: Claro, ahora, ¿Cómo cree usted que se podría mejorar la experiencia del turista a la hora de brindar el desayuno en un restaurante en el Pueblo de Mollepata? Digamos ¿El restaurante que cosa debería tener? Además de una variedad de productos, digamos, buena ubicación, puede ser, variedad de la carta, calidad de los alimentos tal vez, servicio al cliente, ambientación, decoración, temática, no sé. ¿Cuáles serían esos puntos? ¿Qué puntos serian esos?

Entrevistado: El lugar de Mollepata es bastante estratégico, pero se debe capacitar a los pobladores locales

Entrevistador: Que le parece si el restaurant estaría ubicado lejos del pueblo Entrevistado: A mi parecer si es lejos del pueblo se disfruta más de la naturaleza, el turista está cansado de comer bajo las cuatro paredes

Entrevistador: En cuestión al menú cual considera un buen menú:

Entrevistado: En el caso de desayunos creo yo siempre debe haber 3 opciones, yo he visto que las personas del trekking quieren comer bien y se alimentan más los días normales, porque saben que se van a exigir en las caminatas. Lo que no veo mucho son ensaladas de frutas, creo que hace falta eso. 
Entrevistador: Perfecto, ahora, teniendo en cuenta que Mollepata es un punto importante en el circuito de trekking, al ser el punto de partida a Salkantay ¿Qué servicios turísticos considera usted que se debería implementar o mejorar en este poblado? Para ser más positiva la experiencia a los turistas, entiéndase por servicios turísticos, como museos, centro de interpretación, restaurantes, abarrotes, no sé, farmacias tal vez, servicios higiénicos o algún otro servicio para los turistas ¿Qué de estos servicios, se necesitaría en Mollepata?

Entrevistado: lo que la gente más busca por allá al inicio del trekking es una tienda o market donde pueda haber facilidades de encontrar productos para consumir durante el viaje. Las tiendas de hoy en Mollepata no ofrecen esos productos, aguas, hidratantes, cereales. También el tema del baño es importante

Entrevistador: Bien, efectivamente, perfecto, ahora ¿Cree usted que la creación de un centro de interpretación, justamente, en el poblado de Mollepata, permitiría al turista tener una previa conexión creativa, educativa sobre los valores más importantes de circuito Mollepata Salkantay - Machupicchu para que pueda ser valorado positivamente por los turistas?

Entrevistado: sería muy bueno porque también te hablaría sobre la conservación del medio ambiente, enseñar a las personas que actividades están en contra de la naturaleza. En otras rutas prohíben, dan restricciones, pero en Mollepata muchas no hacen ni respetan que están en un área natural y un santuario de respeto al Apu.

Entrevistador: Ahora ¿Qué características o temáticas de concepto cree usted que debería tener el centro de interpretación en el poblado de Mollepata? Ósea ¿Qué temática debería tener el centro de interpretación? Temática, ósea, ¿Qué características debería tener el centro de interpretación? De repente, un pizarrón, de repente, no sé, fotogramas de los paisajes que van a visitar en Salkantay, no sé, ¿Qué características más o menos podría tener?

Yo que he visitado algunos centros de interpretación en la selva y algo interesante me pareció las fotografía, donde el guarda parque ye da a conocer los mejores puntos de observación, 
zonas de descanso. Sería interesante tener un mapa para que los guías ayudarse a explicar. En esta explicación también se les puede hablar en este mapa sobre las zonas donde hay fauna y flora determinada

Entrevistador: Claro, perfecto, ahora ¿Estaría de acuerdo usted con la creación de un centro de interpretación en el distrito de Mollepata, que además ofrezca otros servicios a los turistas como los de restaurante por ejemplo para desayunos, incluso un abarrote, donde puedan comprarse aguas, repelentes y servicios higiénicos? ¿Sí o no? ¿Estaría usted de acuerdo? Entrevistado: Si estoy totalmente de acuerdo, es muy necesario que exista un negocio así en Mollepata.

Entrevistador: Ahora, la última pregunta ¿Cuánto tiempo como máximo, estaría usted dispuesto, a que sus turistas, sus pasajeros, se queden en el Poblado de Mollepata? Y ¿Cuánto como máximo podría pagar, por pasajero, por el desayuno en un restaurante turístico si es que se crea en Mollepata?

Entrevistado: el tiempo es entre 45 minutos a 1 hora, es lo máximo para desayunar, y se podría agregar unos 15 a 25 minutos más para visitar el centro de interpretación. El precio normal para pagar creo que entre 15 a 20 soles. A pesar de incrementar un centro de interpretación. El turista no pagaría más de 20 soles por el mismo hecho de que ellos son jóvenes.

Entrevistador: Perfecto, muchas gracias por su tiempo, esta información no solamente es valiosa para la investigación, sino también enriquecedora para nuestros proyectos personales. Muchas gracias por su tiempo.

Entrevistado: A usted Joseph.

Entrevistador: Que tenga un buen día, hasta luego. 


\section{Entrevista de profundidad número 2 - Gerente de ventas de la agencia de viajes y turismo Valencia Travel}

\section{Perfil del Participante número 2}

- Experto del Sector: Lic. Kennet Romero

- Gerente de ventas de la agencia de viajes Valencia Travel

- Conocimiento y experiencia en el sector de agencias de viajes de turismo como guía profesional en tours culturales como Machupicchu, Valle Sagrado y circuitos de Aventura como Camino Inca.

- Desde el año 2011 al 2015 se encargó de ser guía exclusivo de la agencia Valencia Travel en la ruta de Mollepata - Salkantay- Machupicchu,

- A la actualidad es el responsable de establecer relaciones comerciales con los viajeros del mundo que desean realizar rutas de trekking en Perú.

\section{Desarrollo de la entrevista a profundidad número 2}

Entrevistador: Buenas tardes, mi nombre es Pabel Gustavo, soy estudiante de posgrado de la Universidad San Ignacio de Loyola, en este momento, estoy realizando un proyecto de investigación que tiene su desarrollo en el ámbito turístico, en específico sobre los circuitos de trekking para turistas, que existen en la región Cusco, tales como Camino Inca, Lares, Salkantay, Ausangate, entre otros. Por tanto, me gustaría conocer Sr. Kenneth, su posición, yo formularé algunas preguntas para conocer su opinión respecto al sector y, en primer lugar, quisiera que nos presentemos, como ya le comenté, mi nombre es Pabel Gustavo, estudiante de la Universidad San Ignacio de Loyola, le agradecería que se presente por favor. Entrevistado: Buenas noches, mi nombre es Kenneth Romero Echevarría, bachiller de la Universidad Nacional San Antonio Abad del Cusco, tengo experiencia en turismo ya 
aproximadamente unos cuatro años a cinco años, me desempeñe en varias agencias, en estos momentos estoy haciendo un proyecto para el tema de hacer una agencia propia.

Entrevistador: Gracias Sr. Kenneth, por favor, siéntase libre de expresar su opinión, ideas con respecto a este tema, de forma abierta y sincera, así mismo le recuerdo que la información producto de esta entrevista será utilizada con el único y exclusivo fin de enriquecer nuestra investigación, uniéndose a la opinión de otros expertos, de forma anónima y confidencial. Su opinión va a ser muy valiosa para nosotros y con la finalidad de no perder ningún detalle de la misma, estamos grabando esta conversación, por favor, siempre y cuando con su autorización.

Entrevistado: Claro, no hay problema.

Entrevistador: Perfecto, muchas gracias, bueno, empecemos con la primera pregunta, la primera pregunta es; Como ha evolucionado la actividad de trekking en el circuito Mollepata - Salkantay- Machupicchu y otros circuitos de aventura en la región Cusco hasta la actualidad.

Entrevistado: En mi experiencia en las agencias, la evolución de trekking de rutas alternas, como las conocemos, por ejemplo, tomando en cuenta ya que la ruta principal y la más demandada es la del Camino Inca, que empieza en el kilómetro 82, esta ruta al ser copada muchas veces demanda la necesidad de establecer nuevas rutas alternas como las conocemos nosotros, entre ellas esta Salkantay y Lares, que en la última agencia en donde yo estaba laborando, ofrecíamos. Estas rutas evolucionan por la necesidad de diversificación, como le dije, muchas veces cuando nosotros vendemos la ruta de camino a inca o Inca Trail, como le decimos, llega un punto en que, simplemente, ya no hay más cupos, incluyendo a los porters, incluyendo a los turistas y guías y la opción más solicitada es la de Salkantay. La ruta a Salkantay tiene un potencial paisajístico muy grande y hoy últimamente está considerado entre una de las mejores rutas del mundo. Entonces, el potencial que tiene Salkantay es 
grande y pienso que todavía tiene mucho por explotar, también necesita mucha tecnificación, de repente infraestructura, existencia y uno de los grandes problemas que tiene un turista que siempre va a ser la altura. La altura en la zona del Cusco y en los treks, incluyendo al Inca Trail, es un gran "En contra", un gran punto en contra.

Entrevistador: Correcto, muchas gracias y bueno, siguiendo entonces con esto, ¿Cuál es entonces su percepción del futuro del turismo de trekking en el Cusco y en especial en el circuito digamos Salkantay - Mollepata - Salkantay - Machupicchu? teniendo en cuenta los cuellos de botella que enfrenta la región como la capacidad de carga limite en lo que usted ha mencionado en el Camino Inca, problemas de accesibilidad a Machupicchu, el transporte ferroviario, saturación del Camino Inca, teleférico a Choquequirao, el Aeropuerto Internacional de Chinchero ¿Cuál es su percepción del futuro del turismo de trekking en el Cusco, teniendo en cuenta estos detalles?

Entrevistado: Lo que yo pienso personalmente es que el turismo solo va a atender a subir la demanda turística para el Cusco, pese a la falencia de infraestructura va a ser siempre positiva, debido a que Cusco se está conociendo como una ruta alterna o un destino alterno a los ya conocidos, la gente busca siempre una nueva aventura y en mi experiencia al tratar con turistas es que Perú es como un nuevo boom, ya sea gastronómico, cultural, digamos que el turismo en los años 80 casi 90 era un turismo de elite para gente que era, digamos, un nivel cultural muy alto o gente que tenía nociones muy claras a lo que iba, hoy en día la oferta de nuestros productos, de turismo, se está ampliando y está llegando más a la masa, por ende, simplemente la tendencia es positiva, yo pienso que el turismo en Cusco tiene una tendencia positiva, va a seguir adelante, la demanda va a ser más alta y es por eso que nosotros necesitamos estar preparados con nuevas ofertas, diversificar más aún y lograr una calidad de servicio optima ya sea en infraestructura, más que todo que es lo que carecemos, para rehacer todo el potencial que tiene. 
Entrevistador: Perfecto, muchas gracias. Y entonces ¿Cuál es el perfil del turista que viene a realizar trekking de varios días en la región del Cusco? si pudieras definirlo, digamos en su mayoría, en cuanto a edad, en cuanto a nacionalidad, en cuanto a, no sé, en qué tipo de hoteles se hospedan, cinco, cuatro, tres, ¿cuáles son más o menos sus gustos, preferencias en el servicio?

Entrevistado: La edad promedio de las personas con las que, últimamente, he trabajado va desde los dieciocho, diecinueve años hasta los treinta cinco, cuarenta años, generalmente jóvenes, también hay personas de mayor edad, hay un grupo considerable de gente a partir de los sesenta años. Hasta hemos atendido gente de ochenta años, pero me acuerdo un caso en especial, el de ochenta años llegó a Cusco, apenas llegó a Cusco se enfermó, por la altura, entonces, como que tienen la voluntad de hacerlo es una cosa, pero que lo logren.

Mayormente el grupo de veinte, empezando desde los 18 hasta los cuarenta, cuarenta cinco años, mayormente, son gente con un perfil de aventura, ósea, son gente que está en buena forma, son gente activa, deportistas, que le gustan los retos. Yo me acuerdo que el tipo de hoteles que ellos buscaban era de tres estrellas, por ejemplo, al que mandábamos bastantes turistas era al hotel Casa Andina Cusco Plaza, más que todo buscaban la buena posición, buen posicionamiento del hotel, le gustaba un hotel donde este todo cerca, todo a la mano y como son gente que se puede catalogar como "Outdoor", no tiene mayor problemas en adaptarse, porque justamente están en busca de aventura, una experiencia única, muchas veces, en las opiniones que recibíamos, decían que era un "Life Changing Experience” ósea una experiencia que cambiaba la vida, porque todo lo que enmarca hacer Camino Inca, el reto y el premio que es al final ver el complejo arqueológico de Machupicchu, la ciudadela. Entrevistador: Y ¿Qué tipo de nacionalidad, más o menos?

Entrevistado: Mayormente, americanos.

Entrevistador: americanos. 
Entrevistado: americanos, mayormente americanos, ingleses muy poco, australianos también, ingleses y australianos. Trabajábamos con cuentas ingleses y australianos, pero la mayoría eran americanos, estadounidenses, canadienses, de ahí le seguirían los ingleses y de ahí los australianos.

Entrevistador: Ahora, ¿Cuáles considera que son los principales circuitos de trekking en el Cusco, de mayor demanda? Si pudiese mencionarlo alguno y ¿Por qué, por qué son los principales?, usted cree.

Entrevistado: Mira, definitivamente el que está en la cabeza es el Inca Trail o Camino Inca, el clásico de cuatro días, de ahí le sigue, en mi experiencia, hay más que yo decía, está el Salkantay Trek y después le sigue Lares Trek, también se hacia el Choquequirao, pero era mucho menos demandado, era como que, por cada veinte Camino Incas, aparecía un Choquequirao y eso. Por cada veinte Camino Incas, unos ocho Salkantay y unos cuatro Lares. Entrevistador: ¿Por qué?

Entrevistado: Porque en primer lugar Camino Inca está muy promocionado, ósea hacer el Camino Inca en el mundo es una marca registrada, creo que está considerada en el top diez de caminos alternos a nivel mundial, ósea, es una cosa que todos quieren hacer, ya cuando muy pocas personas se animan al de Salkantay Trek, cuando no encuentran disponibilidad de espacios en el Inca Trail. Entonces, es como que es el segundo plato, es como la opción que no querías, pero tienes que tomar si quieres aun visitar Machupicchu de una manera deportiva, en una manera de trekking y experiencia de caminata y Lares es más que todo experiencia por sugerencia de otra persona que ya lo hizo y le pareció agradable, pero no está promocionado. Salkantay está relativamente promocionado, pero, como te digo, no es pues lo que buscan, lo que todo el mundo busca es el Inca Trail y Choquequirao, en lo que he leído, tiene un nivel de; el problema de Choquequirao hasta donde les he escuchado a los pasajeros es que la exigencia que tiene para llegar a Choquequirao, la caminata es muy fuerte, muy 
demandante, entonces, definitivamente es un lugar muy bonito para llegar pero lo que desanima a muchas personas es la intensidad que tiene, las caminatas, los tiempos de caminata, todo lo que alberga, lastimarse, además que mucho del perfil, que era muy general, en la agencia era que la mayoría de personas que venían acá, vivían al nivel del mar, entonces, era doblemente reto para ellos llegar acá, tomar una caminata intensa que en cualquier lugar seria intensa y el problema, el tema de la altura.

Entrevistador: Perfecto, ahora, teniendo en cuenta que existen al menos cinco rutas de trekking consolidadas para llegar a Machupicchu, como, también usted muy bien lo ha indicado, Camino Inca, el clásico, Lares, el camino de Lares, Salkantay, incluso también el Ausangate, debe haber por ahí. ¿Cómo considera usted que es la distribución de turistas que visitan estos circuitos cada año? Si pudiese indicarlo en porcentajes, ya lo dijo, le puso un orden, pero, digamos le pudiese poner a la demanda, a la cantidad que hay de visitantes a estos circuitos por porcentajes ¿Cómo lo haría?

Entrevistado: Como te decía, por cada veinte Caminos Incas habría pues unos 8 Salkantay, unos cuatro Lares, Choquequirao uno, que no tiene nada que ver con llegar a Machupicchu, pero, el Ausangate era muy poco demandado. Creo que, imagino que también es falta de Merchandising.

Entrevistador: Digamos al Camino Inca ¿Cuánto le pondría en porcentajes? ¿Noventa por ciento?

Entrevistado: No, un ochenta por ciento. El Camino Inca es algo que todos quieren hacer, de preferencia, el Salkantay un veinticinco a treinta por ciento, el Lares un diez a doce por ciento, el, que te digo, Ausangate, uno por ciento, hasta la última experiencia que tuve en ventas solo ha llegado, es más, no ha venido ni un señor hasta acá.

Entrevistador: Perfecto, ahora, de los cinco circuitos de trekking antes mencionados ¿Cuál cree usted que tiene mayor proyección a crecer en afluencia turística? Y ¿Por qué? 
Entrevistado: Pienso que Salkantay.

Entrevistador: ¿Por qué?

Entrevistado: Porque tiene, mira, el Salkantay Trek tiene lo que es belleza paisajística, que es un plus, el plus de ver el nevado, los paisajes típicos, gente de la zona, en trajes, en una vida diaria de campo, son factores que incrementan a la aventura de llegar y ver Machupicchu. Porque pienso que tiene para crecer bastante también, porque el cupo para llegar a Camino Inca ya está establecido, ósea, no vas a pasar, creo que son quinientos por día, no vas a pasar de quinientos cupos por día, ya hay un límite, pero no para Salkantay, este lugar no tiene un límite establecido, ósea no es que te vendan la ruta, ósea el Gobierno Peruano no vende la ruta a Salkantay, lo que te vende es el Inca Trail, igual Lares, que tiene el tour en la ruta que nosotros ofrecíamos era con los baños termales más. Pero como que la gente iba más por ver el detalle del ande, Salkantay, el ande mismo, ver los nevados, de las comunidades y eso llamaba más.

Entrevistador: Claro, como usted lo ha dicho, belleza paisajística.

Entrevistado: Claro, tiene un plus.

Entrevistador: Un valor agregado.

Entrevistado: Claro, es un valor agregado, es otro "Reward", es otra recompensa ver caminata y lograr ver paisajes muy típicos nuestros que atraen tanto, entonces yo pienso que, dentro de las rutas alternas, llamémoslo así, Salkantay es la que definitivamente tiene más para crecer. Entrevistador: Ahora ¿Cuál son los atractivos turísticos que más disfruta un turista que viene a hacer trekking en nuestra región Cusco? Creo que ya usted lo mencionó, pero, si pudiese profundizarlos.

Entrevistado: Al turista con el que yo he tenido trato, mayormente eran norteamericanos, estadounidenses, canadienses, ingleses, australianos, lo que ellos buscan es lo típico, ósea, ¿Qué les gusta? Les gusta una caminata en los que ellos puedan ver la cultura viva, tu sabes 
que el Perú tiene mucho de cultura viva, hay mucha gente que sigue sus tradiciones, especialmente en el ande, las tradiciones son fuertes, muy arraigadas todavía, cosa que se ha perdido mucho a nivel mundial, entonces, para una persona que vive en un medio totalmente moderno, de urbe, las personas a las que nosotros tratábamos, que siempre busca y también el otro perfil era que eran de "Outdoor", que son gente que le gusta la aventura, tener la oportunidad de ver a personas en un ambiente tradicional, típico nuestro andino, es una experiencia muy reconfortante, les gusta eso, yo he tratado con esa gente y les gusta eso, de ver algo que todavía no está modificado por la modernidad, que la gente todavía use un azadón, en vez de usar un tractor, que tenga mulas, caballos, o tenga un rebaño pequeño y Salkantay ofrece eso, eso lo hace pasar como una atracción más.

Entrevistador: Ahora, ha trabajado mucho tiempo en agencias de viajes, que ofrecía este tipo de servicio en turismo de aventura ¿Cuan perjudicial para la economía de una empresa es hoy la temporada baja en los circuitos de trekking en la región Cusco y que acciones están tomando las empresas para afrontar este tema o deberían tomar para afrontar este tema? Entrevistado: Mira, yo te digo que últimamente, lo que se conocía como temporada baja más está siendo marcado por el clima; la temporada de lluvia es lo que espanta al trekking, nadie quiere, y es lógico, de acá o seas de Europa o donde sea, no quiere caminar bajo la lluvia, clima pesado, te va a quitar mucho de la experiencia de paseo. Este año sinceramente, se ha vendido casi para todo el año Salkantay. Pero siempre preguntan y el limitante ahora es el clima, nadie quiere a excepción de unos cuantos casos que quieren en la época de lluvia, quieren un clima seco en el cual puedan caminar tranquilos, pero de temporada baja la verdad que, por ejemplo en la agencia no estaba viendo eso, no estaba viendo temporada baja, se vendió para todo el año, semi - parejo y lo único que marcaba temporada baja era el detalle del clima, ahora que, como te digo, el volumen no era alto, ósea, a pesar de que Salkantay es una ruta que tiene mucho potencial, aun el volumen no era alto, pero en cuanto a temporada 
baja, no la podría calificar así porque como te digo, fue parejo, ósea, me acuerdo desde Febrero está cerrado el Camino Inca, todo Febrero, Enero, Marzo, Abril estaban dudosos para venir en temporada de lluvias, pero a partir de Marzo hasta Noviembre todo era parejo, no era una época en la que te diga, aquí había más grupos o menos grupos, por ahí iba, un promedio de cuatro a cinco grupos por mes.

Entrevistador: Ya y digamos si había un equilibro en la demanda para los trekking en Salkantay u otra ruta ¿Qué se podría mejorar para que aumento un poco la demanda? Entrevistado: Marketing

Entrevistador: Marketing, lo que es agencias, promoción de rutas y ofrecer al turista la seguridad que va a tener na buena experiencia, de que va a ser, que te digo, bien cuidado, que, si va a haber algún percance, algún accidente, se va a poder atender con métodos propios. Se le tiene que ofrecer al turista y es el medio que tienen todavía para llegar a Perú, el medio de que pase algo con ellos, pase un percance y que van a estar tirados, ósea, digamos, pase un accidente, se tuerza un pie o que se fracture un pie o que les falte el aire y que no va a haber un método para socorrerlos, es el gran miedo que tienen. Hasta donde yo tengo enterado, en Inca Trail, Camino Inca en cada cierto puesto hay asistencia médica, ósea, siempre hay personal que se va a preocupar por tomarse la molestia de atenderte, hasta en el peor de los casos en helicóptero te recogen.

Entrevistador: Digamos lo que en Salkantay no habría. Ósea, falta digamos de una infraestructura turística allí.

Entrevistado: Claro, puestos para atender a un turista, puestos médicos.

Entrevistador: En eso se debería mejorar sí o sí.

Entrevistado: Mejorar infraestructura.

Entrevistador: Perfecto, ahora, desde su percepción ¿Cuáles considera que son las debilidades del circuito de trekking Mollepata - Salkantay - Machupicchu, ósea, el circuito de trekking 
de Salkantay? Ya lo dijo una vez, la falta de infraestructura ¿Otras cosas? Incluso lo puede comparar con Camino Inca; esto tiene y Salkantay no lo tiene.

Entrevistado: Una cosa que definitivamente es una debilidad y no va a cambiar es la altura, la altura es un factor que, aunque no lo creas, espanta a muchos. En las ventas muchas veces era la mera preocupación y eso del nivel del mar, pero quiero hacer ese Trek. Una debilidad es la altura, otra es la infraestructura como te había dicho. Debilidades, la infraestructura, la altitud que quita mucho las ganas de venir y en cuanto al staff, no, seria estos los que te he dicho. Entrevistador: Perfecto, ahora, hablemos de la oferta de restaurantes que se dan en los circuitos de trekking en Cusco y en especial en el trekking de Mollepata - Salkantay Machupicchu ¿Cuál es su diagnóstico del servicio que viene ofreciendo los restaurantes para turistas en los distintos circuitos de trekking en la región Cusco? en especial los que brindan desayuno, por favor, considerar en su respuesta las siguientes variables, la ubicación, la variedad de la carta del menú, la calidad de los alimentos, la higiene, servicios al cliente, la ambientación, decoración, temático o concepto del restaurante.

Entrevistado: Pero para trekking hablas del primer desayuno, porque si es trekking es campamento.

Entrevistador: Claro, es el primer desayuno. Digamos, un desayuno para que después empiecen la caminata y ahí si ya se lleven sus cocineros, todo.

Entrevistado: Por ejemplo, nunca hemos tenido problema con el hotel Casa Andina Cusco Plaza, ósea el buffet, nunca, nunca hemos tenido alguna queja, porque una cosa que se preocupan bastante, creo que tuve la oportunidad de desayunar allí, es la calidad y el frescor de los productos y una cosa que, pues Perú tiene, que está teniendo una tendencia, una marca registrada es en la calidad de comida que puedas encontrar. Mayormente una persona que tiene el perfil de ser "Outdoor" tiene una dieta especial, tiene.

Entrevistador: ¿Necesidades especiales? 
Entrevistado: Necesidades especiales, pero también como te digo, son bastante adaptables, se adaptan bastante, porque parte de la aventura es adaptarse a lo que te ofrece la ruta y, mira, en cuanto a eso, es un detalle que no he encontrado mayor problema, nunca ha habido una queja sobre el primer desayuno. Ahora más, me acurdo que siempre hablaban de granolas, ósea cereales, yogurt y jugos de naranja, de piña, es que siempre han encontrado. Esta bastantemente proporcionado.

Entrevistador: La siguiente pregunta es; desde su perspectiva ¿Cuál cree que es el mejor restaurante que ofrece desayuno a los turistas en Mollepata? Y ¿Por qué?

Entrevistado: Mira, yo he estado en Mollepata, pero digamos que un restaurante a nivel turístico, no necesariamente de nivel turístico, un restaurante de calidad para cualquier persona que busca algo de cierto estándar, no hay, entonces no hay como responder a eso. Entrevistador: Claro, y ¿Considera usted que los turistas salen satisfechos después de haber tomado desayuno en uno de esos restaurantes en Mollepata?

Entrevistado: Definitivamente no.

Entrevistador: ¿Por qué?

Entrevistado: Por la falta de variedad en productos, en la falta de variedad de alimentos, más o menos lo que puedas encontrar en Mollepata será un café con pan.

Entrevistador: Claro, lo ha dicho bien, ahora ¿Cómo su empresa elige al proveedor de desayunos para sus turistas cuando hacen un trekking a Salkantay, en el poblado de Mollepata?, ¿Cuál es el rol del guía de turismo a la hora de contactarse con los restaurantes turísticos en Mollepata? Ósea, a que es a lo que voy, digamos, cuando la agencia ofrece una ruta de Salkantay, la agencia le dice al guía "Oye, ya tenemos convenio con este restaurante, ¿Vas a desayunar acá? o algo, o el guía tiene la potestad de elegir libremente allí en que restaurante puede desayunar.

Entrevistado: El turista ya salía desayunado. 
Entrevistador: Claro.

Entrevistado: Ya salía desayunado, como dices, ya tomaba su desayuno, entonces no esperaban gran cosa de Mollepata más que empezar el tour.

Entrevistador: Efectivamente, efectivamente, perfecto.

Entrevistado: Entonces no había mayor logística en eso.

Entrevistador: No sería tan determinante.

Entrevistado: Se llamaban los productos, pero para los guías de caminata, para los campamentos.

Entrevistador: Claro, ahora, ¿Cómo cree usted que se podría mejorar la experiencia del turista a la hora de brindar el desayuno en un restaurante en el Pueblo de Mollepata? Digamos ¿El restaurante que cosa debería tener? Además de una variedad de productos, digamos, buena ubicación, puede ser, variedad de la carta, calidad de los alimentos tal vez, servicio al cliente, ambientación, decoración, temática, no sé. ¿Cuáles serían esos puntos? ¿Qué puntos serian esos?

Entrevistado: Bueno, si es una empresa con experiencia la que vas a mandar, digamos, se puede esperar varios estándares, pero si es una persona local, suficiente con que esté limpio, con que haiga cierta variedad, con qué, que te digo, se le ofrezca cierta calidez, no vas a esperar una atención de un restaurante top.

Entrevistador: Pero digamos, las agencias que digamos manejan turistas de ese nivel, que exigen una cierta, que necesitan un cierto nivel de calidad de servicios ¿Cuáles serían estas? Digamos, ¿El restaurante tendría que estar en una buena ubicación?

Entrevistado: Claro, una buena ubicación, variedad de productos, una atención especializada, personalizada.

Entrevistador: Claro, se sobreentiende que turismo, servicio al cliente A1. 
Entrevistado: Pero, Mollepata pienso que no esté preparada para eso, en ningún aspecto, ósea, no tiene un, más allá de ser un punto de inicio para un Trek, de un nivel como es el Inca Trail, no tiene otro, pienso que no tiene otra, por el momento un potencial fuerte para ser que el turista desee quedarse en Mollepata, de lo más, no lo tiene.

Entrevistador: Perfecto, ahora, teniendo en cuenta que Mollepata es un punto importante en el circuito de trekking, al ser el punto de partida a Salkantay ¿Qué servicios turísticos considera usted que se debería implementar o mejorar en este poblado? Para ser más positiva la experiencia a los turistas, entiéndase por servicios turísticos, como museos, centro de interpretación, restaurantes, abarrotes, no sé, farmacias tal vez, servicios higiénicos o algún otro servicio para los turistas ¿Qué de estos servicios, se necesitaría en Mollepata? Entrevistado: Un centro de interpretación, un centro de interpretación, definitivamente infraestructura de baños, infraestructura de servicios higiénicos, un lugar donde tengan información, donde le expliquen muy bien la ruta, bueno, las agencias mayormente se ocupan en eso al mandar los itinerarios. En el itinerario te explican la ruta y te explican los puntos que vas a visitar y que vas a ver, entonces ya tienen una información clara, pero definitivamente un centro de interpretación para preparar al turista.

Entrevistador: Para mostrarle digamos, cuál va a ser la ruta, en este caso.

Entrevistado: Y sobre lo que es primeros auxilios también, primeros auxilios, estar preparados para cualquier emergencia en ruta.

Entrevistador: Bien, efectivamente, perfecto, ahora ¿Cree usted que la creación de un centro de interpretación, justamente, en el poblado de Mollepata, permitiría al turista tener una previa conexión creativa, educativa sobre los valores más importantes de circuito Mollepata Salkantay - Machupicchu para que pueda ser valorado positivamente por los turistas? Entrevistado: Claro, definitivamente, como digo, es una ruta alterna, que no digamos que es nueva, pero que falta de ciertas herramientas para ser más popular, por ende si es más 
popular, si es más aceptada y ofrecer confianza, pues el turismo va a responder de una manera positiva, él va a venir acá al tour, va a venir acá para hacer el tour, porque va a decir "Es un tour que me ofrece ciertos estándares que busco" y porque aparte de eso ofrece una belleza paisajística, ofrece una experiencia gratificante al ver a la gente andina, en su ambiente natural y al final Machupicchu, que más, ósea, tiene mucho potencial. Pero necesita más infraestructura y más, lo que dices.

Entrevistador: Un centro de interpretación.

Entrevistado: Exacto, si, sería muy bueno, muy positivo.

Entrevistador: Ahora ¿Qué características o temáticas de concepto cree usted que debería tener el centro de interpretación en el poblado de Mollepata? Ósea ¿Qué temática debería tener el centro de interpretación? Temática, ósea, ¿Qué características debería tener el centro de interpretación? De repente, un pizarrón, de repente, no sé, fotogramas de los paisajes que van a visitar en Salkantay, no sé, ¿Qué características más o menos podría tener?

Entrevistado: Podría ser un proyector que te una explicación, de que va a haber, que riesgos ahí, que partes son interesantes, puntos de interés.

Entrevistador: Porque, en Salkantay, también se pasa de Sierra a Selva, también.

Entrevistado: Por eso pues, hay puntos de interés, hay un punto, digamos, de que tienes un paisaje o mostrar algo muy puntual, entonces, toda esa información tendría que estar agregado en un proyector, por ejemplo, puede ser un proyector, que esté pasándose una y otra vez en una sala especial. Haya un stand, recepción, donde haya personal que se encargue de aclarar alguna duda extra, mayormente las agencias lo hacen ya, ósea, el guía está capacitado y dentro de su obligación es decir estas cosas.

Entrevistador: Creo que les dan un briefing incluso más informativo ¿No?

Entrevistado: Si, pero, siempre hay cosas que se pueden ir y que un puesto como este. Entrevistador: ¿Lo puede absolver? 
Entrevistado: Puede absolver, sí.

Entrevistador: Ahora, este ¿Estaría de acuerdo usted?

Entrevistado: Y sabes que sería interesante, este centro lo que haría sería estandarizar la atención, ósea, digamos, que no todas las agencias o el guía por x motivos no estuvo capacitado para responder todo, entonces, al tener un puesto como este, lo que haces es que el nivel de servicio se estandarice para bien, ósea que la calidad sea igual, se equidiste en las agencias que ofrecen este servicio, pero de una manera positiva. Porque también ahí turistas que lo hacen por su cuenta, entonces.

Entrevistador: Claro, perfecto, ahora ¿Estaría de acuerdo usted con la creación de un centro de interpretación en el distrito de Mollepata, que además ofrezca otros servicios a los turistas como los de restaurante por ejemplo para desayunos, incluso unos abarrotes, donde puedan comprarse aguas, repelentes y servicios higiénicos? ¿Sí o no? ¿Estaría usted de acuerdo? Entrevistado: Si, definitivamente.

Entrevistador: ¿Por qué?

Entrevistado: Porque, como te digo, ofrecerías al turista la sensación de que estas con un back up, con un soporte, de que no es una ruta salvaje, en medio de un País que no conoces, en que te libras a la suerte de un personal de una agencia, sino ves que hay inversión, de parte e interés de parte del estado y que no es un lugar que está abandonado en medio de la nada, entonces, un puesto como este también produce un efecto psicológico positivo, porque te dice que hay algo o alguien detrás de ti, que está monitoreándote y que es una ruta que está contando con ciertos estándares de calidad.

Entrevistador: Ahora, la última pregunta ¿Cuánto tiempo como máximo, estaría usted dispuesto, a que sus turistas, sus pasajeros, se queden en el Poblado de Mollepata? Y ¿Cuánto como máximo podría pagar, por pasajero, por el desayuno en un restaurante turístico si es que se crea en Mollepata? 
Entrevistado: Tal cual como está ahora, solo para el punto de partida.

Entrevistador: Solo para el momento de partida sería el tiempo máximo.

Entrevistador: Si, tiempo de partida y como te dije, como hablábamos del centro, que se actualicen, se informen allí.

Entrevistador: Digamos, ese tiempo, ¿Cuánto duraría ese tiempo?

Entrevistado: Un par de horas, dos horas, una hora y media.

Entrevistador: Perfecto.

Entrevistado: Exagerando.

Entrevistador: Claro y digamos ¿Cuánto estaría dispuesto a pagar por pasajero si es que encuentra en Mollepata un restaurante turístico? Si es que, digamos, los pasajeros no han tomado desayuno en su hotel.

Entrevistado: Quince a veinte soles, quince soles si es una buena opción, quince a veinte soles.

Entrevistador: Quince a veinte soles.

Entrevistado: Sí, no veo más.

Entrevistador: ¿Para una carta de desayunos, que ofrezca un desayuno completo?

Entrevistado: Claro, pero como te digo, Pabel, hasta donde yo he visto, ya todos van desayunados.

Entrevistador: Si, claro, por el hotel.

Entrevistado: Si, ósea, que es un punto de partida, ósea, al menos que alguien encuentre un motivo especial, personal, no hay mayor atracción allá, al menos que intentes hacer un turismo vivencial allá, pero eso ya sería otro proyecto.

Entrevistador: Ya es otro proyecto, está claro, como tú lo señalas, los pasajeros ya van desayunados, porque toman el desayuno en su hotel.

Entrevistado: O que hayan tomado desayuno en el carro, dos desayunos. 
Entrevistador: Esa operatividad, porque es una operatividad que el pasajero tome desayuno en el hotel, ¿Es tomado por el agente de viajes?, es decisión del agente de viajes, de la cuenta obviamente, ¿no es decisión del guía de turismo?

Entrevistado: Claro, pero es algo que se hace así, se hace así, ósea, ya es así.

Entrevistador: Ya viene ya, previamente coordinado por el agente de viajes.

Entrevistado: $\mathrm{Si}$, ya está así.

Entrevistador: Perfecto, muchas gracias por su tiempo, esta información no solamente es valiosa para la investigación, sino también enriquecedora para nuestros proyectos personales. Muchas gracias por su tiempo.

Entrevistado: A ti Pabel.

Entrevistador: Que tenga un buen día, gracias por todo. 


\section{Entrevista de profundidad número 3 - Gerente Propietario de la agencia de viajes Inca}

\section{Trail Reservations}

\section{Perfil Del Entrevistado}

Entrevistado: Jose Manuel Becerra Torres.

Cargo: Gerente propietario de la agencia de viajes Inca Trail Reservations.

Inca Trail Reservations es una agencia de viajes con más de ocho años en el rubro, creciendo exponencialmente en el mercado virtual del internet debido a que el nombre de INKA TRAIL RESERVATIONS, son palabras claves para los viajeros que quieren conocer Machupicchu. Esto permitió que esta empresa sea una de las más importantes que opera la ruta de camino inca tradicional, el que empieza en el riel del tren y llega a Machupicchu en 4 días y 3 noches. Además de la gran afluencia de turistas en el camino tradicional, desde el 2014 vienen operado también la ruta de Mollepata Salkantay - Machupicchu con proyecciones de crecimiento para los siguientes años.

Su opinión es de suma importancia para hacer contraste de realidades con lo que sucede en el camino inca tradicional.

\section{Desarrollo de la entrevista a profundidad}

Entrevistador: Buenas tardes, mi nombre es Ángel Joseph, soy estudiante de postgrado de la Universidad San Ignacio de Loyola, en este momento, estoy realizando un proyecto de investigación que tiene su desarrollo en el ámbito turístico, en específico en el circuito de trekking Mollepata - Salkantay - Machupicchu. Por tanto, me gustaría conocer Sr. Jose Manuel su posición, yo formularé algunas preguntas para conocer su opinión respecto al tema En base a su opinión usted como gerente propietario de la agencia de viajes Inca Trail Reservations, agradecería nos dé su opinión con respecto a los siguientes puntos: 
Entrevistador: Bueno Jose, empecemos con la primera pregunta, la primera pregunta es; Como ha evolucionado la actividad de trekking en el circuito Salkantay Machupicchu y otros circuitos de aventura en la región Cusco hasta la actualidad.

Entrevistado: Gracias Joseph por la entrevista... bueno estos últimos años creo que los turistas ya no quieren visitar los atractivos tradicionales es decir los atractivos culturales clásicos como son city tour Valle Sagrado o Valle Sur, creo q como leía en ese boletín de MINCETUR, la tendencia es que los turistas quieran mochilear y aventurarse por lugares inexplorados, vivir con la lluvia, respirar el aire del campo, compartir con los campesinos, yo creo que por eso las rutas de caminata de montaña están dando la hora.

Entrevistador: perfecto, totalmente de acuerdo, siguiendo entonces con esto, ¿Cuál es entonces su percepción del futuro del turismo de trekking en el Cusco y en especial en el circuito digamos Salkantay, Mollepata - Salkantay - Machupicchu? teniendo en cuenta los cuellos de botella que enfrenta la región como la capacidad de carga limite en lo que usted ha mencionado en el Camino Inca, problemas de accesibilidad a Machupicchu, el transporte ferroviario, saturación del Camino Inca, teleférico a Choquequirao, el Aeropuerto Internacional de Chinchero ¿Cuál es su percepción del futuro del turismo de trekking en el Cusco, teniendo en cuenta estos detalles?

Entrevistado: Mira, recuerdo que desde el 98 que sucedió lo de los rieles de Hidroeléctrica Mollepata ha cambiado mucho y el turismo viene creciendo cada vez más por que los turistas quieren llegar a Machupicchu caminando. Yo creo q eso va a seguir creciendo con más fuerza, por eso los empresarios están empezando a comprar terrenos en esa ruta para construir campamentos, aunque me preocupa la contaminación que pueda aparecer en uno años cuando se sobrecargue la ruta.

Entrevistador: claro, y ila influencia del nuevo aeropuerto? 
Entrevistado: Ah, por su puesto eso es otra oportunidad de crecimiento, hablando geográficamente toda esa zona se va a beneficiar sobre todo hacia el lado de Apurímac y Abancay porque va a estar conectado, aunque repito hay que estar alertas a la contaminación, por eso debe haber planificación.

Entrevistador: Gracias Jose por el aporte. Y entonces ¿Cuál es el perfil del turista que viene a realizar trekking de varios días en la región del Cusco? si pudieras definirlo, digamos en su mayoría, en cuanto a edad, en cuanto a nacionalidad, en cuanto a, no sé, en qué tipo de hoteles se hospedan, cinco, cuatro, tres, ¿cuáles son más o menos sus gustos, preferencias en el servicio? ¿Qué tipo de nacionalidad, más o menos?

Entrevistado: Yo pienso que los trekeros no tienen una edad o país en específico, pues yo opero grupos de chiquillos de 18 y señores de 60 años para camino inca, pero si habría que establecer un estándar te diría que más son los jóvenes que desean hacer caminatas de montaña, más o menos de 18 a 35 años, solteros o en pareja, pero sin hijos. Sobre su nacionalidad más creo son los norteamericanos y europeos en gran volumen, y en temporada baja los latinos, sobre todo los argentinos que tienen el sueño de hacer camino inca. Y sobre el tipo de hotel, yo diría que son más de tres estrellas y hostels

Entrevistador: Ahora, ¿Cuáles considera que son los principales circuitos de trekking en el Cusco, de mayor demanda? Si pudiese mencionarlo alguno y ¿Por qué, por qué son los principales?, usted cree.

Camino inca del $\mathrm{Km} 88$ es creo el principal referente de trekking en el cusco, y después de este es Salkantay por que también lo conecta con Machupicchu, aunque hay un tramo corto en tren, luego estarían Lares y Choquequirao que le falta mejorar sus caminos Entrevistador: Perfecto, ahora, teniendo en cuenta que existen al menos cinco rutas de trekking consolidadas para llegar a Machupicchu, como, también usted muy bien lo ha indicado, Camino Inca, el clásico, Lares, el camino de Lares, Salkantay. ¿Cómo considera 
usted que es la distribución de turistas que visitan estos circuitos cada año? Si pudiese indicarlo en porcentajes, ya lo dijo, le puso un orden, pero, digamos le pudiese poner a la demanda, a la cantidad que hay de visitantes a estos circuitos por porcentajes ¿Cómo lo haría?

Las lluvias son los que crean las temporadas para el trekking, como sabes es bajo de enero a marzo de ahí empieza a subir y desde junio a setiembre es full y luego baja nuevamente. Entrevistador: Perfecto, ahora, de los cinco circuitos de trekking antes mencionados ¿Cuál cree usted que tiene mayor proyección a crecer en afluencia turística? Y ¿Por qué?

Entrevistado: Definitivamente Salkantay, pero con planificación.

Entrevistador: ¿Por qué?

Entrevistado: Por varias razones, primero que es el reemplazante del camino inca tradicional cuando este se satura con los tickets, segundo porque aún no cobran entrada para hacer este trek, excepto los 10 soles, pero no es mucho, y tercero por su belleza paisajística, belleza en variedad de climas, y el nevado Salkantay que es todo un tema místico para los visitantes Entrevistador: Claro, el tema de los tickets permita reducir el costo de venta ¿no?

Entrevistado: Así es, el ministerio de Cultura cobra casi 180 soles por ingreso y Mollepata solo cobra 10 soles, eso marca la diferencia en muchos turistas.

Entrevistador: Ahora, ha trabajado mucho tiempo en agencias de viajes, que ofrecía este tipo de servicio en turismo de aventura ¿Cuan perjudicial para la economía de una empresa es hoy la temporada baja en los circuitos de trekking en la región Cusco y que acciones están tomando las empresas para afrontar este tema o deberían tomar para afrontar este tema? Entrevistado: Los empresarios debemos acomodarnos a las temporadas, para eso están los latinos peruanos y las ofertas especiales, sabemos que van bajar los ingresos, pero es tiempo también para descansar porque en temporada alta no paramos. 
Entrevistador: Perfecto, ahora, desde su percepción ¿Cuáles considera que son las debilidades del circuito de trekking Mollepata - Salkantay - Machupicchu, ósea, el circuito de trekking de Salkantay?

Entrevistado: Pienso que faltan mejorar los servicios turísticos en toda la ruta, especialmente desde Mollepata hasta antes de Santa Teresa, los caminos en mal estado, los arrieros malogran las vías, falta la señalización y eso es perjudicial para el turista.

Entrevistador: ¿A qué se refiere con malos servicios turísticos?

Entrevistado: Ósea los servicios higiénicos desde que llegas al pueblo de Mollepata todo es precario, los restaurantes son malos, las personas no hablan inglés, los arrieros son a veces mal educados.

Entrevistador: Perfecto, ahora nos direccionamos a esta problemática en especial, hablemos de la oferta de restaurantes que se dan en los circuitos de trekking en Cusco y en especial en el trekking de Mollepata - Salkantay - Machupicchu ¿Cuál es su diagnóstico del servicio que viene ofreciendo los restaurantes para turistas en los distintos circuitos de trekking en la región Cusco? en especial los que brindan desayuno, por favor, considerar en su respuesta las siguientes variables, la ubicación, la variedad de la carta del menú, la calidad de los alimentos, la higiene, servicios al cliente, la ambientación, decoración, temático o concepto del restaurante.

Entrevistado: Hay mucho por trabajar, mira yo empecé a operar camino inca tradicional y cuando buscábamos restaurant no había más que un café con pan en la ruta, hoy eso ha cambiado, las personas se han puesto las pilas y por ejemplo el restaurant Vilcanota es un ejemplo de que las cosas pueden mejorar si trabajas bien, ellos cobran como 30 soles del desayuno, pero es un súper desayuno con vista al rio buenos baños y hasta dan comida para mi personal, creo que las demás rutas deben imitar a este y otras restaurantes que están creciendo para los viajeros de trekking. 
Entrevistador: La siguiente pregunta es; desde su perspectiva ¿Cuál cree que es el mejor restaurante que ofrece desayuno a los turistas en Mollepata? Y ¿Por qué?

La verdad todos son muy parecidos, el servicio es regular.

Entrevistador: Claro, y ¿Considera usted que los turistas salen satisfechos después de haber tomado desayuno en uno de esos restaurantes en Mollepata?

Entrevistado: No, pero por eso nosotros les hacemos saber que ellos son los que deciden si quieren pagar o prefieren llevarse sus frutas.

Entrevistador: Claro. ¿Cómo su empresa elige al proveedor de desayunos para sus turistas cuando hacen un trekking a Salkantay, en el poblado de Mollepata?

Entrevistado: yo tengo el contacto del restaurant que esta por la quebrada en el terminal, y le aviso día antes para que me prepare un desayuno y atienda a mi guía y chofer Entrevistador: Claro, ahora, ¿Cómo cree usted que se podría mejorar la experiencia del turista a la hora de brindar el desayuno en un restaurante en el Pueblo de Mollepata? Digamos ¿El restaurante que cosa debería tener? Además de una variedad de productos, digamos, buena ubicación, puede ser, variedad de la carta, calidad de los alimentos tal vez, servicio al cliente, ambientación, decoración, temática, no sé. ¿Cuáles serían esos puntos? ¿Qué puntos serian esos?

Entrevistado: primero que nada, se debe invertir en hacer un restaurant y no así improvisado, luego se debe capacitar con un buen cocinero que prepare bien la comida y personal que sepa cómo atender a un turista, esto no quiere decir que sea un mozo profesional... basta con entrenarlos y exigirlos para que atiendan como para el turismo.

Entrevistador: Claro que sí. Que le parece si el restaurant estaría ubicado lejos del pueblo Entrevistado: Genial, sería mucho mejor, ese clima de Mollepata es muy bonito y sobre todo el aire fresco que aún se puede respirar, estoy de acuerdo Entrevistador: En cuestión al menú cual considera un buen menú para el desayuno: 
Entrevistado: En el caso de desayunos creo que el turista siempre va a llegar con hambre porque además el guía les exige que estén bien alimentados antes de empezar el trekking, aunque también deben existir opciones para las personas light.

Entrevistador: Perfecto, ahora, teniendo en cuenta que Mollepata es un punto importante en el circuito de trekking, al ser el punto de partida a Salkantay ¿Qué servicios turísticos considera usted que se debería implementar o mejorar en este poblado? Para ser más positiva la experiencia a los turistas, entiéndase por servicios turísticos, como museos, centro de interpretación, restaurantes, abarrotes, no sé, farmacias tal vez, servicios higiénicos o algún otro servicio para los turistas ¿Qué de estos servicios, se necesitaría en Mollepata? Entrevistado: Pienso que Mollepata tiene mucho por crear, podrían hacer exhibición de textiles, danzas, o alguna explicación extra del lugar, el turista quiere eso... quiere conocer más de los pueblos que visita... por eso creo q deben organizarse porque si no otro pueblo lo hará a futuro y luego se lamentaran.

Entrevistador: Bien, efectivamente, perfecto, ahora ¿Cree usted que la creación de un centro de interpretación, justamente, en el poblado de Mollepata, permitiría al turista tener una previa conexión creativa, educativa sobre los valores más importantes de circuito Mollepata Salkantay - Machupicchu para que pueda ser valorado positivamente por los turistas? Entrevistado: sería estupendo, nosotros como profesionales del turismo sabemos que la cultura, las tradiciones vende a los turistas, así que eso le falta a Mollepata, además como indicas el tema de ser inicio de trekking puede ser educativo con un centro de interpretación donde el turista sea concientizado sobre su rol en una ruta de alta montaña, muy buena propuesta.

Entrevistador: Ahora ¿Qué características o temáticas de concepto cree usted que debería tener el centro de interpretación en el poblado de Mollepata? Ósea ¿Qué temática debería tener el centro de interpretación? Temática, ósea, ¿Qué características debería tener el centro 
de interpretación? De repente, un pizarrón, de repente, no sé, fotogramas de los paisajes que van a visitar en Salkantay, no sé, ¿Qué características más o menos podría tener?

Yo creo q pueden contar la historia de ese camino, sobre los sitios arqueológicos, y también sobre el cristo que tienen en la capilla.... Si mas no me equivoco ese cristo es desde el siglo XVII, y tiene una bonita historia que contar solo que nadie lo aprovecha.

Entrevistador: ¿y cómo lo implementarías?

Entrevistado: Lo más natural posible, no vayas a hacer el mamarracho que hizo el gobierno en el km. 88 con su centro de interpretación de cemento, yo pienso que debe ser full flores, plantas nativas, decoración rustica, etc.

Entrevistador: Claro, perfecto, gracias por el aporte... ahora ¿Estaría de acuerdo usted con la creación de un centro de interpretación en el distrito de Mollepata, que además ofrezca otros servicios a los turistas como los de restaurante por ejemplo para desayunos ¿Sí o no? ¿Estaría usted de acuerdo?

\section{Entrevistado Por supuesto que si}

Entrevistador: Ahora, la última pregunta ¿Cuánto tiempo como máximo, estaría usted dispuesto, a que sus turistas, sus pasajeros, se queden en el Poblado de Mollepata? Y ¿Cuánto como máximo podría pagar, por pasajero, por el desayuno en un restaurante turístico si es que se crea en Mollepata?

Entrevistado: El tiempo establecido de 45 minutos a 1 hora. Ahora sobre el precio como te dije en la ruta del km 82 dan hasta 30 soles, pero para esta ruta yo creo que mis pasajeros pagarían 25 soles con normalidad.

Entrevistador: Perfecto, muchas gracias por su tiempo, fue un honor y una experiencia muy enriquecedora para nuestro proyecto haber compartido con usted, muchas gracias.

Entrevistado: A usted Joseph y suerte con el proyecto

Entrevistador: Que tenga un buen día, hasta luego. 


\section{Anexo 4. Ficha Técnica de Investigación Cualitativa - Entrevista a Expertos en Centros de Interpretación Turística}

\section{Objetivo De La Investigación}

El objetivo es llevar a cabo la entrevista a los expertos que tienen amplia experiencia y/o conocimiento sobre centros de interpretación turística en nuestro destino turístico, con el objetivo de tener una visión clara de las experiencias reales de centros de interpretación en la región del Cusco.

Los objetivos específicos del mismo son:

1. Conocer la definición, el objetivo y características que debe tener un centro de interpretación según los expertos.

2. Identificar cuáles son los nuevos retos y tendencias para la creación de centros de interpretación en el Perú y el mundo.

3. Conocer por medio del experto, cual es el perfil, los intereses y magnitud de turistas demandan actualmente un centro de interpretación, en la región Cusco.

4. Conocer la experiencia del experto en el centro de interpretación que dirigió o dirige a la actualidad.

5. Conocer cuál es la apreciación del experto sobre la creación de un centro de interpretación en el circuito de trekking Mollepata - Salkantay - Machupicchu

\section{Contenido}

1. Definición, objetivos y características importantes que tienen los centros de interpretación

2. Evolución y proyección de la oferta de centros de interpretación en el Perú y el mundo.

3. Evolución y proyección de la demanda de centros de interpretación en la región Cusco y el Perú 
4. Perfil y nuevas tendencias de los usuarios a los centros de interpretación en el mundo y sobre todo en la región Cusco.

5. Descripción de la experiencia del experto en su centro de interpretación.

6. Análisis de lo que debería tener un centro de interpretación en los circuitos turísticos de aventura.

7. Análisis de la creación de un centro de interpretación en el punto de inicio del circuito de Trekking Mollepata - Salkantay - Machupicchu.

\section{Perfil Del Entrevistado}

Persona con más de tres años de experiencia en la dirección, gerencia o administración de Centros de Interpretación natural o cultural del destino turístico Cusco. Es también valido incluir a quienes dirigen o dirigieron los museos de sitio.

\section{Cuestionario}

- ¿Cuáles son los objetivos de un centro de interpretación cultural y natural?

- ¿Cómo se ha ido desarrollando la oferta de centros de interpretación en el Perú y en especial en nuestra región Cusco?

- ¿Por qué cree usted que son importantes los centros de interpretación en nuestros destinos turísticos?

- ¿Qué es lo que más disfrutan los turistas de los centros de interpretación en la región Cusco?

- ¿Por qué cree usted que varios de los centros de interpretación creados por el estado en el punto de inicio de los atractivos turísticos no han tenido éxito?

- Desde su experiencia ¿cuáles son las debilidades de muchos centros de interpretación privados, en la región Cusco? 
- ¿Coméntenos cuáles son ventajas competitivas que tiene el centro de interpretación que usted dirige o dirigió?

- ¿Cuántos turistas aproximadamente visitan mensualmente su centro de interpretación tanto en temporada alta como baja?

- Cual consideran que debería ser la temática para un centro de interpretación donde los visitantes son turistas que están a punto de realizar la ruta de trekking Mollepata Salkantay- Machupicchu.

- Además de la interpretación educativa, que otros servicios turísticos cree usted que sea provechoso ofrecer en un centro de interpretación que está ubicado en una zona rural (entiéndase por servicios turísticos como, restaurantes, abarrotes, farmacias, servicios higiénicos, o algún otro servicio útil para los turistas)

- ¿Conocen algún centro de interpretación que brinde otros servicios turísticos a los clientes? y ¿está de acuerdo con la existencia de estos? Sí, no y ¿por qué?

- ¿Cuáles deberían ser los canales de promoción y publicidad para un centro de interpretación en la región del Cusco?

- ¿De quién depende la asistencia de clientes al centro de interpretación, del guía turístico o del mismo cliente? y ¿por qué?

- ¿Qué acciones realiza su negocio para fidelizar a los guías de turismo con el centro de interpretación?

- Cuál es su apreciación sobre la creación de un restaurante, que permita que a los comensales visitar gratuitamente un centro de interpretación el cual este ubicado en el poblado de Mollepata, siendo este un punto de inicio para la ruta de trekking Mollepata Salkantay- Machupicchu 


\section{Entrevista de profundidad número 1 - Gerente General del centro interpretativo Museo del Chocolate}

\section{Perfil del Participante número 1.}

- Experto del Sector: Martin, Oscar

- Gerente del Museo del Chocolate Cusco: Desde el 2014 junto a los propietarios se encargaron del diseño del proyecto el cual consiste en potenciar el chocolate cusqueño y mostrarlo a los visitantes con una propuesta de centro de Interpretación. El Museo del Chocolate se ha convertido en el lugar favorito para los turistas que desean llevarse un suvenir, probar una taza de chocolate y a la vez conocer un poco más de la historia y la producción artesanal del típico chocolate cusqueño.

- Conocimiento y experiencia del mercado turístico cusqueño: el entrevistado posee 15 años de experiencia en el área comercial de agencias de viajes, hospedajes y restaurantes del Cusco, perteneció al directorio corporativo del grupo Milla Turismo del 2008 al 2013, encargándose del liderazgo del área comercial

- Referencia de éxito en centros de interpretación turística de la ciudad del Cusco

- Persona cuyas ideas, opiniones y valoraciones son relevantes para los objetivos de la investigación.

\section{Desarrollo de la entrevista a profundidad}

Entrevistador: Bueno, muy buenas tardes, mi nombre es Pabel Gustavo Surco Dueñas, soy estudiante de posgrado de la universidad San Ignacio de Loyola, en este momento estoy realizando un proyecto de investigación que tiene su desarrollo en el ámbito turístico, en específico, sobre la creación de un Centro de Interpretación en la ruta de Trekking Mollepata - Salkantay - Machupicchu, la cual es una ruta que tiene valores naturales y culturales de 
suma importancia, por tanto me gustaría conocer su posición por favor, yo formularé algunas preguntas para conocer su opinión respecto al sector, este, en primer lugar quisiera que nos presentemos, por favor, si pueden decir su nombre, el cargo que tienen en la empresa, más que todo:

Entrevistados: (Oscar) Mi nombre es Osca, Oscar García y soy el encargado del área de Marketing del Choco museo. (Martín) Que tal, mi nombre es Martín Aranda y soy de apoyo de Marketing.

Entrevistador: Perfecto, por favor siéntase libre de expresar su opinión e ideas con respecto a este tema de forma abierta y sincera, así mismo les recordamos que la información producto de esta entrevista es, exclusivamente, con el fin de enriquecer nuestro proyecto de investigación, esto no va a salir publicado en ninguna parte, solamente procesos para presentar nuestro plan de negocio. Su opinión va a ser muy valiosa para nosotros, va a ser muy valiosa para nosotros y con el fin de no perder ningún detalle de lo que ustedes puedan decir, por favor, justamente estamos filmando esta entrevista.

Bueno, en primer lugar, quisiera saber, ¿Cuáles son los objetivos o cuales creen ustedes que son los objetivos de un museo, tanto de un museo como de un centro de interpretación? ¿Cuáles son los objetivos, digamos?

Entrevistados: (Oscar) Bueno, en mi parecer, no solamente informar, no solamente brindar información, sino que sea algo evidentemente, como decirlo, la gente pueda aprender, entonces, brindar información y conocimiento.

Entrevistador: Claro, efectivamente y ¿Cómo? Digamos, seria digamos, correcto, digamos es el objetivo principal, brindar información, digamos, incluso hasta un tema pedagógico ahí allí ¿No?

Entrevistados: (Oscar) Uhm. 
Entrevistador: Dar a conocer un producto, ¿Esto tiene que ver con la rentabilidad que tenga el lugar, no es cierto? Ósea, digamos y ¿Si tendría que generar una rentabilidad el lugar? Como digamos; cobrar una entrada o ¿Ustedes que piensan?

Entrevistados: (Oscar) Depende de qué tipo de rentabilidad se quiera buscar, puede ser una rentabilidad económica.

Entrevistador: Claro.

Entrevistados: (Oscar) O rentabilidad social, quiere decir que lo que se busque, no sea tanto el beneficio económico, sino la difusión, por ejemplo, ese es otro de los objetivos.

Entrevistador: Perfecto, ahora ¿Cómo se ha ido desarrollando la oferta de centros de interpretación, de museos acá, en el Perú, especialmente en el Cusco? ¿Cómo ustedes ven la oferta?

Entrevistados: (Oscar) Eso tú lo vas a saber mejor que yo, Martín.

(Martín) Jajaja, bueno, en realidad el turismo está creciendo lo bastante y creo que estamos recién empezando con experiencias nuevas, recién usamos esta palabra de experiencias y esto es algo muy nuevo, yo creo que, como oficinas de información, deberíamos de trabajar más en explicar al pasajero que puede generar s propia experiencia en Cusco sin la necesidad de generar o coger directamente un paquete armada por alguien que quiere ganara netamente dinero. Creo que hay mucha gente aquí, que trata de preguntarse y no trabajamos directamente en las preguntas exactas. Hasta ahora, no he visto en ningún lugar, siendo también parte de, trabajador de oficinas de información, preguntas frecuentes y saber cómo contestarlas y tenerlas allí ya publicadas para que la gente simplemente, vaya, las vea y ya. Entrevistador: Claro.

Entrevistados: (Martín) Sin embargo, se sigue usando el tipo de modalidad, vienen y conversa, el informador sabe que la pregunta es obvia, así que la responde sin más ni menos, sin embargo, no incentiva a que pueda preguntar algo más. Dentro de museos, creo que 
estamos mejorando bastante, en el Choco museo, tratamos de dar una experiencia mucho más global, tratamos de que la gente experimente la idea de Cacao, que la pruebe y que la lleve a compartir con sus seres queridos, con su familia que es lo más importante dentro del turismo, al final, la persona.

Entrevistador: Claro, efectivamente, y tú, como bien dices, centros de información ¿No? Entrevistados: (Martín) Que se deba al pasajero, al visitante. ¿Por qué creen ustedes que son importantes los museos y centros de interpretación en nuestros destinos turísticos? Entrevistados: (Oscar) Para evidentemente poner en conocimiento lo que es lugar, que se quiere dar a, que se está visitando.

Entrevistador: Claro, efectivamente.

Entrevistados: (Oscar) ¿No? No solamente que la gente visite, sino que sepa que es lo que está visitando.

Entrevistador: Ahora ¿Qué es lo más, que es lo que más disfrutan los turistas dentro o bueno, de un centro de interpretación, en este caso del Choco museo? ¿Qué es, digamos, o ustedes que creen que más disfrutaría el turista entrando a un museo, entrando a un centro de interpretación?

Entrevistados: (Oscar) Bajo mi punto de vista, creo que la gente no solamente busca aprender, sino también busca entretenerse, divertirse, la mayoría de la gente está de vacaciones, la gente que nos visita, entonces, evidentemente, buscan ese punto lúdico, de diversión, no solamente que sea algo muy teórico, que les llegue a cansar o aburrir, sino que sea algo totalmente didáctico y dinámico.

Entrevistador: Efectivamente, y participativo también, porque participan ellos, ¿No? Entrevistados: (Oscar) Si.

Entrevistador: Ahora, ¿Por qué creen ustedes que varios de los museos y centros de interpretación creados por el estado, en el punto de inicio de los atractivos turísticos? Yo les 
pongo un ejemplo, por ejemplo, antes de llegar a Machupicchu hay un centro de interpretación, Manuel Ballón, que no es, pues, utilizado muy bien, está vacío, más que todo, todos los días del año ese centro de interpretación. ¿Por qué creen ustedes que estos centros de interpretación creados por el estado, no son tan atractivos para la oferta, para la demanda turística? ¿Por qué no han tenido éxito?

Entrevistados: (Martín) Yo la verdad, creo que es porque depende mucho de los objetivos que tiene el estado, uno de sus objetivos más reales es, hasta los dos mil veintiunos, es reducir la informalidad, esto quiere decir que, cuanta importancia le dan a promocionar nuestros lugares. PROMPERU es demasiado joven para la oferta turística que tenemos, ofertamos centros arqueológicos en un noventa por ciento y no ofertamos más, ese es el tema, un centro de información que solo te brinde la misma información que te va dar un guía de turismo, de la misma información que te va a dar una agencia que te quiere dar un paquete, no tiene un sentido de existencia. Sin embargo, centros de información que pueda darte una experiencia más global creo que ayudaría mucho más.

Entrevistador: Perfecto ¿Y por qué creen ustedes que varios de los? Ya, y desde su experiencia ¿Cuáles son las debilidades, digamos, de muchos centros de interpretación o museos privados acá en la región Cusco? Digamos ¿Cuáles es pueden identificar ustedes como las debilidades que existen?

Entrevistados: (Oscar) Quizá, que no estén bien adaptados a lo que es buscar una experiencia global, tan solamente van a buscar una, como se, no me sale la palabra, un beneficio económico, que es lo que generalmente les interesa y no buscan tanto un beneficio social, que la gente aprenda.

Entrevistador: Claro.

Entrevistados: (Oscar) Entonces, lo ideal, para ofrecer una experiencia global, como ha dicho Martín, es que ambas este combinadas. 
Entrevistador: Perfecto, Ahora, este, comentemos cuales son las ventajas, también ahora, competitivas que tiene, que tendría un centro de interpretación, como ustedes dicen, digamos, integrado global, este, con respecto a la competencia. Digamos ¿Cuáles serían esas ventajas? Las ventajas competitivas, digamos.

Entrevistados: (Oscar) Bueno, bajo mi punto de vista, creo que sería, poner eh, dar mucho valor, ósea, dar un mayor valor al sitio al que se está, al que se está visitando, sería una de las ventajas que yo mencionaría. No se Martín.

(Martín) Algo que me parece bastante interesante igual que, lo que dice Oscar, es que cuando algo nuevo, algo especial sale, hace que el resto se ponga activo a volverse especial, también, porque si no, no va a vender, cuando un centro de información va a mejorar y se va a diferenciar del resto y va a realizar relaciones con el resto, le va a decir: "Hay, podemos hacerlo de esta forma" Lo que va a ser es que todo el turismo crezca, que se crezca o se genere un mejor estándar, que es lo que no tenemos hoy en día, cualquier persona habla lo que sabe, sin embargo, realmente no tiene una biblia de información real como rutas, recorridos, tiempo, altura, siempre le bajan uno o dos metros o le suben algo.

Entrevistador: Si, sí, sí.

Entrevistados: (Martín) Y eso es lo que el turista se da, totalmente cuenta y si no tiene confianza, entonces tu centro de información no funciona.

Entrevistador: Perfecto, perfecto. Ahora, aterrizando la idea ¿Cuáles son las ventajas competitivas del Choco museo en relación a otros museos?

Entrevistados: (Oscar) Bueno, creo que una de las ventajas es que, para empezar, es gratuito, que siempre el hecho de que algo sea gratuito, como que ya te impulsa a ir, muchas veces si algo ya es de pago, como que ya te frena un poco ¿No? Porque venir a Cusco, en comparación con otros destinos, es un destino caro, entonces el hecho de que algo sea gratuito, pues, siempre evidentemente llama la atención y luego, pues, evidentemente, el 
hecho de que sea, creo, creemos que sea Chocolate, que a todo el mundo le gusta el chocolate, es algo que hace que la gente venga y luego la gente se pasa la voz, porque no solamente lo que queremos es que la gente compre chocolate, sino que aprenda cuál es el proceso de elaboración y sobre todo, como viven las familias peruanas que se dedican a la producción de Cacao.

Entrevistador: Digamos, claro, les hacen ver toda la cadena de valor, ¿No?

Entrevistados: (Oscar) Si, entonces eso es algo que nos diferencia mucho, por ejemplo, de nuestros competidores.

Entrevistador: Si, si, si, efectivamente. Ahora ¿Cuántos turistas aproximadamente visitan mensualmente su centro de interpretación o museo? Tanto en temporada alta como baja. Entrevistados: (Oscar) Buena pregunta, porque, como el museo es gratuito, no tenemos una. Entrevistador: ¿Un registro?

Entrevistados: (Oscar) Un registro, nos cuesta mucho, entonces, nos guiamos más por el registro de ventas, el registro de ventas nos es cien por cien exacto, pero a veces hay gente que viene y no compra y luego recomienda a sus amigos que son los que compran, he más o menos, en temporada baja al día, estarán viniendo unas ciento cincuenta personas aproximadamente y en temporada alta, al día entre trecientas y cuatrocientas, aproximadamente.

Entrevistador: Claro, perfecto, ahora ¿Cuáles consideran que debería ser la temática para un centro de interpretación? Ya aterrizando la idea en el plan de negocio que queremos hacer, donde los visitantes son turistas que están a punto de realizar la ruta, que están a punto de empezar una ruta de trekking en Salkantay. Si ustedes tuviesen un centro de interpretación allí ¿Cuál sería la temática? ¿Ustedes que creen?

Entrevistados: (Oscar) un momento Katia, un momento. Creo que los puntos que se deberían de recalcar, bueno además del recorrido que se va a hacer, es evidentemente que la gente sepa 
qué tipo de rocas, por ejemplo, hay y que tipo de fauna y que tipo de flora, qué tipo de climas, por ejemplo, también el tipo de alturas que se va a encontrar, precauciones.

Entrevistador: Claro.

Entrevistados: (Oscar) Temperaturas, sí, creo que también lo que le interesa mucho a la gente es también, por ejemplo, el tipo de roca, que hay, el tipo de fauna, por ahí el tipo de flora. Entrevistador: Claro, efectivamente.

Entrevistados: (Oscar) y los puntos arqueológicos o culturales que puedan haber dentro de la misma ruta.

Entrevistador: Claro, interesante. Ahora, además de la interpretación educativa, pedagógica ¿Qué otros servicios turísticos creen ustedes seria provecho ofrecer en un centro de interpretación, que está ubicado en una zona rural como el que pensamos hacer? Entiéndase por servicios turísticos como restaurantes, abarrotes, no sé, farmacias, servicios higiénicos, algún otro servicio útil que vaya complementado aun centro de interpretación. Entrevistados: (Oscar) Haber, lo que está claro es que, si estamos hablando de un recurso natural, lo que se tiene que preservar es la naturaleza misma, ¿No?

Entrevistador: Humm.

Entrevistados: (Oscar) Lo que no se puede convertir es en otro Aguas Calientes, que está. Entrevistador: Claro.

Entrevistados: (Oscar) Está muy mal hecho, entonces siempre tener muy en cuenta el respeto por el medio ambiente y sobre todo orientar, también, este tipo de centros de interpretación a las familias, que a fin de cuentas, son clientes que gastan bastante, que a veces, ni los niños pequeños no pueden hacer, por ejemplo, un trekking, pero si en el centro de interpretación les ponen, no sé, que puedan los niños ver llamas, alpacas, animales oriundos de esa zona o actividades, o un pequeño trekking de no sé, un circuito de una hora para niños pequeños, saber que no va a ser necesario un trekking de tres o cuatro días. Actividades más pensadas 
también, no solamente para público joven, sino para familias que, quizás no dispongan de tres o cinco días.

Entrevistador: Claro, efectivamente. Ósea, estamos diciendo que, en el centro de interpretación, este además del centro de interpretación ¿Que otro servicio iría ligado a este centro de interpretación?, de repente un abarrote, una farmacia, no sé, hay dentro, en esa zona rural, en ese lugar donde se va a empezar el trekking.

Entrevistados: (Martín) Yo igual que Oscar, pienso mucho que, creo que es demasiado importante la ecología y creo que no se trabaja, casi nada. En Perú hay muchos productores que son ecológicos y se puede trabajar con ellos directamente, si las comunidades producen un tipo de grano o cereal, trabajar con ellos como generar barras energéticas, que no sean las barras comunes que nos venden y que compramos siempre, que no contienen ningún beneficio dentro del, alimentario, sino que realmente sean artesanales y que se puedan llevar los controles de calidad y de higiene, sí. Yo creo que alguien va a comprar este tipo de producto si sabe que no está dañando el ambiente y si también sabe que forma parte de un apoyo a las comunidades.

(Oscar) Si, además de eso puede haber, como hemos dicho, no sé, un restaurante o un hotel, siempre teniendo en cuenta de que las personas que, por ejemplo, deben estar contratadas, deben de ser, gente de la misma zona o que parte de los beneficios del restaurante y beneficios del hotel contribuyan a la economía de la zona, pero siempre respetando lo que es el medio ambiente.

Entrevistador: El medio ambiente, claro, esa política. Ahora ¿Conocen algún centro de interpretación o museo que brinde otros servicios turísticos a los clientes? y ¿Está de acuerdo con la existencia de estos? Digamos, ¿Conocen otro museo o centro de interpretación que además de, bueno obviamente, además del objetivo pedagógico y de enseñanza, ofrecen mismos productos en base a lo que están mostrando? Pero, digamos, la pregunta va a lo que, 
este, si conocen otros museos que también hagan lo mismo y si están de acuerdo con esto ¿Por qué?

Entrevistados: (Oscar) Yo, el único centro de interpretación que así, que he visto es el de Paracas.

Entrevistador: Ya.

Entrevistados: (Oscar) Que, a mí, me pareció realmente muy buen centro de interpretación, ¿No? Porque realmente te explican la formación de cómo se originó toda esa zona, que tipo de fauna, de flora, que, recorridos, entonces sí, que hacen una puesta en valor de todo lo que es esa zona y el conjunto global de la experiencia es muy positiva. Yo no sé Martín que otros centros.

(Martín) La verdad, yo conozco solamente centro de informaciones.

Entrevistador: Si, centros de información, sí.

Entrevistados: (Martín) Centros interpretativos, sin embargo, me parece interesante que se pueda llevar una experiencia global, el pasajero, cuando tú ya llegaste a confiar en él, él confía, ha hablado con una persona, no con una máquina, tiene más confianza de llevarse cualquier producto que tú le vendas a tratar de ir más allá y comprar.

Entrevistador: Claro.

Entrevistados: (Martín) Lo importante creo que es la confianza.

Entrevistador: La confianza que tenga, el contacto humano.

Entrevistador: Ahora, este, a ver ¿Cuáles deberían ser los canales de promoción y publicidad para un centro de interpretación en la región del Cusco?

Entrevistados: (Oscar) Primero hay que tener en cuenta a qué tipo de público al que se tiene que.

Entrevistador: ¿Que llegar? 
Entrevistados: (Oscar) Que llegar, si se quiere llegar a un público extranjero, siempre es necesario trabajar, mano a mano, con las agencias de viajes mayorista, a fin de cuentas, son los que crean los paquetes.

Entrevistador: ¿Un B2B? Digamos.

Entrevistados: (Oscar) Si, efectivamente, eso es necesario, he, agencias y sobre todo guías, porque hay muchos, bueno, hay clientes que directamente contratan a su guía y aparte de eso, pues, si, yo creo que básicamente es agencias mayoristas y luego, si se puede trabajar de la mano con PROMPERU.

Entrevistador: Claro, claro, también.

Entrevistados: (Oscar) Seria de bastante apoyo.

Entrevistador: En el caso de Choco museo, eh, como, digamos, en que canales más tienen ustedes su oferta de promociones, digamos ¿Qué canal utilizan más? ¿Internet, netamente? o ¿Redes sociales? Si tienen videos en YouTube, de repente.

Entrevistados: (Oscar) Lo que nos funciona bastante bien, y es, en verdad es bastante simple y es lo que mejor funciona, es la boca a oreja. Si un cliente se va satisfecho, siempre te va a traer a más clientes, es lo que mejor funciona. Además de eso, evidentemente, lo que nos beneficia es estar bien posicionados, por ejemplo, en Tripadvisor, ¿No? Por ejemplo, estamos posicionados como el segundo mejor museo de toda la región, eso nos ayuda bastante y bueno, evidentemente, trabajar mano a mano, con los hoteles, los guías y las agencias, que son los que nosotros promocionamos.

Entrevistador: Perfecto, ahora, este ¿De quién depende la asistencia de clientes al centro de interpretación o al museo, del guía turístico, del mismo cliente o de la agencia de viajes? Lo acabas de mencionar muy bien, pero digamos, en tu opinión ¿Cuál es el agente de mayor decisión, de mayor poder de decisión ahí, un guía turístico o un agente de viaje? 
Entrevistados: (Oscar) Como ha dicho Martín, el guía, el cliente se fía mucho más de la opinión del guía.

Entrevistador: Del guía.

Entrevistados: (Oscar) Si.

Entrevistador: Perfecto, ahora, este ¿Qué acciones realiza su negocio para fidelizar a los guías de turismo en el centro de interpretación?

Entrevistados: (Oscar) En nuestro caso lo que ofrecemos, evidentemente, es una comisión y descuentos personales para los guías, para que luego puedan venir a realizar actividades con sus familias.

Entrevistador: Claro, perfecto, perfecto. Ahora, este ¿Cuál es su apreciación sobre la? bueno, netamente sus opiniones sobre lo que les he mencionado, un centro de interpretación en una zona donde se va a iniciar un trekking a Salkantay, la zona se llama Mollepata. Que no es un museo, netamente, es un centro de información, como ustedes muy bien lo han dicho, es un centro, más que todo para transmitir información previa antes del trekking, información valiosa, útil ¿Cuál es su opinión? Digamos y yo les pido que sean muy sinceros ¿Estaría bien? ¿Les parece una idea no tan buena, porque no irían muchos pasajeros? ¿Ustedes que piensan?

Entrevistados: (Oscar) A mí me parece bien, más que nada, sobre todo porque el turista extranjero no conoce la región, con lo cual el Trek de Salkantay no sabe todo, ósea, lo que es ¿No? Que áreas comprende, o que se va a encontrar durante el camino, entonces si es necesario ofrecer una buena experiencia. Bajo mi punto de vista, algo que no se debe hacer, en mi opinión.

Entrevistador: $\mathrm{Si}$, por favor.

Entrevistados: (Oscar) Es, por ejemplo, Sacsayhuaman, porque el turista va, ve piedras, pero no sabe, ósea, sino contrata a un guía, no sabe qué es eso. 
Entrevistador: Claro, claro.

Entrevistados: (Oscar) No sabe cómo se ha formado o porque esta así, entonces el turista va y dice: "Bueno, vale, son piedras, pero yo no sé, que hace todo esto aquí"

Entrevistador: Claro.

Entrevistados: (Oscar) Entonces, si es necesario ofrecer información para que el cliente, realmente, tenga una buena experiencia.

Entrevistador: Perfecto.

Entrevistados: (Martín) Yo pienso que hay que trabajar, también, en entender al público. Si bien, tenemos un público que le gusta la información, tenemos muchísima gente que le gusta la "Selfie", aunque parezca un poco divertido decirlo, tenemos que trabajar con este tipo de personas, porque también, compran los paquetes y también disfrutan las experiencias, si nosotros no solamente nos centramos en algo y tratamos de abarcar mayor clientela, como encontrar los lugares perfectos para hacer una "Selfie" Entrevistador: Efectivamente.

Entrevistados: (Martín) A cualquiera le va a gustar saberlo y el otro punto, es trabajar con lo blogueros, hay mucha gente que está viajando y que, si tú tienes alguna recomendación, ponerte a pensar, si tu viajas ¿Qué es lo primero que ve1s? ¿Qué es lo primero que lees? Hay mucha gente, que, por ejemplo, Lonely Planet, es su biblia para viajar y dice: "No, aquí dice que el taxi me cuesta cinco" Trata de bajarlo a cinco totalmente, tener toda esa información y tratar de entender el nuevo público con el que trabajamos y no hacer que el centro se quede ahí, sino que se trate de innovar siempre, para que no se quede olvidado en algún momento. Entrevistador: Claro, claro, efectivamente. Bueno, eso es, este, eso es todas las preguntas de la entrevista. Muchas gracias por su tiempo, esta información no solamente va a ser valiosa para nuestra investigación, sino, también para tener una idea de creación de negocios allí. Muchas Gracias. 
Entrevistados: (Oscar) De nada.

(Martín) Gracias. 


\section{Entrevista de profundidad número 2 - Administradora del centro de interpretación Museo de la Coca}

\section{Perfil del Participante número 2.}

- Experto del Sector: Ingrid Solórzano (Antropóloga de profesión y encargada de la elaboración del guion museográfico de Museo de la Coca); Kelly Ochoa Aedo (Administradora del Museo de la coca). El museo de la coca es el lugar más representativo del Cusco en cuanto al tema de la hoja de Cuca, este es un lugar para que los turistas puedan entender la importancia de la hoja de coca como símbolo de espiritualidad andina, así como medicina y alimento básico en la elite cusqueña. El museo de la es un proyecto que se inició hace 10 años aproximadamente y a la actualidad se ha posicionado como una marca reconocida al punto de que además del museo existe una tienda donde venden productos con la marca "Museo de la Coca" como llaveros, polos, gorros, bolsos, billeteras. Otro punto de ventas importante es la venta de mates de coca al estilo Museo de la Coca, el cual es indispensable para los turistas que visitan el barrio artesanal de San Blas en la ciudad de Cusco.

\section{Desarrollo de la entrevista a profundidad}

Entrevistador: Buenas tardes, mi nombre es Joseph Bonnet, él es Pabel Surco, somos estudiantes de la maestría de la Universidad San Ignacio de Loyola, en esta ocasión, estamos haciendo una tesis de investigación, un plan de negocios sobre la implementación de un centro de interpretación y un restaurante en el Distrito de Mollepata, como parte de la ruta de trekking Mollepata - Salkantay- Machupicchu. Para este punto estamos realizando una entrevista a expertos que son los administradores del Museo de la Coca. Por favor, solo su nombre y lo que hacen aquí. 
Entrevistadas: ¿Yo empiezo?

Entrevistador: $\mathrm{Si}$, por favor.

Entrevistadas: Bueno, buena tarde, gracias por vuestra atención, vuestro interés también, yo recién estoy trabajando aquí, no es mucho tiempo, pero si me encanta, porque, además del trabajo, solamente, de por sí, también soy antropóloga y me gusta, entonces, mi cargo acá es sobre todo ser guía de sitio y en ese sentido, doy las razones porque es importante la hoja de Coca y, claro, por esta parte de la controversia y eso es lo que queremos reivindicar acá, de la hoja de la Coca, que es una planta natural, que nos ha dado la naturaleza y tiene bastante significado, porque es parte de nuestra cultura y de nuestra identidad y todo eso y para des estigmatizarla y yo me aboco más en la parte antropológica, los usos y costumbres y bueno, mi compañera tiene más experiencia también lo que es el aspecto más general, así que ella tal vez les pueda decir. De hecho, que les va a decir.

Entrevistador: Gracias Ingrid, ¿Tu eres Kelly?

Entrevistadas: Yo soy Kelly.

Entrevistador: ¿Antropóloga también?

Entrevistadas: No, de hecho, yo estudie para guía, pero en Lima, estudie Ingles y bueno, estoy aquí, porque, mi interés era desempeñarme en la carrera de guidismo, entonces, me dio una oportunidad el museo como para empezar digamos esta carrera en el Cusco y pues hace dos años, más o menos, que vengo trabajando aquí, como guía. En realidad, nuestro, el trabajo que tenemos aquí es más como explicar y dar información, no tanto hacer un recorrido en el museo, sino básicamente aquí, los grupos vienen aquí y nosotros les transmitimos lo que queremos, que es lo bueno y lo malo, digamos así, de la planta de la Coca.

Entrevistador: De la planta, porque es bien controversial esto de la hoja de la Coca. Bueno, como decía, en esta ocasión vamos a hacer la entrevista a los expertos del Museo de la Coca, 
el Museo de la Coca, como ya nos indicaron, es un centro de interpretación, que se encarga de mostrar los distintos valores hasta controversiales que tiene la hoja de Coca y que, de hecho, son muy interesantes para los turistas. Bueno, la primera pregunta es ¿Cuáles son los objetivos de un centro de interpretación cultural o natural, ¿cuál es el objetivo principal de este lugar?

Entrevistadas: (Kelly) Por el dueño, les puedo transmitir, más o menos, lo que él busca, pienso, su visión es básicamente, mostrar tanto a nacionales y extranjero, visitantes lo que es la hoja de Coca para nosotros, para nuestro país en general, nuestra cultura, lo que significa y lo que simboliza en nuestra cultura. Entonces, lo que él busca es educar a la gente, porque él mismo considera que es un centro donde buscamos educar a la gente y mostrándoles la importancia que tiene la planta culturalmente, la importancia que tiene la planta, biológicamente tiene una composición de alcaloides, químicamente, su composición de alcaloides y los nutrientes, por ejemplo. Entonces, es lo que busca él, educar a la gente, de algún modo cambiar su perspectiva y esta idea pre concebida que tienen, por ejemplo, los europeos, los extranjeros, acerca de la planta de la Coca, él busca cambiar, eso, porque los turistas lo que asumen es que la Coca es Cocaína, hoja de Coca en Cocaína, entonces él busca es eso, cambiar esa mentalidad.

Entrevistador: Es como una intención más educativa que comercial.

Entrevistadas: (Kelly) Exactamente, educativo.

Entrevistador: Educativo.

Entrevistadas: (Kelly) Educativo, sí, yo pienso que inicialmente nació como una curiosidad, un curiosidad porque, les voy a contar un poquito de cómo inició este negocio y te hable, creo que ayer, de que, él estando en la universidad, ya egresando de la UNSAAC (Universidad Nacional San Antonio Abad del Cusco) pienso yo, él estudió Ingeniería Industrial, resulta que en ese tiempo, tenía un amigo, que era uno de sus mejores amigos y pues, el chico cayó en el 
vicio de la Cocaína y justamente él estaba pensando, viendo de que, más o menos, en que iba a enfocarse su tesis, pero tenía el caso de su amigo, que le fue muy mal, pienso yo, en ese tiempo, ya a punto de fallecer por el abuso de la Cocaína, pues en si el joven se llamaba Javier y él falleció por sobredosis, entonces, allí mismo empezó con la tesis y tuvo la idea de, allí esta Javier, falleció por Cocaína, y tuvo la idea, la gran idea, de pensar y enfocarse un poquito más en la hoja de la Coca y de cómo, a partir de la hoja de la Coca, la Cocaína produce un elemento tan nocivo que acabo con la vida de su amigo, entonces él se dedicó a investigar acerca de la hoja de la Coca y como la Cocaína llegaba a hacer eso. Entonces, es así como inicia, más o menos, la tesis.

Entrevistador: La tesis.

Entrevistadas: (Kelly) La tesis.

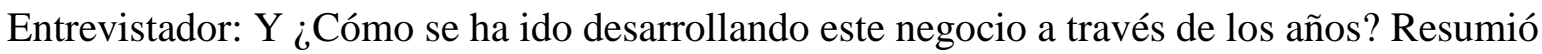
parte de esa idea, pero ¿Cómo ha ido creciendo este proyecto? Y en base, también, a otros lugares que quieren también hacer competencia ¿Cómo están viendo ustedes este crecimiento?

Entrevistadas: (Kelly) Pienso yo, el museo tiene casi diez, once años, por ahí un poquito más y, de hecho, si, empezaron muy, así, muy pequeño, inclusive la tienda que tiene, que de ahí un momento tuvieron la idea de hacer sus propios productos en base a la hoja de la Coca para, de algún modo, sostener el negocio, entonces, ha ido creciendo de poco en poco, pero, pues lo que buscas, ¿me dices? Lo que buscaba realmente el señor con el negocio, pienso que sostener el negocio a través de sus productos y por eso que él tiene un espacio donde él elabora la mayoría de los productos que tenemos en la tienda, pero en ese aspecto, pienso yo que ha ido, porque hasta hace poco, dos, tres años tal vez, no tenía ciertos productos que tiene actualmente.

Entrevistador: $\mathrm{Si}$, exacto. 
Entrevistadas: (Kelly) Pues, ahora, por ejemplo, tiene la cerveza, que lo tiene más o menos hace un año, la cerveza es de algún modo, esta enlazada al muso porque lo producen especialmente para el museo la cerveza, entonces es una cerveza de Coca y pues, él de esa forma está buscando otros productos que tengan como un ingrediente principal la hoja de la Coca, para que de esa forma, él pueda vender un poco más el museo y también mantener y poder solventar todos los gastos que implica el museo de la Coca.

Entrevistador: Claro, pero, ósea, el inicio es mostrar la cultura gratuitamente, pero con el tiempo se da cuenta que necesita pagar e inste tiene que crear productos.

Entrevistada: (Kelly) Necesito, exactamente, porque, como tú lo has dicho, inicialmente, el museo de la Coca era gratis, no había un ingreso, se les invitaba a los visitantes y podían pasar los turistas, pero ya desde hace tres años, más o menos, hay un ticket de ingreso que también ayuda, para poder correr con los gastos de la gente.

Entrevistador: ¿Qué es cinco soles?

Entrevistadas: (Kelly) es diez soles adultos y 5 soles estudiantes, si se trata de grupos, por ejemplo, lo que hace el dueño es ocho soles adultos y, bueno, el precio estudiante que es cinco soles.

Entrevistador: Entonces ¿Ustedes creen que es importante este museo de la Coca o un centro de interpretación?

Entrevistadas: (Ingrid) Bueno, en mi parecer, si es importante, porque el sistema manipula muchas cosas, entonces, manipula la información también y la información no llega tal cual al común de la gente, digamos, o en todo caso a las masas, entonces, cuando la gente viene acá, sale con otro pensamiento, otro modo de ver y no es algo que nosotros nos inventemos ni nada, sustentamos y les mostramos que también hay evidencias, no solamente, tal vez, nos basamos en las evidencias también históricas, incluso ahora último, también científico y toda evidencia científica, pruebas científicas, entonces, si es importante, porque también, no es 
algo que nosotros coaccionemos sobre todo, es algo libre, entonces las personas, cada quien hace su propio, decodificar la información y saca sus propias conclusiones y su comportamiento también ya no va a ser el mismo, entonces, eso es sobre todo y si, para mí, si es importante, porque también abre puertas también para las relaciones interpersonales, porque por ejemplo, yendo más a un aspecto más antropológico, también tocan el eurocentrismo, puede venir un europeo acá y decir: "Estas personas no saben lo que están haciendo, comen Coca y es Cocaína" y no es cierto, entonces, eso crea una barrera cultural que impide que, tal vez, ellos puedan tener una relación más fluida, por ejemplo, con la gente de acá, es un poco, algo, otro recurso más, digamos, que hace que estas relaciones fluyan un poco más y que todos también nos veamos entre nosotros como semejantes y cada quien tiene su comportamiento basado en ciertas cosas, no solamente es porque lo hace como una máquina.

Entrevistador: Exacto, exacto ¿Cuáles son las diferencias entre los perfiles de los turistas que viene aquí? A los que más les gustan, los que más disfrutan, hay de todo tipo de turistas. Entrevistadas: (Kelly) Si, de hecho, de hecho, de acuerdo al lugar de donde vienen, al menos los dos años que he estado aquí ha sido, como, el primer paso para ingresar a este mundo del turismo, he aprendido a diferenciar entre los visitantes de cada país, como los alemanes, los franceses, los japoneses, entonces, pues lo que nosotros, me decías la pregunta.

Entrevistador: Quienes son. ¿Cómo es el perfil del turista que más disfruta esto? Su perfil en base a su nacionalidad, sus edades, sus gustos.

Entrevistadas: (Kelly) Ya, pienso que la persona, las personas que están enfocadas un poco en lo místico, ellos, realmente, lo disfrutan, ósea, hay gente que lo disfrutan de otra forma, los europeos que son un poquito más, los alemanes por ejemplo, los ingleses lo ven un poco, así como de aprendizaje, de culturizarse un poco más y todo esto, pero los místicos, son los que realmente lo disfrutan, disfrutan de verdad y vienen y es como que se emocionan mucho 
viendo la hoja de la Coca y de cómo puede haberse utilizado esta plantita desde hace muchos años en los Andes en sí, entonces, como es que todavía nosotros preservamos ese legado que nos dejaron nuestros ancestros y que todavía lo utilizamos y básicamente, el hecho de que le digas, que lo utilizamos masticándolo, a ellos les fascina eso, porque estas tomando algo natural, que estas tomándolo directamente de la planta, entonces, los místicos quienes buscan conexión con la naturaleza, quienes buscan proteger a la naturaleza, los chicos, que, de algún modo, siempre buscan armonía entre ellos y su entornos, ellos son quienes realmente disfrutan del museo, yo creo.

Entrevistador: Una Edad ¿Tienes alguna edad en específico? Más o menos, entiendo que les gusta a los místicos ese tema del museo de la Coca, pero ¿Qué personas disfrutan un espectáculo de un centro de interpretación? Te digo porque hay turistas, tú los llevas a Sacsayhuaman, tú los llevas a Machupicchu, tú los llevas a cualquier lugar y simplemente quieren la foto, no interesa el lugar que le lleves, lo mismo yo pienso que existe un perfil para un turista de centro de interpretación, yo le puedo llevar a un centro de interpretación de la Coca, del Agua, del Apu, de la Pachamama y tal vez va a disfrutar, entonces es un perfil de turista que estoy buscando. Ustedes más o menos ¿Cómo definen, de que nacionalidades, de qué edad?

Entrevistadas: (Ingrid) Bueno, basado en mi experiencia, bueno, primero quisiera, tal vez, aclarar el punto, bueno decirles que entre museo y centro de interpretación hay una diferencia. Entonces, acá, esto es un museo y en ese sentido y basada en mi experiencia como les dije, a mí también me han tocado diversas personas de diferentes edades, claro también sexo y nacionalidad y si puedo decir, tal vez, yo no pueda catalogar tanto si cierta persona es místico y el otro no, pero sí, claro, un poquito uno puede, tal vez, especular según el comportamiento, quien sabe pero en ese sentido si he encontrado, también, personas, digamos más, que se apoyan un poco más en la ciencia y te preguntan y cómo es esto y que es lo que 
tienen y quien lo ha comprobado, qué se yo. Pero también, las otras personas que tal vez, incluso depende de la profesión, entonces otras personas que puedo decir, que podríamos decir que son místicas o místicos, entonces a ellos también, como que, acá también al mostrarles las evidencias científicas, es como también ponerles un granito de arena más, tal vez, dentro de sus conocimientos, digamos, para que también ellos tengan un recurso para entonces tener un conocimiento más consiente, tal vez. Entonces, bueno, acá recibimos, yo creo que es relativo, en mi punto de vista, porque si he tenido personas a las que les he explicado sobre la hoja de Coca por ejemplo australianos, porque trabajamos con agencias australianas y aparte, por ejemplo ayer hubo una señora, una señorita australiana yo no sé tampoco a que se dedica, yo me pregunto, a veces si también, como un modo de sociabilizar, pero ayer yo no sabía, ella también, hay algunas personas que se cierran por ejemplo de probar la hojita, porque, uno, tal vez no les gusta, ya lo probaron, otro porque siempre hay ese temor que pueda ser Cocaína, que le va causar alguna dependencia, es droga, bueno, ellos ya sabrán y otra que, simplemente no quieren, pero a veces también, dentro de lo que ya se está compartiendo acá, se animan, pueden venir con su idea, como dijo mi compañera, pre concebida y no importa a lo que se dediquen, las inclinaciones que pueden tener, pero en ese momento, es como que entran, adquieren un poquito más de flexibilidad, entonces, como que ya seden, normal también, y claro que es libre y ellos eligen, aceptan, compartimos y degustamos.

Entrevistador: A ya, entonces también por curiosos. Lo que yo concluyo es que les gusta también a los expertos, a los que tienen buen nivel de formación y también a los curiosos. Entrevistadas: (Kelly) Si, siempre, ósea, de hecho, tenemos visitantes creo que, movidos por el interés, sean personas muy preparadas, o sean chicos muy místicos y jovencitos, inclusive estudiantes, personas muy muy mayores, pienso yo, todos vienen con el mismo interés, de querer aprender, conocer un poquito más y de diferentes países, ósea, muchos, podemos 
hablar de muchos, muchos países, no específicamente de un solo lugar, sino de muchos, muchos países.

Entrevistador: Una consulta, ¿Conocen ustedes centros de interpretación construidos por el Estado, en las puertas de los atractivos turísticos?

Entrevistadas: (Ingrid) Honestamente no.

Entrevistador: Ninguno.

Entrevistadas: (Ingrid) Ninguno.

Entrevistador: ¿Qué centros de interpretación del Cusco, conocen ustedes o una especie? Porque también tenemos el Museo del Chocolate.

Entrevistadas: Si.

Entrevistador: ¿Conocen?

Entrevistadas: Si.

Entrevistador: ¿Llegaron a conocer?

Entrevistadas: (Ingrid) Yo solo pase, la verdad.

Entrevistador: ¿Conocen algún otro centro de interpretación o museo? porque, la verdad, entiendo que, la definición de museo tiene sus propias características, el centro de interpretación, pero, delante la ley, le ponen el nombre comercial de museo, pero son un centro de interpretación, por eso es que lo estamos, como que mezclando.

Entrevistadas: Ah ya.

Entrevistador: ¿Conocen alguno acá en el Cusco?

Entrevistadas: (Ingrid) Acá en el Cusco, no. Museos, claro, el Museo Inca, la Casa Concha, está el Museo de la Coca, que más.

Entrevistadas: (Kelly) El Museo del Café, que viene a ser, más o menos, lo mismo, el Museo del Café, también, que es básicamente lo mismo.

Entrevistador: El Museo del Café. 
Entrevistadas: (Ingrid) Pero fuera de Cusco, si me permites.

Entrevistadas: (Kelly) El Parque de la Papa, de repente, he escuchado del Parque de la Papa, he escuchado mucho, pero, iba, estaba planeando visitarlo pero todavía no he llegado, porque aquí tenemos mucho de los productos que ellos elaboran, que son naturales y orgánicos, entonces, si, me nació un interés visitar el Parque de la Papa, me parece muy interesante, porque ellos, inclusive tienen todo desarrollado desde un inicio, las plantas y ellos los cultivan y todo y ya es pues, hacen todo el proceso de sus productos elaborados, es muy interesante.

Entrevistador: Ya, este, de todos estos centros de interpretación que nos han mencionado y conocen ¿Cuáles creen ustedes que son las debilidades de ellos? Incluidos también a este lugar ¿Cuáles, ustedes sienten, que, digamos, pueden mejorar, porque hay una falencia? Acá y también en los demás.

Entrevistadas: (Kelly) Yo, algo que critique en el museo aquí, por ejemplo, es el hecho de que, y lo digo así, honestamente, porque de repente en un momento se dejó de lado el hecho de hacer más investigaciones y de recopilar, un poco, más de información científicas y cosas, actualizarse un poquito en eso, por lo que era los productos en sí, ósea, el negocio, en algún momento se lo dije al dueño, ósea, cual es el fin de esto, el vender los productos, o realmente, mejorar el museo.

Entrevistador: O a la par, también, ¿No?

Entrevistadas: (Kelly) También, de hecho, sí, sí, pero yo pienso que, si tenemos muchas deficiencias en lo que es la información, la misma traducción de la información que tenemos en Ingles que todavía hay muchas cosas por corregir, entonces, tal vez, descuido de este lado, por, de algún modo, lograr un crecimiento económico con los productos.

Entrevistador: ¿Los productos están bien?

Entrevistadas: (Kelly) Pero que es bien, que es bueno, porque de esa forma también. 
Entrevistador: Porque es negocio.

Entrevistadas: $\mathrm{Si}$, incluso he escuchado muchas personas que han venido, que me lo han dicho "Esto no es un museo, es una tienda, esto es un negocio, ¿Qué es lo que buscan? están explotando el recurso que es la planta" Lo he escuchado de algunos visitantes, no siempre pero le he escuchado, entonces y todavía me comentan: "Es lo mismo que hace el Choco Museo" explotan el Chocolate por hacer un negocio en el mercado, todo eso, pero, ósea, yo me voy al hecho del descuido, del no crecer y no buscar, no mostrar mejorar la información, pues hacer un mejor estudio de lo que es la Coca en sí, ósea, me parece súper eso, pero también, no descuidar de este lado.

Entrevistador: ¿Algo para criticar del Choco Museo?

Entrevistadas: (Kelly) ¿Del Choco? Yo le he visitado varias veces, tengo amistades allí también, ¿Algo de criticar de allá? No, en realidad, no, no, no podría tanto porque, no soy parte de allá, de repente, pero, me parece súper también el hecho de que muestren, porque te diré, mira, por ejemplo, vienen muchos turistas aquí, los gringuitos entran y me ha pasado que yo les explico y les hablo y les hablo de la Coca y de repente me dicen: "Y, pero ¿De dónde viene el Chocolate?” y yo: “¿El Chocolate? no, yo te estoy hablando del Coca Lips, no del Cacao" Es como, confunden ellos el Coca Lips con el Cacao y me ha pasado muchas veces: “QQue estamos en el Museo del Cacao, del Chocolate? No esto es Coca Lips” Entonces, me parece súper que haya este tipo de lugares, donde uno pueda, realmente, enseñar a la gente, educar, ósea, educar, eso es lo que yo, lo pongo así, como muy primordial, muy primero, que estas enseñándoles, porque ellos no saben, de hecho, nosotros podemos saber, entonces ellos dicen: “¿Cómo es eso, Coca Lips no es lo mismo?” o te dicen: ¿De dónde sale el Chocolate?, si la planta es así, puras hojas" Entonces, totalmente ignorantes de lo que puede ser o desconocimiento total de lo que son las plantitas. Entonces, yo pienso que es eso. 
Entrevistador: ¿Algún factor competitivo que ustedes hayan notado de este lugar y también de los otros, de la competencia?

Entrevistadas: (Ingrid) Yo, bueno yo volviendo, también, un poco a la pregunta anterior, tal vez, de hecho, está ligado con competitividad, como estas preguntando ahora, creo que también tiene que ver un poco con la infraestructura, a parte de la información, que, si, también, estoy de acuerdo, porque también hay algunas fallas ortográficas que incluso también les he dicho, es que también, bueno, nosotras trabajamos acá, podemos dar ideas pero, también es una empresa privada, en ese sentido, el dueño es el que sabe cómo está la administración, es decir, él es el que administra más la parte económica - financiera, entonces, ese es un poco también, creo, la falencia, porque al entrar, por ejemplo, solamente se muestra este lado y todo el mundo cree que solamente es esto y, entonces, se quedan como, ósea, vienen con una idea, también, pre concebida de lo que es un museo. Entrevistador: Efectivamente.

Entrevistada: (Ingrid) Un museo se lo imaginan como algo grande, no sé, una presentación, tal vez, diferente, a esta, entonces, entran acá y se encuentran con dos muros y una tienda, pero, claro que ya, también, poco a poco ahí es donde nosotras entramos y les decimos:” Que tal, bienvenido ¿Desea visitar el museo? Esta es la tarifa, si desea, puede ser esto, que es de la tienda" pero, entonces, es como les decía, la infraestructura, porque, al entrar acá atrás, en la parte de atrás, ustedes, tal vez después puedan verlo, ahí más información, hay más cosas para observar, para ver, pero es también como está ambientado por el espacio y todo ello, entonces, no, tal vez, esa es una falencia también. Pero, imagino, yo también, que es porque es algo privado, entonces, el señor administra con sus propios recursos y los productos, aunque esté ligado al museo y tal vez desvirtúen un poco, su, para lo que está destinado en un principio, fue destinado, también es un recurso y tiene que mantenerlo y ese sería un poco mí. 
Entrevistador: Pero, ellos se quejan cuando ven solo esto, pero cuando entran a los demás salones, ya como que.

Entrevistadas: (Ingrid) Si. Hay es cuando después cambian, salen por allá o en ese momento, te lo dicen en ese momento o bien todavía, también se ponen a ver los productos y allí también ya van cambiando aún más, porque, tal vez, al principio, como dice mi compañera, entran y dicen: "Esto es un negocio" pero después dicen: "Ohh, interesante, tienes chocolate de Coca, tienes esto de Coca y tienes esto de Coca” entonces después ya, al salir por la puerta, pues ya para despedirse: “Ah, bonito, gracias” y no sé qué, todas sus apreciaciones. (Kelly) La palabra de ellos, perdón Ingrid, que utilizan al final es: "Fue muy interesante". Lo tenemos ahí en el cuadernito de comentarios.

Entrevistador: Porque si tienen, ósea, acá a simple vista, si pues no, parece una tienda, pero cuando entras a los recintos, si, si tiene buena información.

Entrevistadas: (Kelly) A pesar de nuestras deficiencias, como decía Ingrid, en infraestructura y en información, que la información es súper, así, para criticarlo porque hay muchas fallas ortográficas en Ingles, a pesar de todo, ósea, yo veo a los turistas y dicen: "Wao, interesante, ha sido uno de los lugares que me ha parecido más interesante comparando a todos los demás museos que he visitado" ¿Puedes creerlo? Ósea, a pesar de todo. Entrevistador: Y ¿Eso por qué? ¿Por qué creen ustedes? ¿Por la información? Entrevistadas: (Kelly) Porque, alguna vez escuché a uno de ellos que me dijo porque le parece que la Coca es algo muy, muy interesante, si bien es cierto, no tiene que ver nada con Arqueología, por ejemplo.

(Ingrid) Con restos.

(Kelly) Con varias cosas, ósea con historia sí, pero no tanto, ¿Cómo se diría esto? (Ingrid) ¿Restos Arqueológicos? 
(Kelly) Exacto, con Arqueología en general, pero es igual de interesante, porque es una planta milenaria, ósea es interesante, es muy interesante, porque en Museo inca es lo mismo, el Museo de Arte Contemporáneo es casi lo mismo, el museo, pues, hay muchos museos de historia, ves casi lo mismo, pero esto es algo totalmente diferente, dicen ellos: “Ósea nunca me imaginé que la Coca fuera tan importante en vuestra cultura”. Entonces, eso y lo he escuchado de varios.

Entrevistador: Y ustedes responden bien, tienen buena información de eso. Entrevistadas: (Kelly) Si, hay muy buena información.

(Ingrid) Si, aparte de eso, si también he visto, no solo hay, fallas ortográficas sino que es el Inglés, también y en Español, abecés también en algunos folletos que tenemos, pero, muy aparte de eso, y ahorita es lo que veo también, creo que esto es diferente también al museo de Arte Contemporáneo, como dijo mi compañera o al Museo Inca también, porque, es que la hoja de Coca tiene vigencia, aparte de que mostremos acá las evidencias arqueológicas de una historia que ya pasó, de algo que forma parte de nuestro pasado también expresamos o demostramos dentro de la información en la parte de atrás su estado actual contemporáneo, entonces como que la gente también, tiene más relación, está ligado a su presente, entonces es ahí donde tal vez, la información para ellos es más, parte de su vida. Entonces, es ahí donde salen ya con otras ideas, otras concepciones y, bueno, ya pueden salir al mundo y decir cuando vean en la tele: "Es Cocaína" y esta es la hoja de Coca y decir: "No son los mismo". Entrevistador. Claro, entonces el proceso lo hace más competitivo a este lugar. Ahora, al museo del Cacao o a otro centro de interpretación que ustedes conocen, algo competitivo que ustedes hayan visto.

Entrevistadas: (Ingrid) Yo, bueno, centro de interpretación en ese sentido estricto, digamos, de las palabras, yo he visto, más bien, fuera de Cusco, no sé si se les interesará. Entrevistador: Si, si, por favor. 
Entrevistadas: (Ingrid) En uno de mis viajes, cuando fui por Tumbes, si no me equivoco, hay si había centro de interpretación pero de las aves, entonces, no estuve, creo que yo no visité, no me acuerdo bien, pero, tal vez para hacer la diferencia, honestamente yo no he buscado en un diccionario el centro de interpretación, solo tengo una idea, lo que puede ser, pero, allí si, en ese centro muestran, por ejemplo, las aves, también, como fueron antes en fotografías y todo eso, pero también te llevan a un lugar donde ves a las aves en su estado natural, están vivos y cada quien puede observarlas. Están allí en el campo, en el aire libre y creo que es diferente en ese sentido, para mí, un museo a un centro de interpretación. Muestra también, esto es un museo y solamente tenemos la información, las evidencias, pero en un centro de interpretación es un poco más, también muestra la realidad, digamos, entonces ya la persona ve tal cual, digamos, en ese lugar, tal cual viven las aves y están allí.

Entrevistador: Una consulta ¿Cuántos turistas aproximadamente visitan usualmente este lugar tanto en temporada alta como en temporada baja?

Entrevistadas: (Kelly) ¿En un día?

Entrevistador: Más o menos, un promedio.

Entrevistadas: (Kelly) ¿Diario?

Entrevistador: Diario o mensual.

Entrevistadas: (Kelly) Ósea, acortándolos por persona, ¿Así?

Entrevistador: Más o menos, si, ¿Cuántos te visitan diario en temporada alta?

Entrevistadas: (Kelly) Wao, por ahí, más de cien, tal vez, en temporada alta. De los grupos, normalmente, son de dieciséis, a veces veinte, a veces catorce, entre catorce y veinte, entonces en un día, algunas veces vienen cinco grupos o a veces cuatro grupos fuera de la gente que ingresa libre que son muchos más, ósea, hablamos de.

Entrevistador: Un promedio de.

Entrevistadas: (Kelly) Tal vez, doscientos cincuenta. 
Entrevistador: ¿Ciento cincuenta?

Entrevistadas: (Kelly) Doscientos cincuenta.

Entrevistador: ¿Diarios?

Entrevistadas: (Kelly) sí.

Entrevistador: ¿En temporada alta?

Entrevistadas: (Kelly) si, en temporada alta.

Entrevistador: Que eso es desde.

Entrevistadas: (Kelly) Es imparable.

Entrevistador: De abril a.

Entrevistadas: (Kelly) De abril a agosto.

Entrevistador: ¿Y en temporada baja?

Entrevistadas: (Kelly) Wao, no sé, unos veinte.

Entrevistador: Diarios.

Entrevistadas: (Kelly) Por ahí diez, es que a veces, ahorita, tuvimos, ¿Hoy cuantos tuvimos más o menos?

(Ingrid) Creo que cinco a seis.

(Kelly) Cinco, o sea súper bajo.

(Ingrid) Bueno, desde que entré, porque entro a la una.

Entrevistador: ¿Cuáles considera? Conocen la ruta Salkantay ¿Verdad?

Entrevistadas: (Ingrid) Bueno, no.

(Kelly) Lo conozco, pero.

Entrevistador: En teoría.

Entrevistadas: (Ingrid y Kelly) Si en teoría.

Entrevistador: Tu como Antropóloga y tu como guía.

Entrevistadas: (Ingrid y Kelly) Si. 
Entrevistador: ¿Cuál consideran ustedes que debería ser la temática para crear un centro de interpretación en el inicio de esta ruta? Y ¿Qué tema debería de tener para ustedes? (Pabel) Digamos, poniéndolo en la idea de que, digamos, ustedes, digamos con el conocimiento que tienen sobre este museo, desean poner no un museo, un centro de interpretación ahí en Salkantay. Como les explicó Joseph, este es una entrada para un trekking a Salkantay.

(Joseph) Que dura cuatro días, tres noches.

(Pabel) ¿Qué cosa debería, digamos, mostrar o tener, más o menos?

Entrevistadas: (Kelly) Wao, muchas cosas, muchas cosas, ósea en general, incluso la hoja de la Coca, ¿Por qué? Porque los turistas vienen y dicen: "Voy a hacer el Trek a Salkantay y quiero Coca" y son cuatro días.

Entrevistador: Efectivamente.

Entrevistadas: (Kelly) Entonces, es como que vienen: “Ah ya, para cuatro días necesitas tantas bolsitas, tantos gramos" Para que sea mucho mejor efecto necesitas llevar el alcaloide para que te ayude, ósea que, Coca básico, porque los turistas lo mismo que están subiendo y mal de altura, van a padecer muchas cosas, entonces, pienso yo.

Entrevistador: Un tema puede ser.

Entrevistadas: (Kelly) Un tema súper, súper importante.

Entrevistador: ¿Algún otro tema? Lo hemos pensado también. Si, nos pareció también. Entrevistadas: (Kelly) Yo, ósea, tengo dos años trabajando aquí, para mí, ósea, el señor y la idea de hacer este museo me pareció genial, genial, genial. Yo adoro estar en el museo, me encanta, desde que empecé, yo crecí desde pequeñita con la hoja y la Coca para mi es importante y yo le digo: "Señor, usted es un genio" porque, un museo de la Coca, para mí el museo del Chocolate podría ser en el cualquier lugar ¿me entiendes? Porque, es, bueno, chocolate y vender chocolates, pero el museo de la Coca es como, decía yo, educacional y es 
increíble lo que abarca esto, entonces, pienso yo que la Coca es un elemento muy, así, importante, en un lugar así.

Entrevistador: ¿Algún otro? ¿Alguno otro tema? Tal vez tú como Antropóloga puedes. (Pabel) Digamos, ¿Qué cosa podría necesitar, ¿no?

Entrevistadas: (Ingrid) Bueno, tal vez, sería un poco, de ver para qué era esa ruta también, para qué era esa ruta, como es ahora y en el sentido de preservarla también. Entrevistador: Exacto.

Entrevistadas: (Ingrid) Entonces, tal vez también mostrar la vivencia del lugar.

Entrevistador: De los pobladores.

Entrevistadas: (Ingrid) De esa parte, yo creo que todo eso.

Entrevistador: Exacto.

Entrevistadas: (Kelly) Y, así como, hablando de preservar, ver el modo, la forma de cómo es que convive gente de por allí con la naturaleza, ose preservando y la forma de convivencia y de respeto, que todavía se debería de mantener entre su entorno natural, del Nevado y tantas cosas que deben de haber allí, con la gente misma, ósea, mostrarles lo que la gente realmente disfruta y lo que la gente vive con eso que tiene a su alrededor, como es que ello valoran que todavía todo eso es natural.

(Ingrid) Lo recursos.

(Kelly) Si, los recursos.

Entrevistador: Ya, prefecto. Además de la interpretación educativa ¿Qué otros servicios turísticos creen usted que se pueden ofrecer en un centro de interpretación rural? Hablando de Mollepata. Entendiéndose como servicios turísticos, como abarrotes, farmacias, un shop, servicios higiénicos ¿Qué más?

(Pabel) Entendiendo porque van a empezar la ruta y ahí posibilidad de que compres nada, como una botella de agua. 
(Joseph) ¿Están de acuerdos ustedes, con eso del shopping, de crear un centro de shopping? Entrevistadas: (Ingrid) Bueno, si ya hubo, hay opiniones, hubo opiniones de que están mezclando museo, por ejemplo, acá estamos mezclando museo con negocio, y ha sido como una crítica, tal vez, creo que no sería tan conveniente.

Entrevistador: Si pones en la balanza los que te critican, con los que compran.

Entrevistadas: (Kelly) Ah no, definitivamente la gente lleva, que se lleva un producto de Coca, es la gente, la mayoría, son la mayoría y pues yo creo que la satisfacción de llevarse un producto de Coca, sea un dulce, una galleta es lo máximo. Es mínimo, ósea, las personas que vienen con ese comentario son mínimo, porque, realmente, lo he escuchado, pero la mayoría de ellos se van súper complacidos, al menos con una galleta.

Entrevistador: Un shop.

Entrevistadas: (Kelly) Si.

Entrevistador: (Pabel) Porque también puede haber, digamos, esa mala idea de que un museo, un centro de interpretación, justamente un centro donde tú vas a adquirir conocimientos. Digamos, cuando ya ven, digamos, no sé, un shopping o algo, ya, como que, pueden malentender el visitante y "Me están llevando acá, no para conocer, sino para que yo gaste" Entrevistadas: (Kelly) Si, perdón, en todo caso, hay algo que esté relacionado con lo que, que viene, ósea, que sea todo, un todo, que esté relacionado con lo que se ofrece, que alguna vez, si se dan cuenta, allá al frente tenemos ese espacio, ahí teníamos tipos unos stand y teníamos gaseosas, teníamos galletas, esas galletas que las vendían en todas partes y todo tipo de golosinas y la impresión del turista era como que "No, esta es una tienda de abarrotes" Pero allá dentro no escuchas sus comentarios, porque saben que todo es de Coca y dicen "Uh, todo esto es de Coca y Wao" mientras que veían esas cosas y caramelos y dulces y chicles y estaba todo eso lleno de productos, de gaseosas.

Entrevistador: Y ¿Lo sacó? 
Entrevistadas: (Kelly) Lo saco, por las críticas, porque, yo era la que tenía, recibía a los turistas y era como que: "Esta es una tienda de dulces y golosinas"

Entrevistador: Pero también tienen Coca Colas adentro, he visto.

Entrevistadas: (Kelly) Si hay Coca Cola porque estaban relacionados con la Coca. Sí.

Entrevistador: Ah, claro.

Entrevistadas: (Kelly) Hay, este, de hecho, una y otra bebida, porque, básico, el turista siempre va a buscar agua, agua que es el elemento líquido y una y otra cosa que algunas veces buscan como licor, por ejemplo, el Pisco que es súper de nosotros, el Pisco, el Pisco Sour. Pero esas cosas que había allí eran totalmente, como Pringles, que se yo, caramelos, cajas de caramelos, chicles y bombones y una y otra bebida que no venía al caso, entonces, era muy feíto escuchar comentarios de los turistas: “¿Qué es esto? Esto es un market” o algo así y entonces el dueño decidió, hace poco, sacar todo eso, ya no lo tenemos.

Entrevistadas: (Ingrid) Tal vez, dependerá también, pero, bueno a parte de todo ello, lo que, no sé, se me estaba viniendo a la mente, era recreación, por un lado. Claro que, es nada más que para un descansando, porque van a estar en movimiento y tienen que empezar el trekking para, no sé, esto que se me vino a la mente. Recreación, pero, también en un sentido de, de acuerdo al contexto también.

Entrevistador: ¿Cómo recreación?

Entrevistadas: (Ingrid) No sé, por allá, por ejemplo, lo que se hace en esa zona, cabalgata. Entrevistador: Ah ya, claro.

Entrevistadas: (Ingrid) Un poco de lo que acostumbran hacer por allá. Sentido recreacional. Entrevistador: $\mathrm{Si}$, Si, esas son, eso es el participativo, que también lo estamos evaluando, que también podría ser. ¿Cómo influye el guía de turismo para que aumenten el número de visitas aquí? ¿Es importante la labor del guía? 
(Pabel) Digamos, ¿Es un agente decisivo el guía de turismo? Digamos, bien un grupo con un guía y te dice "Oye, mira, les ha encantado, voy a traer otro grupo" o digamos, ¿Tu recibes reservas de un agente de viajes? Que también es otro factor decisivo acá.

Entrevistadas: (Kelly) Ósea, ¿Si es indispensable el guía?

Entrevistador: Yo pienso que sí, porque como dice el dueño, es la imagen del museo, es la persona que al menos, desde que ingresa el turista los recibimos.

Entrevistador: Claro.

Entrevistadas: (Kelly) Y, pues, pienso yo que, el hecho que le transmitas desde ya lo que tenemos en el museo, entonces, eso me pareció bueno.

Entrevistador: Si un grupo viene con su guía ¿El guía hace su explicación? O siempre les deja a ustedes.

Entrevistadas: (Kelly) Normalmente, los grupos, al menos, con los que trabajamos vienen con su TC, con el Tour Conductor, o con el guía, pero normalmente con el trasladista, entonces, al ingresar ellos, nos ceden al grupo, nos presentan, es ahí donde nosotros ingresamos. Entrevistador: Pero ¿Siempre hacen ustedes el tour? Nunca han dejado que el guía lo haga: Entrevistadas: (Kelly) Una y otra, algunas veces pasa que los guías, están súper, así, como, con el tiempo y dicen: "Sabes que, tu información es un poco amplia y no quiero estar cortándote y esto, yo le voy a explicar algo que yo tengo allí en mente, muy rápido”. Entonces raras veces ellos sí, son raras las veces.

Entrevistador: Y, ahora, ustedes a los guías ¿Los motivan con alguna comisión o algo así? Entrevistadas: (Kelly) No, no es la política del museo de la Coca. No se puede. Entrevistador: (Pabel) Una consulta, tus reservas, porque recibes reservas, a parte que digamos, que vienen en lo que sería, las reservas más que todo ¿Te la hacen agentes de viajes o guías?

Entrevistadas: (Kelly) Uhmm, pienso yo agentes. 
Entrevistador: (Pabel) Los agentes de viajes.

Entrevistadas: (Kelly) Los agente, con uno que otro guía que viene libre.

Entrevistador: (Pabel) Claro, que tiene su grupo libre.

Entrevistadas: (Kelly) Si.

Entrevistador: (Pabel) Pero, digamos, grupos que vienen con agentes de viajes.

Entrevistadas: (Kelly) Si, exacto, porque hay agencias que llaman y dicen: "Sabes que, tengo un grupito que les interesa el museo de la Coca porque lo vieron en tal, tal, tal link, de tal página web" porque hay el Tripadvisor, ¿No es cierto? Muchos de ellos vienen por allí, es como que: "Mi grupo llegó y están bien interesados en el museo"

Entrevistador: $\mathrm{Y}_{¿}$ Ustedes los fidelizan?

Entrevistadas: (Kelly) ¿Fidelizar?

Entrevistador: A los agentes de viajes o a los guías.

Entrevistadas: (Kelly) Uhmm, no.

Entrevistador: ¿No, en ningún tipo? Por ejemplo, te comento, en algunos casos al guía, cuando viene el guía lo invitan a algún lugar para que almuerce a un centro.

Entrevistadas: (Kelly) No.

Entrevistador: $\mathrm{O}$ ¿Les dan algún tipo de incentivo económico a los agentes de viajes?

Entrevistadas: (Kelly) Bueno, la agencia, esta especifica con la que trabajamos que es Pick, que tiene muchas marcas, lo que el dueño hace es, no tanto darles un incentivo económico, sino invitarles, no sé, chicos ¿Se sirven una galletita de Coca? ¿Se sirven una Coca Cola? Entonces, normalmente los guías, por ahí, se sirven un dulce o algo.

Entrevistador: Ah, ustedes les invitan ahí, gratis.

Entrevistadas: (Kelly) Si, si, no siempre pero obviamente siempre se les ofrece, pero algunas veces, ellos pueden recibirlo o no, también. Sí, pero el dueño mismo es quien les ofrece, les ofrece a ellos para que lo degusten. 
Entrevistador: Entonces, y esa es su forma de fidelizar.

Entrevistadas: (Kelly) Si, ahora, cuando son libres, cuando son guías que vienen con grupos así, independientes, que están por ahí, lo que hace es: "Ya te voy a dar o les voy a cobrar a tu grupo ocho soles adultos, ya no diez sino ocho y cinco estudiantes" Pero no es que les va a dar el dinero que, a cambio, ósea de lo.

Entrevistador: (Pabel) Claro, de una comisión.

Entrevistadas: (Kelly) Simplemente pagan ese monto, le das ese mismo monto.

Entrevistador: Ya, listo ¿Considera usted que se debería cobrar un ticket para el centro de interpretación?

Entrevistadas: (Kelly) Eso es súper, así, como que, te diré que yo estoy aquí casi dos años y ha sido así todo el tiempo, la pregunta que se hace el mismo dueño, que de tiempo en tiempo aparece, es como: "No sé ¿Qué les parece, seguimos cobrando? O de repente es mejor decirles que pasen y colabóranos, contribuyan con algún producto”.

Entrevistador: Exacto.

Entrevistadas: (Kelly) Porque, pasa de que una vez quiso poner el letrero este en la puerta y con los precios, los costos de ingresos y yo le dije, no creo que sea buena idea, porque muchos turistas, aquí suben y ven eso y se van: "Hay un ticket de ingreso". Si esta fuera, imagínate, no vamos a tener chance de ni siquiera decirte: "Bienvenido y sonreírles y decirles; pasen te invitamos". Se van a ir apenas ven eso.

Entrevistador: Exacto.

Entrevistadas: (Kelly) Entonces es como que no. El dueño tenía muchas dudas por eso, cobrábamos les parece que tenemos que invitarles a hacer el recorrido ya después nos pueden contribuir con un producto, también les parece bueno.

Entrevistador: Es bien debatible eso, Por ejemplo, en Chinchero hay un centro textil, donde los comuneros ofrecen sus textiles. 
Entrevistadas: (Kelly) Si, si, si,

Entrevistador: Y tu entras y la señora te explica como quince minutos como se tiñen las telas, como se saca la lana de la oveja y todo eso y al final te agarra un huesito y te empieza a jalar la lana y te dice "Con este huesito vamos a jalar la lana "y tu esta ya y te dice "¿Saben ustedes que es este huesito?" y dicen: "No" dicen los turistas; "Este huesito es de un turista que no me quiso comprar"

Entrevistadas: (Kelly) Lo he escuchado, lo he escuchado.

Entrevistador: Y todos ahí se miran y ya “Por favor, pasen acá a comprarnos”. Entonces, ya les hizo el gancho.

Entrevistadas: (Kelly) Si, eso me parece, a mí, yo particularmente, pienso, ósea, que es bueno, yo haría algo así ¿Me entiendes? Hacer toda una explicación y mostrarles y al final ofrecer lo que tú tienes y de la forma como tu mantienes, si se puede decir, el museo o centro de interpretación. Entonces, yo pienso que es bueno, el hecho de no tener que cobrarles un ingreso, porque ellos se van a sentir como que, no tanto obligados, pero de algún modo, pues bien, recibidos, visitarlo y todo, pero sentirse con la, tal vez, obligación de contribuir con la línea del producto.

Entrevistador: Exacto.

(Pabel) Comprometidos.

Entrevistadas: (Kelly) Si

Entrevistador: Comprometidos.

Entrevistadas: (Kelly) Si, están como comprometido, exactamente, de llevar algún producto. Entrevistador: Y los precios que ofrecen ustedes ¿Es muy caro?

Entrevistadas: (Kelly) No, no, para nada, para nada. El señor maneja sus precios súper, súper económicos, yo te digo de verdad, cuando entran, algunas veces yo les digo: "Pasen chicos" 
igual nacionales, porque los precios, de verdad, todos son en soles y son costos muy, muy económicos, dos soles.

Entrevistador: ¿A cuánto está la Coca Cola?

Entrevistadas: (Kelly) Un sol cincuenta, dos cincuenta.

Entrevistador: Demasiado barato.

Entrevistadas: (Kelly) Ósea, inclusive han venido guías mismos, más los TCs que entran con sus grupos y dicen: “Oye, pero ustedes están vendiendo el agua parecido a la gente que vende en la calle, este es un lugar turístico, reciben gente, turistas que manejan su dinero ¿Por qué no lo venden en cuatro o cinco soles?" Y el dueño nunca hizo caso a eso. Incluso, yo misma le dije, porque no sube un poquito, pero no, él vende precios súper módicos, así que otro lugar.

Entrevistador: Tal vez, si dejan de vender tickets, tendrían que subir el precio de los productos.

Entrevistadas: (Kelly) Si, que, por ahí, tal vez que sí, sí, sí, puede ser.

(Ingrid) En mi opinión, si me permiten, en mi punto de vista, esto de cobrar o no cobrar, yo no lo veo, tal vez, como algo bueno o malo, sino más bien algo necesario, creo. Porque, así como un investigador hace su trabajo, ustedes ahorita están estudiando, tienen que pagar por vuestros estudios, cuando alguien hace un estudio necesita comer, alimentarse, necesita vestir, necesita lo mínimo para la impresión. Entonces, yo creo, en ese sentido, es necesario cobrar, claro que también hay que ver otros aspectos, para eso, pero acá, esto no es algo que haiga salido de la nada tampoco, y aparte de ello, para hacer los productos, detrás de ellos hay trabajadores, hay personas que también necesitan o, aunque no necesitaran simplemente uno trabaja y el trabajo no puede ser así nomás, mínimamente necesitamos siempre las existencias, entonces en ese sentido, yo creo que es algo necesario. 
(Kelly) El señor en realidad, él, lo que le escucho, porque converso con él y todo, él siempre aduce el hecho de que el alquiler en San Blas no es cualquier cosa.

Entrevistador: Si.

Entrevistadas: (Kelly) Puedes hacer tus donde sea, pero en San Blas, es zona súper, súper caro. Incluso, a nivel Cusco, es el barrio súper caro en alquileres, es muy costoso y por eso, por esa razón es que el decidió hacer el ticket, pienso yo, porque, él, así, personalmente, yo pienso que no, no tendría un ticket de ingreso, un costo para ingresar al museo, pero por esto se le ha obligado, por el alquiler, que te digo, más de, tal vez, cinco mil soles, seis mil soles y por el personal que él tiene a cargo, que son dos, tres chicas en producción, más las guías de aquí, entonces obligado, es obligado casi.

Entrevistador: $\mathrm{Y}_{¿}$ Ustedes reciben, ganan más en los tickets o lo que venden en el shopping? Entrevistadas: (Kelly) En las ventas.

Entrevistador: En las ventas de shopping.

Entrevistadas: (Kelly) Si, en las ventas, pienso yo, si porque, si bien es cierto, vienen, a lo mucho, cuatro, cinco grupos al día y desde ahí el ingreso es ocho soles adultos, cinco estudiantes, puede venir una parejita de turistas y dicen: "Yo me quiero llevar" y se llevan casi toda la tienda, hacen compras de cuatrocientos, quinientos soles, licores y chocolates, igual, viene otro grupito y se lleva uno y otro producto. Es mucho más, creo, en ventas, ¿Qué piensas tú?

(Ingrid) Creo que no podría hacer tanto balance, pero, es que es muy relativo también.

(Kelly) Si, es relativo.

(Íngrid) A veces, también entran y solamente quieren museo.

(Kelly) Exacto.

(Íngrid) Y bueno, pagan su ticket y después se van. Tampoco no han comprado nada. O bien, también, a veces, incluso no entran ni al museo. 
(Kelly) Exacto.

(Íngrid) Porque a veces decimos y bueno: "Bienvenidos y que cobramos esto, que es una contribución” pero aparte, a veces, no sé, como también les dije, ven esto y tal vez no se animan y bueno, por los productos y porque y le decimos: “Ahí si pues también es gratis y es gratis, si quieren pueden pasar”. Entonces, ven un rato y compran, entonces, en ese momento, podemos decirles, bueno: "Por la compra también gracias, por cortesía si desean, entonces, pueden pasar al museo"

(Kelly) Eso es variable, de acuerdo a la decisión del dueño, es variable, ósea, el dueño, hace poco, hace pocos meses decidió y nos dijo: "Saben que, van a invitar a los turistas a entrar a la tienda, si no quieren visitar el museo, invítele a entrar a la tienda y pues, por su contribución, les vamos a invitar al museo" y parece mentira entraban a la tienda y compraban muchos productos, de lo que había podido ser, tal vez, esos diez soles de ingreso, entonces, allí invitamos a recorrer el museo, incluso a turistas que para nada quieren el museo: "No gracias, no, no me interesa mucho" y van a la tienda y se compran todos los productos que buscan, entonces, hay algunos que entran, pagan su ticket y simplemente salen, gracias y ya no visitan la tienda, también.

(Ingrid) Hay otros, que también entran al museo y también compran.

(Kelly) Como que no decide aun, no, de qué forma. Ahorita en temporada baja, lo que estamos haciendo es: "Por favor, pasen, visite el museo” y al final un producto: “¿Les gusta esto y esto?" y compran.

Entrevistador: Ósea, esta época, si dejan entrar gratis.

Entrevistadas: (Kelly) Si, si, es lo que estamos haciendo nosotras, ósea no a todos, pero: "Pasen pueden visitarnos" y al final nos compran el producto. Eso puede variar, es relativo. 
Entrevistador: La última pregunta ¿Cuál es su apreciación de la creación de un restaurante que permita que los comensales puedan visitar gratuitamente el centro de interpretación en el lugar que les estaba mencionado Mollepata?

Entrevistadas: (Kelly) ¿La presencia de un restaurante?

Entrevistador: Ósea un restaurante que les, crear un restaurante donde puedan desayunar. Entrevistadas: (Kelly) Calidad de servicio.

Entrevistador: Y desayunan, cuando acaban de desayunar pueden ir el centro de interpretación.

Entrevistadas: (Kelly) ¿Libremente?

Entrevistador: Libremente, gratuitamente y de paso también comprar. Ya segaña con el restaurante, pero también un plus, con el tema del centro de interpretación.

Entrevistadas: (Kelly) Si, yo pienso que es bueno.

(Ingrid) Si, también viendo, tal vez también no, la zona, si, ya en el transcurso del, la experiencia es más que solamente la especulación. Así que, está bien, porque si es necesario, si hace falta, un restaurante. Claro, también, tendría que verse, creo que hay que hacer un estudio, también, de las personas que van por allá, que hacen esas rutas, creo.

Entrevistador: Claro, yo lo digo desde su punto de vista. Ustedes como expertos en centros de interpretación.

(Pabel) Bueno, con la experiencia que tienen, acá digamos, si estuviese un restaurante.

Entrevistadas: (Kelly) Ósea, yo lo veo así, como que de pende de la ubicación que tenga el restaurante, porque lo primero que esta, en tu vista, que hay un restaurante, es como que, ingresa y bueno, te dejan subir, después, como que le invitan a pasar libremente a visitar tal espacio, la impresión que se va a llevar el turista es como: “Uy, qué bueno” porque aquí pasa, ósea: "Compra mis productos, encima contribuye y pasas al museo" y ellos, como que: "Wao, que bien, voy a visitar el museo porque contribuí con un producto" entonces y ahora, 
si el restaurant está muy detrás, que impresión se va a llevar el turista, ósea, tal vez primero ingresar al centro de interpretación, ya después tiene chance a invitar o a pasar a un café o a un restaurante.

(Ingrid) Pero están priorizando el restaurante.

Entrevistador: El restaurante, si, en este caso que pasa, que aproximadamente quinientos turistas diarios llegan a ese pueblo y van a desayunar y tienen un desayuno muy básico que son los campesinos que les han preparado algo y es muy deficiente. Lo que queremos darle es, entrar en el mercado dándoles un buen desayuno y algo competitivo el centro de interpretación.

Entrevistadas: (Kelly) Súper, yo pienso que es una buena idea. De hecho, seria súper, bien podríamos dar, tal vez una opinión mucho más clara, conociendo el lugar y conociendo y viendo todas las deficiencias que dices que hay en lo que es el servicio de restaurantes, porque, un guía, mi enamorado está aquí, él es guía y el conoce súper bien esa ruta, entonces, como que, si viéramos desde ese punto de vista, tal vez, seria súper, buenísima la idea para un turista ofrecerle un servicio mejor en esa ruta, súper, yo me imagino que agreste, muy desolado, donde pasan una y otra cosa los turistas y de haber una comodidad pienso yo que muy buena, muy buena.

Entrevistador: Bueno Ingrid, Kelly, muchas gracias por su tiempo, la entrevista a concluido. Entrevistadas: (Kelly) Gracias a ustedes. 


\section{Entrevista de profundidad número 3 - Administrador del centro de interpretación}

\section{Museo Quechua}

\section{Perfil del Participante número 3.}

- Experto del Sector: Rafael Peña Humán (Artista Plástico de profesión y curador de las muestras artísticas del Museo Quechua, con más de 7 años de experiencia);

El museo Quechua es un centro de interpretación de piezas artísticas elaborado por artesanos cusqueños, en la cual, para cada descripción se utiliza el idioma Quechua, también llamado Runasimi. El museo tiene más de 8 años de funcionamiento y representa una plaza importante para la exposición de obras de arte locales, demostración de tejidos y exposición de colecciones. Junto al Museo de la Coca y el Museo de Chocolate, presenta un crecimiento y desarrollo importante en la ciudad del Cusco.

\section{Desarrollo de la entrevista a profundidad}

Entrevistador: Buenas noches, mi nombre es Pabel Gustavo Surco Dueñas, estudiante de postgrado de la Universidad San Ignacio de Loyola, en estos momentos estoy realizando un proyecto de investigación, que tiene su desarrollo en el ámbito turístico, en específico sobre la creación de un centro de interpretación o museos en el Cusco, por lo tanto, me gustaría conocer, señor, su posición, por favor, yo formularé algunas preguntas para conocer su opinión respecto al sector. En primer lugar, quisiera que nos presentemos, por favor, si me puede dar su nombre, el cargo que ocupa y el museo, el centro de interpretación, el cual usted administra.

Entrevistado: Buenas noches, mi nombre es Rafael Peña Humán, soy representante del museo Quechua, bueno, el museo Quechua es un lugar donde nos convergen varios puntos respecto 
al arte y a nuestra cultura y también lo que fue nuestros antepasados, como el legado y también como el idioma Quechua.

Entrevistador: Muchas gracias por esa introducción, bueno, yo le voy a formular algunas preguntas básicas y por favor, siéntase libre de expresar sus conocimientos, los cuales son muy provechosos para el proyecto, la investigación que estamos haciendo.

En primer lugar ¿Cuáles son los objetivos o cual es el objetivo de un centro de interpretación, llámese cultural o natural?

Entrevistado: Dentro de esto, lo que nosotros, somos un grupo de artistas y profesionales de turismo que decidimos creer en una idea, que es la cultura en sí misma, hablar lo que en otros países se determina como industrias culturales, ya que somos una cultura viva que se expresa de diferentes formas en la danza, en la música, en la pintura, en la escultura y en todas sus variedades de expresión que tenemos en la actualidad y decidimos montar todos estos conocimientos atrayendo, abstrayendo y haciendo lo más legible para captar un público nacional, extranjero y todo el que quiera hacer de interés el arte Quechua y el idioma también. Y bueno dentro de esto, manejamos un concepto más que todo de arte, por ejemplo, lo que es la escultura, la pintura, dentro de esto, las vertientes de los murales, ya que trabajamos con un personaje muy importante, que es Edwin Chávez, que es hijo de Manuel Chávez Ballón, que es considerado como el padre de la Arqueología en el Cusco y también con su esposa Karen Mour. Y también hemos sido asesorados por diferentes museólogos, también la señora Vera, que es parte de la USIL.

Entrevistador: De la USIL.

Entrevistado: Exactamente, entonces, hemos querido hacer todo esto para que también el arte que nosotros damos a conocer acá también lo puedan adquirir. Parte de las industrias culturales, la artesanía, la pintura y todo lo que nosotros ofrecemos acá en el museo. 
Entrevistador: Correcto, y ¿Cómo se ha ido desarrollando la oferta de centros de interpretación en el Perú y en especial en nuestra región Cusco? ¿Cuál es su opinión? Respecto a este desarrollo en centros de interpretación, si usted ha podido conocer digamos en el Cusco y en el Perú, centros como este u otro conocimiento que usted tenga. Entrevistado: Bueno, lo que yo he logrado captar al momento, con mi experiencia en el museo Quechua es que el turista y también el público en general busca ya no algo más parametrado, sino busca experiencias, busca experiencias culturales y esas experiencias culturales tienen que ser bastantes resumidas y que tengan un trasfondo muy amplio, eso es lo que le gusta al turista y en general al público y por ejemplo, nosotros damos talleres también, talleres de lo que es el tejido, incluso, este mismo ambiente antes era el Awanacancha, donde de este nombre también viene Awacpinta, entonces, damos estos cursos de tejido, de pulseras del Away, y también el idioma, el idioma Quechua y también cuentos y fabulas que tenemos dentro de la mitología andina, que estamos al lado de un recinto, el más importante, que es el Qoricancha, de acá parte un sistema llamado el sistema de seques, que une todo el imperio Inca. Entonces, esa es mi posición de que nosotros no debemos hacer algo parametrado, cuadrado, sino debe ser algo más, una palabra que me gusta en el Quechua es el Tinkuy, que es algo como un punto de encuentro, que esto debe ser como un punto de encuentro, no solamente de culturas, sino de idiomas, de razas, y todo lo que fue el Cusco en si mismo. También, algo fundamental de que el Qosqo era el centro, pero antes de que se llame Qosqo, se llamaba Ajamama y el Ajamama es la madre maíz o la madre chicha, que lo conocemos, hasta olvidar esta bebida tan sagrada, entonces, también difundir estos conocimientos de cómo era nuestra bebida tan importante, que unía un movimiento de trabajo, como el Ayni, la Minca, y toda esta filosofía andina.

Entrevistador: Correcto, correcto, ahora, usted ya me lo dijo, pero, también, quisiera que me lo especifique ¿Por qué cree usted que es importante estos centros de interpretación? Ya me 
lo dijo, pero si es que me ahonda más, como este museo, digamos, este museo Quechua, en los destinos turísticos ¿Por qué cree que es importante?

Entrevistado: Es que te dan otra opción, a parte de la cantidad de museos que ahí aquí, como te dije, desde pequeños a nosotros nos dan ese concepto de que un museo es un lugar aburrido que más te muestran piezas arqueológicas y no en sí mismas. Los que han hecho, todas esas piezas arqueológicas, como se les llama, entre paréntesis, es arte y son hechos por artistas. Entonces, si tú vas a Italia y ves el David, ves La Piedad, ellos no lo consideran arqueologías, lo consideran arte y son museos de arte. Entonces, en acá, los museos, nos mandan todo, de un concepto más arqueológico, entonces un niño, desde pequeño, tiene ese concepto de que es arqueología y no arte y todos los arqueólogos tienen ese concepto de que están buscando algo de una manera científica que no lo van a lograr, porque esas piezas son artísticas. Entonces, debemos borrar ese tipo de conceptos a la actualidad, que todo lo que nosotros conocimos de arte, es hecho por artistas de ese tiempo. Ese es mi modo de pensar. Entrevistador: Y, en ese pensar, lo que usted ve, digamos ¿Qué es lo que más disfrutan los turistas al venir a estos museos, centros de interpretación? O específicamente en este centro. Entrevistado: Claro, es más legible en cuanto a la interpretación, no lo hacemos tan parametrado y también nosotros ofrecemos a un guía; un guía que te da los conocimientos y conceptos de que está compuesto este museo y te hace una manera más legible, más didáctica.

Entrevistador: Dinámica, incluso.

Entrevistado: Exactamente, y también, como te digo, con los talleres, y también con las otras cosas que le ofrecemos, también no, es más fácil llegar a su conocimiento.

Entrevistador: Perfecto, ahora, ¿Por qué cree usted que varios de los centros de interpretación creados, o museos creados por el estado? Hay un museo en Machupicchu o antes de llegar, en el punto de inicio de los atractivos turísticos ¿No tienen tanta acogida? Usted mismo lo dijo, 
son tan bien parametrados, tenemos los conceptos que los museos son centros donde te aburres un poco. Es por eso lo que usted dice, no son tan dinámicos, no se diversifica en cierto sentido, pero ¿Es eso? O es algo más.

Entrevistado: Bueno es también la parte museográfica, la museología que mencionas, por ejemplo, el museo Inca, es bastante rico en piezas arqueológicas o en piezas artísticas, como dos vertientes siempre, y incluso yo tuve la oportunidad de entrar a su almacén y su almacén de este museo es mucho más hermoso en piezas artísticas que lo que ofrecen ellos y están embaladas, incluso no se les da el debido mantenimiento. $\mathrm{Y}$ yo pienso que esos museos deben dar otro contexto a la actualidad, es un museo tan rico que puede ofrecer muchas cosas que, incluso en Perú se tiene ya la experiencia el museo Larco, ha sido considerado el mejor museo de Latinoamérica, entonces, yo pienso que estos museos que dan el ejemplo, deben de arraigarse de esto y hacer unos convenios, hacer más, que le digo, más contacto, con otros representantes de otros museos y hacer una alianza y formar nuevas maneras de ver la museología en el Perú y uno de ellos es implementando, sino me equivoco, la museografía que tiene el museo Inca es de los años sesenta todavía o setentas todavía. Entonces, debería cambiarse todo esto, y volverse más, por ejemplo, como el MAP, museo de arte contemporáneo, de arte precolombino, lo ha combinado el arte, sus piezas artísticas, arqueológicas, con lo que es un hotel, ha mezclado esto, ese concepto y también incluso hay un restaurante, hay un café y algo que nosotros también estamos absorbiendo, esto, esta manera de ver un museo, porque en acá, en museo Quechua tenemos un café, tenemos un restaurante y también otra propiedad que es el hotel, que es ajena, pero dentro de esto manejan el concepto de las aves, que por ejemplo el café se llama Anca, el restaurante se llama Alcamari y el hotel se llama Waman, que son aves, entonces dan un concepto de lo andino y que también va relacionado con toda nuestra cultura en lo Quechua. Entrevistador: Claro. 
Entrevistado: Exactamente.

Entrevistador: Entonces, si digamos yo le pediría, sintetizar solamente ¿Cuál es la principal debilidad de muchos centros de interpretación acá en el Cusco? Museos.

Entrevistado: La principal debilidad es la falta de gestión que tienen, incluso los propios museos pueden auto gestionar sus propios recursos. El museo Inca, la otra vez fui hacer unas tomas y te cobran sesenta dólares por tomar una fotografía y nunca he visto en este museo un buen catálogo, un buen brochure que te muestre todas sus obras de arte y nunca y yo pienso que, si este museo hace su propia gestión, en cuanto a fotografías, sacar libros o hacer más cosas que beneficien al museo, puede salir adelante. El museo de acá el Qoricancha no invierte mucho, a pesar que tiene un cuantioso ingreso, sino me equivoco son más de mil doscientos turistas que entran y cada entrada te cubre unos veinte soles. Entonces, es mucho dinero para tan poca museografía que tienen ellos y lo que nos pueden ofrecer a nosotros como ciudadanos cusqueños también, pueden mejorar la calidad del museo de este lugar. Entrevistador: Ahora, coméntenos, con respecto ya también, al museo que usted representa, al museo Quechua ¿Cuáles serían las ventajas, que usted cree, frente a su competencia? Entrevistado: Bueno, yo lo veo no tanto como competencia, porque todos somos, en si, lugares donde brindamos conocimiento, exactamente. Nosotros sintetizamos lo que es la parte artística, la parte, por ejemplo, de la filosofía andina, la cosmogonía, como ver esos conocimientos tan amplios, porque, para la gente que viene, un turista es muy difícil asimilar estas costas, esos conocimientos, ellos nunca lo han vivido y darles algo más sintético y analítico dentro del concepto y hacer que ellos también interactúen con esto, eso es lo que buscamos acá.

Entrevistador: Ahora, ¿Cuántos, en un promedio, visitantes tienen en este centro de interpretación? Digamos, en una temporada alta, como en una temporada baja. 
Entrevistado: Bueno eso, a la par va a haber, en el mes, a partir de mayo hasta octubre se mantiene un promedio de noventa personas diarias o ciento treinta. Y bueno, aparte de eso también, lo que manejamos, a parte de ese público, lo que es el free walking, que vienen guías que hacen el recorrido por las calles y que ellos manejan más o menos un grupo de diez y ocho personas, doce personas.

Entrevistador: Que también entrar acá.

Entrevistado: Que también entrar acá y bueno, eso es otro margen. Pero sumando estos dos grupos, serían más o menos de ciento cincuenta personas al día más o menos.

Entrevistado: $\mathrm{Y}_{¿ \text { En temporada baja? }}$

Entrevistador: Bueno, unos ochenta, noventa personas más o menos.

Entrevistado: Perfecto, ahora ¿Cuál considera que debería ser la temática? Digamos, nosotros en la investigación, no solamente nos abocamos a centros culturales como estos, sino también hay algunos centros de interpretación en la naturaleza, como le mencione Machupicchu, o incluso también en el Manu. Si nos tuviese que dar una opinión suya ¿Cuál consideraría que debería ser la temática para un centro de interpretación en lo natural, donde los visitantes son turistas que están a punto de realizar un trekking? Así como Camino Inca o Salkantay, en un centro de interpretación, que esta, digamos, en el primer punto de campamento. Si tuviera una opinión suya ¿Cuál sería más o menos la temática que debería tener este centro de interpretación?

Entrevistado: Bueno, algo que, es fabuloso en nosotros es el llamado Qapac Nan, que muchas veces no lo, solamente engloba las partes que relativamente son conocidas, por ejemplo, acá tenemos Pumamarca, Pumamarca es una ruta muy bonita que yo la he recorrido y que no está promocionada dentro del siguiente espacio turístico, pero como esas hay muchos espacios, que falta promocionar, incluso yo tuve un amigo que él vive, más o menos, por el lado de Ocongate, me dijo que hay muchas cosas muy interesantes que no le están poniéndolas en 
valor, no se le dan la debida promoción. Bueno, por ejemplo, ahorita la que más ha tenido acogida es la montaña de siete colores, pero irónicamente, la montaña de siete colores, ha sido un nevado que por el calentamiento global o por la contaminación, ya no hay ese nevado y aparecieron la montaña de los 7 colores, entonces, es algo irónico que algo que está en la naturaleza desaparezca pero surja otra cosa que es más, que es casi raro.

Entrevistador: Claro, digamos, digamos, en este caso de la montaña de los siete colores, un centro de interpretación, podría dar esa información, digamos, sobre el calentamiento global y como se ha podido producir esta montaña, o dar a conocer esta montaña de siete colores que antes estaba cubierta por un nevado.

Entrevistado: Por un nevado.

Entrevistador: Correcto.

Entrevistado: Es algo irónico también.

Entrevistador: Correcto, ahora, además de la interpretación educativa que tiene cualquier museo o centro de interpretación ¿Qué otros servicios turísticos? Usted me los mencionó, pero desearía que me lo especifique acá ¿Cree usted que sea provecho para ofrecer en un centro de interpretación que está ubicado en esta zona urbana o también en una zona rural? Como le dije en una de naturaleza. Usted me dijo acá que muchos museos o centros están interrelacionados con un restaurante, incluso también un café.

Entrevistado: Exactamente.

Entrevistador: En el caso de un centro de interpretación en la naturaleza, ¿Qué servicios debería tener, cree usted?

Entrevistado: Casi no he tenido experiencias de estar en lugares abiertos, con ese contacto con lo natural, pero según me contaron, que es en el sitio del Manu, que tienen más contacto con la naturaleza, incluso hay viajes espirituales, entre comillas, lo que es psicotrópicos, plantas psicotrópicas y que también están en ese contexto de buscar más, el turista ya no sabe 
qué experiencia más tomar aquí en el Cusco, siempre va a ese lado de investigar, como hacían los alucinógenos, como funcionan, incluso sus experiencias que dicen que te borra un trauma, que te hacen ver tu futuro, tu pasado, entonces son vivencias nuevas para ellos, que ya lo ven de otra manera, para ser un regulamiento de todo esto, ahorita yo veo que ese turismo se está convirtiendo en un vicio, prácticamente, porque ya le meten al lado de las drogas, entonces eso también, no hay ningún ente regulador de todo esto acá en el Cusco y en el Perú también.

Entrevistador: Claro, efectivamente, efectivamente. Ahora ¿Conoce otro centro de interpretación que brinde otros servicios? Digamos este es un servicio cultural, educativo ¿Otros servicios a turistas acá en el Cusco u otro lugar?

Entrevistado: Bueno, yo he escuchado hablar, ahorita lo que trabajamos nosotros en una alianza son con el museo Laura de Máximo Laura, con el Choco Museo y con el museo de la Coca, son nuestros aliados y nosotros también, cuando vienen a visitar les mandamos y también ellos y viceversa; es un Ayni que hacemos acá, entonces eso es nuestra alianza que tenemos con otros lados.

Entrevistador: Perfecto, ahora ¿Cuál debería ser los canales de promoción y publicidad para un centro de interpretación en la región Cusco? En un centro como este digamos ¿Cuáles son tus canales de promoción? ¿Cómo te haces conocer con el cliente final que es el turista? o ¿Cuáles son tus publicidades?

Entrevistado: Bueno, lo que hemos implementado recientemente es ir a dejar material, volantes a la plaza de armas y también, lo que estamos pensando también es hacer, repartir unos brochures y ofrecer nuestro producto cultural a los hoteles, por ejemplo, al Marriott, a hoteles que manejen otro tipo de cliente. Porque valgan verdades, la cultura es algo que no te genera mucho recurso en lo privado, siempre, en Qoricancha, ya no se puede competir, es un monstro, el Qoricancha, tienen su propio recurso y también tiene su propia infraestructura, 
incluso por el legado de nuestros ancestros todavía. Entonces nosotros darle este producto que también le ofrecemos, dentro de esto, nuestros productos en cuestión de arte, escultura, pintura, talleres, que ellos puedan venir. Y otra cosa es que ellos también, en cuanto al tiempo, no pueden estar mucho tiempo, siempre ellos buscan algo corto y que sea más rápido. Entrevistador: Sintetizar.

Entrevistado: Sintetizar, exactamente, y también lo que es el Shopping, las compras que les gustan y nosotros lo que tenemos acá son productos únicos, no los encuentras en otros lados, entonces eso sería un plus, un valor agregado, que le daríamos a todo el museo Quechua, lo que queremos dar de nosotros.

Entrevistador: Correcto, correcto. Ahora, de acuerdo a lo que me decía anteriormente ¿De quién entonces depende la asistencia del cliente al centro de interpretación? Porque también, algunas veces, el guía turístico es el que también atrae al extranjero.

Entrevistado: Exactamente.

Entrevistador: ¿Es el guía turístico? Usted cree del mismo cliente que tiene el interés de visitar estos centros culturales.

Entrevistado: Bueno, hasta ahorita, lo que hemos recibido de nuestros, se puede decir, visitantes, es cuando salen del Qoricancha y vienen acá y entran y otro también es de los free walking que hacen los recorridos y también por el Tripadvisor. El Tripadvisor es una plataforma digital que si nos da bastante beneficios, porque siempre vienen y preguntan si es el museo y se ubican, y estamos en n buen sitio, puesto en el Tripadvisor, entonces, tenemos también buenas recomendaciones tanto como malas no, ósea que nosotros estamos mejorando porque antes no eran muy difícil para nosotros en cuanto a los recursos, como somos un grupo, entonces no, estamos gestionando todavía, estamos evolucionando y muchos de los turistas que han visitado el museo, bueno del año pasado y también de este año que 
regresaron, tuve esa experiencia, de que dijeron, que ustedes están mejorando. Por ejemplo, no había esta escultura, no había esto, ahora que si hay.

Entrevistador: Notan que hay una mejora.

Entrevistado: Exactamente, ellos mismos se dan cuenta y dicen "Oh si, están mejorando". Entrevistador: Entonces, digamos, más depende del cliente que desea visitar estos centros, que el mismo guía que los lleva.

Entrevistado: Exactamente así.

Entrevistador: Ahora ¿Qué acciones realiza su negocio para fidelizar a los guías de turismo o en todo caso a sus clientes?

Entrevistado: Bueno.

Entrevistador: Digamos ¿Qué acciones el museo hace para fidelizar a los clientes o al guía turístico que trae al cliente?

Entrevistado: Ah bueno, hacemos convenios, siempre se manejan los llamados porcentajes. Entrevistador: Claro, claro.

Entrevistado: Porque ellos también, es un trabajo, el ser guía de turismo, entonces ellos también nos dan un tiempo y nosotros retribuimos su tiempo con un beneficio económico. Porque si no, no se dinamiza eso que queremos, en cuanto a la cultura y nuestro producto como es el Museo Quechua.

Entrevistador: Perfecto, ahora ¿Cuál es su apreciación sobre la creación? Bueno, usted me dijo que esto esta interrelacionado con un restaurante, una cafetería. ¿Cuál es su apreciación sobre la creación de un restaurante, que permita a los comensales visitar gratuitamente un centro de interpretación, que este al lado? El cual está ubicado cerca al centro de interpretación. Sería como usted dice, como jalar al cliente del restaurante al centro de interpretación. ¿Se da esta figura? ¿Se podría dar esta figura? O usted piensa que... 
Entrevistado: Si, si estamos teniendo resultados, pero eso va avanzando con el tiempo, porque, incluso por esta parte, por la parte de la puerta del museo, entran y nosotros le ofrecemos el café restaurante y también lo que ofrecemos dentro del restaurante, lo que ofrece el restaurante es comida Novo andina, acá al turista le da esa curiosidad siempre de comer cosas extrañas, por ejemplo, el Cuy es algo que ellos lo tienen como mascota, pero en acá nosotros lo comemos, ahora la Alpaca ellos , carne de Alpaca, otra cosa es la Papa y la Quinua y cosas así, nosotros le damos todos esos productos, para que ellos prueben, como es una cocina Novo andina o Andina, exactamente.

Entrevistador: Bueno, esto ha sido toda la entrevista, muchas gracias por sus opiniones, estas van a ser muy importante para el trabajo de investigación que está realizando la USIL con alumnos de postgrado. Nuevamente, reiterarle el agradecimiento por su tiempo. Muchas gracias. 


\section{Anexo 5. Entrevistas a expertos en gastronomía}

\section{Objetivo de la investigación:}

El objetivo de estas entrevistas es conocer la apreciación y recomendación de los expertos gastronómicos sobre la idea de desarrollar una propuesta gastronómica de desayunos para los viajeros que se dirigen a realizar una ruta de caminata de montaña desde Mollepata a Salkantay y Machupicchu.

\section{Contenido:}

Conocer los nuevos retos de la gastronomía local para el turismo

Conocer sobre la dieta de desayunos que debería seguir un viajero de montaña

Recibir las recomendaciones y aportes sobre la propuesta de negocio

\section{Perfil del entrevistado:}

El evento "Moments Matters" es un evento desarrollado en las instalaciones del hotel Inkaterra del Valle Sagrado de los Incas en febrero del 2016, y reunió a las connotadas figuras del mundo gastronómico a nivel mundial, como es Gastón Acurio, Virgilio Martínez, Franchesco Di Sanct, Pia Sorensen, Renzo Garibaldi entro otros prestigiosos expertos. Es necesario mencionar que debido a la trascendencia del evento y el gran prestigio de los expositores que eran siempre asediados por la prensa, no se pudo seguir la secuencia de un cuestionario, y tampoco realizar grabaciones. 


\section{Entrevista experto gastronómico - Pia Sorensen, Phd, Consultora internacional en temas nutricionales}

\section{Perfil del entrevistado}

Pia Sorensen es una profesional Biofísica Molecular de la Universidad de Harvard, experta en temas nutricionales, quien tiene una alta reputación en el mundo gastronómica y viene haciendo consultorías y conferencias auspiciada por la UNICEF para mejorar las dietas alimenticias de las personas alrededor del mundo.

Suss aportaciones son de suma importancia para la investigación pues además Pia tuvo la oportunidad de realizar el trekking Mollepata Salkantay el año 2016

Nos gustaría saber cuál es tu opinión sobre la creación de un restaurant que ofrezca desayunos en el pueblo de Mollepata, que como sabrá es el primer punto para empezar el trekking de Mollepata - Salkantay- Machupicchu.

\section{Desarrollo de la entrevista}

Entrevistada: Buenos días mi nombre es Pía Sorensen, yo soy profesora en la universidad de Harvard, además de haber estudiado en Cambridge y Massachussets, me especializo en la química bio-molecular y como esta influencia en las dietas alimenticias

Entrevistador: Que bueno, como usted sabrá Mollepata es el punto de inicio para hacer la ruta de trekking a Salkantay y existen restaurantes que ofrecen desayunos en ese lugar y estamos pensando crear un nuevo restaurant que intente incorporar alimentos locales orgánicos como la quinua, sacha tomate, entre otros, pero la duda va por entender si es que este tipo de desayuno puede ser muy fuerte para viajeros de alta montaña.

Entrevistada: Esa es una buena pregunta, en realidad estoy muy emocionada porque en realidad yo y mi hermana hicimos la ruta de Mollepata a Salkantay seis meses atrás. 
Entrevistador: esto es impresionante porque encontramos a una experta en temas nutricionales y que además realizo la ruta de Mollepata Salkantay hace seis meses Entrevistada: Yo recuerdo todo acerca de eso, el desayuno del primer día, el camping en Soraypampa y les puedo dar mi opinión como viajera y experta en temas nutricionales. Bueno para responder tu pregunta, los males de altura son una constante en lugares cerca a nevados, si tienes comidas pesadas no son necesariamente buenas y sería conveniente que la comida sea más suave, por otro lado yo recuerdo que para el trekking el primer día despiertas muy temprano y llegas a Mollepata muy hambrienta, fue bueno encontrar opciones para comer poco o bastante, pero considero que deberían haber mejores opciones de desayuno, las que se deberían complementar con otras nuevas opciones. Por ejemplo, si no te gustan los huevos que otro buen alimento puede complementar tu dieta, a veces no basta con el café y los panes, por ejemplo, también para los vegetarianos o veganos.

Entrevistador: cuanta energía traducida en alimentos se necesita para hacer una caminata de cinco horas.

Entrevistada: Creo que agregar más opciones a la carta de desayunos sería estupendo sobre todo si se toma en cuenta productos locales, ahora mismo estamos en este lujoso hotel (Inkaterra) y me pareció súper lujoso que en el desayuno me ofrezcan los panes que los campesinos elaboran y que los quesos también sean de la zona, eso sí me parece súper lujo y es bien valorado por la gente del extranjero.

Entrevistador: El proyecto será realizar probablemente para el siguiente año, así que muchas gracias por sus opiniones.

Entrevistada: sí que bueno, esa ruta es muy importante, a muchos les gusta cruzar las montañas y también escuche que está cerca a otro lugar arqueológico llamado Choquequirao, así que te deseo buena suerte.

Entrevistador: Muchas gracias por tu tiempo. 


\section{Entrevista experto gastronómico - Gaston Acurio Jaramillo, chef y empresario representante de la marca Perú}

\section{Perfil del entrevistado}

Gastón Acurio es tal vez el personaje más emblemático de la revolución de la gastronomía peruana. Además de ser chef es escritor, hombre de negocios y promotor de la gastronomía peruana. Desde el año 1994 ha abierto más de 35 restaurantes en todo el mundo siendo el más emblemático Astrid y Gastón.

\section{Desarrollo de la entrevista}

Entrevistador: Gastón muchas gracias por tu tiempo solo para ser breve, te comento que estamos realizando un plan de negocio para crear un restaurant turístico dirigido para viajeros que hacen el camino inca por la montaña de salkantay y quisiera tener tu apreciación en algunos temas. Por ejemplo, cuál es tu apreciación para quienes desean emprender restaurantes para los visitantes del mundo.

Entrevistado: La gastronomía peruana esta en los ojos del mundo, pero tenemos que entender que la gastronomía peruana nace no en los grandes restaurantes del extranjero, sino nace en los hogares peruanos, donde la sazón peruana es heredada por nuestros abuelos, si nosotros entendemos que el corazón de un restaurant esta en tu identidad familiar no dudes en emprender un negocio gastronómico para los visitantes del mundo.

Entrevistador: Disculpa Gaston que tipo de comida recomiendas para un nuevo restaurant entonces

Entrevistado: Depende, depende sobre todo del lugar donde te encuentres, por eso te digo que la identidad es básica, si estas en los andes no te vas a poner a vender ceviche de mariscos para los turistas, eso no es trascender. 
Entrevistador: que te parece la idea de abrir un restaurant en la zona cerca al Valle de Apurímac, donde muchos turistas empiezan a caminar rumbo a la montaña de Salkantay. Entrevistado: Me parece importante descentralizar los corredores gastronómicos por todo el Perú, todos los pueblos se merecen a dar a conocer su gastronomía local y todos los visitantes tienen el derecho de saborear los múltiples sabores peruanos de cada región.

Entrevistador: Gastón, solo para acabar, que características debe tener el restaurant peruano del futuro

Entrevistado: Identidad, Productos naturales y creatividad, mucha creatividad.

Entrevistador: Muchas gracias Gastón por tu tiempo

Entrevistado: Gracias a ti y éxitos. 


\section{Entrevista experto gastronómico - Virgilio Martínez Veliz, chef y empresario representante de la marca Perú}

\section{Perfil del entrevistado}

Virgilio Martínez es uno de los chefs más importantes del mundo, representante de la nueva generación de chefs que viene impulsando la difusión de la gastronómica peruana. Ha sido condecorado con múltiples reconocimientos a nivel mundial siendo los más representativos el premio" Best Chef Award el 2014" y sus estrellas Michelin el 2015 por su prestigioso restaurant en Londres llamado Lima.

\section{Desarrollo de la entrevista}

Entrevistador: Virgilio gracias por tu tiempo, como te comenté tu opinión sería muy valiosas para el plan de negocio que estamos realizando para un restaurant turístico en un área rural del Cusco. ¿Cuál es tu consejo para los nuevos restaurantes turísticos en nuestro país? Entrevistado: En un mundo como hoy donde no existen barreras de información la innovación debe estar adherido a la genética de un emprendedor gastronómico Entrevistador: Disculpa, ¿cómo es eso?

Entrevistado: Significa que si quieres hacer un negocio en gastronomía debes dar una oferta que tenga un valor agregado basado en la innovación. Esto no quiere decir que vayas a crear cualquier cosa rara, sino significa que tu propuesta gastronómica debe tener mucha investigación de por medio.

Entrevistador: Te comentaba que deseábamos hacer un restaurant para los trekeros que hacen el camino inca en un pueblo muy alejado de la ciudad, cuál es tu recomendación. Entrevistado: Investiga antes de innovar, tienes mucho por recorrer y así rescatar de los campesinos. Si tu restaurant va a ser en el campo, ponte tu mochila y visita las chacras de los 
campesinos, investiga sus nutritivas y milenarias dietas alimenticias... Nosotros estamos trabajando un proyecto para un restaurant turístico en Moray que se va a llamar "100 km", el cual consiste en ofrecer un menú con productos encontrados en un radio de $100 \mathrm{~km}$ alrededor de Moray, eso es investigación y luego yo ya le pongo mi creatividad.

Entrevistador: Claro te entiendo, osea crear una carta con ayuda de la producción local suena bien.

Entrevistado: Pero tienes que abrir tu mente, y ver que eso impacte a tu mercado.... No se.... Yo en vez de darles un desayuno americano, les daría un emoliente, o un desayuno de kiwicha con maca, y lo pondría en una carretilla, y le diría al gringo que esa quinua con maca es más nutritiva y sabrosa que su cereal con yogur tan sintético que está acostumbrado en su país.... Pero ojo la kiwicha y la maca nace de tu investigación... si investigas bien podrás innovar de mejor manera.

Entrevistador: Gracias Virgilio, por tu colaboración.

Entrevistado: Gracias a ti y éxitos. 


\section{Anexo 6. Ficha técnica de investigación cuantitativa}

\section{Encuesta de aceptación de una nueva empresa de servicios turísticos en el distrito de Mollepata}

\section{Objetivo de la investigación}

Evaluar el grado de aceptación en el mercado para un nuevo restaurant turístico y centro de interpretación en el pueblo de Mollepata, a partir de la indagación sobre la percepción de la realidad del mercado, expectativas, preferencias, necesidades y la posibilidad de lanzar productos nuevos y/o diferenciados.

\section{Contenidos}

1. Proyección del volumen de ventas del encuestado

2. Apreciación de las fortalezas y debilidades servicios de alimentación a los turistas que hacen el circuito Salkantay - Mollepata - Machupicchu

3. Características y necesidades del turista que desayuna en Mollepata

4. Opinión acerca de la propuesta de producto (menú) en el restaurant turístico en el pueblo de Mollepata.

5. Opinión acerca de la temática, concepto y nombre comercial del restaurant turístico y centro de interpretación en el pueblo de Mollepata

6. Valoración sobre las estrategias de comunicación a realizar en el restaurant turístico.

7. Apreciación sobre la política de precios a implementar en el restaurant turístico y centro de interpretación

8. Opinión acerca de la creación de un centro de interpretación en el distrito de Mollepata 
9. Opinión acerca de la temática que debería tener el centro de interpretación en el distrito de Mollepata

\section{Perfil del Cliente}

El perfil del cliente en el plan de negocio son las personas que gerencian, administran o toman decisiones con respecto a elegir restaurantes turísticos en el pueblo de Mollepata. Están aquí ubicadas las empresas agencias de viajes tour operadoras que diariamente trabajan en la ruta turística que es materia de estudio. Esto muestra que es un negocio B2B (business to business)

\section{Cálculo y tamaño de la muestra.}

Universo: Para el proceso de muestreo se hizo una segmentación por actividad y tamaño de la empresa (B2B), en la descripción del segmento de mercado se reconoció que existen 62 agencias de viajes de turismo que regularmente ingresan a Mollepata (más de veinte turistas al año).

Tipo de muestreo: No probabilístico, intencional o de conveniencia. En este caso se selecciona directamente o intencionadamente los individuos de la población, se toma en cuenta a las agencias de viajes tour operadoras que mayor volumen de ventas y participación del mercado tienen en el área de estudio.

Muestra: Está formada por 25 agencias elegidas por conveniencia para los objetivos del plan de negocio, estas son las que tienen más del $88.62 \%$ del mercado con 30,127 turistas al año (entre 6,880 a 165 turistas al año). Con las 25 encuestas se determinará el target. 


\section{Diseño de trabajo de campo}

Organización: El trabajo de campo se organiza en función al número de encuestas a aplicar a la población de estudio. El trabajo se planifica de la siguiente manera:

Numero de encuestas: 25

Zonas a encuestar: Agencias de viajes tour operadoras ubicadas en la ciudad de Cusco Tiempo: 15 días

Cantidad de encuestadores: Tres (un encuestador por cada ocho agencias de viajes) Tiempo estimado de la aplicación de la encuesta: 35 minutos

\section{Requerimientos:}

Personal: Encuestadores (03)

\section{Materiales}

Tableros (06)

Lápiz (05)

Papel bond x 80 gr (1/2 millar para los cuestionarios e informes)

Objetos de merchadising con logo de la USIL (fólderes, block de notas y lapiceros)

\section{Servicios de terceros}

Impresiones

Transporte 


\section{Desarrollo del Cuestionario}

Buenas tardes, mi nombre es , soy estudiante de post grado de la

Universidad San Ignacio de Loyola, en este momento estoy realizando un proyecto de investigación que tiene su desarrollo en el ámbito turístico, por tanto, me gustaría conocer encuestarlo. Yo formularé algunas preguntas para conocer su opinión respecto al sector. Por favor, siéntase libre de expresar su opinión e ideas con respecto a este tema, de forma abierta y sincera. Así mismo, le recordamos que la información producto de esta encuesta será utilizada con el único y exclusivo fin de enriquecer nuestra investigación, uniéndose a la opinión de otros expertos de forma anónima y confidencial.

¡Gracias anticipadas por su tiempo!

\section{N: INFORMACION DEL ENCUESTADO Y LA EMPRESA}

N1. Nombre del encuestado:

N2. Agencia de Viajes a la que pertenece:

N3. Puesto que ejerce en la empresa

N4. Cuantos pasajeros aproximadamente envía su agencia de viajes en los meses de temporada alta (de marzo a octubre)

N5. Cuantos pasajeros aproximadamente envía su agencia de viajes en los meses de temporada baja (de noviembre a febrero)

N6. La mayoría de sus consumidores finales y/o visitantes que realizan el circuito de trekking Salkantay - Mollepata - Machupicchu, se hospedan en: (Vale máximo dos respuestas)
A. Hoteles de 4 y 5 Estrellas
B. Hoteles de 3 Estrellas
C. Hoteles de 2- 1 estrella
D. Hostales 
E. Hostels

N7. A qué horas su agencia de viajes llega a Mollepata para desayunar. Vale más de una respuesta indicando en orden porcentual (\%).

\begin{tabular}{|c|c|c|c|c|c|c|c|c|c|c|}
\hline Horario & $5: 00$ & $5: 30$ & $6: 00$ & $6: 30$ & $7: 00$ & $7: 30$ & $8: 00$ & $8: 30$ & $9: 00$ & $9: 30$ \\
\hline Orden $\%$ & & & & & & & & & & \\
\hline
\end{tabular}

Existe otro horario y ¿por qué?

N8. De cuantas personas están formados los grupos de viajeros que su agencia opera. Vale más de una respuesta indicando en orden porcentual (\%).

\begin{tabular}{|c|c|c|c|c|c|}
\hline Horario & $\begin{array}{c}\text { De 1 a 3 } \\
\text { viajeros }\end{array}$ & $\begin{array}{c}\text { De 2 a 5 } \\
\text { viajeros }\end{array}$ & $\begin{array}{c}\text { De 5 a 8 } \\
\text { viajeros }\end{array}$ & $\begin{array}{c}\text { De 8 a 12 } \\
\text { viajeros }\end{array}$ & $\begin{array}{c}\text { Más de 12 } \\
\text { viajeros }\end{array}$ \\
\hline Orden $\%$ & & & & & \\
\hline
\end{tabular}

Existe otra cantidad, especifique:

\section{F. PREGUNTA FILTRO}

F1. Donde programa el desayuno para sus viajeros el primer día del trekking Mollepata

Salkantay

A. Desayunan en los restaurantes turísticos del pueblo de Mollepata Si respondieron esto preguntar ¿Cuáles son los restaurantes?

B. Mis cocineros de la agencia de viajes prefieren preparar un desayuno a las afueras del pueblo de Mollepata. Si respondieron esto preguntar ¿por qué no desayunar en el pueblo de Mollepata?

C. Prefiero que desayunen en el hotel por su cuenta y ya no paramos hasta el almuerzo

Si respondieron B o C, pasar a preguntas de TESTEO P1O

\section{P. CUESTIONARIO DE PREGUNTAS}

P1. Como su empresa elige un restaurant para que los turistas desayunen en el poblado de Mollepata

A. La agencia de viajes lo reserva con anticipación 
B. El guía de turismo o chofer eligen el restaurant al azar el mismo rato que llegan al pueblo C. Otro:

P2. Que es lo que más le agrada o valora del lugar donde sus turistas desayunan en Mollepata. Referirse a cada lugar que menciono en la pregunta F1 y colocarlo en "Lugar Nro"

\begin{tabular}{|c|l|}
\hline LUGAR 1 & \\
\hline LUGAR 2 & \\
\hline LUGAR 3 & \\
\hline
\end{tabular}

P3. De cada 10 turistas que llegan al pueblo de Mollepata cuantos cree usted que deciden tomar desayuno.

\begin{tabular}{|l|l|l|l|l|l|l|l|l|l|}
\hline 1 & 2 & 3 & 4 & 5 & 6 & 7 & 8 & 9 & 10 \\
\hline
\end{tabular}

Si su respuesta fue menor a 10, porque usted considera que algunos turistas no deciden desayunar en el pueblo de Mollepata.

P4. Cuál es su satisfacción con la oferta de restaurantes turísticos en el poblado de Mollepata
A. Estoy muy satisfecho
B. Estoy satisfecho
C. Estoy regularmente satisfecho
D. Estoy insatisfecho
E. Estoy muy insatisfecho

P5. Que es lo que más le desagrada o ve como debilidad del lugar donde sus turistas eligen desayunar. Referirse a cada lugar que menciono en la pregunta F1 y colocarlo en "Lugar N" 


\begin{tabular}{|c|c|}
\hline LUGAR 1 & \\
\hline LUGAR 2 & \\
\hline LUGAR 3 & \\
\hline
\end{tabular}

P6. Para elige un restaurante en el poblado de Mollepata para que sus turistas puedan desayunar ¿Cuáles son los aspectos más importantes para su elección? (Califique del 1 al 10 siendo 1 factor menos importante y 10 factor más importante)

\begin{tabular}{|l|l|l|l|l|l|l|l|l|l|l|}
\hline & 1 & 2 & 3 & 4 & 5 & 6 & 7 & 8 & 9 & 10 \\
\hline $\begin{array}{l}\text { A. Variedad e innovación } \\
\text { en la carta de desayunos }\end{array}$ & & & & & & & & & & \\
\hline $\begin{array}{l}\text { B. Calidad y salubridad } \\
\text { en la elaboración de los } \\
\text { alimentos }\end{array}$ & & & & & & & & & & \\
\hline $\begin{array}{l}\text { C. Calidad en la atención } \\
\text { a los turistas (servicio) }\end{array}$ & & & & & & & & & & \\
\hline $\begin{array}{l}\text { D. Servicios higiénicos en } \\
\text { perfectas condiciones }\end{array}$ & & & & & & & & & & \\
\hline $\begin{array}{l}\text { E. Ubicación cerca a la } \\
\text { plaza de Armas del } \\
\text { Pueblo }\end{array}$ & & & & & & & & & & \\
\hline $\begin{array}{l}\text { F. Decoración rustica y } \\
\text { con variada flora }\end{array}$ & & & & & & & & & & \\
\hline $\begin{array}{l}\text { G. Facilidades y eficacia } \\
\text { del restaurant para hacer } \\
\text { la reserva previa }\end{array}$ & & & & & & & & & & \\
\hline $\begin{array}{l}\text { H. Rapidez en la atención } \\
\text { al cliente }\end{array}$ & & & & & & & & & & \\
\hline $\begin{array}{l}\text { I. Precio más económico } \\
\text { del desayuno }\end{array}$ & & & & & & & & & & \\
\hline
\end{tabular}


P7. De total de turistas que desayunan en el pueblo de Mollepata, cual es el desayuno que ellos más eligen

A. Desayuno simple o continental: (bebida fría, caliente, pan)

B. Desayuno Americano (bebida fría, caliente, pan, huevos, ensalada de frutas)

C. Otro:

P8. Cuanto tiempo como máximo destina usted para que el turista desayune en el pueblo de Mollepata

P9. Cuanto es el gasto promedio del turista que desayuna en Mollepata

P10. Según su experiencia ¿Cuáles son aquellos productos que adquiere el turista en una compra de último minuto (abarrotes o souvenir)?

\section{T. TESTEO DE LA PROPUESTA DE NEGOCIO}

ahora le voy a mostrar una tarjeta donde se describe lo que podría ser un nuevo restaurant para ofrecer desayunos en el pueblo de Mollepata y que además tenga un centro de interpretación, por favor léalo y luego le hare unas cuantas preguntas

T1. Que es lo que más le ha llamado la atención de esta nueva propuesta

De todas las ideas que se han mencionado en el nuevo concepto, cuáles son las que más le gustaron. Mencione hasta tres

\begin{tabular}{|c|l|}
\hline Idea 1 & \\
\hline Idea 2 & \\
\hline Idea 3 & \\
\hline
\end{tabular}


T2. De la lista que le presentamos a continuación califique usted cuál de estas propuestas

tienen mayor grado de importancia para que la propuesta de restaurant sea más atractiva para

usted.

Califique del totalmente desacuerdo al totalmente de acuerdo. En caso que su respuesta sea

totalmente desacuerdo o desacuerdo, indíquenos el porqué de su respuesta

\begin{tabular}{|c|c|c|c|c|c|}
\hline Propuestas & $\begin{array}{l}\text { Totalmente } \\
\text { desacuerdo }\end{array}$ & Desacuerdo & $\begin{array}{c}\text { Regularmente } \\
\text { de acuerdo }\end{array}$ & De acuerdo & $\begin{array}{l}\text { Muy de } \\
\text { acuerdo }\end{array}$ \\
\hline \multicolumn{6}{|l|}{ Propuesta de producto } \\
\hline \multicolumn{6}{|l|}{$\begin{array}{l}\text { Carta Balanceada en proteínas y } \\
\text { carbohidratos recomendada por } \\
\text { nutricionista para hacer caminatas de } \\
\text { montañas (jugos de quinua con maca, } \\
\text { panqueques de kiwicha). }\end{array}$} \\
\hline \multicolumn{6}{|l|}{\begin{tabular}{|l|} 
Utilización de productos agrícolas de \\
Mollepata elaborados por los campesinos \\
(ejemplo: huevos de chacra fritos con \\
tomates cherry de Marcahuasi, palta de la \\
comunidad de Humanpata, mermelada de \\
membrillo de la comunidad de Bellavista \\
en vez de la mermelada de fábrica)
\end{tabular}} \\
\hline \multicolumn{6}{|l|}{$\begin{array}{l}\text { Ofrecer } 3 \text { opciones de desayuno: } \\
\text { continental andino, americano andino y } \\
\text { vegetariano andino. Además de una } \\
\text { opción de buffet para grupos de más de } \\
10 \text { turistas }\end{array}$} \\
\hline \multicolumn{6}{|l|}{$\begin{array}{l}\text { Creación de un pequeño stand de } \\
\text { abarrotes con snacks para el trekking } \\
\text { (aguas, chocolates, cereales, frutos secos) } \\
\text { y un pequeño souvenir con polos, } \\
\text { bastones, etc. }\end{array}$} \\
\hline \multicolumn{6}{|l|}{ Propuesta de ubicación y diseño } \\
\hline \multicolumn{6}{|l|}{$\begin{array}{l}\text { Restaurante al aire libre sin muros con } \\
\text { vista al campo, jardines con plantas } \\
\text { nativas }\end{array}$} \\
\hline \multicolumn{6}{|l|}{$\begin{array}{l}\text { Infraestructura con materiales de la zona } \\
\text { (mesas y sillas de eucapalipto, piso de } \\
\text { pasto, techo de paja) Casa antigua. } \\
\end{array}$} \\
\hline \multicolumn{6}{|l|}{$\begin{array}{l}\text { Servicios higiénicos de material noble, y } \\
\text { bien equipados para varones y mujeres } \\
\text { por separado. }\end{array}$} \\
\hline \multicolumn{6}{|l|}{$\begin{array}{l}\text { Ubicado saliendo del pueblo de } \\
\text { Mollepata ( } 7 \text { min de la plaza de bus en la } \\
\text { carretera a Salkantay) }\end{array}$} \\
\hline \multicolumn{6}{|l|}{$\begin{array}{l}\text { Comedor grande con } 15 \text { mesas y } \\
\text { capacidad para } 60 \text { personas }\end{array}$} \\
\hline \multicolumn{6}{|l|}{$\begin{array}{l}\text { Propuesta de Centro de } \\
\text { Interpretación }\end{array}$} \\
\hline \multicolumn{6}{|l|}{$\begin{array}{l}\text { Exposiciones fotográficas de flora y fauna } \\
\text { de todo el área a visitar }\end{array}$} \\
\hline \multicolumn{6}{|l|}{$\begin{array}{l}\text { Historia del poblador de Mollepata desde } \\
\text { la época inca hasta las costumbres típicas } \\
\text { del día de hoy }\end{array}$} \\
\hline \multicolumn{6}{|l|}{$\begin{array}{l}\text { Exposición sobre el nuevo proyecto de } \\
\text { trekking que se hace a Choquequirao }\end{array}$} \\
\hline \multicolumn{6}{|l|}{$\begin{array}{l}\text { La religiosidad andina por la montaña } \\
\text { "Salkantay"y como influencia en el } \\
\text { hombre }\end{array}$} \\
\hline Propuesta Precio & & & & & \\
\hline \multicolumn{6}{|l|}{$\begin{array}{l}\text { Precio del desayuno entre } 22 \text { o } 27 \text { soles, } \\
\text { guía y chofer también desayunas }\end{array}$} \\
\hline \multicolumn{6}{|l|}{$\begin{array}{l}\text { El centro de interpretación siempre será } \\
\text { gratuito pero, invitaremos a los turistas a } \\
\text { que puedan comprar productos de } \\
\text { abarrotes o souvenir para el trekking }\end{array}$} \\
\hline \multicolumn{6}{|l|}{$\begin{array}{l}\text { Promoción y marca } \\
\end{array}$} \\
\hline \multirow{2}{*}{\multicolumn{6}{|c|}{\begin{tabular}{|l}
$\begin{array}{l}\text { Hacer fam trip para invitar a guías y } \\
\text { operadores turísticos a degustar el } \\
\text { producto }\end{array}$ \\
Mostrar material multimedia y papelería
\end{tabular}}} \\
\hline & & & & & \\
\hline $\begin{array}{l}\text { Nombres tentativos "Museo Salkantay" } \\
\text { "Mollepata land" "Casa del Apu" }\end{array}$ & & & & & \\
\hline
\end{tabular}


T3. Que otros servicios cree usted que la propuesta de negocio debería adherir para ser más atractivo de acuerdo a sus intereses como agencia de viajes.

\begin{tabular}{|l|l|l|l|l|l|}
\hline \multicolumn{1}{|c|}{ Propuesta de producto } & $\begin{array}{c}\text { Para nada } \\
\text { atractivo }\end{array}$ & $\begin{array}{c}\text { No muy } \\
\text { atractivo }\end{array}$ & $\begin{array}{c}\text { Regularmente } \\
\text { atractivo }\end{array}$ & Atractivo & $\begin{array}{c}\text { Muy } \\
\text { atractivo }\end{array}$ \\
\hline $\begin{array}{l}\text { Implementar un centro de catering para } \\
\text { elaborar picnics, box lunches, box snacks } \\
\text { para el primer día de trekking. }\end{array}$ & & & & & \\
\hline $\begin{array}{l}\text { Implementar equipos de oxígeno para la } \\
\text { aclimatación de viajeros con problemas } \\
\text { de altura }\end{array}$ & & & & & \\
\hline $\begin{array}{l}\text { Desarrollar excursiones culturales y de } \\
\text { aventura dentro de Mollepata. }\end{array}$ & & & & & \\
\hline $\begin{array}{l}\text { Casa hospedaje para conocer más sobre } \\
\text { los lugares que ofrece Mollepata }\end{array}$ & & & & & \\
\hline Algún otro en particular: & & & & & \\
\hline
\end{tabular}

T4 ¿Cambiaría su restaurant habitual o forma de dar desayunos a sus turistas en Mollepata por esta nueva propuesta?

A. Definitivamente si la cambiaria

B. Posiblemente la cambiaria

C. No sé si cambiaria

D. No cambiaria

\section{T5. SI EN LA ANTERIOR PREGUNTA RESPONDIÓ B O C PREGUNTAR}

Que debería cumplir este nuevo restaurante turístico que usted definitivamente cambie su restaurant habitual o forma de dar desayunos a sus turistas, por esta propuesta. 


\section{Anexo 7. Ficha Técnica - Encuestas a propietarios de Restaurantes turísticos en el distrito de Mollepata}

\section{Objetivo De La Investigación}

El objetivo es realizar una encuesta a los propietarios de los restaurantes turísticos en el distrito de Mollepata para poder conocer la realidad de cada uno de estos con respecto a su volumen de ventas, tipo de clientela, tipo de comida y otros factores útiles para el estudio de la competencia. Cabe resaltar que esta encuesta se hizo con un colaborador incognito quien se hizo pasar como un trabajador de empresas de mercadeo para que los dueños de las empresas puedan facilitar la información necesaria para la investigación.

\section{Contenido}

Datos generales del entrevistado

Información sobre la estructura organizacional del recurso humano

Información sobre los clientes directos de cada restaurant.

Información sobre las proyecciones de ventas diarias y por temporadas.

Información sobre el desarrollo del servicio, tiempos de operación, horarios, etc.

Información sobre la carta y proceso de producción

Información sobre el precio de venta

\section{Perfil del encuestado}

Propietario o responsable de los restaurantes turísticos ubicados en el pueblo de Mollepata, dicho encuestado debe tener amplio conocimiento de los contenidos que se desarrollaran en la encuesta. 


\section{Cálculo y tamaño de la muestra.}

Universo: De acuerdo al registro municipal existen un total de 12 restaurantes en el distrito de Mollepata, de los cuales muchos de ellos tienen vocación para el turismo, pero esta información no está registrada en el municipio, según observación y por información brindada por pobladores que trabajan en turismo son siete los restaurantes que trabajan casi constantemente para el turismo.

Tipo de muestreo: No probabilístico, intencional o de conveniencia. En este caso se selecciona directamente o intencionadamente a los restaurantes turísticos.

Muestra: está formado por siete restaurantes los que por observación simple y por recomendación de pobladores vinculados al turismo son los que tienen mayor participación de mercado. Los restaurantes seleccionados para la encuesta son:

\begin{tabular}{ccc}
\hline $\begin{array}{c}\text { Nombre del } \\
\text { establecimiento }\end{array}$ & $\begin{array}{c}\text { Nombre del } \\
\text { encuestado }\end{array}$ & Cargo en el establecimiento \\
\hline $\begin{array}{c}\text { La Herradura Restaurant } \\
\text { Turistico }\end{array}$ & $\begin{array}{c}\text { Sr. Wilbert } \\
\text { Ocampo }\end{array}$ & Propietario \\
$\begin{array}{c}\text { Sumaq Terminal } \\
\text { Restaurant turistico }\end{array}$ & $\begin{array}{c}\text { Sra. Yulissa } \\
\text { Almirón Concha }\end{array}$ & $\begin{array}{c}\text { Esposa del propitario y } \\
\text { encargada de la atencion }\end{array}$ \\
Don Julio Coffee & Sr. Julio Peña & Propietario \\
Restaurant turistico & Dávalos & Pra. Lina Portillo \\
Restaurante Humantay & Sierra & Propietario \\
Restaurante turistico Alto & Sra. Nancy & Propietario \\
Salkantay & $\begin{array}{c}\text { Orellana Sotelo } \\
\text { Sra. Mery Sotelo }\end{array}$ & Propietaria \\
Restaurant Turistico Tillqa & Paullo & Propietario \\
Restaurant Apu Salkantay & Sr. Julio Cardenas &
\end{tabular}




\section{Diseño de trabajo de campo}

Organización: El trabajo de campo se organiza en función al número de encuestas a aplicar a la población de estudio. El trabajo se planifica de la siguiente manera:

Numero de encuestas: 7

Zonas a encuestar: Poblado de Mollepata donde se encuentras los restaurantes turísticos Tiempo: 03 días

Cantidad de encuestadores: Uno

Tiempo estimado de la aplicación de la encuesta: 20 minutos

\section{Requerimientos:}

Personal: Encuestadores (01)

\section{Materiales}

Tableros (01)

Lápiz (02)

Papel bond x 80 gr (50 unidades para los cuestionarios e informes)

Objetos de merchadising (se regala chocolates de la marca Ibérica a los encuestados)

\section{Servicios de terceros}

Impresiones

Transporte 


\section{Desarrollo de la Encuesta}

Nombre de la empresa

Nombre del encuestado

Cargo del encuestado

P1: Cuantos trabajadores tiene en su empresa para la temporada alta y baja

P2: Cuales son las agencias de viaje con las que más trabaja. Ordénelas en orden de importancia

P3: Cuantos desayunos vende su restaurant en las siguientes temporadas. (Indicar proyecciones diarias y mensuales

\begin{tabular}{|l|l|l|}
\hline TEMPORADAS & $\begin{array}{l}\text { DESAYUNOS } \\
\text { DIARIOS }\end{array}$ & $\begin{array}{l}\text { DESAYUNOS } \\
\text { MENSUALES }\end{array}$ \\
\hline Enero - Febrero (BAJA) & & \\
\hline Mayo - Octubre (ALTA) & & \\
\hline $\begin{array}{l}\text { Marzo, Abril, Nov y Dic. } \\
\text { (media) }\end{array}$ & & \\
\hline
\end{tabular}

P4: Cuales son los horarios de atención, y cuál es la hora donde llegan más turistas (descríbala).

P5: Cuales son los tipos desayunos que más consumen los turistas. Indique por favor en porcentajes del 1 al 100\%

\begin{tabular}{|l|l|}
\hline TIPO DE DESAYUNO & PORCENTAJE\% \\
\hline Desayuno Continental simple & \\
\hline Desayuno Americano & \\
\hline Otro: & \\
& \\
\hline
\end{tabular}

P6: Cuanto gasta en dinero un turista aproximadamente que visita su restaurant P7 Además del desayuno que otras cosas compran los turistas en Mollepata 
Anexo 8. Alimentos no perecibles y perecibles para la elaboración de desayunos

\begin{tabular}{lccccc}
\hline Artículo & Cantidad & Unidad de Medida & Frecuencia Mensual & Precio (S/.) & Costo mensual (S/.) \\
\hline Mantequilla & 2 & molde & 2 & 19 & 38 \\
Mermelada & 4 & sachette & 4 & 7.5 & 30 \\
Aceite & 1 & botellon & 1 & 12 & 12 \\
Sal & 2 & bolsa & 2 & 1.2 & 2.4 \\
Harina & 3 & bolsas & 3 & 12 & 36 \\
Café & 3 & paquete & 3 & 10.8 & 32.4 \\
Leche & 1 & caja & 1 & 38.4 & 38.4 \\
Pimienta & 1 & frasco & 1 & 1.2 & 1.2 \\
Quinua & 2 & bolsa & 2 & 14 & 28 \\
Infusiones & 4 & cajas & 4 & 10 & 40 \\
Azucar & 1 & saco & 1 & 94 & 94 \\
Total & & & & 220.1 & 352.4 \\
\hline
\end{tabular}

\begin{tabular}{|c|c|c|c|c|c|c|}
\hline Artículo & Cantidad & Unidadedes & Unidad de Medida & $\begin{array}{c}\text { Frecuencia } \\
\text { Mensual }\end{array}$ & Precio unitario (S/.) & $\begin{array}{c}\text { Costo mensual } \\
(\mathrm{S} / .)\end{array}$ \\
\hline Naranja & 1,200 & 1.00 & $\mathrm{U}$ & 4 & 0.20 & 240.00 \\
\hline Papaya & 50 & 2.50 & $\mathrm{~kg}$ & 4 & 2.00 & 250.00 \\
\hline Piña & 90 & 1.50 & $\mathrm{~kg}$ & 1 & 3.50 & 472.50 \\
\hline Sandia & 15 & 3.50 & $\mathrm{~kg}$ & 4 & 2.50 & 131.25 \\
\hline Miel & 2 & 1.00 & $\mathrm{Lt}$ & 1 & 8.00 & 16.00 \\
\hline Yogurt & 45 & 1.00 & $\mathrm{Lt}$ & 2 & 3.50 & 157.50 \\
\hline Granola & 15 & 1.00 & paquete & 1 & 14.00 & 210.00 \\
\hline Pan & 1,500 & 0.25 & $\mathrm{u}$ & 2 & 0.20 & 75.00 \\
\hline huevos & 5 & 1.00 & paquete & 1 & 50.00 & 250.00 \\
\hline Queso & 22 & 1.00 & unidad & 2 & 12.00 & 264.00 \\
\hline Jamon & 23 & 1.00 & $\mathrm{~kg}$ & 4 & 18.00 & 405.00 \\
\hline Papas nativas & 60 & 1.00 & $\mathrm{~kg}$ & 2 & 1.20 & 72.00 \\
\hline Tomate & 54 & 1.00 & $\mathrm{~kg}$ & 1 & 1.30 & 70.20 \\
\hline cebollines & 18 & 1.00 & $\mathrm{~kg}$ & 2 & 1.50 & 27.00 \\
\hline Espinaca & 6 & 1.00 & $\mathrm{~kg}$ & 4 & 7.00 & 42.00 \\
\hline Hongos & 5 & 1.00 & $\mathrm{~kg}$ & 4 & 16.00 & 80.00 \\
\hline Total & & & & & 116.30 & 2,762 \\
\hline
\end{tabular}




\section{Anexo 9. Ficha Técnica - Encuestas a viajeros que realizan la ruta Mollepata -}

\section{Salkantay - Machupicchu}

\section{Objetivo del instrumento}

El objetivo es realizar una encuesta a los viajeros que hacen la ruta turística, Mollepata Salkantay - Machupicchu - para poder determinar un patrón de opinión y comportamiento de los consumidores finales. Es importante conocer el perfil y opinión de los viajeros para poder generar la propuesta de valor en el plan de negocios.

\section{Perfil del encuestado}

Viajeros de nacionalidad extranjera, que llegan a Soraypampa como parte del tour de trekking Mollepata - Salkantay - Machupicchu

\section{Cálculo y tamaño de la muestra.}

Universo: De acuerdo al registro municipal existen un promedio de 40 mil viajeros al año que ingresan a Mollepata

Tipo de muestreo: No probabilístico, intencional o de conveniencia. En este caso se selecciona directamente o intencionadamente a los viajeros a encuestar Muestra: está formado por quince turistas extranjeros que se encontraban en el campamento de Soraypampa como parte del primer día de la ruta Mollepata, Salkantay Machupicchu

\section{Diseño de trabajo de campo}

Organización: El trabajo de campo se organiza en función al número de encuestas a aplicar a la población de estudio. El trabajo se planifica de la siguiente manera:

Numero de encuestas: 15

Zonas a encuestar: Campamento turístico de la familia Mayhua Huari en la zona de Soraypampa - Mollepata 
Tiempo: 01 días

Cantidad de encuestadores: Uno

Tiempo estimado de la aplicación de la encuesta: 07 minutos

\section{Requerimientos:}

Personal: Encuestadores (01)

\section{Materiales}

Tableros $(01)$

Lápiz (02)

Papel bond x 80 gr (50 unidades para los cuestionarios e informes)

Objetos de merchadising (se regala chocolates de la marca Ibérica a los encuestados )

\section{Servicios de terceros}

Impresiones

Transporte

\section{Desarrollo de la Encuesta}

Nombre del encuestado

\section{¿Dónde usted desayuno el primer día del trekking Mollepata Salkantay?}

A. Desayunan en los restaurantes turísticos del pueblo de Mollepata.

Si respondieron esto preguntar continuar con el cuestionario

B. Otra respuesta

El encuestado no puede continuar con el cuestionario, se paraliza la encuesta.

¿Cuál es su satisfacción con la oferta de restaurantes turísticos en el poblado de Mollepata?
A. Estoy muy satisfecho
B. Estoy satisfecho
C. Estoy regularmente satisfecho
D. Estoy insatisfecho
E. Estoy muy insatisfecho 
De la lista que le presentamos a continuación califique usted cuál de estas propuestas tienen mayor grado de importancia para que su desayuno en el pueblo de Mollepata sea una mejor experiencia.

Califique del totalmente desacuerdo al totalmente de acuerdo. En caso que su respuesta sea totalmente desacuerdo o desacuerdo, indíquenos el porqué de su respuesta

\begin{tabular}{|c|c|c|c|c|c|}
\hline $\begin{array}{l}\text { PROPUESTA DE } \\
\text { PRODUCTO }\end{array}$ & $\begin{array}{l}\text { Totalmente } \\
\text { desacuerdo }\end{array}$ & Desacuerdo & $\begin{array}{l}\text { Regularmente } \\
\text { De acuerdo }\end{array}$ & $\begin{array}{l}\text { De } \\
\text { acuerdo }\end{array}$ & $\begin{array}{l}\text { Muy de } \\
\text { acuerdo }\end{array}$ \\
\hline $\begin{array}{l}\text { Carta Balanceada en } \\
\text { proteínas y carbohidratos } \\
\text { recomendada por } \\
\text { nutricionistas para hacer } \\
\text { caminatas de montañas } \\
\text { (jugos de quinua con } \\
\text { maca, panqueques de } \\
\text { kiwicha,) }\end{array}$ & & & & & \\
\hline $\begin{array}{l}\text { Utilización de productos } \\
\text { agrícolas de Mollepata } \\
\text { elaborados por los } \\
\text { campesinos (ejemplo: } \\
\text { huevos de chacra fritos } \\
\text { con tomates cherry de } \\
\text { Marcahuasi, palta de la } \\
\text { comunidad de } \\
\text { Humanpata, mermelada } \\
\text { de membrillo de la } \\
\text { comunidad de Bellavista } \\
\text { en vez de la mermelada } \\
\text { de fábrica) }\end{array}$ & & & & & \\
\hline $\begin{array}{l}\text { Añadir opciones } \\
\text { vegetarianas y opción de } \\
\text { buffet para grupos de más } \\
\text { de } 10 \text { turistas }\end{array}$ & & & & & \\
\hline $\begin{array}{l}\text { Creación de un pequeño } \\
\text { stand de abarrotes con } \\
\text { snacks para el trekking } \\
\text { (aguas, chocolates, } \\
\text { cereales, frutos secos) y } \\
\text { un pequeño souvenir con } \\
\text { polos, bastones, etc }\end{array}$ & & & & & \\
\hline $\begin{array}{l}\text { PROPUESTA DE } \\
\text { UBICACIÓN Y }\end{array}$ & & & & & \\
\hline
\end{tabular}




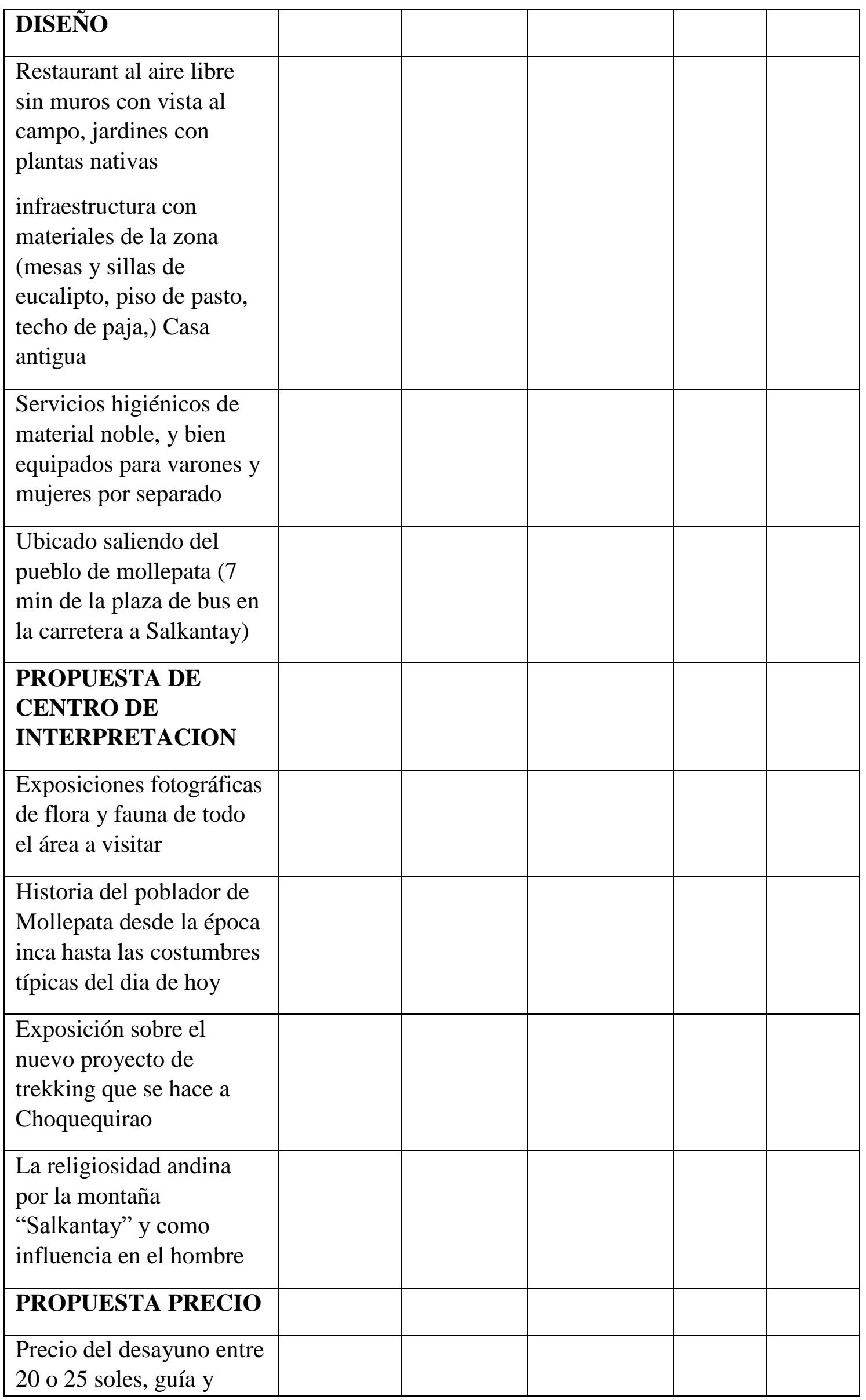




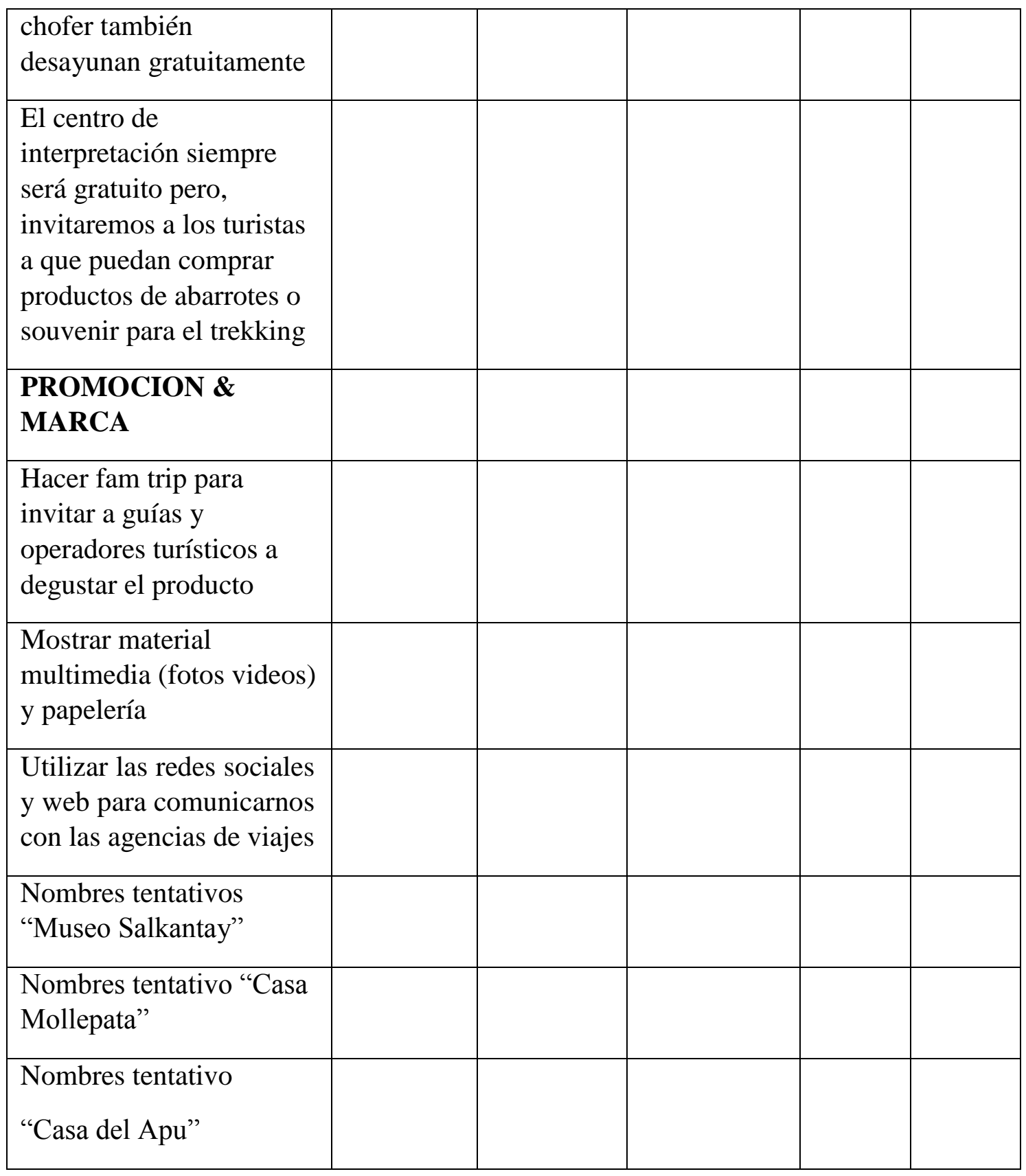




\section{Bibliografía}

- Alvarez, M. G. (2006). Manual para Elaborar Manuales de Politicas y Procedimientos. México: Editorial Panorama S.A.

- Arango. (2011). Análisis de Datos Cualitativos. Medellín, Colombia: Universidad de Antoquia.

- Chiavenato, I. (2009). Capital Humano. Mexico: McGraw-Hill Interamericana.

- David, F. R. (2013). Administración Estratégica. Ciudad Juarez: Pearson Educación.

- Hair, Bush, Ortinau. (2012). Investigación de Mercados en un ambiente de información digital. México.: The McGrown Hill Companies Inc.

- Hernandez, J. A., Gallarzo, M., \& Medina, J. d. (2011). Desarrollo Organizacional. México: Person Educaciòn.

- Kotler, P., \& Armstrong, G. (2008). Fundamentos de Marketing. México: Pearson Educación.

- Kotler, P., \& Keller, K. L. (2012). Dirección de Marketing. México: Pearson Educación.

- Larrache, H. Boyd and J. (2011). Marketing Strategy Planning and Implementation. Nueva York: Mc Graw Hill.

- Lehmann, D. R. (2007). Administración del Producto. Mexico: Editorial Mc Graw Hill.

- Lovelock, C., \& Wirtz, J. (2009). Marketing de servicios: personas, tecnología y estrategia. México: Pearson - Prentice Hall.

- Ministerio de Comercio Exterior y Turismo (MINCETUR). (2015). Plan Estratégico Nacional de Turismo 2012-2021. Lima: Comisión de Promoción del Perú.

- Ministerio de Comercio Exterior y Turismo (MINCETUR). (2015). Plan Estrategico Nacional de Turismo 2015-2025. Lima: Comisión de Promoción del Perú. 
- Ministerio de Comercio Exterior y Turismo (MINCETUR). (2016). Medicion Economica del Turismo. Ministerio de Comercio Exterior y Turismo, Dirección General de Investigación y Estudios en Turismo y Artesania. Lima: Oficina de Informática.

- Phillips, V. (2002). Manual para la modificación de senderos interpretativos en Ecoturismo. México: Global Environmental Management.

- Pope. (2012). Investigacion de Mercados. España: Editora Norma segunda Edicion.

- Porter, M. E. (2013). Estrategia Competitiva. Técnicas para el análisis de los sectores. México: Grupo Editorial Patria.

- Ramirez, M. A. (2012). Conceptualización, origen y evolución del turismo. Mexico: Trillas.

- Rideout-Civitarese, L. y. (2008). Interpretación del patrimonio.Barcelona: Editorial UOC.

- Saavedra, A. (2011). Manual de Terminología Especializada en Turismo. Cusco: Editorial D' Gráficos.

- Sapag, N. (2011). Evaluacion de proyectos de inversión en la empresa. Argentina: Pearson Education.

- Thompson, A. A., \& Strickland, A. J. (2004). Administración Estratégica. Mexico: Mc Graw Hill Interamericana.

- William, S., Michael, E., \& Bruce, W. (2004). Fundamentos de Marketing. México: McGraw-Hill Interamericana. 


\section{Referencias Electrónicas}

- Beta sector (2016). Recuperado de http://pages.stern.nyu.edu/ adamodar/New_Home_Page/datacurrent.html http://www.stern.nyu.edu/\%7Eadamodar/pc/datasets/betas.xls

- Comisión de Promoción del Perú para la Exportación y el Turismo (2016). Perfil del Turista Extranjero 2015. Recuperado de http://www.promperu.gob.pe/TurismoIN//Sitio/VisorDocumentos?titulo=Perfil\%20Del\%2 0Turista\%20Extranjero\&url=Uploads/publicaciones/2022/PERFIL\%20EXTRANJERO_P DF\%20BAJA.pdf\&nombObjeto=Publicaciones\&back=/TurismoIN/Sitio/Publicaciones\&i ssuuid=1760695/42132098

- Damodaran online (2016). Recuperado de http://pages.stern.nyu.edu/ adamodar/

- Diario Gestión (2015). Sector Servicios aporta más al PBI que Mineria y Comercio. Recuperado de Gestion: http://gestion.pe/economia/sector-servicios-aporta-mas-al-pbique-mineria-y-comercio-2136170

- Diario Gestion (2016). ¿Por qué ha crecido el turismo peruano y por qué no crece aún más? Recuperado de http://gestion.pe/economia/que-ha-crecido-turismo-peruano-y-queno-crece-aun-mas-2157127/5

- Diario La Republica (2012). Cusco producirá alimentos alternativos y desarrollará turismo vicencial. Recuperado de http://larepublica.pe/28-06-2012/cusco-producira-alimentosalternativos-y-desarrollara-turismo-vivencial.

- Dirección General de Salud Ambiental (2015). Proyecto: "Norma sobre el procedimiento para la aplicación del sistema HACCP en la fabricación de alimentos y bebidas". Recuperado de http://www.digesa.minsa.gob.pe/norma_consulta/proy_haccp.htm 
- El Economista América (2016). CCL: Sector Servicios en el Perú crecerá 4.8 \% en el 2016 y $4.9 \%$ en el 2017. Recuperado de http://www.eleconomistaamerica.pe/empresas-eAmperu/noticias/7835084/09/16/CCL-Sector-servicios-en-el-Peru-creceria-48-en-el-2016-y49-en-el-2017-.html

- Future Brand. (2013). Country Brand Index 2012-2013. Recuperado el 02 de Noviembre de 2016, de http://www.bloomconsulting.com/pdf/rankings/Bloom_Consulting_Country_Brand_Ranking_Tourism.pdf

- Human Level Communications (2016). Business to Business (B2B): negocio entre empresas. Recuperado de http://www.humanlevel.com/diccionario-marketingonline/business-to-business-b2b

- Instituto Nacional de Estadistica e Informatica (2017). Informe Tecnico Na 1 Producción Nacional - Noviembre 2016. Recuperado de https://www.inei.gob.pe/media/MenuRecursivo/boletines/01-informe-tecnicon01_produccion-nacional-nov2016.pdf

- Masias, J. (19 de Enero de 2016). Las tendencias de la gastronomía peruana en el 2016. Recuperado de http://www.semanaeconomica.com: http://semanaeconomica.com/article/entre-parentesis/estilo-de-vida/176373-lastendencias-de-la-gastronomia-peruana-en-el-2016/

- Ministerio de Comercio Exterior y Turismo (2009). Guia para la formulación de proyectos de inversión exitosos. Recuperado de http://www.mincetur.gob.pe/wpcontent/uploads/documentos/turismo/

- Ministerio de Comercio Exterior y Turismo (2013). Reglamento de Agencias de Viajes y Turismo. Recuperado de http://www.mincetur.gob.pe/newweb/Portals/0/transparencia/proyectos\%20resoluciones/P royecto_Reglamento_AV_Reglamento.pdf 
- Ministerio de la Producción. Sector Mype e Industria. Recuperado de http://www.produce.gob.pe/index.php/ministerio/sector-mype-e-industria

- Momentos Andes Cusco ( 2017). Participantes. Recuperado de http://www.momentomater.com/

- Rendimiento bonos (2016). Recuperado de http://pages.stern.nyu.edu/ adamodar/New_Home_Page/datafile/histretSP.html

- Riesgo Mercado (2016). Recuperado de http://pages.stern.nyu.edu/ adamodar/New_Home_Page/datafile/ctryprem.html

- Sociedad Peruana de Gastronomia (2012). El boom de la cocina peruana. Recuperado de www.apega.pe: http://www.apega.pe/noticias/prensa-y-difusion/el-boom-de-la-cocinaperuana.html

- Stamato, S. (2012). ¿Sabes cuáles son las actividades que aportan valor a tu empresa?. Recuperado de http://silviastamato.blogspot.com/2012/07/sabes-cuales-son.lasactividades-que.html?m=1

- Superintendencia Nacional de Aduanas y de Administración Tributaria (2008). Impuesto a la renta. Recuperado de www.sunat.gob.pe: http://www.sunat.gob.pe/legislacion/renta/ley/capxv.pdf 